\title{
EXPERIMENTAL INVESTIGATION \\ OF SPUR GEAR EFFICIENCY
}

\author{
A Thesis \\ Presented in Partial Fufillment of the Requirements for \\ The Degree of Master of Science in the \\ Graduate School of the Ohio State University
}

By

Travis T. Petry-Johnson, B.S.

$* * * * *$

The Ohio State University

2007

Masters Examination Committee:

Dr. Ahmet Kahraman

Approved by

Dr. Mark Walter

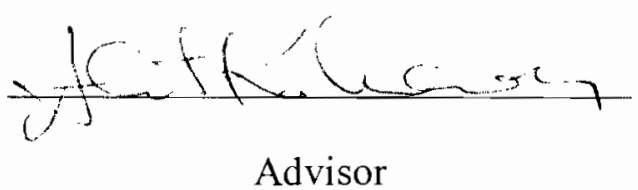

Graduate Program in Mechanical Engineering 


\begin{abstract}
An experimental investigation of high-speed spur gear efficiency was conducted for both jet-lubricated, dry sump conditions and dip-lubricated conditions. Inspection methodologies were developed for the documentation of gear surface roughness and wear after each test. An experimental test matrix including gears of two different modules and surface roughness levels operating under jet-lubrication conditions with four different gear lubricants was developed to quantify the influence of these parameters on loaddependent (mechanical) and load-independent (spin) power losses.

The spur gear efficiency test machine was modified for dip-lubricated loadindependent power loss measurements, allowing direct comparison to jet-lubricated conditions using the same test fixtures. An experimental test matrix including unity ratio gears of different module and face width operating in an oil bath of four different levels for a range of rotational speed and oil viscosity was developed. The influence of rotational speed, oil viscosity, oil bath level, and rotational direction on load independent power loss was quantified.
\end{abstract}


Dedicated to my parents 


\section{ACKNOWLEDGMENTS}

I would like to express my sincere appreciation to Dr. Ahmet Kahraman, from whom I have learned a great deal, for inviting me to work on this project, and providing patient leadership throughout the process. I would like to thank the sponsor, GM Powertrain, for their support and assistance, in particular Neil Anderson and Don Maddock. I express my appreciation to Sam Shon and the members of the Gleason Gear and Power Transmission Laboratories for their enthusiastic support throughout this project. I would also like to thank Dr. Mark Walter for his careful review of this thesis.

I am forever indebted to my wonderful parents for their endless encouragement and assistance throughout my education and my life. Without their selfless dedication these accomplishments would not have been possible. Lastly, I would like to thank Barbara Barash, whose love and support has been invaluable. 


\section{VITA}

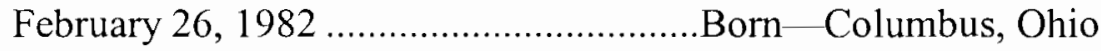

Sept. 2003 - April 2005 ...........................Engineering Intern

Worthington Steel

Columbus, Ohio

April 2005 - June 2005 ...........................Undergraduate Research Assistant

The Ohio State University, Dept. of Mech. Eng. Columbus, Ohio

June 2005 .................................................S. Mechanical Engineering The Ohio State University

Columbus, Ohio

June 2005 - March 2007

Graduate Research Associate

The Ohio State University, Dept. of Mech. Eng. Columbus, Ohio

\section{FIELDS OF STUDY}

Major Field: Mechanical Engineering 


\section{TABLE OF CONTENTS}

\section{Page}

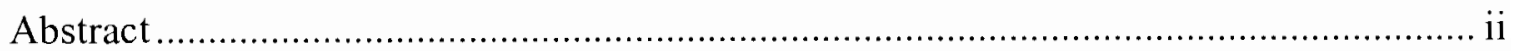

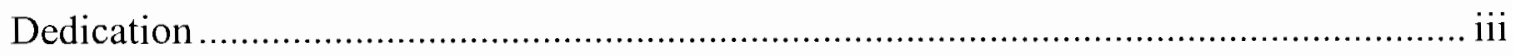

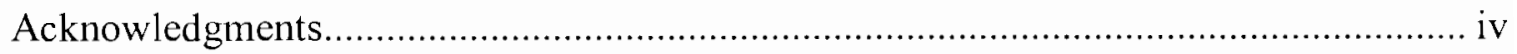

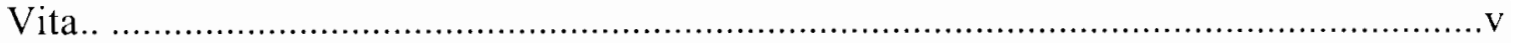

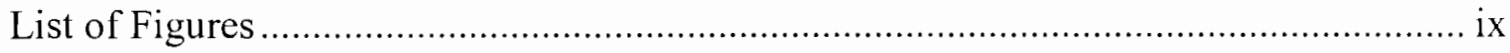

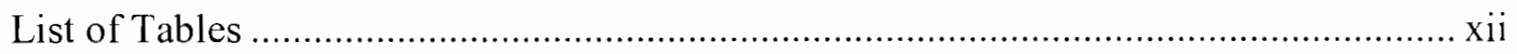

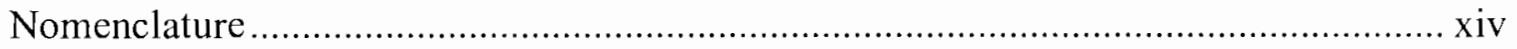

Chapters:

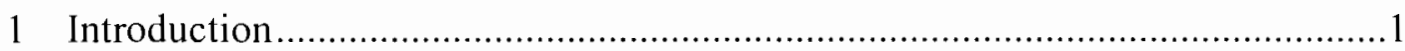

I.1 Background and Motivation ...................................................

1.2 Literature Review.................................................................... 4

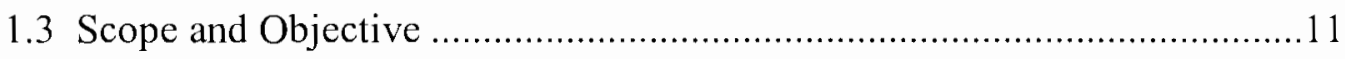

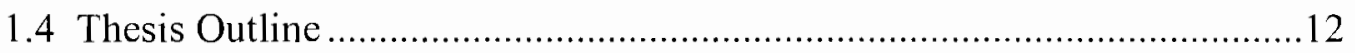

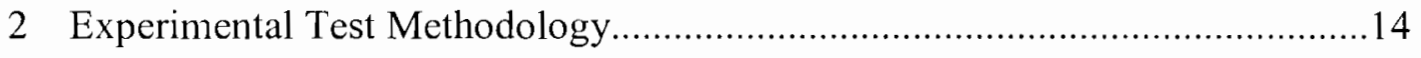

2.1 Description of Gear Efficiency Test Machine ................................. 14

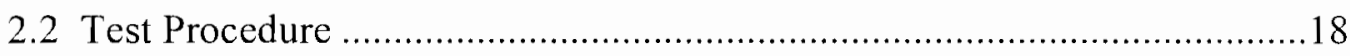

2.3 Inspection Procedure for Gear Specimens ...........................................20 


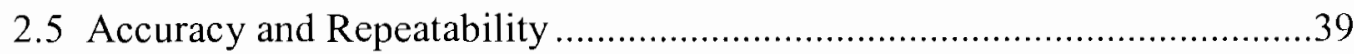

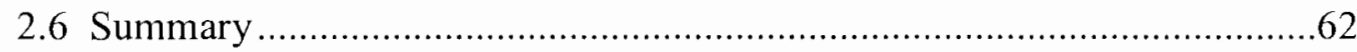

3 Efficiency Experiments Under Jet-Lubricated Conditions ...............................63

3.1 Components of Power Loss and Efficiency Losses....................................63

3.2 Calculation of Power Loss and Efficiency from Experimental Results ......66

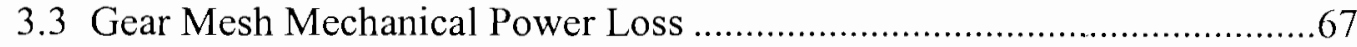

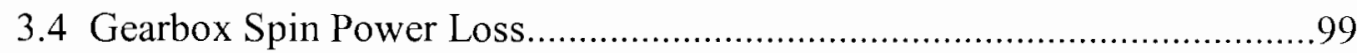

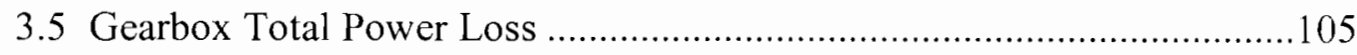

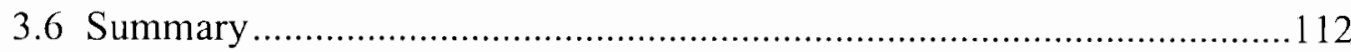

4 Efficiency Experiments Under Dip-Lubricated Conditions ...........................114

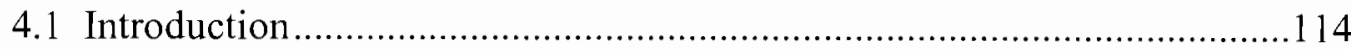

4.2 Description of Dip-Lubricated Test Setup ............................................115

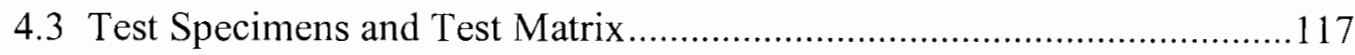

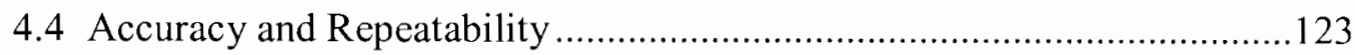

4.5 Experimental Dip Lubricated Spin Power Loss Results............................126

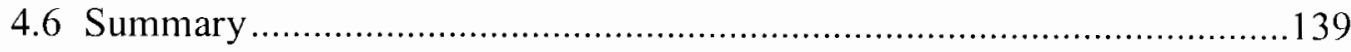

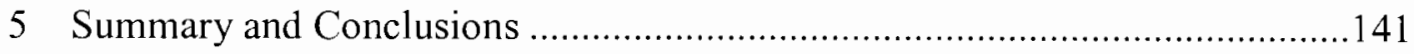

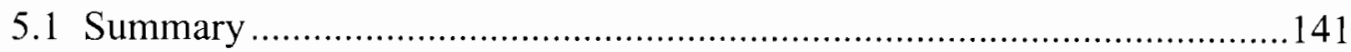

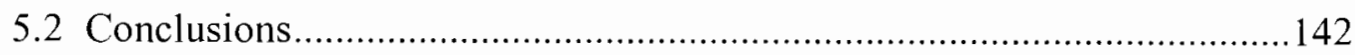




\section{LIST OF FIGURES}

Figure:

2.1 The spur gear efficiency test machine

2.2 A schematic representation of the spur gear efficiency test machine

2.3 Static load application of the power circulation loop

2.4 Gear CMM machine with a test gear mounted on the expanding arbor

2.5 Gear CMM inspection results for a 40 tooth gear prior to run-in; (a) gear tooth lead measurements, (b) gear index measurements, (c) gear pitch measurements, and (d) gear tooth spacing measurements

2.6 The gear locating fixture and probe of the Talysurf surface profiler during a surface roughness measurement

2.7 Typical surface profiles for run-in 40-tooth test gears; (a) ground gears, and (b) chemically polished gears

2.8 Samples of the experimental test gears used in the gear efficiency study

2.9 Various test gear surfaces; (a) 23T ground gear, (b) 23T chemically polished gear, (c) 40T ground gear, (d) 40T chemically polished gear,

(e) 40T hobbed-shaved gear, and (f) 40T DLC coated gear .... 35

2.10 CMM gear accuracy inspection results of new gear surface and gear surface after completion of all testing for one gear in each design category; (a) $23 \mathrm{~T}$ ground gear, (b) $23 \mathrm{~T}$ chemically polished gear, (c) 40T ground gear, (d) 40T chemically polished gear, (e) 40T hobbed and shaved, (f) 40T hobbed and shaved plus chemically polished, (g) 17/26T hobbed and shaved, (h) 17/26T hobbed and shaved plus chemically polished

2.11 Variation of left flank surface roughness measurements for all 23T and 40T gears, and 95\% confidence bands established from right flank measurements; (a) $23 \mathrm{~T}$ gears, and (b) $40 \mathrm{~T}$ gears .

2.12 Typical variation of input driving torque versus time. 40T ground gears, $T_{c}=546 \mathrm{~N}-\mathrm{m}, \Omega=6,000 \mathrm{rpm}$

2.13 Typical variation of rotational speed versus time. 40T ground gears, $T_{c}=546 \mathrm{~N}-\mathrm{m}, \Omega=6,000 \mathrm{rpm}$ 
2.14 Typical variation of temperature signals versus time. 40T ground gears, $T_{c}=546 \mathrm{~N}$-m, $\Omega=6,000 \mathrm{rpm}$

2.15 Comparison of repeatability tests using 40T chemically polished gears in lubricant $\mathrm{A}, 19.5 \mathrm{~mm}$ face width

2.16 Comparison of repeatability tests using 40T ground gears, in Lubricant A, $26.7 \mathrm{~mm}$ face width.

2.17 Comparison of repeatability tests using 23T ground gears, in Lubricant A, $26.7 \mathrm{~mm}$ face width.

3.1 Comparison of measured $P_{m}$ for 23T and 40T gear pairs as a function of $\Omega$ for (a) ground gears and (b) chemically polished gears in Lubricant A. $T_{c}=413 \mathrm{~N}-\mathrm{m}$

3.2 Comparison of measured $P_{m}$ for 23T and 40T gear pairs as a function of $T_{c}$ for (a) ground gears and (b) chemically polished gears in Lubricant A. $\Omega=6,000 \mathrm{rpm}$

3.3 Measured $\bar{\eta}_{m}$ values of 23T and 40T ground gear pairs in Lubricant A at various test conditions listed in Table 2.3

3.4 Influence of $m$ on measured $P_{m}$ for 23T and 40T gear pairs in Lubricant A; (a) ground gears and (b) chemically polished gears

3.5 Influence of $m$ on measured $P_{m}$ for 23T and 40T gear pairs (a) ground gears in Lubricant B, (b) chemically polished gears in Lubricant B, (c) ground gears in Lubricant $\mathrm{C}$, and (d) chemically polished gears in Lubricant $\mathrm{C}$

3.6 Influence of $m$ on measured $P_{m}$ for 23T and 40T gear pairs in Lubricant D; (a) ground gears and (b) chemically polished gears

3.7 Comparison of measured $P_{m}$ for $40 \mathrm{~T}$, hobbed-shaved, and $40 \mathrm{~T}$ ground

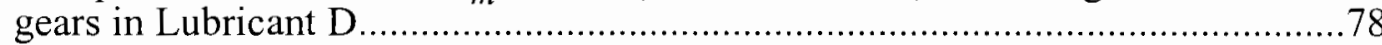

3.8 The run-in flank of a 40T hobbed-shaved gear after efficiency testing................80

3.9 Viscosity-temperature characteristic for the lubricants used in this study.....

3.10 Comparison of measured $P_{m}$ for ground and chemically polished gear pairs in Lubricant A; (a) 23T gears and (b) 40T gears

3.11 Comparison of measured $P_{m}$ for ground and chemically polished gear pairs; (a) $23 \mathrm{~T}$ gears in Lubricant B, (b) 40T gears in Lubricant B, (c) $23 \mathrm{~T}$ gears in Lubricant $\mathrm{C}$, and (d) 40T gears in Lubricant $\mathrm{C}$

3.12 Comparison of measured $P_{m}$ for ground and chemically polished gear pairs in Lubricant D; (a) 23T gears and (b) 40T gears 
4.2 A test gearbox in the dip-lubrication arrangement

4.3 Viscosity-temperature characteristic for Lubricant $\mathrm{E}$

4.4 Variation of oil temperature as a function of time for several values of $\Omega$. $40 \mathrm{~T}$ chemically polished, $19.5 \mathrm{~mm}$ face width gears rotating upward in the oil bath

4.5 Discretization of continuous temperature-torque characteristic. 40T chemically polished, $19.5 \mathrm{~mm}$ face width gears rotating upward in the oil bath

4.6 Repeatability of measured dip-lubricated spin power loss for 40T chemically polished gears as a function of oil bath kinematic viscosity, $19.5 \mathrm{~mm}$ face width, rotating upward in the oil bath

4.7 Measured dip-lubricated spin power loss for $40 \mathrm{~T}$ chemically polished gears as a function of oil bath temperature, $19.5 \mathrm{~mm}$ face width, rotating upward in the oil bath. $h / r=0.0$

4.8 Measured dip-lubricated spin power loss for 40T chemically polished gears as a function of oil bath temperature, $19.5 \mathrm{~mm}$ face width, rotating upward in the oil bath. $h / r=0.5$

4.9 Measured dip-lubricated spin power loss for 40T chemically polished gears as a function of oil bath temperature, $19.5 \mathrm{~mm}$ face width, rotating upward in the oil bath. $h / r=1.0$

4.10 Measured dip-lubricated spin power loss for 40T chemically polished gears as a function of oil bath temperature, $19.5 \mathrm{~mm}$ face width, rotating upward in the oil bath. $h / r=1.5$

4.11 Measured $P_{\text {spin }}$ as a function of $\Omega$ for four oil levels; (a) $53{ }^{\circ} \mathrm{C}$ oil bath temperature, (b) $73^{\circ} \mathrm{C}$ oil bath temperature, and (c) $88^{\circ} \mathrm{C}$ oil bath temperature. 40T chemically polished gears, $19.5 \mathrm{~mm}$ face width, rotating upward in the oil bath

4.12 Influence of rotation direction on measured $P_{\text {spin }}$ for 40T chemically polished gears, $19.5 \mathrm{~mm}$ face width

4.13 Comparison of jet-lubricated spin power loss for $26.7 \mathrm{~mm}$ face width gears at $110^{\circ} \mathrm{C}$ to dip-lubricated spin power loss for $\mathrm{h} / \mathrm{r}=0.0,88^{\circ} \mathrm{C}$, $19.5 \mathrm{~mm}$ face width, upward rotation in the oil bath 
3.13 Comparison of measured $P_{m}$ for 40T hobbed-shaved, and hobbedshaved plus chemically polished gear pairs in Lubricant D

3.14 Comparison of measured $P_{m}$ for hobbed and shaved, and hobbed and shaved plus chemically polished $17 / 26 \mathrm{~T}$ gear pairs in (a) Lubricant $\mathrm{D}$, and (b) Lubricant A.

3.15 Influence of low-friction coatings on measured $P_{m}$ for $40 \mathrm{~T}$ gear pairs in Lubricant A

3.16 Failed DLC coatings after efficiency tests; (a) DLC-B, and (b) DLC-C...............94

3.17 Comparison of measured $P_{m}$ for 23T and 40T, and ground and chemically polished gear pairs in Lubricants A, B, and C; (a) $23 \mathrm{~T}$ ground gears, (b) $23 \mathrm{~T}$ chemically polished gears and, (c) 40T ground gears, and (d) $40 \mathrm{~T}$ chemically polished gears

3.18 Comparison of measured $P_{m}$ for 17/26T hobbed and shaved, and hobbed and shaved plus chemically polished gear pairs in Lubricant D at $90 \mathrm{C}$ and Lubricant $\mathrm{A}$ at $48 \mathrm{C}$; (a) hobbed-shaved gears, (b) hobbedshaved plus chemically polished gears

3.19 Comparison of average measured $\bar{\eta}_{m}$ for $23 \mathrm{~T}$ and $40 \mathrm{~T}$, ground and chemically polished gear pairs lubricated with Lubricants $\mathrm{A}, \mathrm{B}$, and $\mathrm{C}$.

3.20 Comparison of measured $P_{\text {spin }}$ of $23 \mathrm{~T}$ and $40 \mathrm{~T}$ gear pairs lubricated with Lubricants A, B, C, and D as a function of $\Omega$ for (a) 23T ground gear pairs and (b) $40 \mathrm{~T}$ ground gear pairs....

3.21 Influence of $m$ on measured $P_{\text {spin }}$ for 23T and 40T ground gear pairs lubricated with all oils; (a) Lubricant A, (b) Lubricant B, (c) Lubricant $\mathrm{C}$, and (d) Lubricant D

3.22 Comparison of measured $P_{T}$ for 23T and 40T, and ground and chemically polished gear pairs in Lubricants A, B, and C; (a) 23T ground gears, (b) $23 \mathrm{~T}$ chemically polished gears and, (c) 40T ground gears, and (d) 40T chemically polished gears.

3.23 Comparison of measured $P_{T}$ for 17/26T hobbed and shaved, and hobbed and shaved plus chemically polished gear pairs in Lubricant D at $90 \mathrm{C}$ and Lubricant $\mathrm{A}$ at $48 \mathrm{C}$; (a) hobbed and shaved gears, (b) hobbed and shaved plus chemically polished gears.

3.24 Measured $\bar{\eta}_{T}$ values of 23T and 40T ground gear pairs in Lubricant A at various test conditions listed in Table 2.3 .

3.25 Comparison of average measured $\bar{\eta}_{T}$ for 23T and 40T, ground and chemically polished gear pairs lubricated with Lubricants A, B, and C.

4.1 Modifications to the jet-lubricated gear efficiency test machine to allow dip-lubricated spin power loss studies 


\section{LIST OF TABLES}

Table:

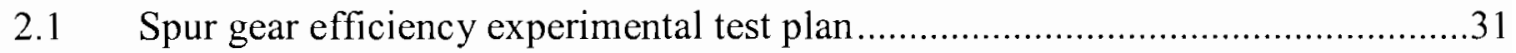

2.2 Gear design parameters for 23T, 40T, 17T, and 26T gears used in the spur gear efficiency study. Units are in mm unless otherwise specified

2.3 Operating test conditions for $23 \mathrm{~T}$ and $40 \mathrm{~T}$ ground, hobbed and shaved, and chemically polished gear pairs operated with lubricants $\mathrm{A}, \mathrm{B}$, and $\mathrm{C}$ at $110^{\circ} \mathrm{C}$, and Lubricant $\mathrm{D}$ at $90^{\circ} \mathrm{C}$ 36

2.4 Operating test conditions for 17/26T hobbed-shaved and hobbedshaved plus chemically polished gear pairs in lubricant $\mathrm{D}$ at $90^{\circ} \mathrm{C}$, and lubricant $\mathrm{A}$ at $48^{\circ} \mathrm{C}$

2.5 Experimental test sequence for all gears and operational parameters .38

2.6 Taylor Hobson Talysurf surface roughness measurements for test gears, measured after testing in the lubricating oil indicated; (a) $R_{a}$, and (b) $R_{q}$. Left flank measurements averaged from two teeth on four gears

4.1 Spur gear dip-lubricated spin power loss experimental test plan 


\begin{tabular}{|c|c|}
\hline Symbol & Definition \\
\hline $\mathrm{b}$ & gear face width, mm \\
\hline $\mathrm{d}$ & diameter, mm \\
\hline $\mathrm{h}$ & oil level height, mm \\
\hline $\mathrm{m}$ & module, $\mathrm{mm}$ \\
\hline M & moment, $\mathrm{N}-\mathrm{m}$ \\
\hline $\mathrm{n}$ & number of samples \\
\hline$\Omega$ & rotational speed, rpm \\
\hline$P$ & power Loss, $\mathrm{kW}$ \\
\hline r & radius, $\mathrm{mm}$ \\
\hline $\mathrm{R}$ & surface Roughness, $\mu \mathrm{m}$ \\
\hline $\mathrm{s}$ & sample standard deviation \\
\hline $\mathrm{T}$ & torque, $\mathrm{N}-\mathrm{m}$ \\
\hline W & load, $N$ \\
\hline$\mu$ & coefficient of friction \\
\hline$\rho$ & density, $\mathrm{kg} / \mathrm{m}^{3}$ \\
\hline$\sigma$ & standard error \\
\hline$\omega$ & angular velocity, rad/s \\
\hline
\end{tabular}




$\begin{array}{ll}\text { Subscript } & \text { Definition } \\ \text { a } & \text { average } \\ \text { b } & \text { bearing } \\ \text { bore } & \text { bore } \\ \text { c } & \text { closed power circulation loop } \\ \text { churn } & \text { churning } \\ \text { drag } & \text { fluid drag } \\ \text { inertia } & \text { acceleration of impinging oil jet } \\ \text { L } & \text { loaded } \\ \text { Trap } & \text { mear mesh } \\ \text { s } & \text { shaliding } \\ \text { mech } & \text { mechanical } \\ & \text { pitch }\end{array}$




\section{CHAPTER 1}

\section{INTRODUCTION}

\subsection{Background and Motivation}

Efficiency of spur and helical gear systems has become an increasingly important research topic as the demand for increased power density and fuel economy for today's passenger vehicles and rotorcrafts are more stringent. Increased requirements on efficiency are not only due to fuel cost, but also due to environmental concerns associated with energy sustainability and air pollution. Improved gear system efficiency also results in less frictional heat generation within the gearbox, improving on several gear failure modes such as scoring and pitting, and requiring a lower-capacity lubrication system, which can lead to improved power density of the geared system. Primary sources of efficiency losses in transmissions include tooth friction in the gear mesh, bearing power loss, and various load-independent power losses stemming from the interactions of rotating components with lubricating oil and air, and frictional losses of various oil seals.

Previous theoretical and experimental studies on gear efficiency focused primarily on friction loss in the gear mesh or overall power loss of geared systems, but little 
research has been dedicated to investigation of individual components of power loss in the same system. Theoretical studies focused on prediction of friction coefficient in the gear mesh, which was then applied to predict gear mesh mechanical efficiency. Only a few of these models were experimentally validated. Experimental studies were generally dedicated to obtaining an average friction coefficient for the theoretical models or defining influences of operating conditions or a specific parameter on efficiency. Design parameters such as module and face width, surface roughness parameters and manufacturing processes, and lubricating oil were also considered in these studies under low to medium speed and load conditions. Recent advancements in gear manufacturing processes have made it possible to apply low fiction coatings to gear surfaces or reduce gear tooth average surface roughness amplitudes significantly. However, very little experimental data is available on the influence of these processes on gear efficiency.

Given the limited volume of experimental data, there is a great need for an extensive database for spur gear efficiency, not only to validate the mathematical models but also to quantify experimentally the influence of gear design parameters, manufacturing process, and lubricant and surface related parameters on spur gear efficiency. Also missing in the literature is experimental data on efficiency of spur gears under high-speed (pitch line velocities to $50 \mathrm{~m} / \mathrm{s}$ ) and high-torque conditions. Development of such a database through tightly controlled experiments is one of the main goals of this study.

Most of the previous studies on spur gear efficiency did not refer to other sources of power loss, especially load independent (spin) losses. Modifications to the gearbox to minimize mechanical power loss might indeed increase spin loss, resulting in larger 
overall power loss. Therefore, it is critical that both mechanical and spin components of gear power loss are considered simultaneously so that overall gear system efficiency can be maximized. Previous efforts in defining these load independent losses generally employed empirical mathematical models for air drag or lubricant churning losses on rotating components based on results from simple bench tests. Most of these models fail to consider the effects of the meshing gear and other sources of power loss present in a gearbox, and thus cannot be validated using geared transmissions. The second goal of this study is to generate experiment data that compares spin and mechanical losses of the same gear sets under a range of operating conditions for various lubricants.

Existing models for spin losses can be sorted in two categories, windage and churning. Windage power loss refers to drag of a disc or gear rotating in air, or an oily atmosphere, and is assumed to apply to dry sump applications in which the gears are not in contact with an oil bath. Churning models refer to viscous drag of a rotating disc or gear that is partially submerged in oil. These models are intended to apply to diplubricated conditions. Existing windage power loss models assume that the gears are fully enveloped in air, while the churning models assume that the only source of drag is from the oil sump. Currently, no published model is available that considers both sources of power loss together. Since any dip-lubricated gear system will simultaneously contain both windage and oil churning power losses, especially when only a small percentage of the gear surface area is submerged, there is a need for a comprehensive spin power loss study to handle both windage and oil churning losses. The third goal of this study is to develop an experimental test methodology for both jet-lubricated and dip-lubricated spur 
gear spin power losses, and develop an experimental database that can be used in the future to validate spin power loss models.

\subsection{Literature Review}

A large number of theoretical studies have been published on the efficiency of gear trains [1-16]. These models typically focused only on the friction related mechanical efficiency losses in the gear mesh for spur and in some cases, helical gears. As a mechanical efficiency model requires a friction coefficient at gear contact interfaces, these models differed mainly in terms of the formulations used to determine the friction coefficient. A group of spur gear efficiency models [1-4] used a uniform and constant friction coefficient $\mu$ along the entire contact surface gears. The normal force acting at a given contact point and this constant $\mu$ was used to calculate a tangential friction force in the direction of sliding, and the reduction in torque transmitted was used to calculate the mechanical efficiency $\eta$ of the gear pair. Another group of models [5-10] adapted the same approach with the exception that their formulation for $\mu$ was not constant, but was based on various empirical formulae obtained from twin-disk tests.

With the concern that these models are as good as their empirical $\mu$ formula, another group of studies aimed at eliminating the need for $\mu$ formulae by using elastohydrodynamic lubrication (EHL) models of varying complexity. Several studies [11-13] considered smooth surface EHL formulae to determine the surface shear stress distribution caused by the fluid film, from which instantaneous friction coefficient can be calculated. Rough surface EHL models were employed by $\mathrm{Wu}$ and Cheng [14], 
Mihalidis et al [15], and more recently by Xu et al [16]. The model of Xu et al [16] incorporated a gear load distribution model, a friction coefficient model, and a mechanical efficiency formulation, which resulted in agreement with experimental measurements to within $0.1 \%$ in terms of gear mesh mechanical efficiency. These models had the advantage of eliminating the need for prior knowledge of $\mu$, at the expense of significantly more computational demand. While these models were sophisticated in handling EHL aspects of the problem, the application was limited to simple spur gears with ideal load distributions and no tooth bending deformations. More importantly, they did not consider other sources of power loss in a gearbox, and were therefore insufficient to predict overall gearbox efficiency.

While the body of theoretical work on spur gear mechanical efficiency is extensive, the same cannot be said for the experimental treatment of the problem. Most experimental studies have been limited to estimating average gear mesh friction coefficient under low to medium speeds and correlating this to gear operating characteristics such as sliding velocity, torque transmitted, and lubricating oil [17-26]. Early studies by Naruse et al [17-19] sought to define influences of certain gear design parameters, manufacturing process, lubricating oil, surface roughness and operating conditions on spur gear efficiency. Naruse and Haizuka [17] demonstrated on a diskmachine that friction coefficient for lubricated rolling-sliding contacts decreases with sliding velocity, and is not clearly dependent on oil viscosity. In the case of geared systems, Naruse et al [18-19] showed from measurements with a power re-circulating loop bench test that spur gear mesh efficiency increases with rotational speed for pitchline velocities below approximately $24 \mathrm{~m} / \mathrm{s}$, and also reported that gear mesh frictional 
power loss increases with transmitted torque at low torque values, but becomes nearly constant at higher loads. Naruse et al [19] showed that reducing module can significantly influence efficiency losses at the gear mesh. In these tests, reducing module from $6 \mathrm{~mm}$ to $2 \mathrm{~mm}$ reduced gear mesh efficiency losses from nearly $1.5 \%$ to $0.5 \%$. In this same study, it was shown that ground gears of $4.5 \mathrm{~mm}$ module operated at approximately $0.25 \%$ lower efficiency losses than shaved gears with the same module and similar surface roughness. These studies also showed that efficiency losses are insensitive to changes in surface roughness between $0.5 \mu \mathrm{m}$ and $3 \mu \mathrm{m}$ for high load, and low to medium speed conditions. However, the influence of gear surface roughness over a wider range of roughness values, operating conditions, and lubricating oil viscosity has not been studied in detail. Yoshizaki et al [20] demonstrated that below $10 \mathrm{cSt}$, gear tooth friction coefficient decreases as lubricating oil viscosity increases, but friction coefficient changes little as viscosity increases beyond that point. Ikejo and Nagamura [21] also concluded from measurements with a similar test setup that gear mesh frictional loss is weakly dependent on oil viscosity, but decreases with increasing viscosity.

Conversely in terms of total power loss, Coy et al [22] reported that the overall efficiency of a helicopter transmission generally decreased with increasing lubricating oil viscosity, indicating that load-independent power losses can be significant in practical applications. Handschuh and Kilmain [23] observed from power loss measurements of a jet-lubricated high-speed helical geartrain that overall efficiency increases with transmitted torque, and decreases with rotational speed. It was shown that at rotational speeds of 5,000 to $15,000 \mathrm{rpm}$, the influence of transmitted torque on total power loss 
was less significant than the influence of rotational speed, but efforts were not made to characterize loaded and unloaded power losses separately.

Martins et al [24] measured average friction coefficient of dip-lubricated FZG gears and reported that friction coefficient decreases with rotational speed, and increases with transmitted torque for pitch-line velocities less than $19 \mathrm{~m} / \mathrm{s}$. Traction measurements of combined rolling-sliding contacts of Xiao et al [25] suggested that gear mesh power loss is lower for smooth surfaces than rough surfaces, but few experimental studies have been pursued to quantify this. One such study by Britton et al [26] reported that reduction of average surface roughness height from 0.4 to $0.05 \mu \mathrm{m}$ through an isotropic chemical polishing technique reduced mesh power loss by between approximately 20 and $30 \%$. The range of operating conditions considered for this study were Hertzian contact pressures ranging from 0.4 to $1.3 \mathrm{GPa}$, pitch-line velocities up to $22 \mathrm{~m} / \mathrm{s}$, and operating temperatures of 50 to $100^{\circ} \mathrm{C}$. While these test conditions represent a wide range of applications, it is desirable to expand this investigation to higher Hertzian pressures and pitch-line velocities in order to encompass the high-performance applications that are more likely to take advantage of a chemical polishing process.

Most of the previous studies on spur gear efficiency did not refer to secondary sources of power loss, especially load independent (spin) losses. Several experimental studies $[5,21,30-31]$ have shown that spin losses, primarily due to windage and/or oil churning, can be rather significant, especially under high-speed operating conditions. Therefore, it is critical that both mechanical and spin components of gear efficiency losses to be considered simultaneously in an effort to maximize efficiency. 
Existing empirical spin power loss models can be categorized into windage or oil churning models. The windage models of Dawson [27-28] and Diab et al [29] were obtained by measuring the deceleration of a single gear or disc in air on a spindle, then applying the kinetic energy theorem to obtain power loss from air drag. Diab et al [29] employed dimensional analysis to define a windage moment coefficient in terms of angular velocity, fluid density and viscosity, Reynolds Number, face width, pitch radius, number of gear teeth, and nearby fluid flow obstructions such as close-fitting gear case walls. While applicable to a single disc or gear rotating in air, these models did not consider the effects of a meshing gear or impinging oil jet, and so cannot be validated using geared transmissions. As an alternative, Anderson and Loewenthal [5] developed a model for meshed spur gears based on pitch radius, face width, rotational speed, and viscosity of the ambient fluid. These models all resulted in a nearly cubic relationship between rotational speed and power loss.

Ariura et al [30] identified sources of load-independent power loss in a spur gear system as (1) the inertial power loss to accelerate the impinging oil jet by the rotating gear teeth, (2) the power to trap and squeeze oil from between gear teeth as they meshed (trapping and squeezing), (3) the power to induce an air draft around the gear (windage), and (4) the churning power loss of the lubricant in an oil bath. Torque measurements of Ariura et al [30] using a jet lubricated spur gear system led to the observation that inertial power losses are linearly related to rotational speed. Ariura et al [30] also proposed a simple model to estimate the power loss due to oil trapping between the gear teeth. Comparison to experimental results indicated that the model qualitatively captured trends 
in the data, but the magnitude of calculated power loss was consistently lower than measured values.

Mizutani [31] reported from measurements of high-speed, long addendum spur gears that windage power loss was proportional to a power of rotational speed of 2.28 and the inertial losses resulting from the impinging oil jet were linearly proportional to rotational speed. Here, the inertial losses from the impinging oil jet were shown to increase with oil jet pressure, and composed a significant portion of load-independent power loss.

An early analytical theory on the fluid flow of air and lubricant around jetlubricated spur gear teeth was proposed by Akin and Mross [32]. This model elucidated the phenomenon of eddy current flow between gear teeth and introduced a vectoral model for penetration depth of impinging fluid on the rotating gear teeth. Later, Pechersky and Wittbrodt [33] introduced a computational method for the trapping and squeezing of fluid between meshing gear teeth. The model suggested that the volume and velocity of the fluid squeezed between gear teeth is higher for coarse-pitch gears than fine-pitch gears. Most recently, Diab et al [34] developed a numerical model to analyze fluid trapping and squeezing in the case of windage by defining a matrix of intertooth volumes and flow restrictions, and numerically solving the equation of continuity for each discretized volume. Analytical results compared favorably to experimental data from pressure transducers placed at the roots of spur and helical gear teeth in a test rig operated without lubricating oil. In the case of helical gears, power loss values calculated by the model indicate that trapping and squeezing power loss decreases as helix angle increases. This 
result can have significant implications in the realm of improving efficiency if it can be validated with in-situ spin power loss measurements.

The study of oil churning power loss has received much attention in the past, but primarily for the rotation of a single disc or bladed rotor in a fluid [35-36]. Like Diab et al [34] for the case of windage, the oil churning studies were mostly devoted to developing empirical equations for the dimensionless moment coefficient. Daily and Nece [35] proposed the existence of four different flow regimes around a rotating disc fully submerged in fluid, and correlated these flow regimes to Reynolds Number and enclosure effects based on experimental results. Mann and Marston [36] studied friction drag of bladed and unbladed discs, and related experimental results to moment coefficient based on Reynolds Number and axial clearance with the chamber. In the case of diplubricated gear applications Terekhov [37] developed empirical relations for dimensionless moment coefficient from numerous experiments on gears rotating partially submerged in a fluid, and identified differing power loss equations for meshed gears rotating upward or downward in an oil bath. Boness [38] conducted friction torque tests with a simple bench setup on smooth discs of various diameter and width partially submerged in high-viscosity oil, and compared these results to results with a gear. Boness' results [38] varied widely from Terekhov [37] in predicted friction torque for similar operating conditions.

More recently, Höhn et al [39] proposed a simpler calculation method for churning friction torque. Luke and Olver [40] investigated the discrepancy between the results of Terekhov and Boness, conducting numerous bench tests of their own with unmeshed and mating nylon and steel gears of varying module, face width, and number 
of teeth. Luke and Olver [40] concluded that the models of Terekhov [37], Boness [38], and Höhn et al [39] were all inadequate in predicting their own measured churning power loss values. Luke and Olver [40] challenged the previous assumption that dimensionless moment coefficient can be related to Reynolds Number for dip lubricated gear systems. Most recently, Changenet and Velex [41] completed an extensive experimental churning power loss study, and proposed a new model that includes the effect of the mating gear depending on the sense of rotation. As in previous studies, empirical formula for dimensionless moment coefficient were developed using dimensional analysis.

The dimensionless moment coefficients calculated by the models of Terekhov [37], Boness [38], Höhn et al [39], and Changenet and Velex [41] have all been shown to agree well with data obtained on the test rigs from which the models were developed, but poor agreement is achieved when comparing moment coefficients to those calculated by other models under similar test conditions [40]. A universally applicable, physics-based churning power loss model still eludes researchers.

\subsection{Scope and Objective}

The existing body of experimental gear efficiency research illuminates useful trends in spur gear efficiency for a wide range of gear designs and operating conditions. However, the influences of recent refinements in manufacturing techniques such as isotropic chemical polishing and low-friction coatings have yet to be studied in detail. Additionally, experimental data for high-power gearing applications, is not readily available in the literature. Even less data is available on load-independent (spin) power 
loss of jet lubricated and dip lubricated gearboxes. Lastly, existing semi-empirical models for both lubrication conditions fail to agree well with experimental data.

The main purpose of this study is to establish a spur gear efficiency database through tightly-controlled gear efficiency experiments. Experimental data will be generated to compare spin and mechanical power losses of the same gear sets under a range of operating conditions for various lubricant types and lubrication methods. Specific objectives of this study are as follows:

- Develop a test methodology that will be capable of measuring power losses of a high-speed spur gear pair operating under a wide range of torque.

- Apply this test methodology to describe trends in spur gear mesh and total efficiency under various operating conditions.

- Investigate the influences of gear module, manufacturing finishing processes such as grinding and shaving, surface finish technologies such as chemical polishing and thin-film coatings, and lubricant type on gear mesh and total power loss.

- Quantify load-independent spin power loss for the same test conditions as loaded power loss measurements.

- Develop a test methodology for dip lubricated churning power loss of spur gear pairs, and quantify the influence of lubricant viscosity, oil level and rotational direction on churning power loss.

- Provide a detailed comparison between the power losses associated with jetlubricated and dip-lubricated gear sets. 


\subsection{Thesis Outline}

Chapter 2 provides a description of the high speed gear efficiency test machine and test plan utilized in this study. Inspection procedures for the test gears are outlined and inspection results are presented. The test specimens and test matrix are described, and the purpose of each test is noted. The accuracy and repeatability of the experimental test machine over the duration of the project are presented.

Chapter 3 presents results of the efficiency experiments under jet-lubricated conditions. Sources of power loss in a gearbox are discussed, as well as the methods utilized to separate certain power losses using the experimental test machine. Measured load-dependent and load-independent power loss results are presented. Heuristic arguments are made for the influence of certain design parameters and operating conditions on components of gear power loss. Influences of the experimentally investigated parameters are discussed in terms of average total and gear mesh mechanical efficiency.

Chapter 4 describes modifications made to the experimental test machine to study dip-lubricated spin power loss. The accuracy and repeatability of the experimental test machine for this mode of operation is presented. The sources of load-independent power loss in a jet-lubrication and dip-lubrication environment are outlined. Experimental results for the influence of several gear design parameters, and operating conditions are presented. Lastly, chapter 5 summarizes the accomplishments of this study, and presents the main conclusions drawn from the experimental results. Finally, recommendations for future work are offered. 


\section{CHAPTER 2}

\section{EXPERIMENTAL TEST METHODOLOGY}

\subsection{Description of Gear Efficiency Test Machine}

The spur gear efficiency test machine used in this study, shown in Fig. 2.1, was designed and procured as part of an earlier spur gear efficiency investigation [42]. A brief description of the test machine will be provided here with only the most relevant features included. Readers are referred to Chase [42] for details of the test machine and its operation.

The test machine consists of two opposing identical gearboxes, each containing one gear mesh, four identical cylindrical roller bearings, and shaft seals. This machine utilizes a four-square, power circulation concept such that one gear from each gearbox is connected to the corresponding gear of the other gearbox. Mounted on one of the flexible shafts connecting the gearboxes is a split coupling that is used to apply a constant torque $T_{c}$ to the system. This torque is transmitted by both test gear meshes. Figure 2.2 shows a schematic of the test machine layout. The two gearboxes are specified "test" and 


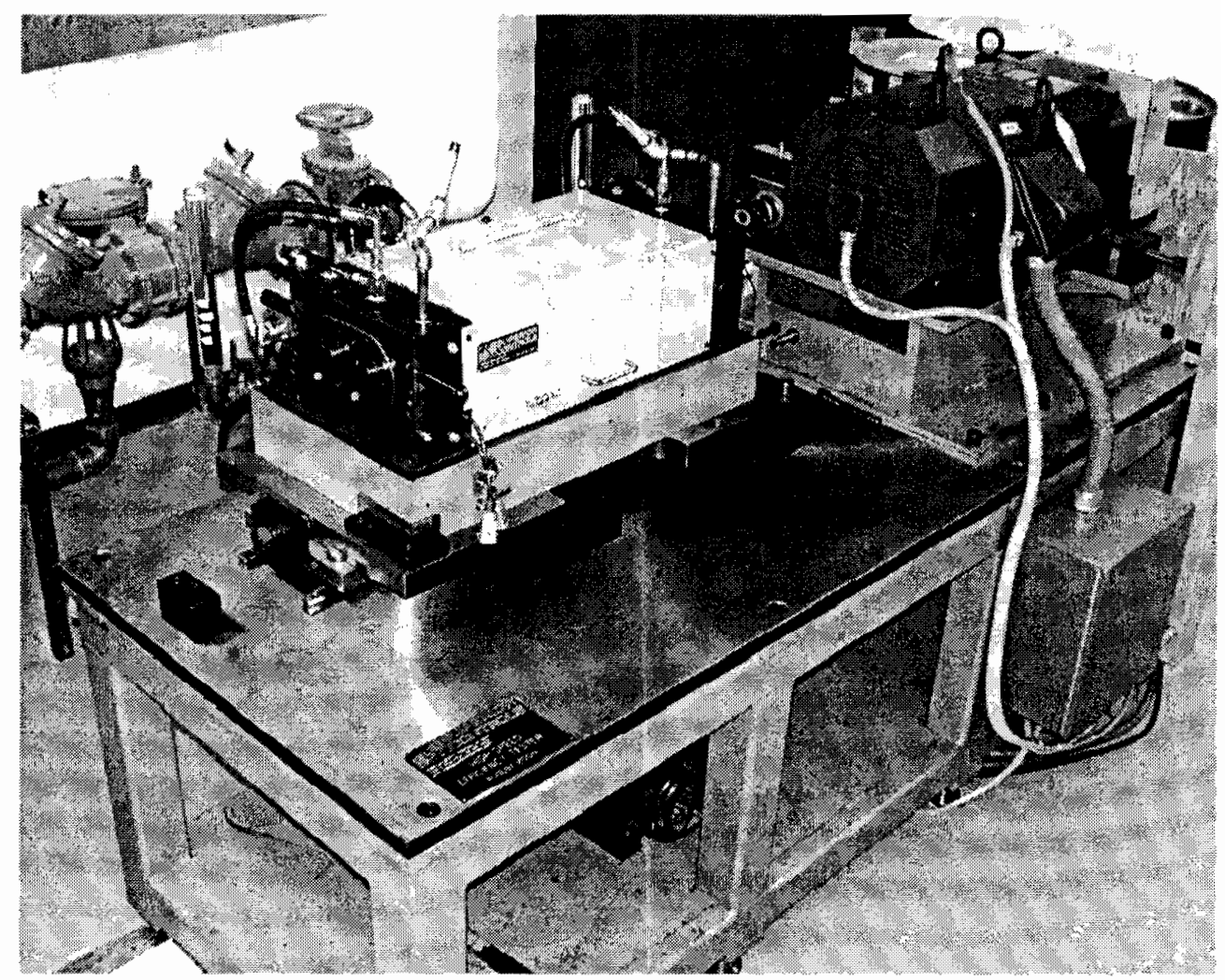

Figure 2.1 The spur gear efficiency test machine. 


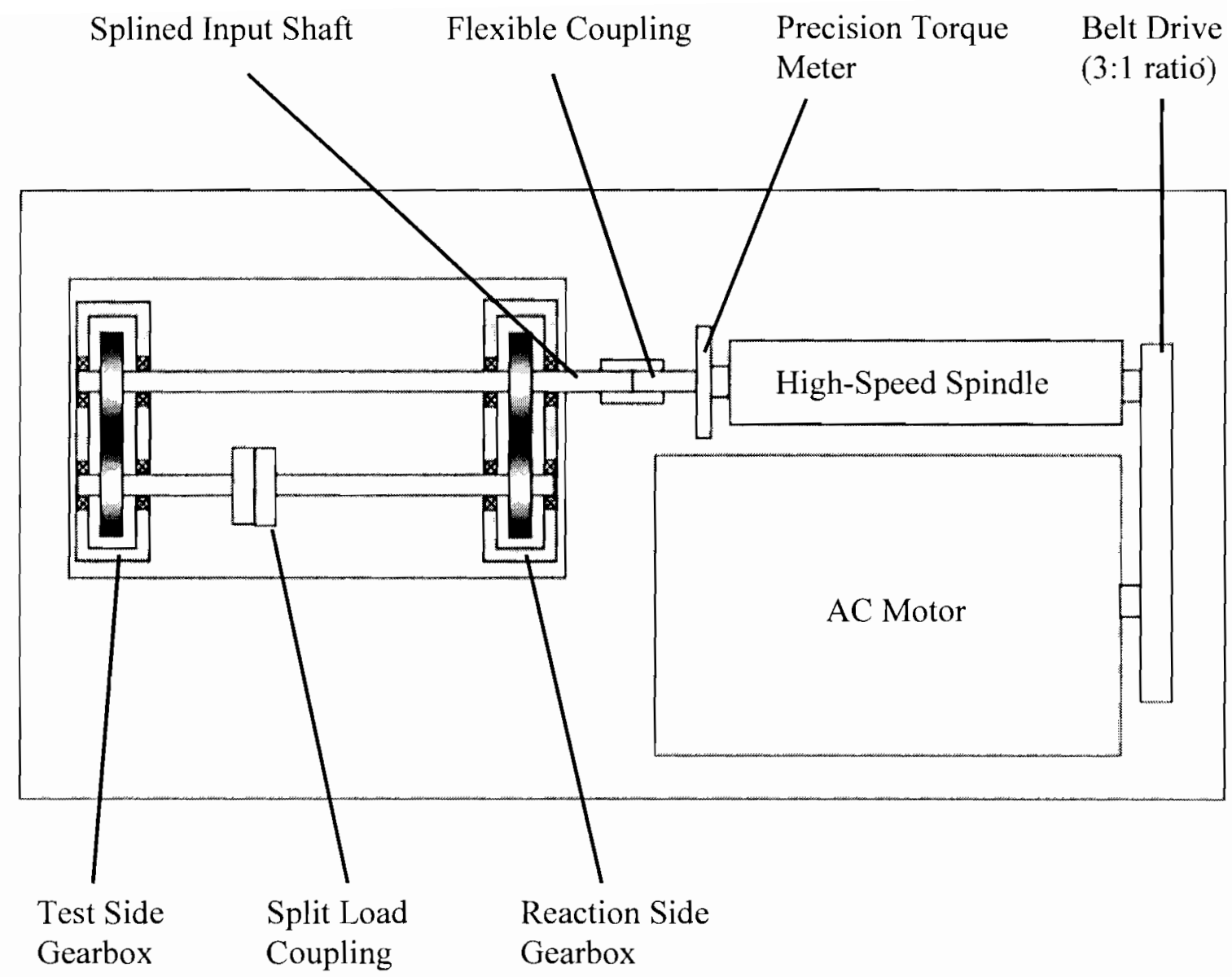

Figure 2.2 A schematic representation of the spur gear efficiency test machine. 
"reaction" to differentiate them, but there is no physical difference except for the input shaft on the reaction gearbox. A flexible coupling connects the input shaft of the reaction gearbox to a high-speed spindle through a high-precision, non-contact type torque-meter. The high-speed spindle is driven by a belt with a $3: 1$ ratio speed increase from a variable speed AC motor. A separate temperature-controlled lubricant circulation system supplies directed oil jets to the gear meshes and bearings. Oil temperature is measured with type-J thermocouples at the supply points as well as return from the gearboxes. The test apparatus shown in Fig. 2.2 sits on a slide mechanism, allowing the splined input shaft to be easily disengaged from the coupling, so that the power circulation loop torque $T_{c}$ can be safely changed and any electronic drift of the torque-meter can be checked and documented between tests.

The test machine is capable of operating at rotational speed up to $\Omega=10,000$ rpm, which corresponds to $48 \mathrm{~m} / \mathrm{s}$ gear pitch-line velocity for unity ratio gears with a fixed center distance of $91.5 \mathrm{~mm}$. With a circulation loop torque $T_{c}$ up to $680 \mathrm{~N}-\mathrm{m}(500$ $\mathrm{ft}-\mathrm{lb})$, circulation loop power $P_{c}=T_{c} \omega\left(\omega=\frac{2 \pi}{60} \Omega\right)$ of over $700 \mathrm{~kW}(950 \mathrm{hp})$ is possible, making the machine capable of running at representative conditions for commercial automotive, racing and some aerospace applications.

The test machine is almost entirely computer controlled and monitored through a LabView interface. Rotational speed, lubricant temperature, and test duration are all controlled through the LabView interface. Oil flow rates are controlled manually with a needle valve on a machine-mounted oil supply manifold. The computer interface permits a number of diagnostics and shutdown limits to be set according to test parameters. 
Limits on oil temperature, oil pressure, rotational speed, and driving torque can be specified by the user. Additionally, the data logging period and test parameter tolerances can be adjusted.

\subsection{Test Procedure}

Most of the high-speed gear efficiency tests are conducted at an oil supply temperature of $110^{\circ} \mathrm{C}$ or $90^{\circ} \mathrm{C}$ depending on the gear application represented. Therefore, the lubricant must be heated to this set operating temperature prior to beginning an efficiency test. Lubricant is circulated throughout both gearboxes to bring their temperatures to the desired temperature level. Test duration and rotational speed are set through the LabView interface.

The gear efficiency test machine is mechanically loaded through the split coupling with a torque arm and deadweights as shown in Fig. 2.3. Once the desired $T_{c}$ is achieved, friction discs in the split coupling are tightened, locking the torque in to the closed loop formed by the two gear pairs and the shafts connecting them. Torque arm angle is measured with a line level attached to the arm and with a compass. This measurement is used to correct for small changes in torque arm length due to its angle, so that applied $T_{c}$ can be determined precisely. The deadweights and torque arm are then removed, and the test machine is readied for testing.

New gears, shaft seals, and bearings typically have a run-in period during which they exhibit elevated levels of frictional power loss. During this period, gear and bearing surface roughness decrease slightly, and seals wear-in with the shaft. At the beginning of 


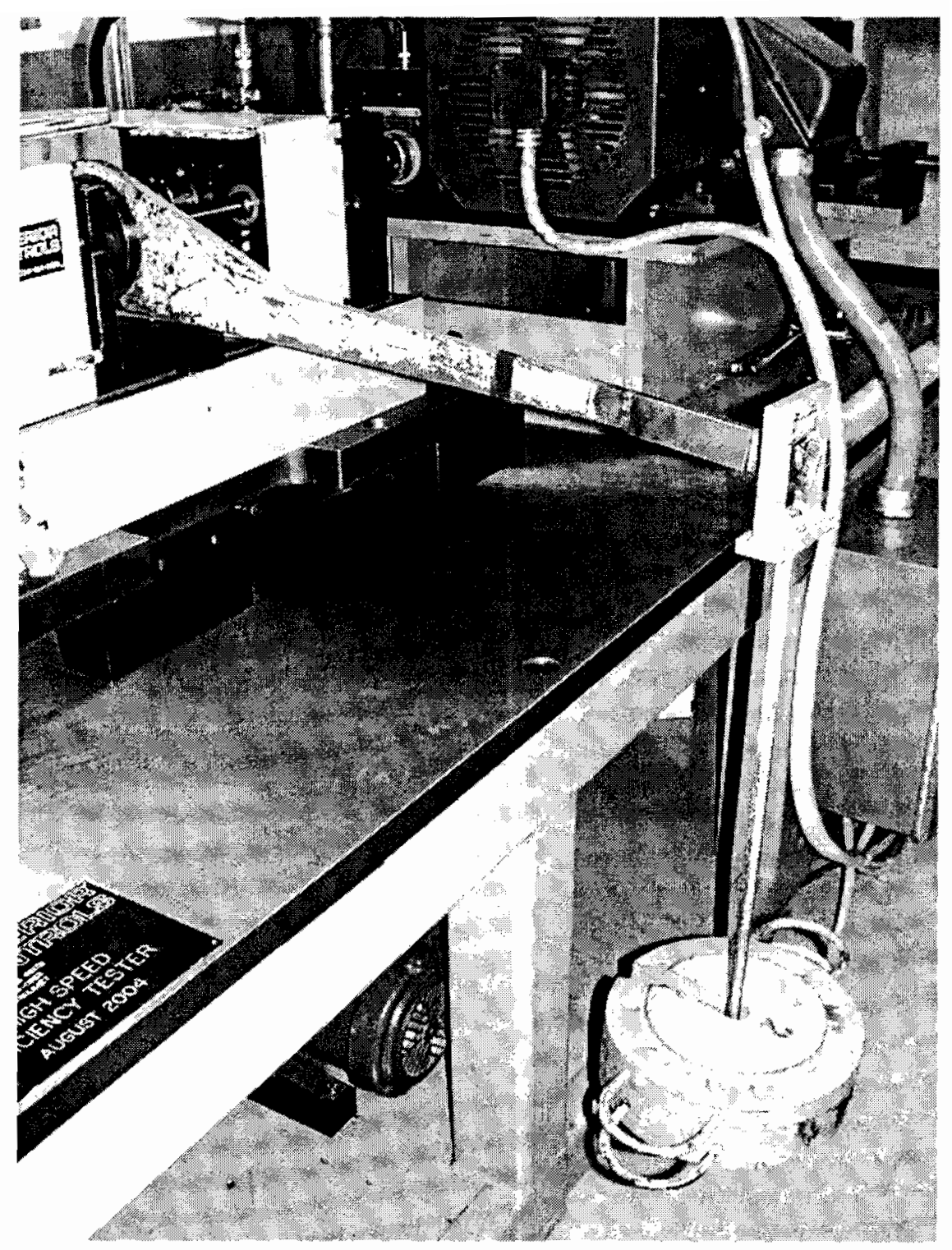

Figure 2.3 Static load application of the power circulation loop. 
this test plan, it was thought that gear run-in time should drive the run-in cycle. For this reason, a run-in cycle formed by one hour of operation at $T_{c}=413 \mathrm{~N}-\mathrm{m}$ and $\Omega=6,000$ rpm is used. This run-in cycle was applied to new gears and bearings. An additional runin cycle of two hours of operation at $T_{c}=0$ and $\Omega=6,000 \mathrm{rpm}$ was used for run-in of the new shaft seals.

Previous experimental studies on gear efficiency using the same machine indicated that most transient temperature behavior is eliminated in the first five to six minutes of a test [42]. Accordingly, ten minutes was selected as the test duration, with the last five minutes averaged together to obtain the values of oil supply temperature, $\Omega$, and torque measured by the torque-meter $\hat{T}_{T}$. Here, $\hat{T}_{T}$ is the total torque provided to the closed loop by the external AC motor to maintain an operation at the set $\Omega$ value, representing the total torque loss of the closed loop. Lastly, after a test is completed, the test apparatus is disengaged from the flexible coupling, and any electronic drift of the torque meter is recorded, regardless how small it is. Electronic drift occurs partly due to thermal expansion of the high speed spindle during the test, so it must be subtracted from $\hat{T}_{T}$ in order to obtain the actual input torque. This drift torque is typically less than $0.3-$ $0.4 \%$ of the measured $\hat{T}_{T}$ value.

\subsection{Inspection Procedure for Gear Specimens}

A total of twelve sets of spur gears were used throughout the experimental test regimen, six of which were used to study the influence of lubricating oil on power loss. Each set is formed by 2 identical gear pairs ( 4 gears). Since the gears were used for more 
than one test, it was critical to qualify that the tooth surfaces did not undergo changes in geometry and roughness throughout testing. For this purpose, two types of gear inspections were performed before and after each test. The first inspection was performed by using a Gleason M\&M 255 gear coordinate measurement machine (CMM), pictured in Fig. 2.4, to measure gear lead and profile variations from a perfect involute. This inspection documented the surfaces of new gears and quantified any wear accumulated after a given test.

Full CMM gear inspections of lead, index, pitch, and spacing were performed on the left flanks of all new gears. Right flanks were not measured, except in a few cases, because the left flanks were the loaded flanks during power loss testing. After each test, gears were removed from the gear efficiency test machine, cleaned with an alcohol solution, and re-inspected. After the first inspection, lead and profile measurements were performed in order to document the amount of wear, if any.

Figure 2.5 shows typical inspection results for a new ground test gear having 40 teeth. For lead measurements, deviation from a horizontal line represents deviation from a perfect involute profile across the face width. Index measurements indicate the deviation of gear tooth position from a perfect gear with no errors. Pitch inspections measure variations in circular pitch from a theoretically perfect tooth. Lastly, gear spacing inspections measure spacing errors between adjacent gear teeth. Pitch and tooth spacing are derived from index measurements. Thus, if the gear teeth are perfectly spaced with a uniform circular pitch, then each bar would be the same height of zero microns. These results show exceptional gear accuracy. The waveform observed in the index measurement is primarily due to the eccentricity introduced by the mounting arbor 


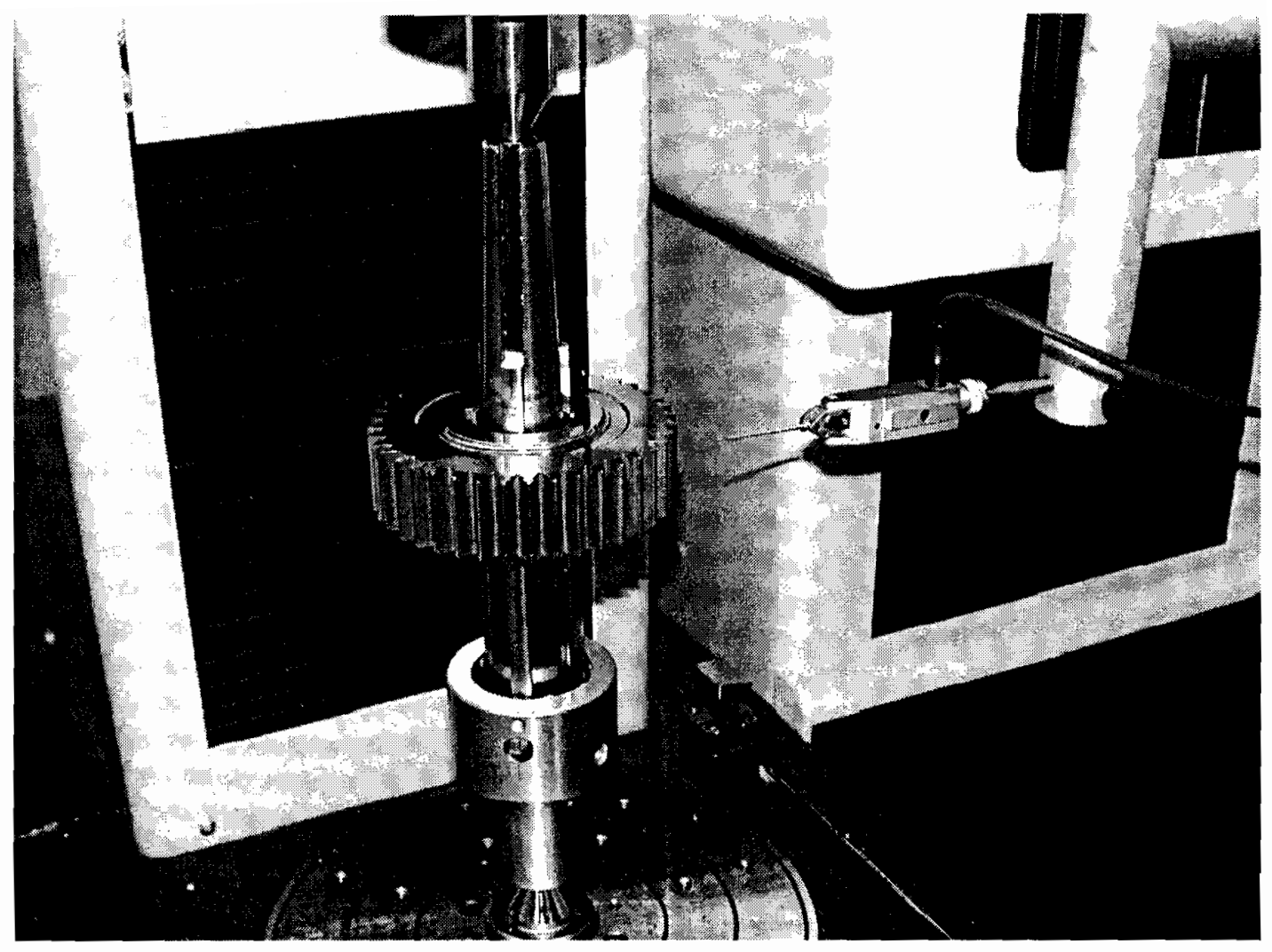

Figure 2.4 Gear CCM machine with a test gear mounted on the expanding arbor. 
(a)

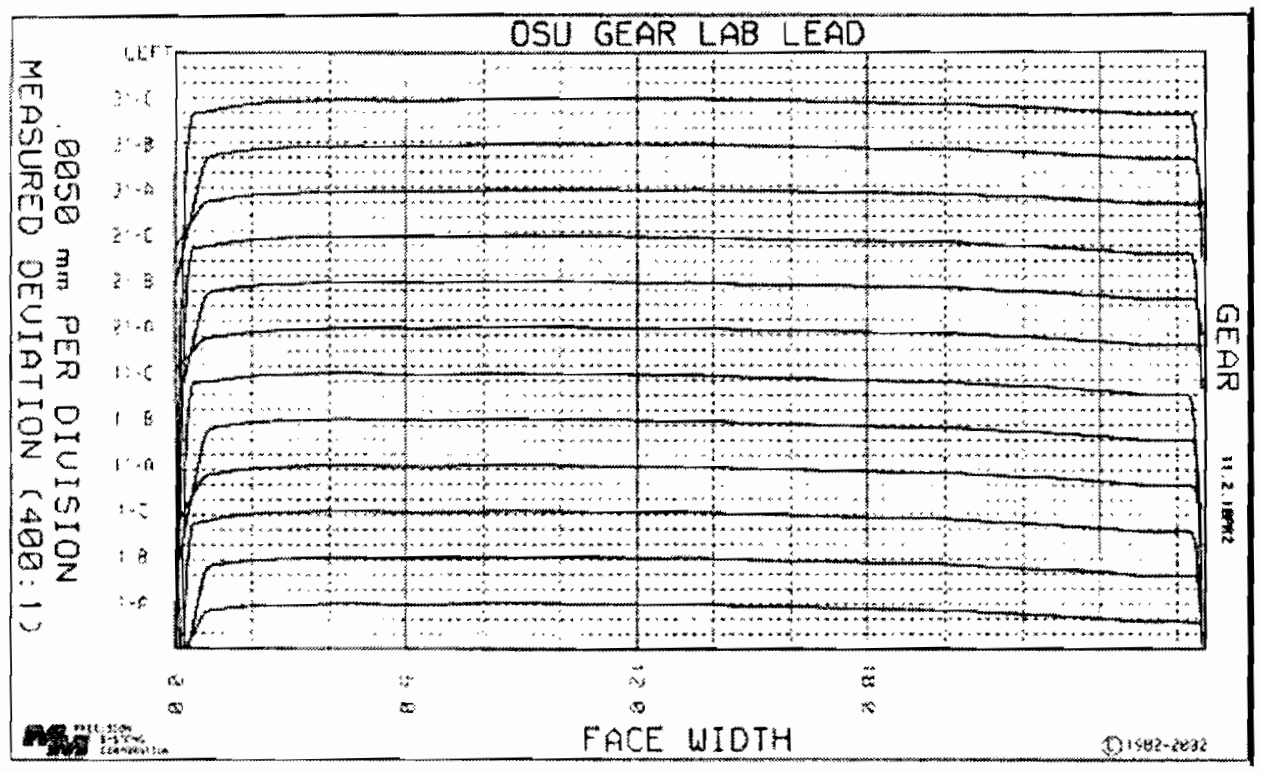

(b)

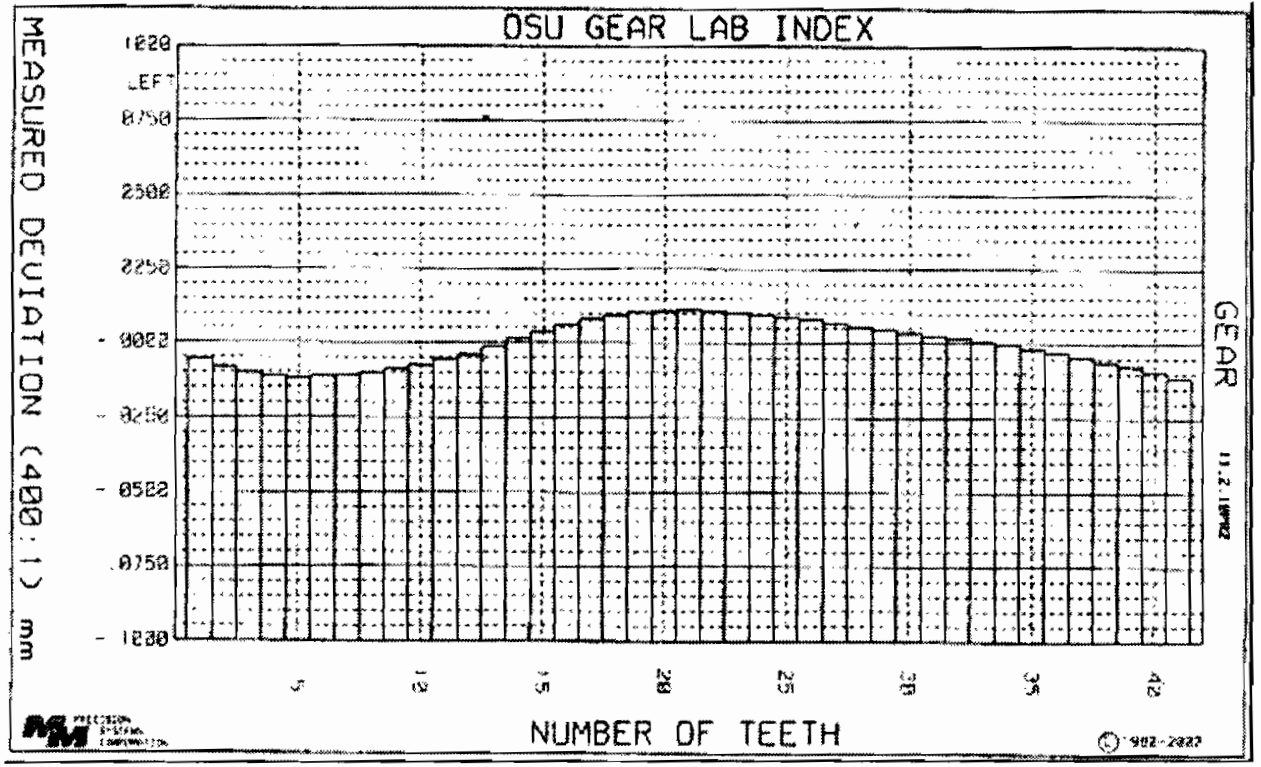

Figure 2.5 Gear CMM inspection results for a 40-tooth gear prior to run-in; (a) gear tooth lead measurements at three roll angles for four gear teeth, (b) gear index measurements, (c) gear pitch measurements, and (d) gear tooth spacing measurements. 
Figure 2.5 Continued.

(c)

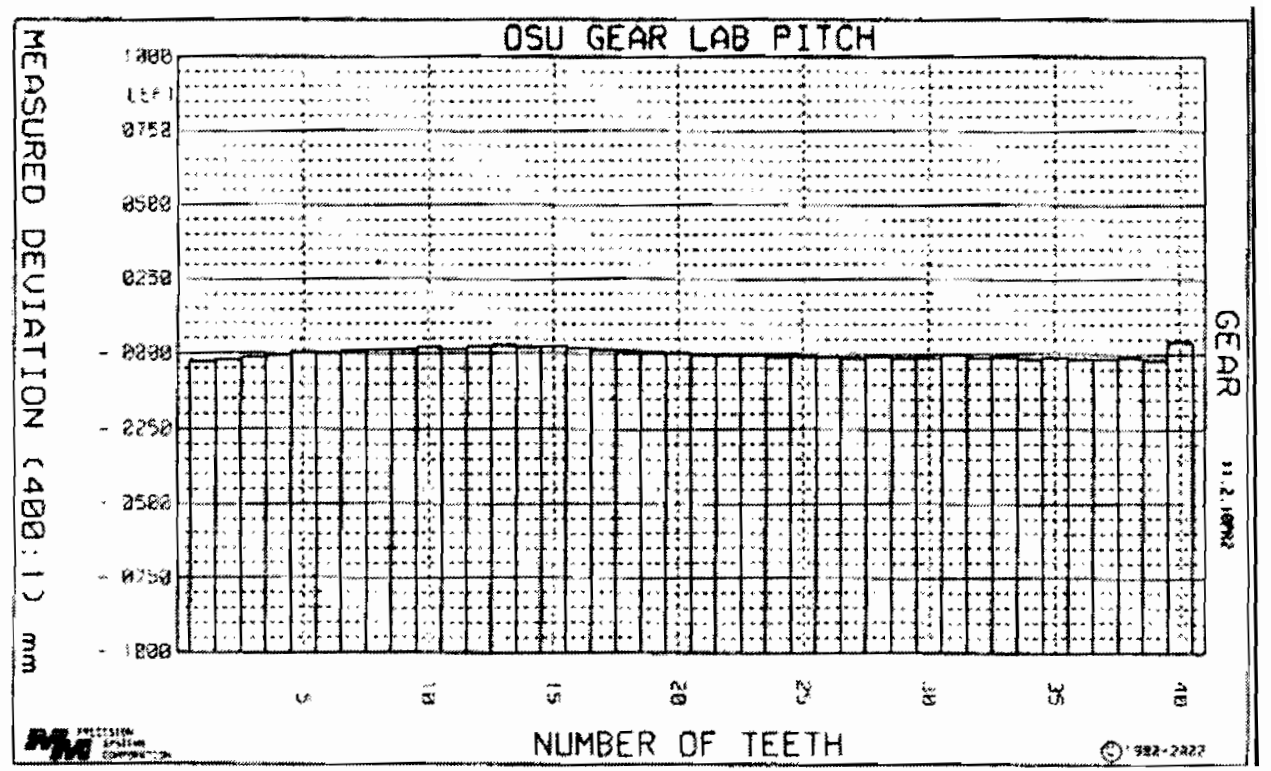

(d)

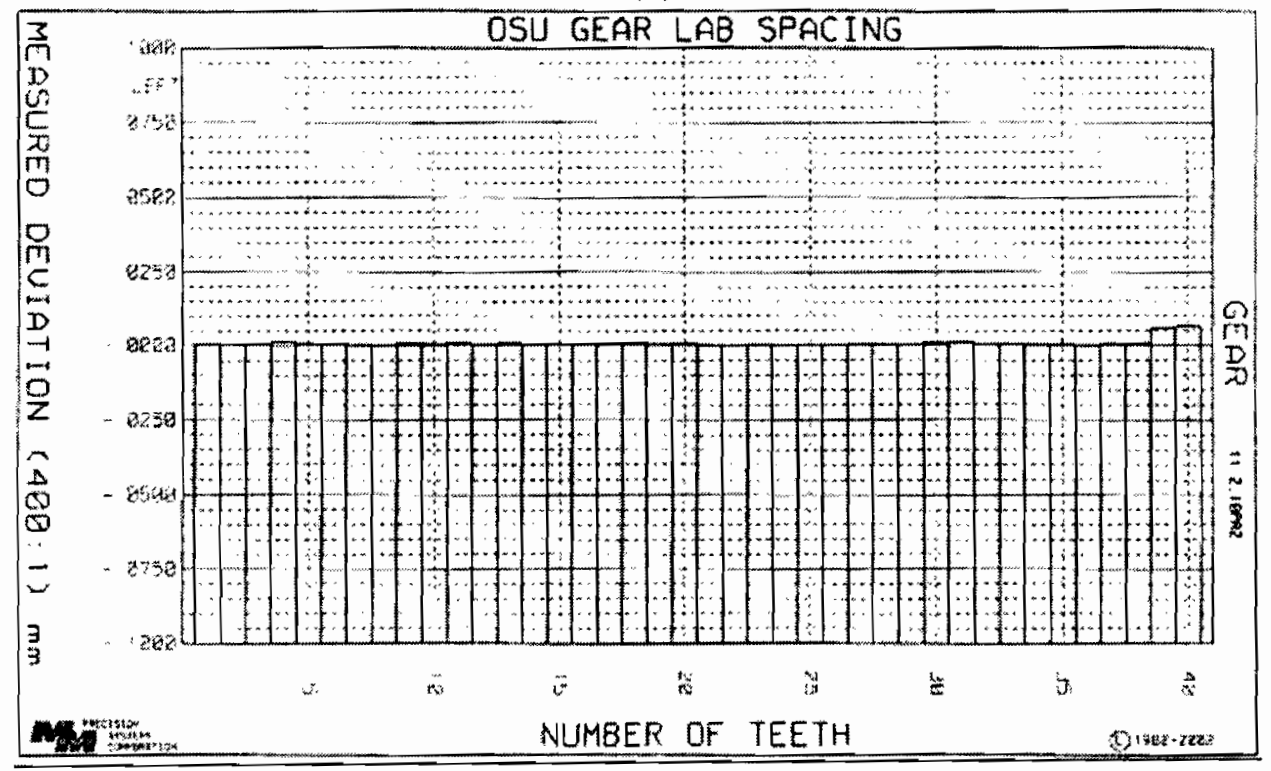


during inspection, rather than being an actual manufacturing error. The waveform is not observed in pitch or spacing figures because pitch and spacing depend on the difference between adjacent index measurements.

The second type of inspection was intended to measure gear tooth surface roughness profiles by using a Taylor-Hobson Form Talysurf-120 surface profiler. This inspection ensured that the changes in surface roughness amplitudes remained minimal throughout the test program. This surface profiler is capable of measuring variations in surface roughness to a resolution of $12 \mathrm{~nm}$. Measured roughness profiles are analyzed to compute typical roughness parameters, including centerline average roughness $R_{a}$, rootmean-square roughness $R_{q}$, and several other relevant surface parameters in characterizing topography. In order to ensure repeatable measurements, a gear-locating fixture was constructed and is pictured in Fig. 2.6 along with the Talysurf surface profiler. This fixture securely holds the gear in a position such that the tooth profile to be measured is mostly horizontal and perpendicular to the inspection probe. This was accomplished by mounting the gear on a pin designed for a close running fit with the gear bore. Above the gear, a bracket holds a brass locating screw against a gear tooth. A rubber band is wrapped between a gear tooth and the locating screw such that the gear is held snugly against the locating screw. The gear fixture has a rectangular locating recess on the bottom that fits the vee-block on the base plate of the surface profiler. This ensures that the desired position of the gear tooth surface is maintained throughout the test and the same exact position can be achieved in subsequent inspections.

Like the CMM gear profile accuracy inspections, gear surface roughness measurements were performed prior to gear run-in and after each subsequent test. 


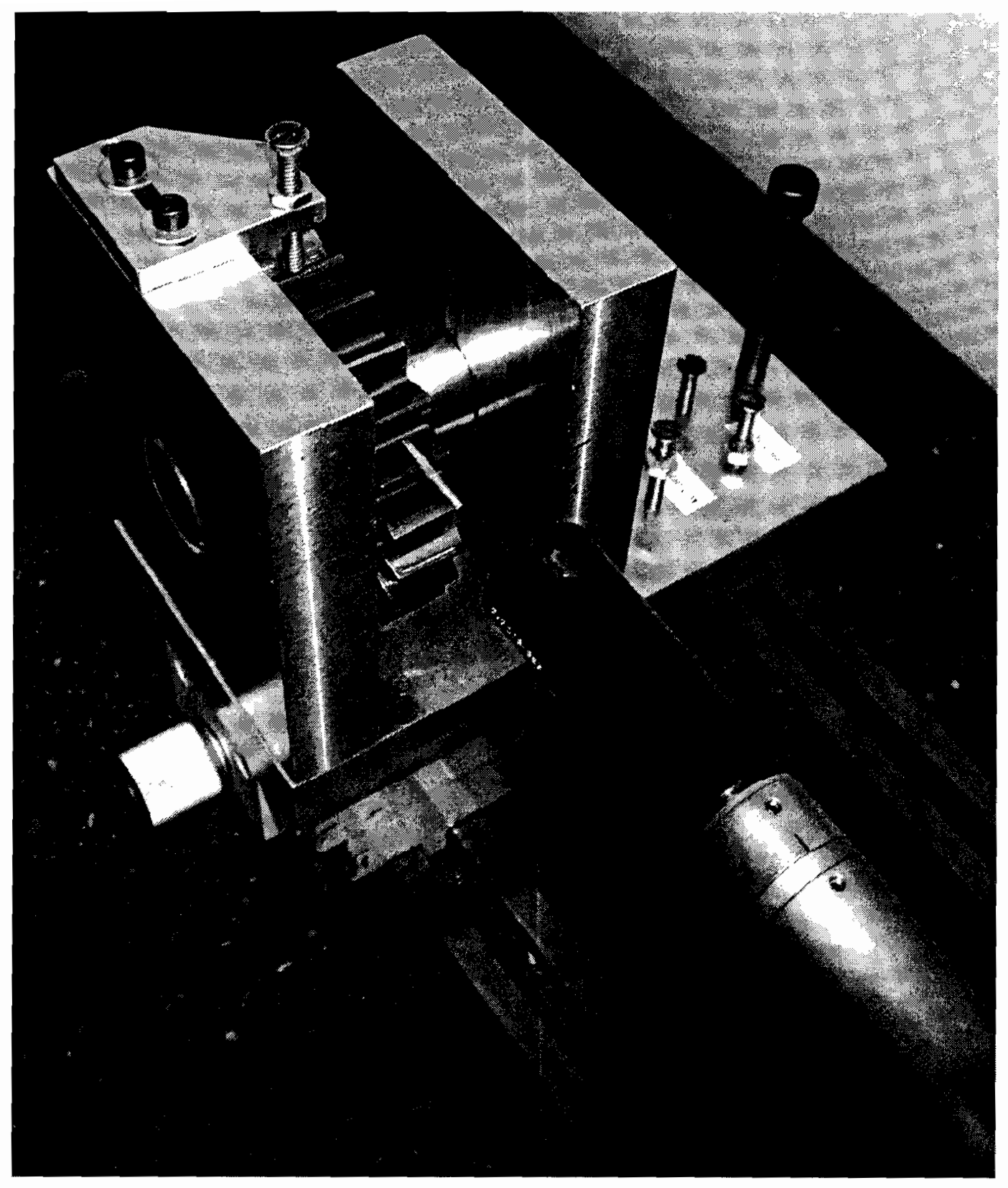

Figure 2.6 The gear locating fixture and the probe of the Talysurf surface profiler during a surface roughness measurement. 
Surface roughness measurements were performed for each test gear on both right and left flanks of two gear teeth spaced 90 degrees apart. Since the right flanks were not used for efficiency measurements, and thus remained unchanged throughout the test regimen, their measurements were used to establish statistical limits on the reliability of left flank measurements. Typical tooth roughness traces in the profile direction of the teeth of the 40-tooth ground and chemically polished run-in gears are illustrated in Fig 2.7.

Since surface topography measurements are highly dependent on the parameters defining the inspection routine, a study was performed in order to determine which inspection parameters resulted in the most accurate surface roughness measurement. Surface roughness measurements with the Talysurf machine were performed with sets of 23-tooth and 40-tooth gears. These measurements were compared to inspection results performed by the sponsor on a similar machine. The study resulted in selection of 16 cutoffs of $0.08 \mathrm{~mm}$ length for 40 -tooth gears, and 16 cutoffs of $0.25 \mathrm{~mm}$ length for 23 tooth and 17/26-tooth gears.

\subsection{Test Specimens and Test Matrix}

The objective of the test program was to investigate the impact of gear module, surface finish, manufacturing processes, low-friction coatings, and lubricant type on spur gear efficiency. Seven different sets of spur gears were procured for this purpose. For the study on gear module, 23 tooth (23T) ground gears with $m=3.95 \mathrm{~mm}$ are compared to 40 tooth (40T) ground gears, having $m=2.32 \mathrm{~mm}$. The center distance was identical for both gear pairs. In order to study the influence manufacturing processes used to finish tooth surfaces, $40 \mathrm{~T}$ hobbed-shaved gears were procured to compare to ground gears. The 
(a)

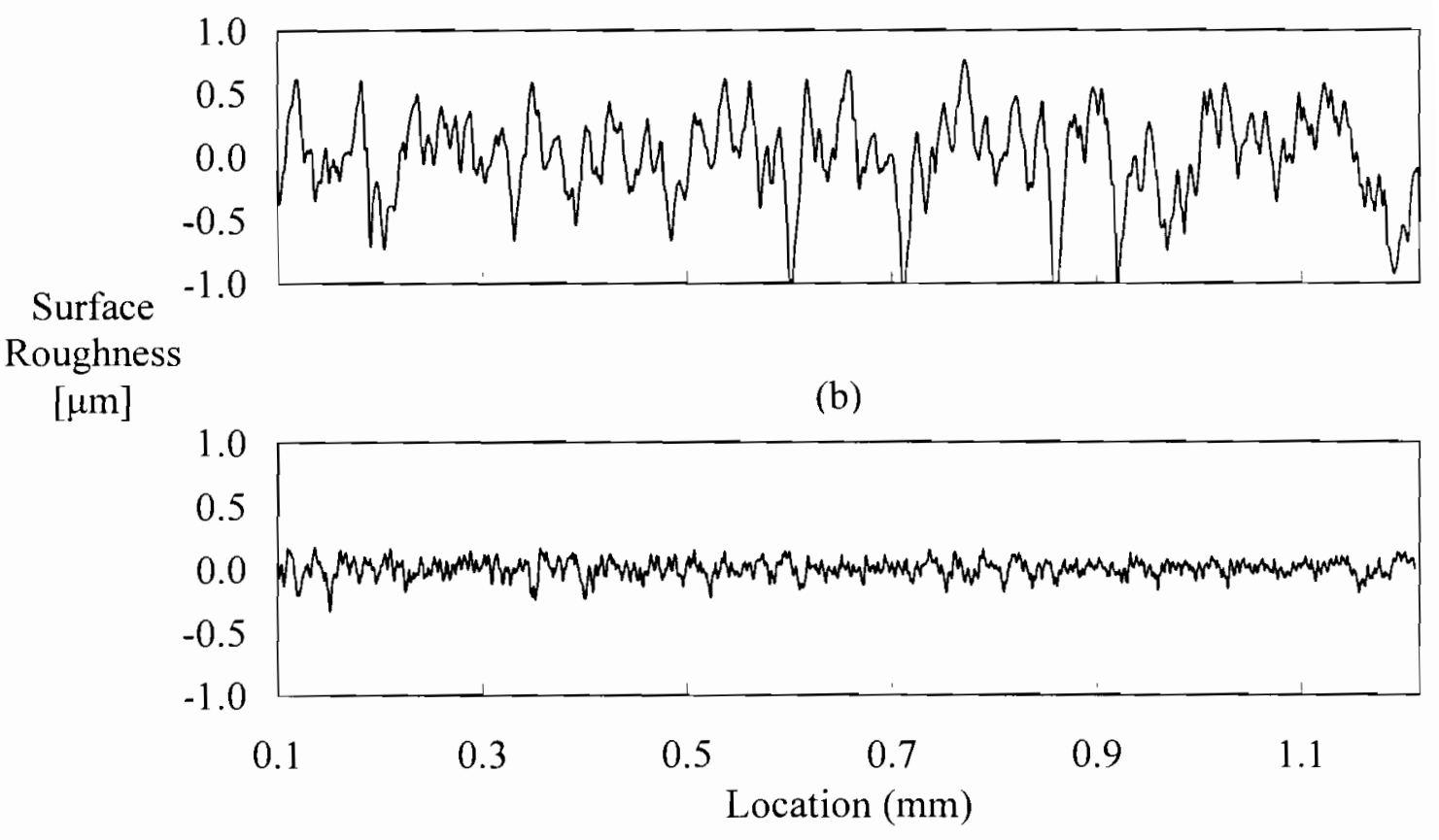

Figure 2.7 Typical surface roughness profiles for run-in 23-tooth test gears; (a) ground gears, and (b) chemically polished gears. 
hob-shaving process produces tooth surfaces that are not as accurate as ground surfaces. In addition, hobbed-shaved gears must be case-hardened after shaving, adding additional profile deviations due to heat treat distortions. Therefore, a comparison of hobbedshaved and hard-ground gears will also provide information about the influence of gear profile accuracy on gear efficiency.

The influence of the surface roughness will be documented by comparing sets of $23 \mathrm{~T}$ ground, 40T ground, and $40 \mathrm{~T}$ hobbed-shaved gears that were finished using a chemical polishing process that reduced $R_{a}$ to below 0.1 micron. Similarly, four sets of $40 \mathrm{~T}$ ground and chemically polished gears were coated with three different diamond-like carbon (DLC) coatings to investigate their influence on gear efficiency. One DLC coating, thought to be most effective, was applied to two different 40T gear sets. Finally, to study the influence of lubricating oil on efficiency, power loss measurements were performed with $23 \mathrm{~T}$ and $40 \mathrm{~T}$ ground and chemically polished gears in four different oils. The first two oils, designated Lubricants A and B, respectively, are heavy synthetic 75 W90 gear oils, the third oil, Lubricant $\mathrm{C}$, is a lower viscosity synthetic gear oil marketed as a more efficient blend, and the fourth oil, Lubricant D, is a common automatic transmission fluid.

Additionally, two sets of non-unity ratio gear pairs (17 tooth pinion and 26 tooth gear, 17/26T) were procured to represent a certain final drive application. Hobbedshaved, and hobbed-shaved plus chemically polished gear pairs were tested in both Lubricants A and D. The purpose of these tests was to approximate the influences of surface roughness and oil type in the actual application without procuring a special test 
machine specifically for the actual production gears. Table 2.1 summarizes the various tests and their purposes for the gear efficiency study. Table 2.2 lists design parameters of the $23 \mathrm{~T}, 40 \mathrm{~T}$ and $17 / 26 \mathrm{~T}$ test gears. Figure 2.8 shows samples of all the experimental test gears, while Fig. 2.9 shows a closer view of the gear tooth surfaces of the $23 \mathrm{~T}$ and 40T gears shown in Fig. 2.8. Figures 2.9(a) and 2.9(b) show 23T ground and chemically polished gear surfaces, respectively, while Fig. 2.9(c) and (d) show 40T ground and chemically polished gear surfaces. Figure 2.9(e) shows the 40T hobbed-shaved gear surfaces, while the $40 \mathrm{~T}$ hobbed-shaved plus chemically polished surfaces look identical to the ground plus chemically polished surfaces shown in Fig. 2.9(d). Figure 2.9(f) shows a 40T DLC coated gear surface.

Operating test conditions were varied for the different gear types and lubricants. The $23 \mathrm{~T}$ and $40 \mathrm{~T}$ gear pairs were used to simulate high performance gearing applications within a transmitted power range of $P_{c}=259$ to $716 \mathrm{~kW}(348-961 \mathrm{hp})$. These gears were operated at rotational speeds of $2,000 \mathrm{rpm}$ to $10,000 \mathrm{rpm}$ for unloaded tests and at 6,000 rpm to $10,000 \mathrm{rpm}$ under $T_{c}=413$ to $684 \mathrm{~N}$-m for loaded efficiency tests. Lubricant temperature for these tests was $110^{\circ} \mathrm{C}$. In order to simulate commercial automotive applications, 23T and 40T gears were operated at lower speed, torque and temperature levels with Lubricant $\mathrm{D}$ as the lubricating oil. In Lubricant $\mathrm{D}$, the gears were tested at $\Omega=2,000$ to $6,000 \mathrm{rpm}$, and $T_{c}=140$ to $413 \mathrm{~N}$-m, with lubricant temperature of $90^{\circ} \mathrm{C}$. These test conditions correspond to $P_{c}=23$ to $259 \mathrm{~kW}$ ( $\left.39-348 \mathrm{hp}\right)$, and represent typical production automotive operating conditions. 40T hobbed-shaved gears were operated 


\begin{tabular}{|c|c|c|c|c|}
\hline Test & Gear & Process & Lube Oil & Purpose \\
\hline 1 & $23 T$ & $\begin{array}{c}\text { Ground } \\
2\end{array}$ & Ground + Chem. Polished \\
\cline { 1 - 2 } & $40 T$ & $\begin{array}{c}\text { Ground } \\
\text { Lubricant A A }\end{array}$ & $\begin{array}{c}\text { Effect of Lubricant A for } \\
\text { Ground and Chemically } \\
\text { Polished Gears }\end{array}$ \\
\hline
\end{tabular}

\begin{tabular}{|c|c|c|c|c|}
\hline 5 & $23 T$ & Ground + Chem. Polished & Lubricant B & $\begin{array}{c}\text { Effect of Lubricant B for } \\
\text { Ground and Chemically } \\
\text { Polished Gears }\end{array}$ \\
\hline 7 & $40 T$ & $\begin{array}{c}\text { Ground } \\
8\end{array}$ & Ground + Chem. Polished &
\end{tabular}

\begin{tabular}{|c|c|c|c|c|}
\hline $\begin{array}{c}9 \\
10\end{array}$ & $23 T$ & Ground + Chem. Polished & Lubricant C & $\begin{array}{c}\text { Effect of Lubricant C for } \\
\text { Ground and Chemically } \\
\text { Polished Gears }\end{array}$ \\
\hline $\begin{array}{c}11 \\
12\end{array}$ & $40 \mathrm{~T}$ & $\begin{array}{c}\text { Ground } \\
\text { Ground + Chem. Polished }\end{array}$ & & Lound \\
\hline
\end{tabular}

\begin{tabular}{|c|c|c|c|c|}
\hline 13 & \multirow{2}{*}{ 40T } & DLC-A & \multirow{4}{*}{ Lubricant A } & \multirow{4}{*}{ Effect of DLC Coatings } \\
\hline 14 & & DLC-B & & \\
\hline 15 & \multirow{2}{*}{ 40T } & $\mathrm{DLC}-\mathrm{C}$ & & \\
\hline 16 & & DLC-D & & \\
\hline
\end{tabular}

\begin{tabular}{|c|c|c|c|c|}
\hline $\begin{array}{l}17 \\
18 \\
\end{array}$ & $23 \mathrm{~T}$ & $\begin{array}{c}\text { Ground } \\
\text { Ground + Chem. Polished }\end{array}$ & \multirow{3}{*}{ Lubricant D } & \multirow{3}{*}{$\begin{array}{c}\text { Effect of Hob/Shave and } \\
\text { chemical polishing - } \\
\text { commercial automotive } \\
\text { applications }\end{array}$} \\
\hline $\begin{array}{l}19 \\
20\end{array}$ & \multirow{2}{*}{$40 T$} & $\begin{array}{c}\text { Ground } \\
\text { Ground + Chem. Polished }\end{array}$ & & \\
\hline $\begin{array}{l}21 \\
22\end{array}$ & & $\begin{array}{c}\text { Hob / shave } \\
\text { Hob / shave + Chem. Polished }\end{array}$ & & \\
\hline
\end{tabular}

\begin{tabular}{|c|c|c|c|c|}
\hline $\begin{array}{l}23 \\
24\end{array}$ & \multirow{2}{*}{$17 / 26 \mathrm{~T}$} & $\begin{array}{c}\text { Hob / shave } \\
\text { Hob / shave + Chem. Polished }\end{array}$ & Lubricant A & \multirow{2}{*}{$\begin{array}{l}\text { Hypoid Simulation - } \\
\text { commercial automotive } \\
\text { applications }\end{array}$} \\
\hline $\begin{array}{l}25 \\
26\end{array}$ & & $\begin{array}{c}\text { Hob / shave } \\
\text { Hob / shave + Chem. Polished }\end{array}$ & Lubricant D & \\
\hline
\end{tabular}

Table 2.1 Spur gear efficiency experimental test plan. 


\begin{tabular}{|c|c|c|c|c|}
\hline Parameter & $23 \mathrm{~T}$ & $40 \mathrm{~T}$ & $17 \mathrm{~T}$ & $26 \mathrm{~T}$ \\
\hline Module & 3.95 & 2.32 & \multicolumn{2}{|c|}{4.23} \\
\hline Pressure Angle, deg. & 25.0 & 28.0 & \multicolumn{2}{|c|}{22.5} \\
\hline Face Width & 19.50 & 26.7 & 14.00 & 20.29 \\
\hline Center Distance & 91.50 & 91.50 & 91.50 & 91.50 \\
\hline Pitch Diameter & 90.86 & 92.74 & 71.97 & 110.07 \\
\hline Base Diameter & 82.34 & 81.89 & 66.49 & 101.69 \\
\hline Outside Diameter & 100.34 & 95.95 & 80.02 & 117.11 \\
\hline Root Diameter & 81.30 & 85.80 & 62.87 & 99.82 \\
\hline Start of Active Profile & 85.38 & 87.73 & 67.92 & 105.33 \\
\hline Circular Tooth Thickness & 6.435 & 2.925 & 7.81 & 5.65 \\
\hline Root Fillet & 1.63 & 0.83 & 1.68 & 2.74 \\
\hline
\end{tabular}

Table 2.2 Gear design parameters for 23T, 40T, 17T, and 26T gears used in the spur gear efficiency study. Units are in mm unless otherwise specified. 


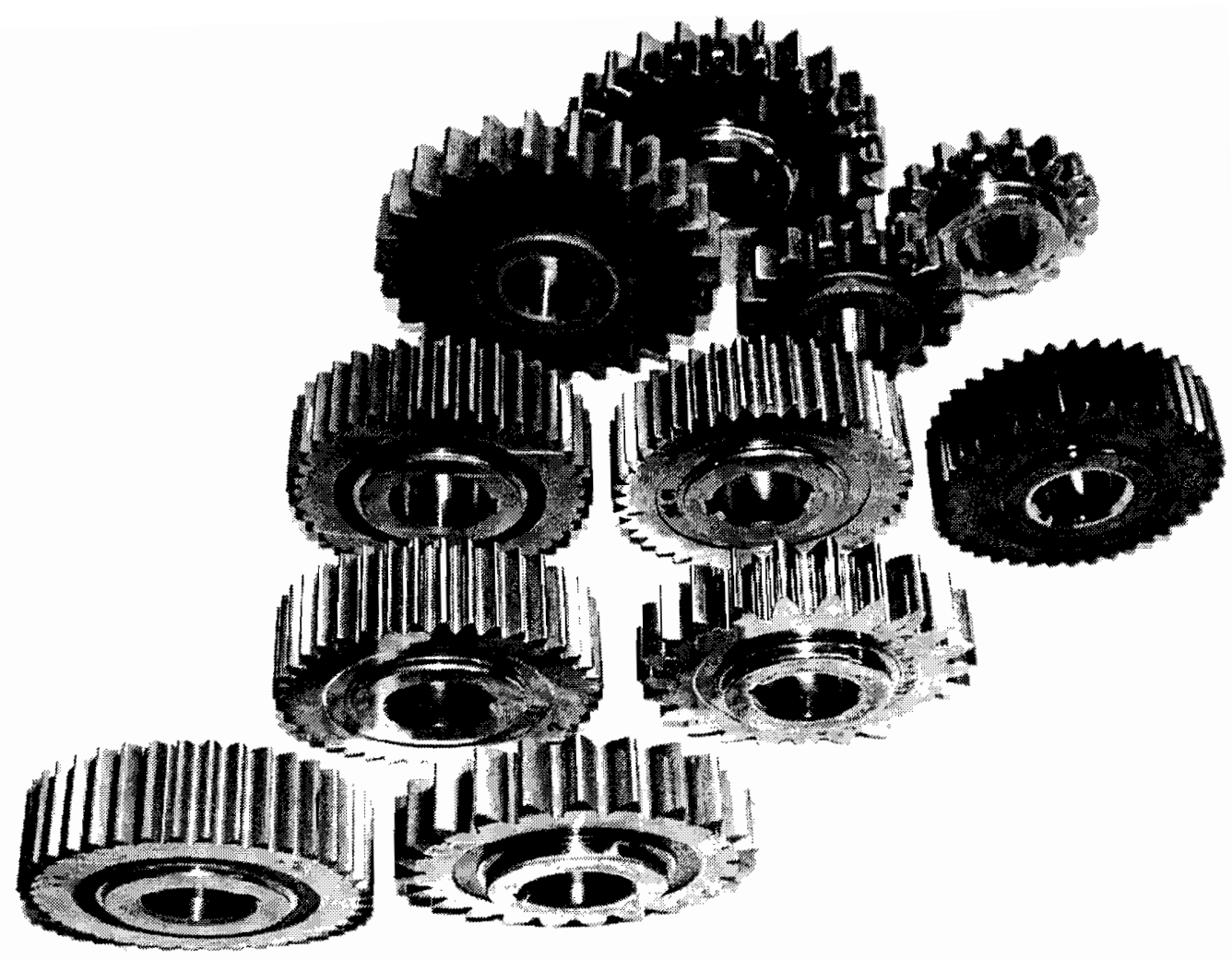

Figure 2.8 Samples of the experimental test gears used in the gear efficiency study 
under these test conditions as well. In accordance with their intended application, tests with $17 / 26 \mathrm{~T}$ gears were performed at pinion (17T) speeds of $\Omega=500$ to $2,500 \mathrm{rpm}$ (gear speeds of $\Omega=327$ to $1,635 \mathrm{rpm}$ ), and pinion torques of $T_{c}=214 \mathrm{~N}-\mathrm{m}$ to $621 \mathrm{~N}-\mathrm{m}$ (gear torques of $T_{c}=140 \mathrm{~N}-\mathrm{m}$ to $413 \mathrm{~N}-\mathrm{m}$, representing $P_{c}=7$ to $106 \mathrm{~kW}(10-142 \mathrm{hp})$. The $17 / 26 \mathrm{~T}$ gears were operated in Lubricant $\mathrm{D}$ at $90^{\circ} \mathrm{C}$, and in Lubricant $\mathrm{A}$ at $48^{\circ} \mathrm{C}$. Tables 2.3 and 2.4 summarize operating test conditions for the $23 \mathrm{~T}$ and $40 \mathrm{~T}$ gears, and 17/26T gears, respectively.

Test sequence was governed by time constraints, torque acquisition system characteristics, and availability of rotating components. Tests generally progressed from low torque to high torque, and high speed to low speed. Testing began with low torques because the gear run-in procedure was at the lowest torque level. That way, $T_{c}$ would be changed a minimum number of times. A typical test sequence started at $10,000 \mathrm{rpm}$ and decreased in subsequent tests due to the most desirable torque-meter operating characteristics. The manufacturer recommends exercising the torque meter to full scale three times before calibration. Since drive torque is higher for higher rotational speeds, operating at the highest speed first had the approximate effect of exercising the torque meter to the highest range first since subsequent measurements at lower rotational speeds would fall below the initial drive torque. Table 2.5 displays the test sequence of operating conditions for all gears. 

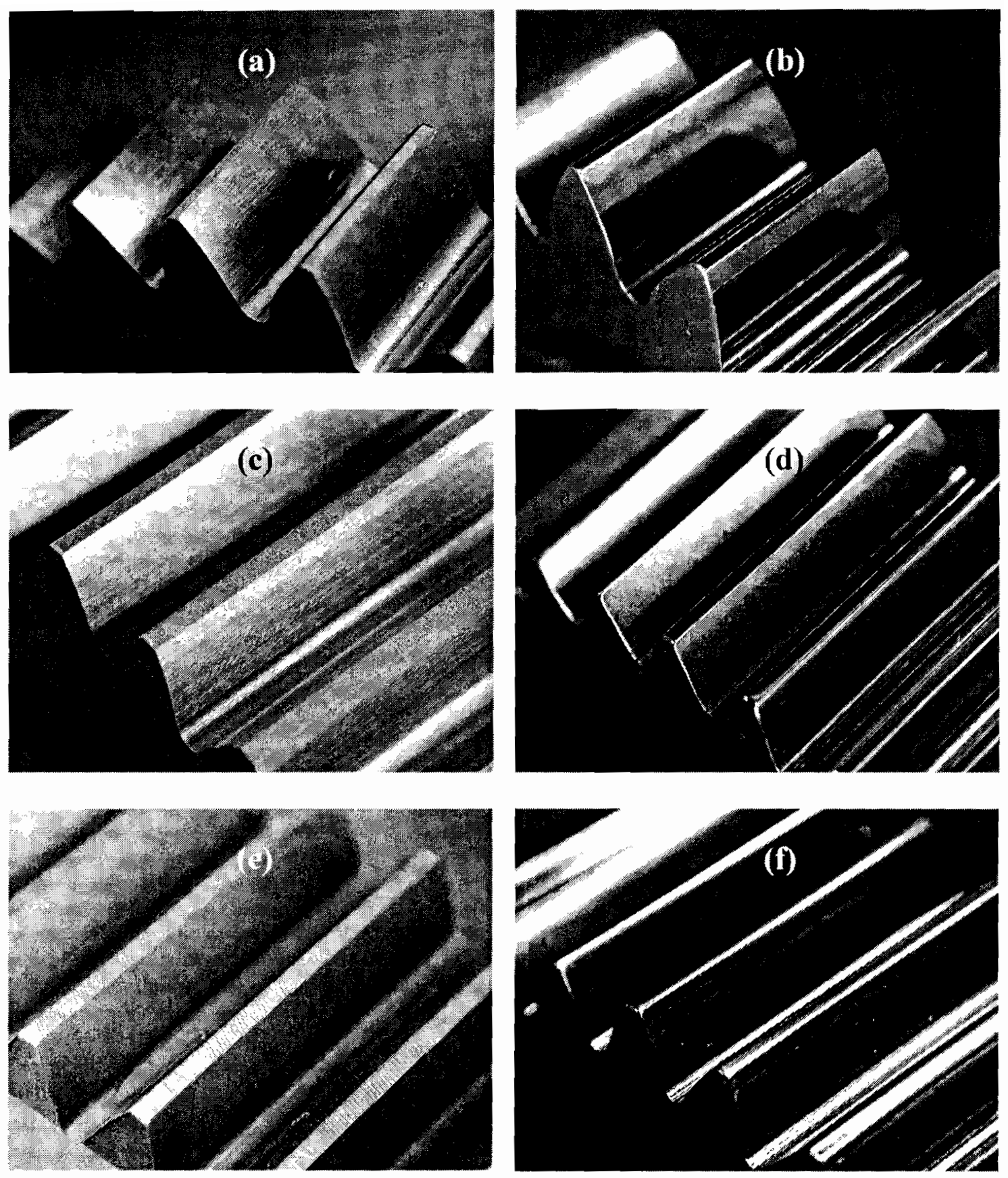

Figure 2.9 Various test gear surfaces; (a) 23T ground gear, (b) $23 \mathrm{~T}$ chemically polished gear, (c) 40T ground gear, (d) 40T chemically polished gear, (e) 40T hobbed-shaved gear, and (f) 40T DLC coated gear. 
Test Condition $\quad$ Rotational Speed, $\Omega \quad$ Pitch-Line Velocity $\quad$ Loop Torque, $T_{c}$ [rpm] $[\mathrm{m} / \mathrm{s}]$ [Nm]

\begin{tabular}{cccc}
\hline 1 & 2,000 & 10 & 239 \\
2 & 2,000 & 10 & 413 \\
3 & 2,000 & 10 & 546 \\
\hline 4 & 4,000 & 19 & 239 \\
5 & 4,000 & 19 & 413 \\
6 & 4,000 & 19 & 546 \\
\hline 7 & 6,000 & 29 & 239 \\
8 & 6,000 & 29 & 413 \\
9 & 6,000 & 29 & 546 \\
10 & 6,000 & 29 & 684 \\
\hline 11 & 8,000 & 38 & 413 \\
12 & 8,000 & 38 & 546 \\
13 & 8,000 & 38 & 684 \\
\hline 14 & - & 48 & 413 \\
15 & 10,000 & 48 & 684 \\
16 & 10,000 & 48 & 0 \\
\hline 17 & 10,000 & 48 & 0 \\
18 & 10,000 & 38 & 0 \\
19 & 8,000 & 29 & 0 \\
20 & 6,000 & 19 & 0 \\
21 & 4,000 & 10 & 0 \\
\hline
\end{tabular}

Table 2.3 Operating test conditions for 23T and 40T ground, hobbed and shaved, and chemically polished gear pairs operated with lubricants $\mathrm{A}, \mathrm{B}$, and $\mathrm{C}$ at $110^{\circ} \mathrm{C}$, and Lubricant $\mathrm{D}$ at $90^{\circ} \mathrm{C}$. 


\begin{tabular}{cccc} 
Test Condition & $\begin{array}{c}\text { Pinion Speed, } \Omega \\
{[\mathrm{rpm}]}\end{array}$ & $\begin{array}{c}\text { Pitch-Line Velocity } \\
{[\mathrm{m} / \mathrm{s}]}\end{array}$ & $\begin{array}{c}\text { Pinion Torque } \\
{[\mathrm{Nm}]}\end{array}$ \\
\hline & 500 & 2 & 140 \\
22 & 500 & 2 & 239 \\
23 & 500 & 2 & 406 \\
\hline 25 & 1,000 & 4 & 140 \\
26 & 1,000 & 4 & 239 \\
27 & 1,000 & 4 & 406 \\
\hline 28 & 1,500 & 6 & 140 \\
29 & 1,500 & 6 & 239 \\
30 & 1,500 & 6 & 406 \\
\hline 31 & & 10 & 140 \\
32 & 2,530 & 10 & 239 \\
33 & 2,530 & 10 & 406 \\
\hline 34 & 2,530 & 2 & 0 \\
35 & & 4 & 0 \\
36 & 500 & 6 & 0 \\
37 & 1,000 & 10 & 0 \\
\hline
\end{tabular}

Table 2.4 Operating test conditions for 17/26T hobbed-shaved and hobbed-shaved plus chemically polished gear pairs in lubricant $\mathrm{D}$ at $90^{\circ} \mathrm{C}$, and lubricant $\mathrm{A}$ at $48^{\circ} \mathrm{C}$. 
23T and 40T gears in Lubricants $A, B$, and $C$

\begin{tabular}{cccccc}
\hline $\begin{array}{c}\text { Loop Torque } \\
{[\mathrm{N}-\mathrm{m}]}\end{array}$ & 2,000 & 4,000 & 6,000 & 8,000 & 10,000 \\
\hline 0 & 20 & 19 & 18 & 17 & 16 \\
413 & 5 & 4 & 3 & 2 & 1 \\
546 & 10 & 9 & 8 & 7 & 6 \\
684 & 15 & 14 & 13 & 12 & 11
\end{tabular}

\section{T and 40T gears in Lubricant $D$}

Loop Torque

$[\mathrm{N}-\mathrm{m}]$

_

2,000

$\frac{\text { Rotational Speed [rpm] }}{4,000}$

\begin{tabular}{cccc}
\hline 0 & 12 & 11 & 10 \\
239 & 9 & 8 & 7 \\
413 & 3 & 2 & 1 \\
546 & 6 & 5 & 4 \\
\hline
\end{tabular}

\section{7/26T gears in Lubricants $A$ and $D$}

\begin{tabular}{ccccc}
$\begin{array}{c}\text { Pinion Torque } \\
{[\mathrm{N}-\mathrm{m}]}\end{array}$ & \multicolumn{4}{c}{ Pinion Rotational Speed $[\mathrm{rpm}]$} \\
\hline 0 & 500 & 1,000 & 1,500 & 2,530 \\
\hline 239 & 16 & 15 & 14 & 13 \\
413 & 4 & 3 & 2 & 1 \\
546 & 8 & 7 & 6 & 5 \\
& 12 & 11 & 10 & 9 \\
\hline
\end{tabular}

Table 2.5 Experimental test sequence for all gears and operational parameters 


\subsection{Accuracy and Repeatability}

In order to have confidence in the efficiency data collected, all test specimens must initially be qualified in terms of their specified dimensions, tooth profile accuracy, and the required initial surface roughness amplitudes. Once qualified, these initial baseline profiles must be regularly compared to profiles measured after each test to ensure that profiles remain relatively unchanged to alter the data and the efficiency comparison. Likewise, the changes in tooth profile surface roughness after each test must also be monitored. If significant changes in surface roughness amplitudes of a test gear are observed, then the interpretation of the collected data must account for such changes. The following sections outline gear CMM and surface roughness measurements performed regularly to ensure the stability of the tooth surfaces in terms of their microgeometry (wear) and surface roughness. Once the consistency of the test specimens throughout the tests are verified, the next item to check is the repeatability and the accuracy of the test machine and its sensors. The last two sub-sections are intended to show the repeatability and accuracy of the test machine and its auxiliary components.

\section{Gear Accuracy and Check for Surface Wear}

In order to document gear tooth surface wear, three CMM lead measurements were performed on four gear teeth for each test gear after every test. $23 \mathrm{~T}$ and $40 \mathrm{~T}$ chemically polished gears were operated for four tests in the four lubricating oils of interest, while $23 \mathrm{~T}$ and $40 \mathrm{~T}$ ground gears were operated in the same tests as well as an additional repeatability test. $40 \mathrm{~T}$ hobbed-shaved gears were only operated in Lubricant D, while the 17/26T hobbed-shaved gears were operated in both Lubricants A and D. 
DLC coated gear pairs were operated in both Lubricant A and Lubricant B. Figure 2.10 compares new CMM inspection results of one of the new gears in each set to the same gear after all tests were completed. Figures 2.10(a) and 2.10(b) show CMM inspection results for a $23 \mathrm{~T}$ ground and a $23 \mathrm{~T}$ chemically polished gear, respectively. Figures 2.10(c) and 2.10(d) show CMM inspection results for a 40T ground, and a 40T chemically polished gear, respectively. Figures $2.10(\mathrm{e})$ and $2.10(\mathrm{f})$ show lead traces for both left and right flanks for 40T hobbed-shaved gears, and 40T hobbed-shaved plus chemically polished gears, respectively. Figures $2.10(\mathrm{~g})$ and $2.10(\mathrm{~h})$ show lead traces for a 17/26T hobbed-shaved gear, and a 17/26T hobbed-shaved plus chemically polished gear, respectively. Results from Figure 2.10 can be summarized as follows:

- All gear surfaces showed little to no discernable wear throughout the test regimen (less than $5 \mu \mathrm{m}$ ).

- Hobbed-shaved gears were characterized by manufacturing profile deviations in surface height of about $5 \mu \mathrm{m}$, each usually less than $1 \mathrm{~mm}$ in length across the face width.

- Ground gears were characterized by flat, uniform lead traces with no local variations in surface height that is characteristic of hobbed-shaved gears.

- $40 \mathrm{~T}$ hobbed-shaved plus chemically polished gears exhibited significantly better lead traces compared to the baseline hobbed-shaved gears.

- $23 \mathrm{~T}$ and 40T gears exhibited a lead slope of nearly $5 \mu \mathrm{m}$ across the face width. 
(a)

New

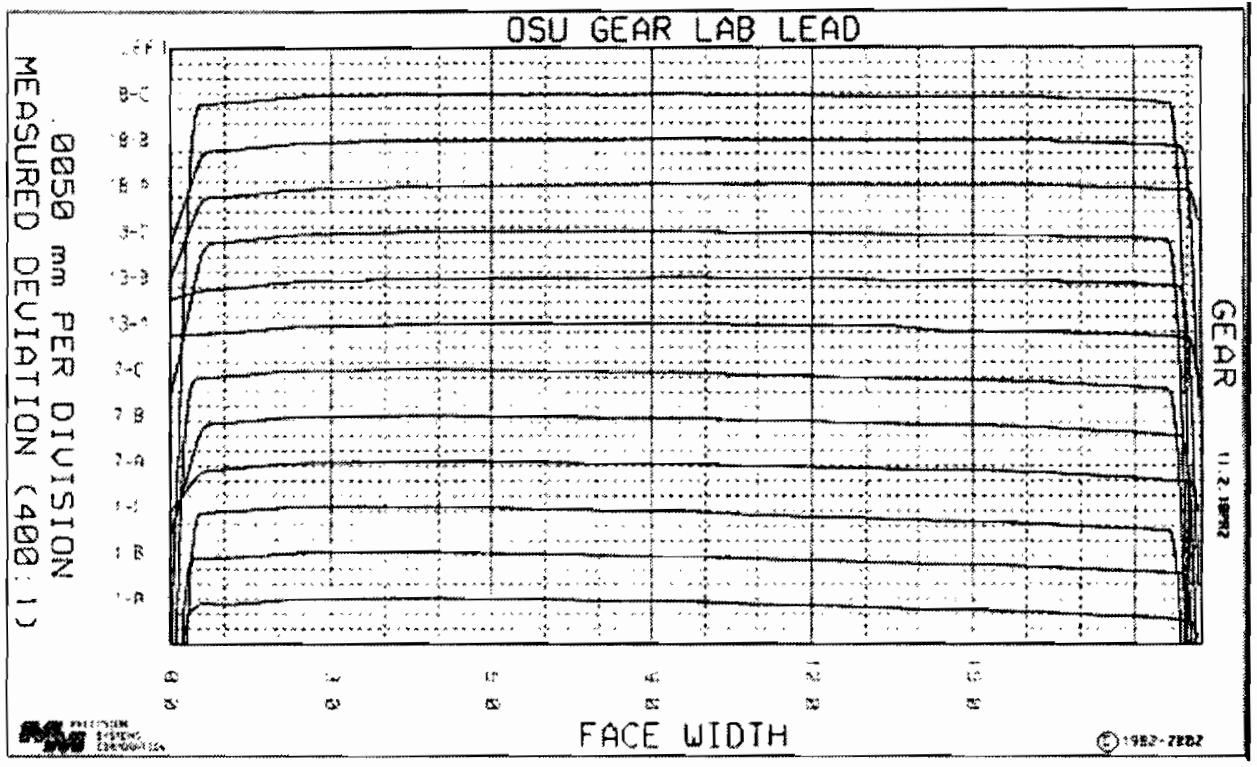

Run-In

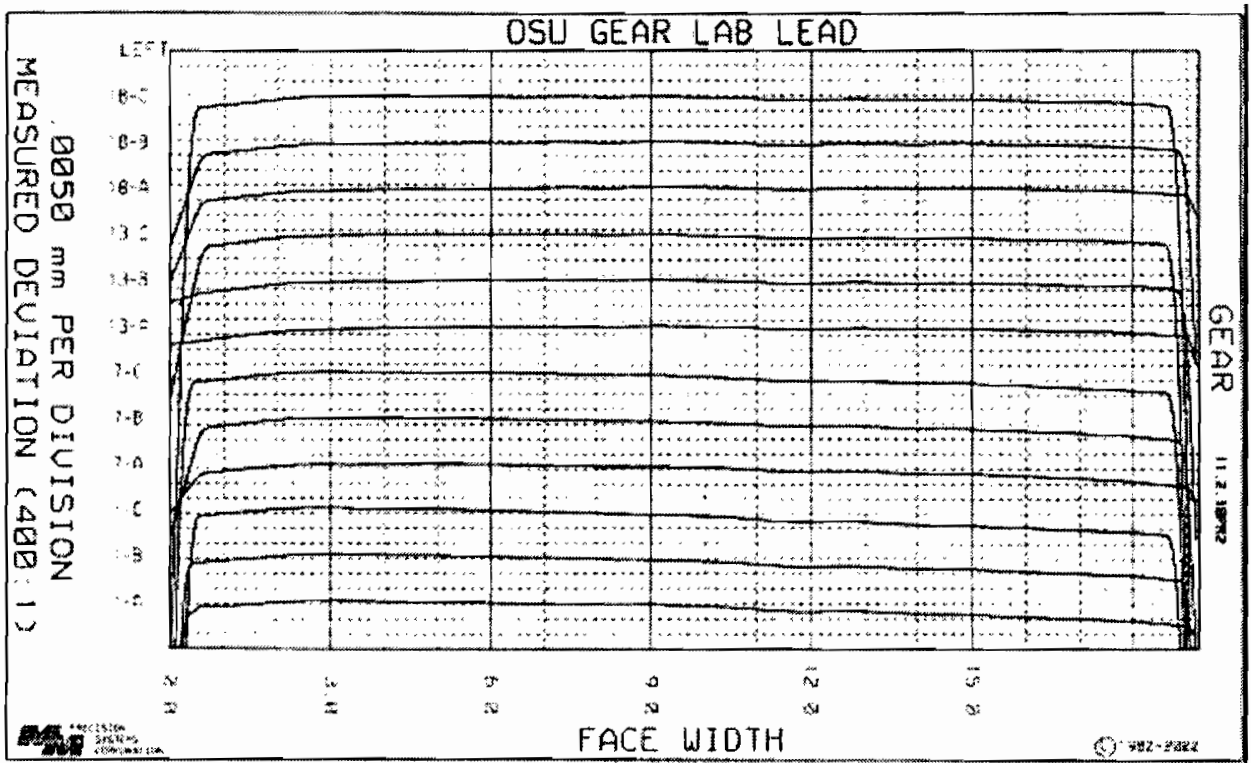

Figure 2.10 CMM gear accuracy inspection results of new gear surface and gear surface after completion of all testing for one gear in each design category; (a) $23 \mathrm{~T}$ ground gear, (b) $23 \mathrm{~T}$ chemically polished gear, (c) $40 \mathrm{~T}$ ground gear, (d) $40 \mathrm{~T}$ chemically polished gear, (e) 40T hobbed and shaved, (f) 40T hobbed and shaved plus chemically polished, (g) 17/26T hobbed and shaved, (h) 17/26T hobbed and shaved plus chemically polished.

(continued) 
Figure 2.10 Continued.

(b)

New

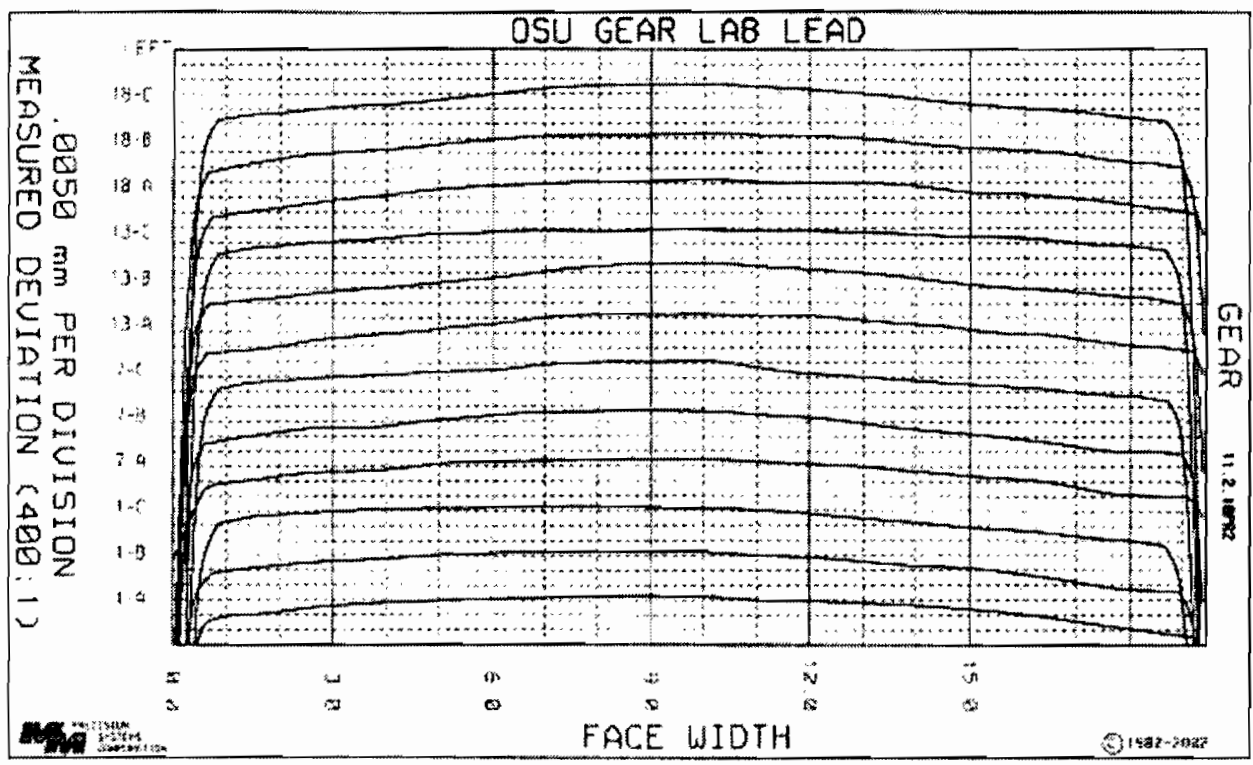

Run-In

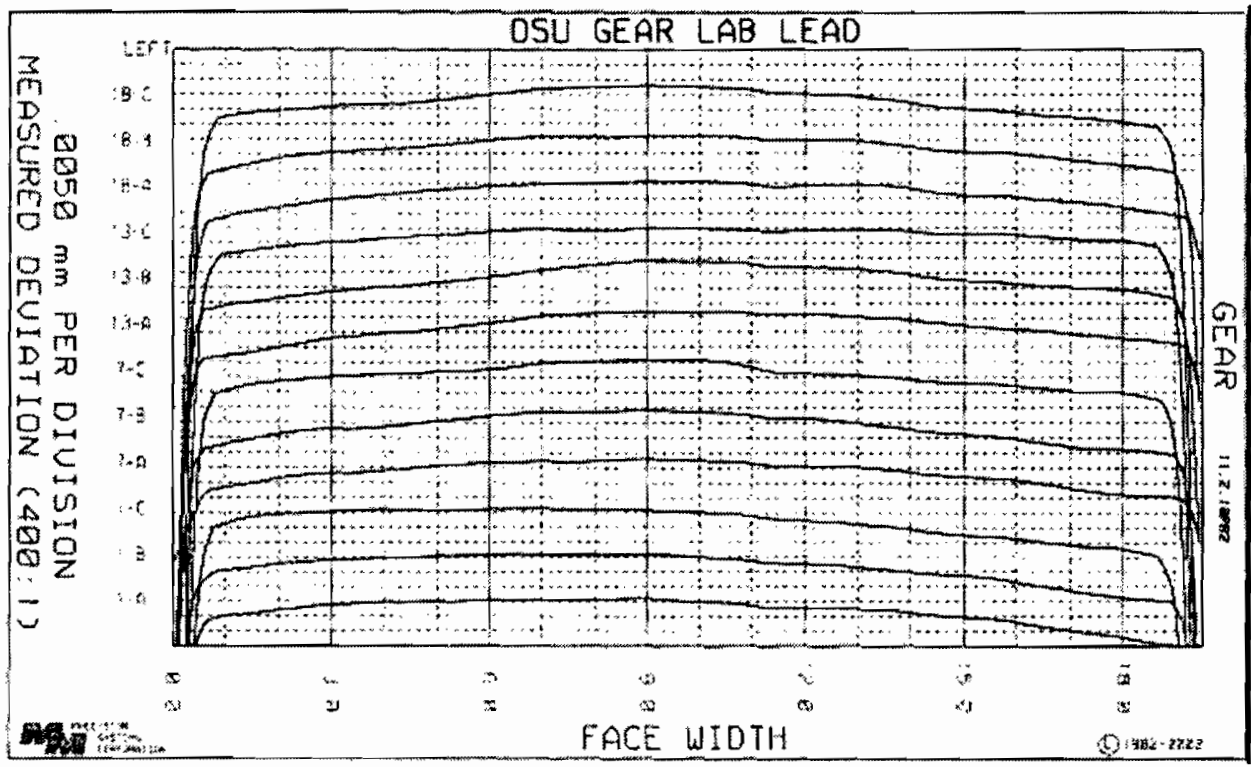

(Continued) 
Figure 2.10 Continued.

(c)

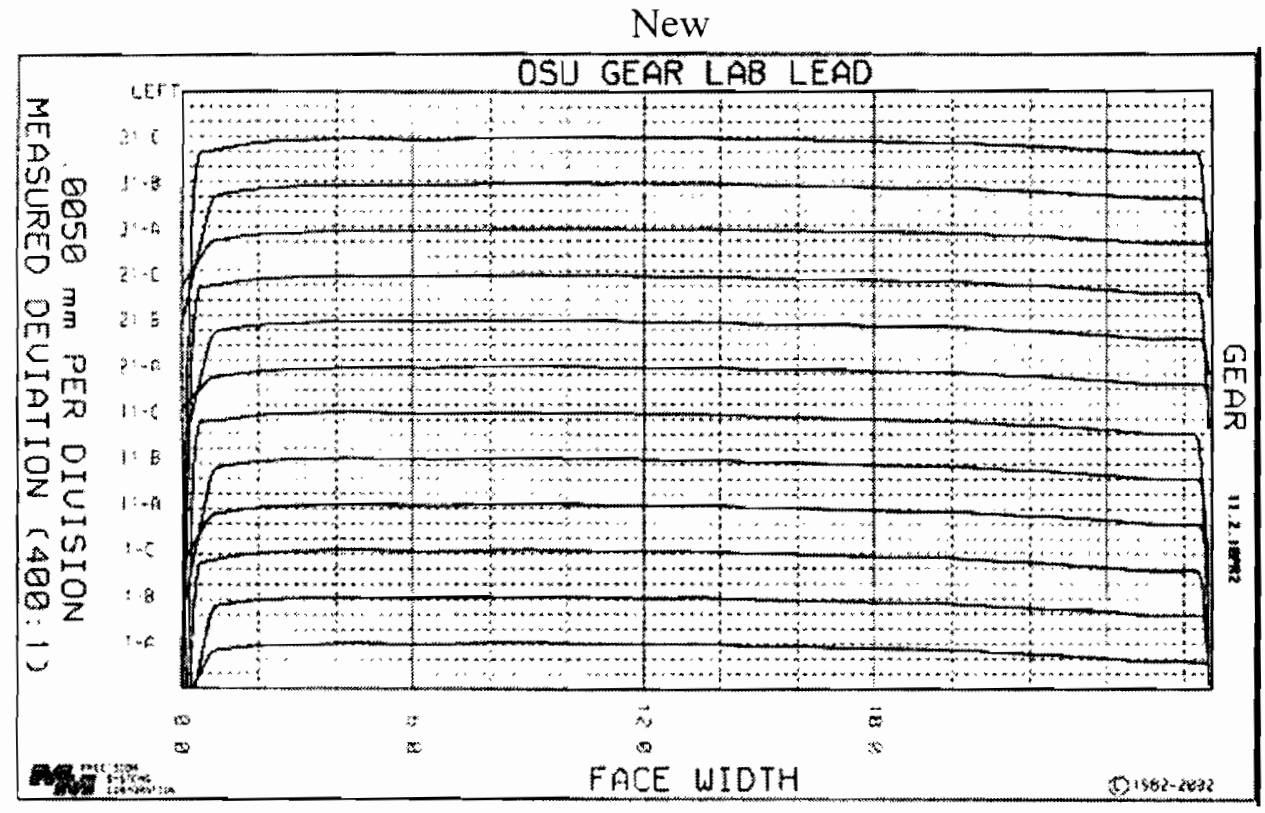

Run-In

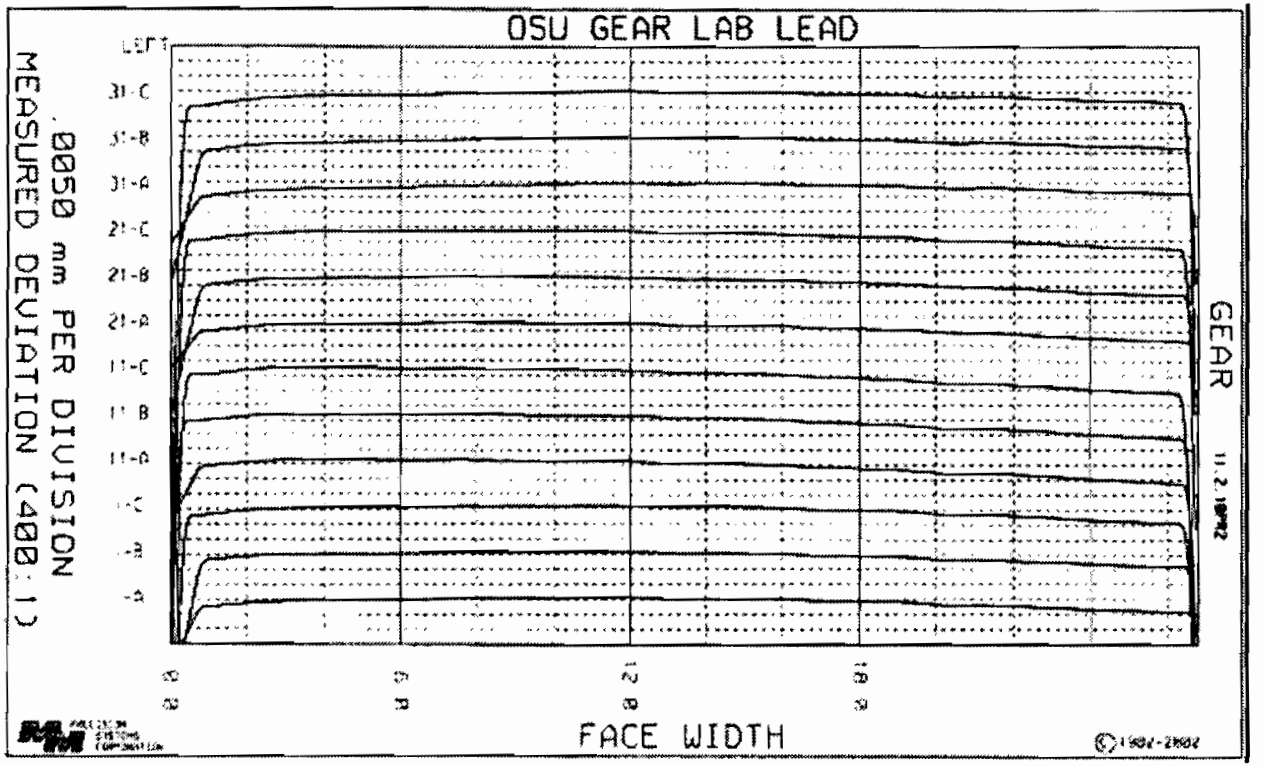

(Continued) 
Figure 2.10 Continued.

(d)
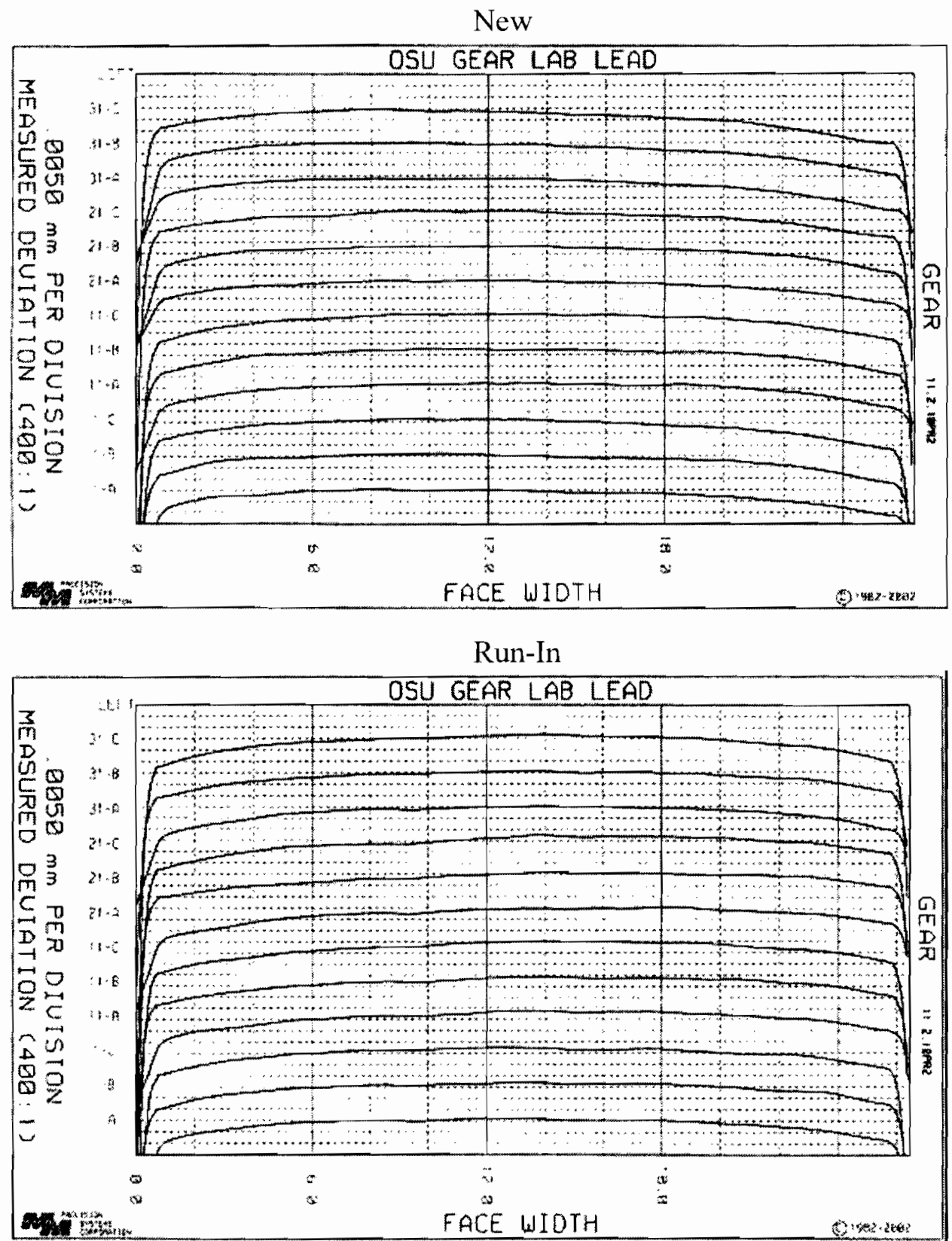

(Continued) 
Figure 2.10 Continued.

(e)
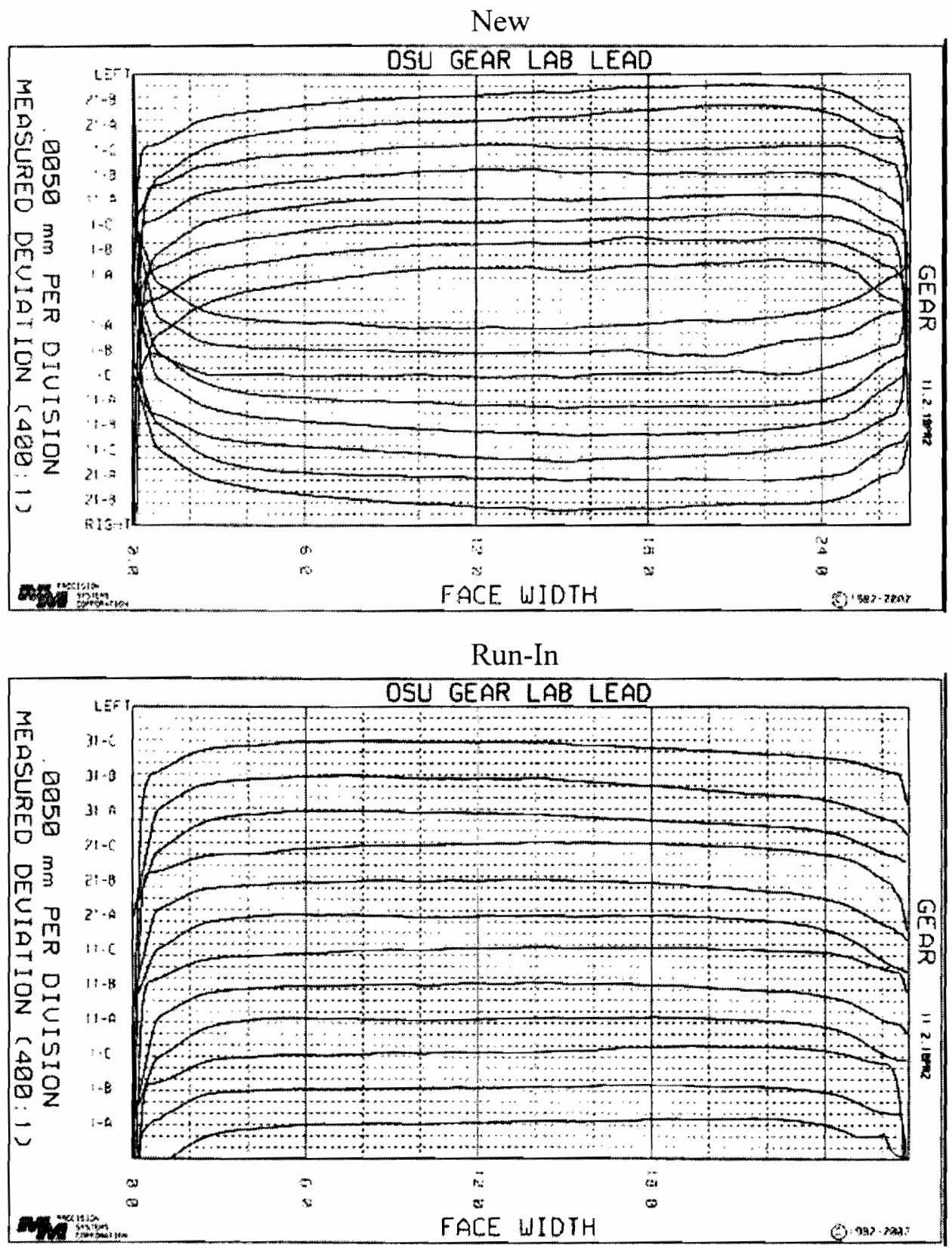

(Continued) 
Figure 2.10 Continued.

(f)

New

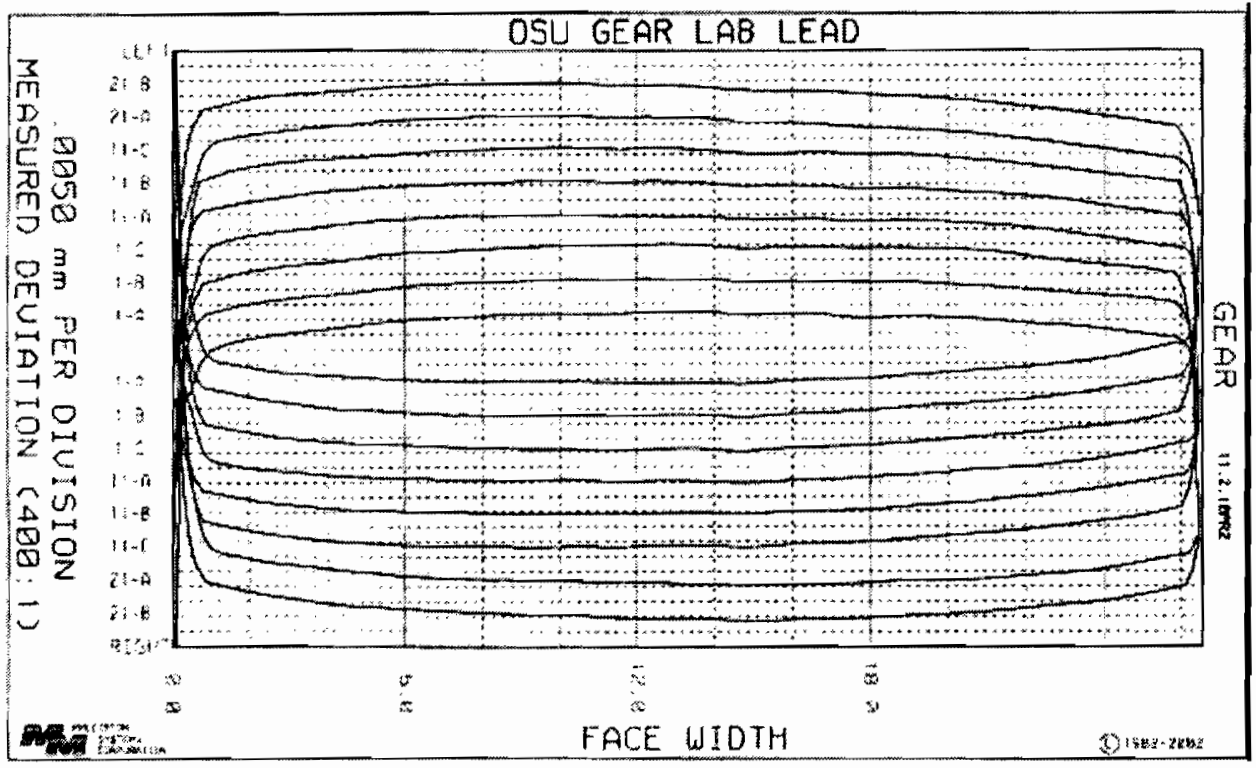

Run-In

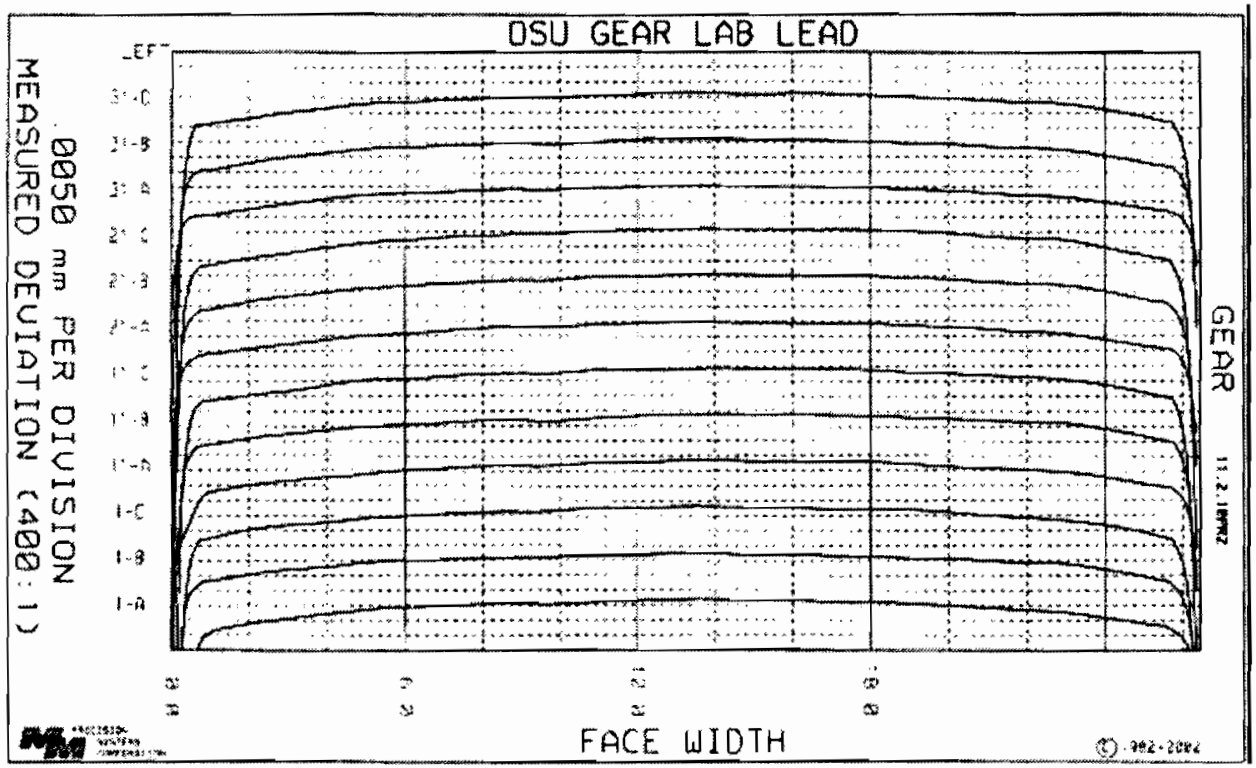

(Continued) 
Figure 2.10 Continued.

(g)

New

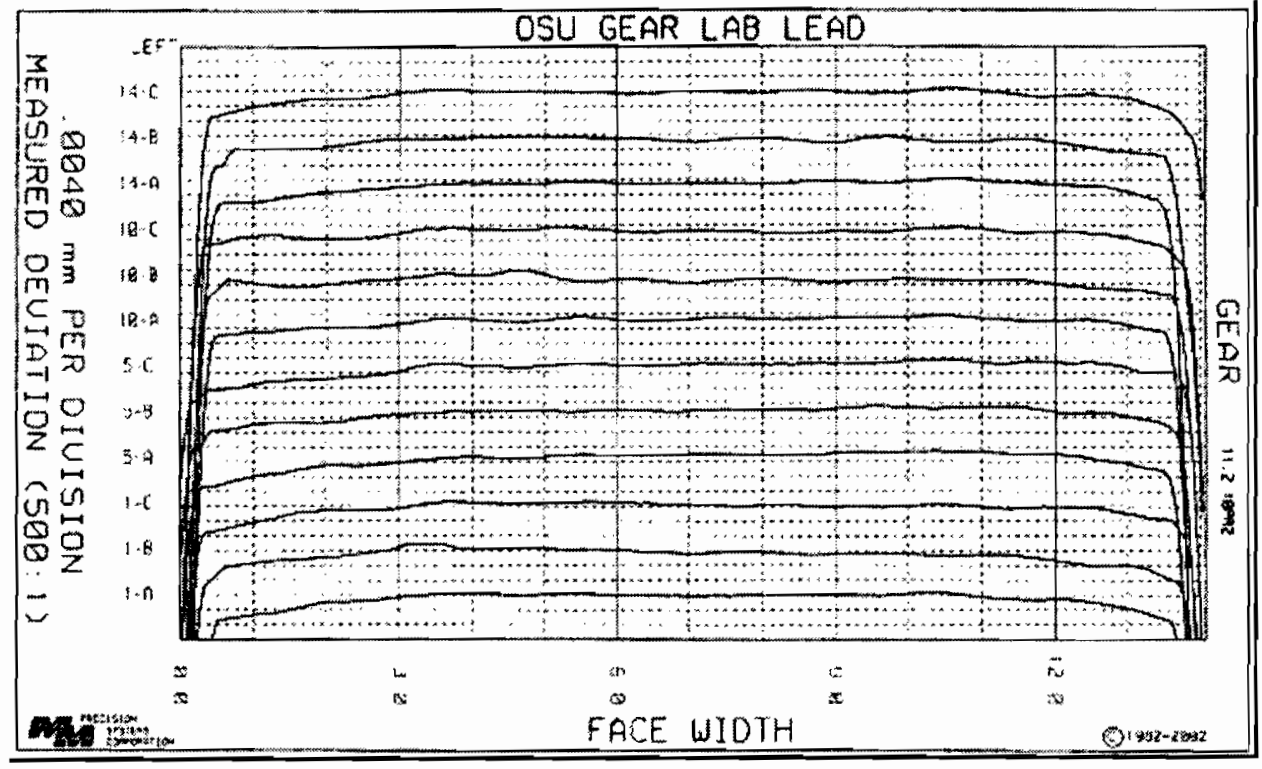

Run-In

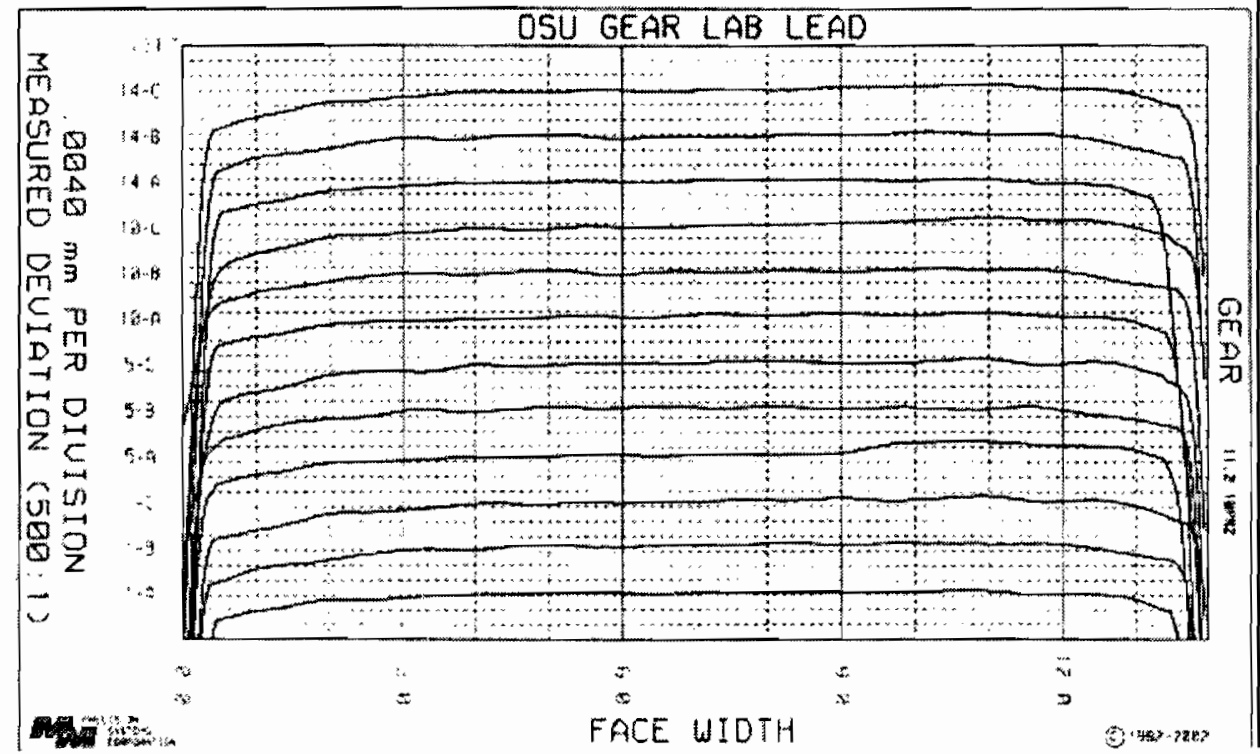

(Continued) 
Figure 2.10 Continued.

(h)
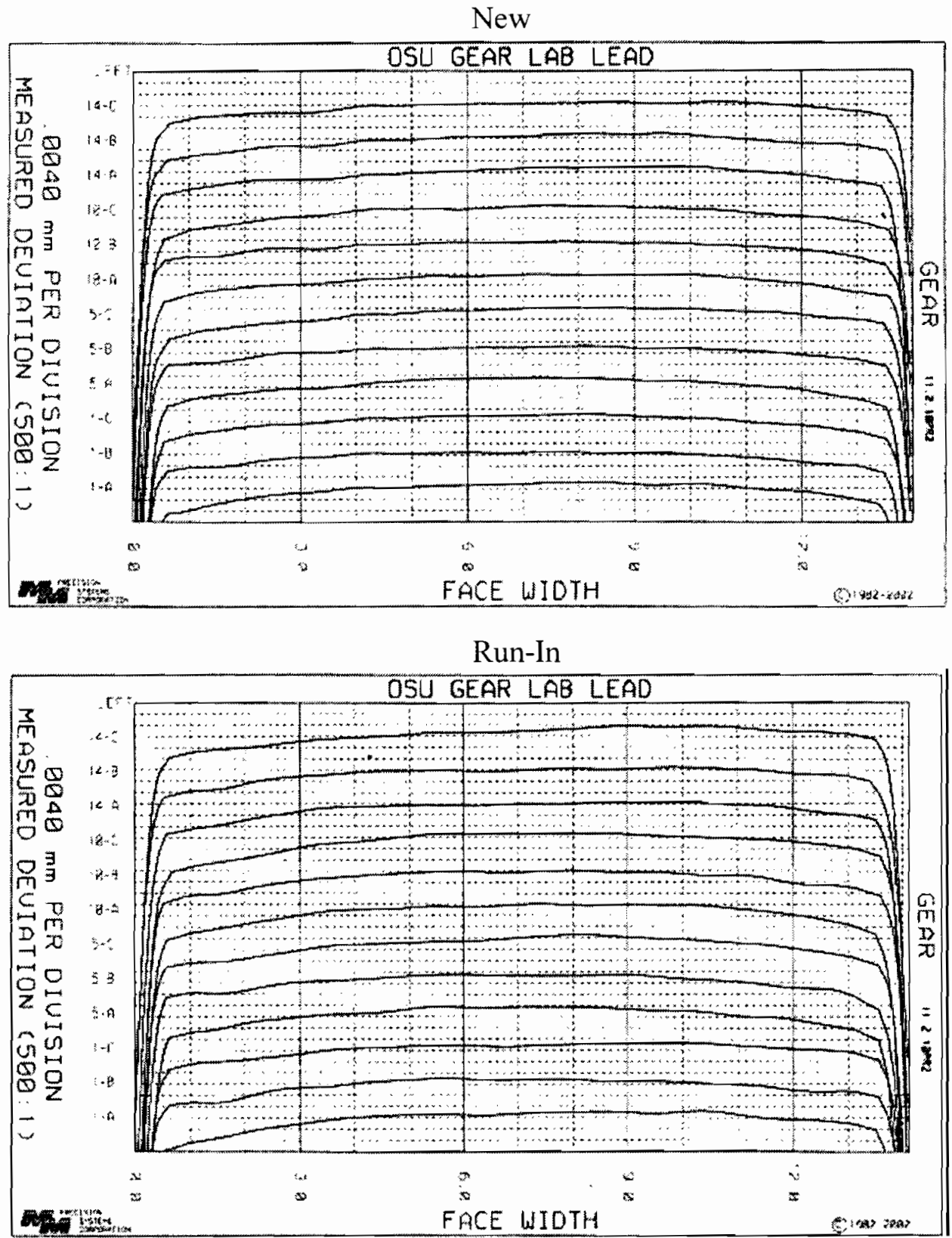
- All 23T and 40T gears had lead crown of between 5 and $10 \mu \mathrm{m}$, consistent with design specifications.

- 17/26T gears had a lead crown of approximately $5 \mu \mathrm{m}$, consistent with design specifications, but comparable in magnitude to local variations in surface height.

\section{Variation of Gear Surface Roughness through Efficiency Tests}

Since gear surface roughness has been shown to be a key parameter influencing efficiency $[4,16,26,42]$, it was important to document surface roughness of the test gears before and after each test. Table 2.6 shows centerline average surface roughness $R_{a}$, and root-mean-square roughness $R_{q}$ for each of the test gear sets, measured after operation in the lubricating oils indicated. Two roughness traces were performed on the left and right flanks of each test gear, resulting in eight measurements per flank per gear set. The surface roughness numbers in Table 2.6 are the average $R_{a}$ and $R_{q}$ of those eight measurements. Table 2.6 indicates that surface roughness of the test gears remained nearly constant throughout testing, stating that surface conditions were quite stable throughout the test program. An initial slight decrease in surface roughness generally due to wear down of asperity peaks is followed by a saddle increase.

Figure 2.11 shows the $R_{a}$ measurements of Table 2.6 for $23 \mathrm{~T}$ and $40 \mathrm{~T}$ ground and chemically polished gears with $95 \%$ confidence limits imposed. These confidence limits were obtained for each gear set using the right flank surface roughness measurements. Since the right flanks were not used in this study, measurements of these 
(a)

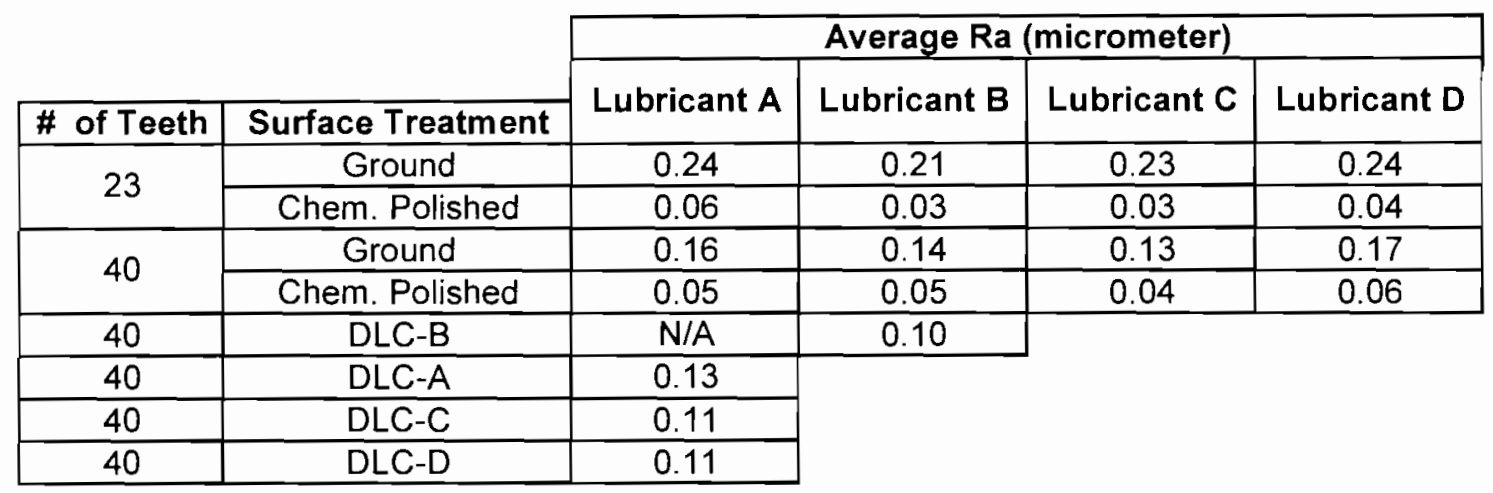

\begin{tabular}{|c|c|c|c|}
\cline { 3 - 4 } \multicolumn{2}{c|}{} & Lubricant A & Lubricant D \\
\hline \multirow{2}{*}{40} & Hob + Shave & 0.10 & N/A \\
\cline { 2 - 4 } & Chem. Polished & 0.06 & N/A \\
\hline \multirow{2}{*}{$17 / 26$} & Hob + Shave & 0.25 & 0.17 \\
\cline { 2 - 4 } & Chem. Polished & 0.03 & 0.03 \\
\hline
\end{tabular}

Table 2.6 Taylor Hobson Talysurf surface roughness measurements for test gears, measured after testing in the lubricating oil indicated; (a) $R_{a}$, and (b) $R_{q}$. Left flank measurements averaged from two teeth on four gears. 
Table 2.6 Continued.

(b)

\begin{tabular}{|c|c|c|c|c|c|}
\hline \multirow{2}{*}{ \# of Teeth } & \multirow[b]{2}{*}{ Surface Treatment } & \multicolumn{4}{|c|}{ Average Rq (micrometer) } \\
\hline & & Lubricant A & Lubricant B & Lubricant $\mathrm{C}$ & Lubricant D \\
\hline \multirow{2}{*}{23} & Ground & 0.32 & 0.28 & 0.31 & 0.32 \\
\hline & Chem. Polished & 0.08 & 0.05 & 0.04 & 0.06 \\
\hline \multirow{2}{*}{40} & Ground & 0.20 & 0.18 & 0.17 & 0.21 \\
\hline & Chem. Polished & 0.07 & 0.06 & 0.06 & 0.09 \\
\hline 40 & DLC-B & N/A & 0.18 & & \\
\hline 40 & DLC-A & 0.17 & & & \\
\hline 40 & DLC-C & 0.19 & & & \\
\hline 40 & DLC-D & 0.22 & & & \\
\hline
\end{tabular}

\begin{tabular}{|c|c|c|c|}
\cline { 3 - 4 } \multicolumn{2}{c|}{} & Lubricant A & Lubricant D \\
\hline \multirow{2}{*}{40} & Hob + Shave & 0.15 & N/A \\
\cline { 2 - 4 } & Chem. Polished & 0.08 & N/A \\
\hline \multirow{2}{*}{$17 / 26$} & Hob + Shave & 0.34 & 0.26 \\
\cline { 2 - 4 } & Chem. Polished & 0.04 & 0.04 \\
\hline
\end{tabular}




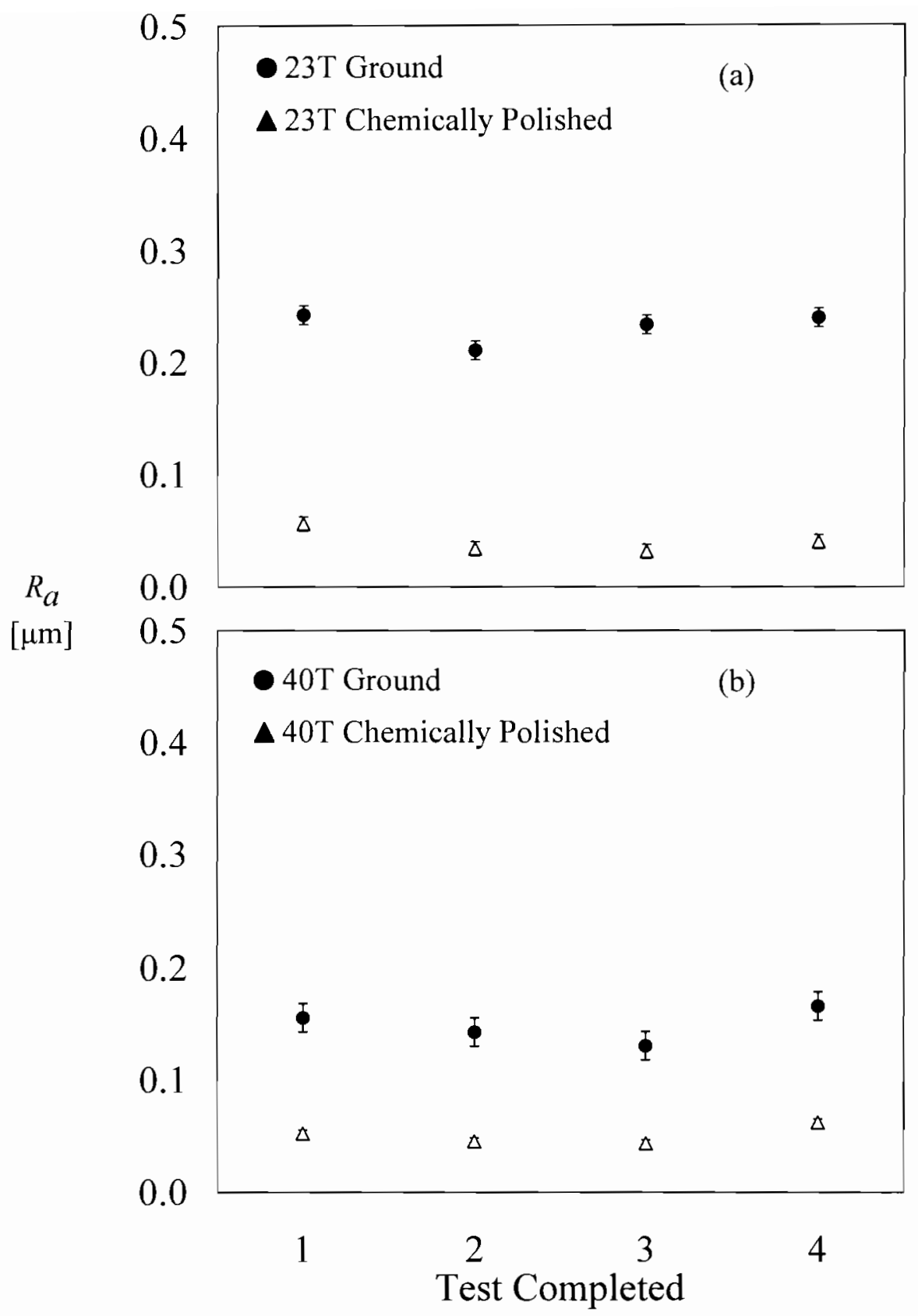

Figure 2.11 Variation of left flank surface roughness measurements for all 23T and 40T gears, and $95 \%$ confidence bands established from right flank measurements; (a) 23T gears, and (b) $40 \mathrm{~T}$ gears. 
flanks represent repeatability of the test machine and fixtures. The $95 \%$ confidence limits are calculated from standard error of the sample mean, given by

$$
\sigma_{\bar{X}}=\frac{s}{\sqrt{n}}
$$

where $s$ is the sample standard deviation, and $n$ is the number of samples. Hence, 95 percent confidence limits are given by $\pm 1.96 \sigma_{\bar{X}}^{-}$. Due to repeatability tests performed by using ground gears, $n$ was not the same for every gear set. However, every gear set was measured at least four times, resulting in a minimum of 32 individual surface roughness measurements for the right flanks of each gear set. Calculated $95 \%$ confidence limits for $R_{a}$ are $\pm 0.008 \mu \mathrm{m}$ for $23 \mathrm{~T}$ ground gears, $\pm 0.006 \mu \mathrm{m}$ for $23 \mathrm{~T}$ chemically polished gears, $\pm 0.013 \mu \mathrm{m}$ for $40 \mathrm{~T}$ ground gears, and $\pm 0.003 \mu \mathrm{m}$ for $40 \mathrm{~T}$ chemically polished gears.

Figures $2.10,2.11$ and Table 2.6 show that the test gear surfaces remained consistent throughout testing, both in terms of profile accuracy and surface roughness. CMM surface inspections revealed key differences in gear accuracy between ground and hobbed-shaved gears, as well as documenting no appreciable wear from the first to last test. The surface roughness measurements indicate with a significant degree of confidence that measured $R_{a}$ values changed very little after run-in. Having documented excellent consistency in the test gears throughout the test sequence, experimental power loss comparisons can be made on basis of the influence of surface roughness, module, gear accuracy, low-friction coatings, and lubricating oil. 


\section{Measurement Accuracy of High-Speed Gear Efficiency Test Machine}

The experimental test parameters that are monitored during gear efficiency testing are the input torque $\hat{T}_{T}$, the rotational speed $\Omega$, the oil reservoir temperature, the oil supply temperatures at the test and reaction side gearboxes, and the oil return temperatures from the test and reaction side gearboxes. Torque is measured with a Lebow 9000 series non-contact digital telemetry torque meter. It has a full-scale range of $50 \mathrm{~N}-\mathrm{m}$, and installed linearity to $0.03 \%$ of full scale. Figure 2.12 shows a typical torque signal for $40 \mathrm{~T}$ ground gears operating under $546 \mathrm{~N}-\mathrm{m}$ at $6,000 \mathrm{rpm}$. The rapid rise in torque at the beginning of the test is due to a 100-point running average in the LabView data acquisition system. Figure 2.13 shows the rotational speed $\Omega$ for the same test where the set speed was $6,000 \mathrm{rpm}$. In most tests, a $0.2-0.3 \%$ deviation of the actual speed from the set value was observed. While this is quite negligible, still the gear efficiency is calculated using the actual speed instead of the set-speed to eliminate any secondary errors coming from the speed condition. Except for the small constant bias between the set and actual $\Omega$ values, rotational speed remained nearly constant within $\pm 2 \mathrm{rpm}$.

Figure 2.14 shows temperature measurements for the same test. Lubricant reservoir and supply temperatures were very close, with supply temperatures usually several degrees higher. This suggests that the oil is further heated as it is forced through the supply system, but it could also be due to location of the thermocouple in the oil stand. Oil return temperatures are higher because the return oil absorbs waste heat from the gear system. For most of the tests, the lubrication system of the test machine was 


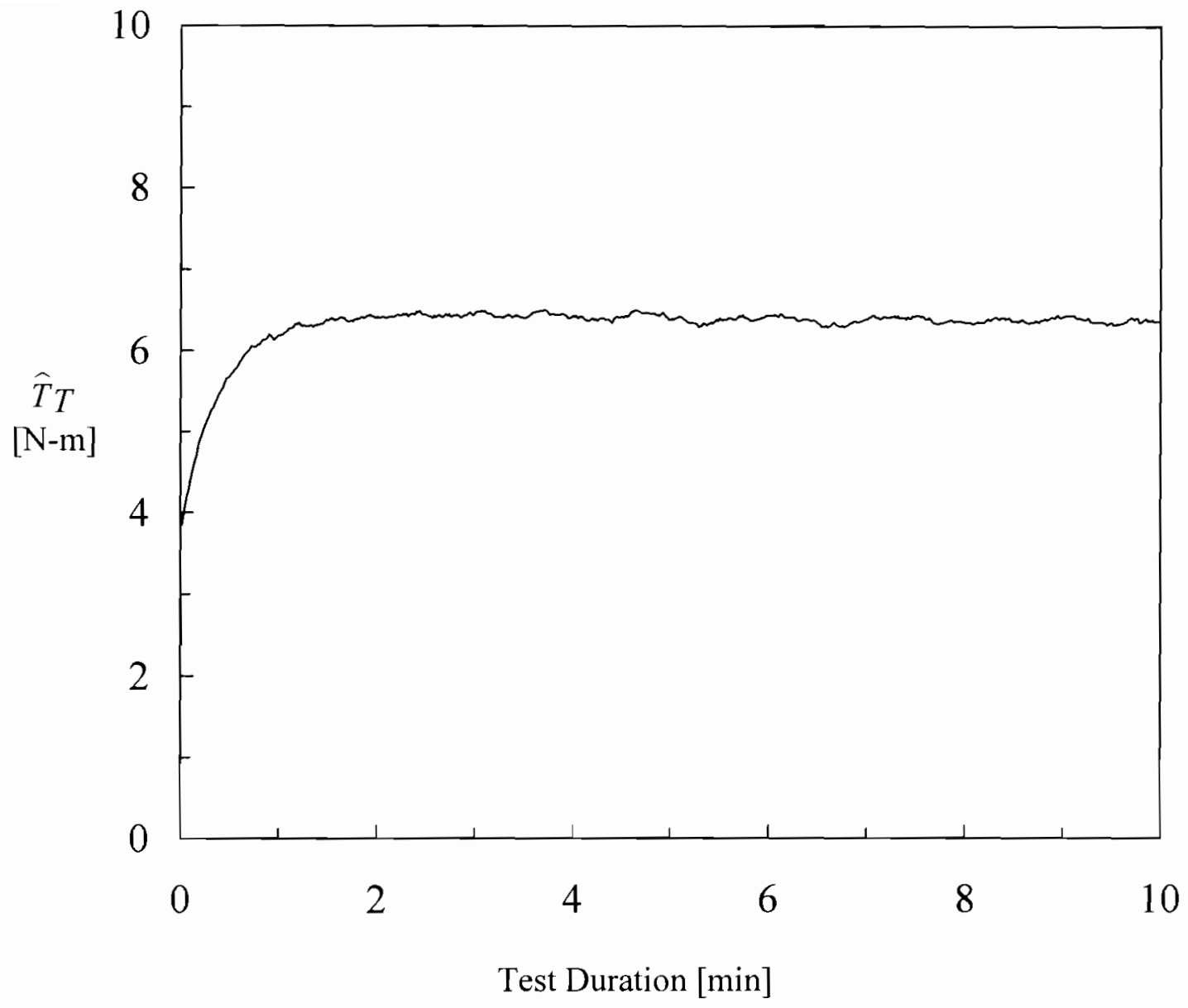

Figure 2.12 Typical variation of input driving torque versus time. 40T ground gears, $T_{c}=546 \mathrm{~N}-\mathrm{m}, \Omega=6,000 \mathrm{rpm}$. 


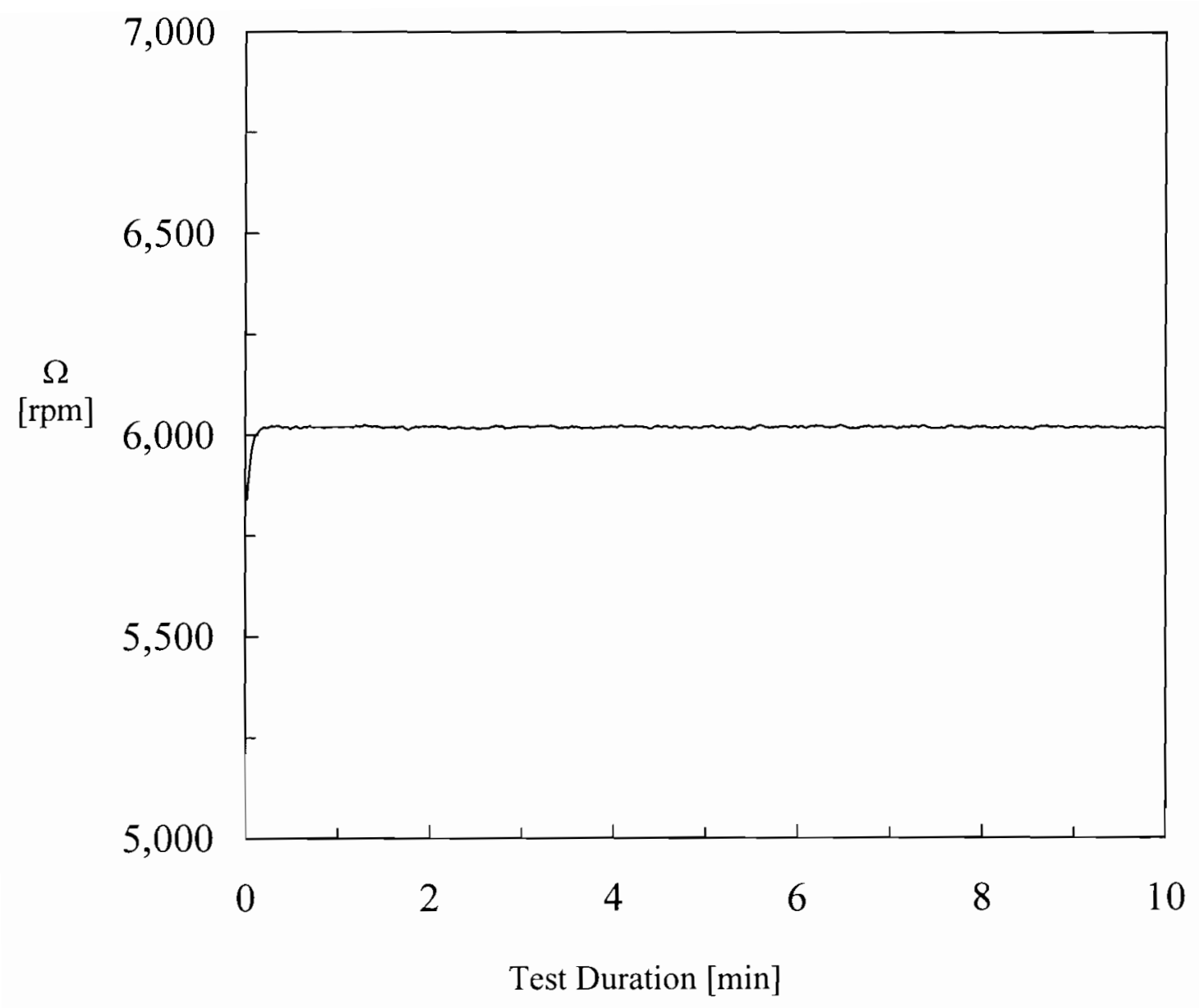

Figure 2.13 Typical variation of rotational speed versus time. 40T ground gears, $T_{c}=$ $546 \mathrm{~N}-\mathrm{m}, \Omega=6,000 \mathrm{rpm}$. 


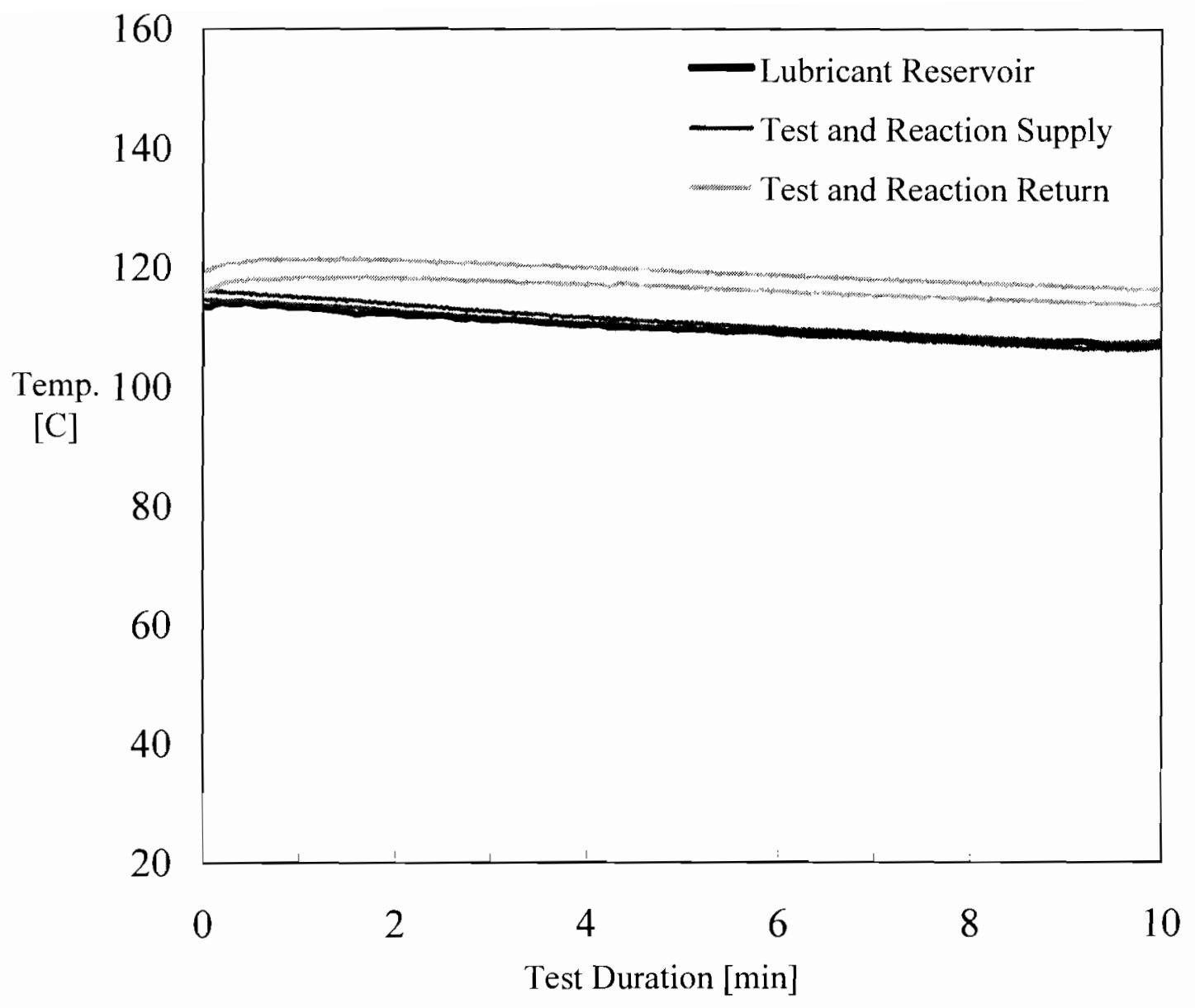

Figure 2.14 Typical variation of temperature signals versus time. 40T ground gears, $T_{c}=546 \mathrm{~N}-\mathrm{m}, \Omega=6,000 \mathrm{rpm}$. 
able to maintain the oil supply temperatures effectively within $110 \pm 2^{\circ} \mathrm{C}$ or $90 \pm 2^{\circ} \mathrm{C}$, based on the set test conditions.

\section{Repeatability of Power Loss and Efficiency Measurements}

In order to quantify the repeatability of loaded power loss measurements for the test machine, three sets of gears were identified and tested periodically. The first set of gears was $40 \mathrm{~T}$ type (ground and chemically polished with $19.5 \mathrm{~mm}$ face width), operated in Lubricant A. These gears were used to demonstrate the repeatability of the test machine in Fig. 2.15 over a 2-year period, through several teardowns, shaft, bearing, and seal replacements. Four sets of $\hat{T}_{T}$ measurements were performed with these gears, except for Test $\mathrm{D}$, for which only test conditions 8,9 , and 10 were tested due to time constraints. The numbers along the $\mathrm{x}$-axis of this figure represent certain test conditions listed in Table 2.3. Figure 2.15 indicates that the test fixtures maintained repeatability to within $0.5 \mathrm{~N}-\mathrm{m}$ in terms of $\hat{T}_{T}$ when $T_{C}=684 \mathrm{~N}-\mathrm{m}$, which corresponds to $0.04 \%$ in total efficiency per gearbox, and this can be considered satisfactory.

The second and third sets of gears were $40 \mathrm{~T}$ ground gears with $26.7 \mathrm{~mm}$ face width, and 23T ground gears with $19.5 \mathrm{~mm}$ face width, respectively. Both of these gear sets were operated in Lubricant A. These gears were used to characterize repeatability of the test machine on a shorter timeline through one replacement of shafts, bearings, and seals. Figures 2.16 and 2.17 show repeatability in terms of $\hat{T}_{T}$ for the $40 \mathrm{~T}$ gears and $23 \mathrm{~T}$ gears, respectively. The $40 \mathrm{~T}$ gears show excellent repeatability in measured power loss, and the 23T gears show satisfactory agreement. 


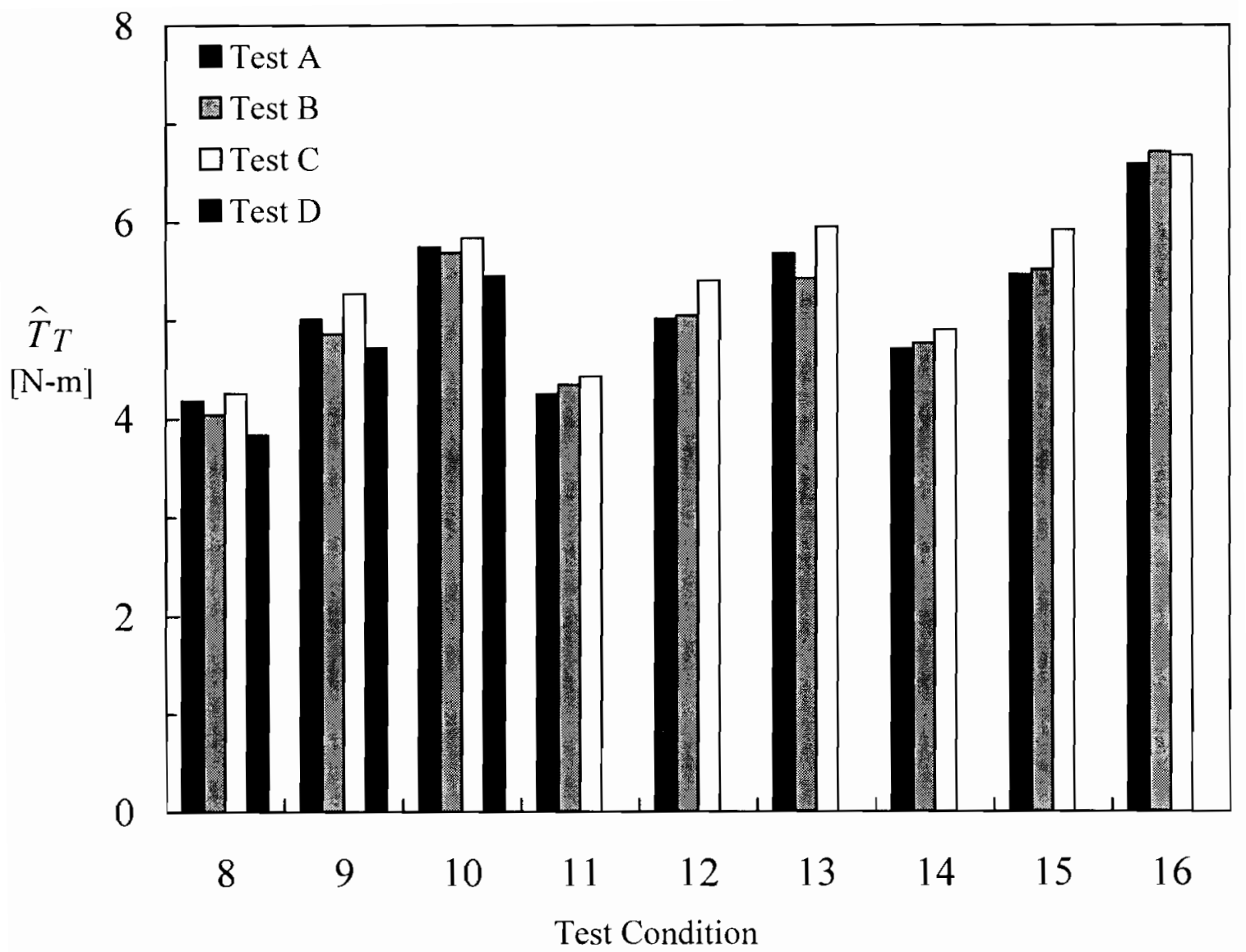

Figure 2.15 Comparison of repeatability tests using 40T chemically polished gears in lubricant $\mathrm{A}, 19.5 \mathrm{~mm}$ face width. 


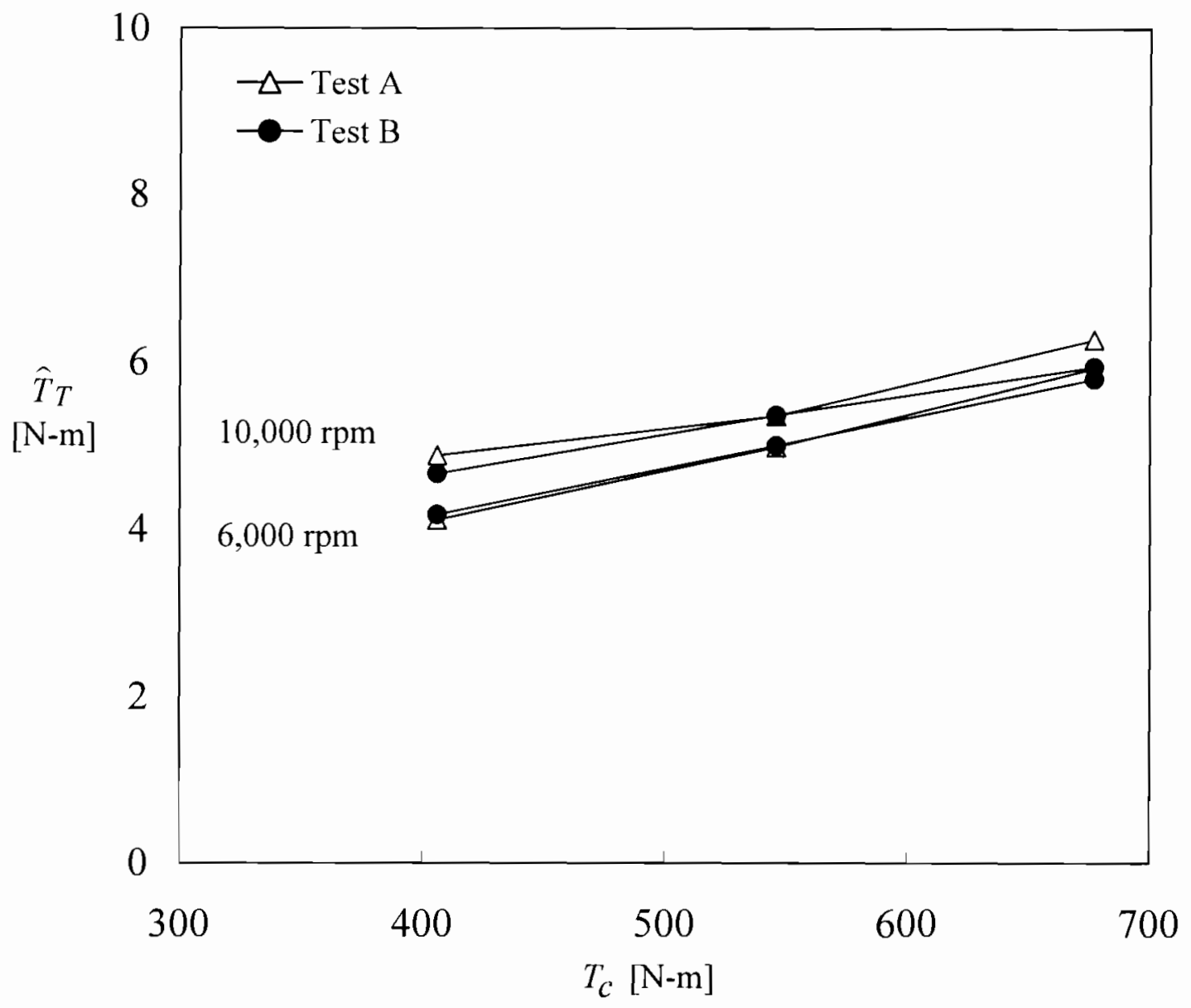

Figure 2.16 Comparison of repeatability tests using 40T ground gears, in Lubricant A, $26.7 \mathrm{~mm}$ face width. 


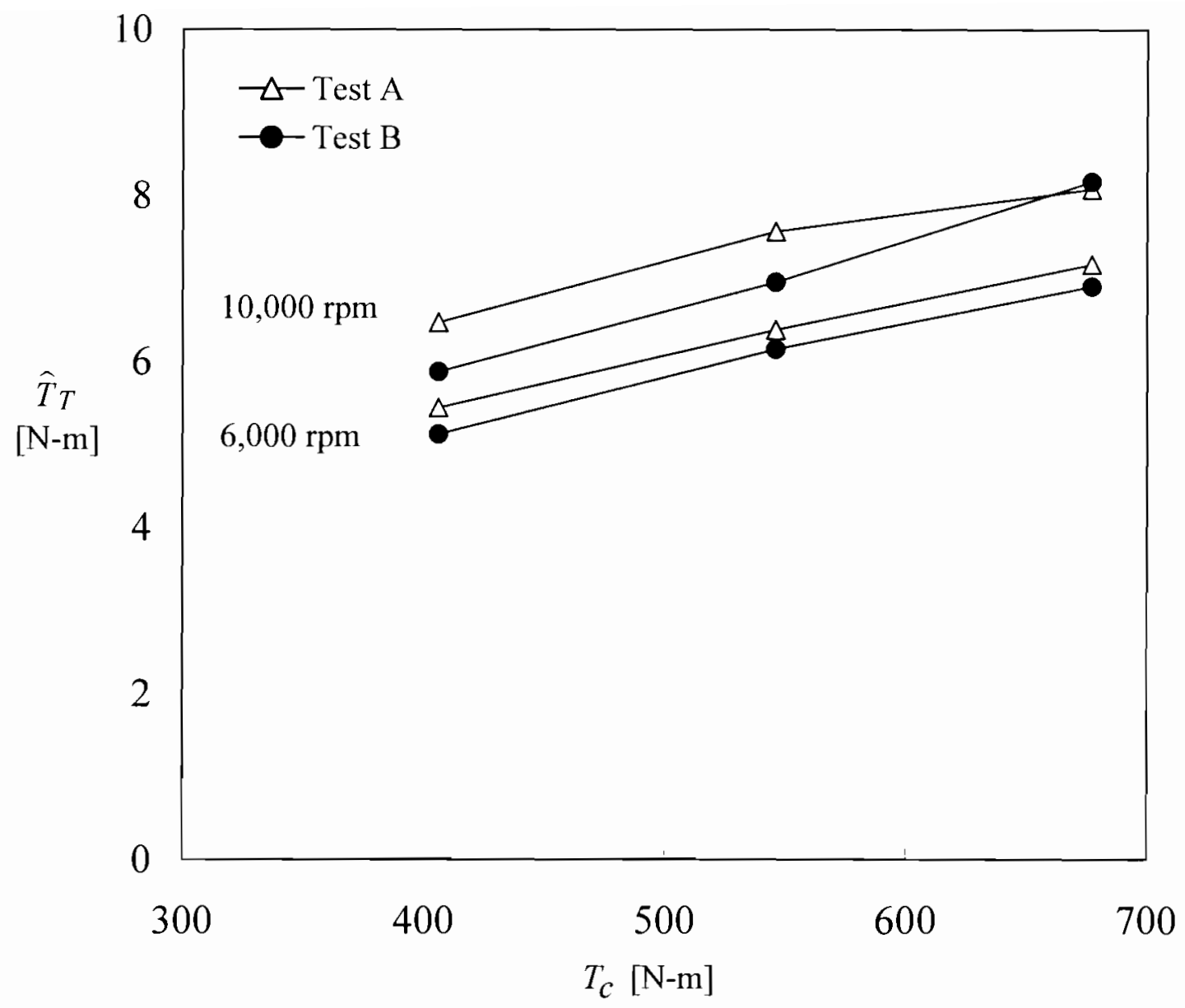

Figure 2.17 Comparison of repeatability tests using 23T ground gears, in Lubricant A, $26.7 \mathrm{~mm}$ face width. 


\subsection{Summary}

Inspection methodologies were developed for the documentation of gear surface roughness and wear after each test. Surface roughness measurements of the unloaded gear flanks were used to establish $95 \%$ confidence limits of about $\pm 0.01 \mu \mathrm{m}$ for all surface roughness measurements. Results show that after the initial run-in phase, gear surface roughness amplitudes remained constant throughout the test regimen. CMM inspections show negligible wear for all gear surfaces. With a high degree of confidence in the integrity of the gears throughout testing and with the demonstrated repeatability of the test machine and instrumentation, experimental results presented in the next chapters for power loss and efficiency can be accepted confidently. 


\section{CHAPTER 3}

\section{EFFICIENCY EXPERIMENTS UNDER JET LUBRICATED CONDITIONS}

\subsection{Components of Power and Efficiency Losses}

There are a large number of sources of power loss in a gearbox due to complex mechanical and fluid-mechanical interactions. Retaining only the primary sources of power loss, the total power loss of a gearbox can written as

$$
P_{T}=P_{m}+P_{\text {churn }}+P_{b}+P_{\text {seal }}
$$

where $P_{T}$ is total gearbox power loss, $P_{m}$ is the mechanical (load-dependent) power loss in the gear mesh, $P_{\text {churn }}$ is the gear fluid churning power loss that includes both oil churning and air windage, $P_{b}$ is the bearing power loss, and $P_{\text {seal }}$ is the shaft seal power loss. $P_{m}$ can be resolved into

$$
P_{m}=P_{s}+P_{r}
$$


where $P_{S}$ is the frictional sliding power loss due to asperity contacts and fluid shearing, and $P_{r}$ is the power loss resulting from fluid viscous resistance to rolling in the gear mesh contact zones. Sliding and rolling friction in a gear mesh cannot be separated experimentally, but predictive methods have been developed to estimate their contributions in combined rolling-sliding contacts $[14,16,45] . P_{\text {churn }}$ applies to both jet-lubricated and dip-lubricated applications and is described by

$$
P_{\text {churn }}=P_{\text {inertia }}+P_{\text {trap }}+P_{\text {drag }}
$$

where $P_{\text {inertia }}$ applies only to jet-lubricated applications, and is the power loss resulting from acceleration of the impinging oil jet by the rotating gear teeth [30-31]. $P_{\text {trap }}$ arises from squeezing oil and air out of the spaces between gear teeth as they mesh [30, 32-34], and $P_{d r a g}$ is the combined fluid drag power loss on the sides of the gears, faces of the gear teeth, and from fluid trapped between gear teeth as the gears rotate.

Widely used formulas for load-depended and load-independent power losses of rolling element bearings were originally developed empirically by Palmgren [46], then later popularized by Harris [47], and further refined by bearing manufacturers [48]. Load-dependent bearing friction torque $M_{L}$ in $\mathrm{N}$-mm is given by [43] as

$$
M_{L}=0.5 \mu_{b} W_{b} d_{\text {bore }}
$$


where $\mu_{b}$ is an experimentally determined average bearing friction coefficient obtained under full film lubrication conditions, $W_{b}$ is radial bearing load in $\mathrm{N}$, and $d_{\text {bore }}$ is the bearing bore diameter in $\mathrm{mm}$. For the NJ $406 \mathrm{~J}$ cylindrical roller bearings used in this study, $\mu_{b}=0.0011$ and $d_{\text {bore }}=30 \mathrm{~mm}$. Load-independent friction torque is caused by viscous shear of the lubricant, and is given in N-mm by

$$
M_{v}=\left\{\begin{array}{ll}
1.6 \times 10^{-5} f_{o} d_{m}^{3}, \\
10^{-7} f_{o}(\Omega)^{2 / 3} d_{m}^{3}
\end{array}\right\} \quad \begin{aligned}
& \Omega<2,000 \\
& \quad \Omega>2,000
\end{aligned}
$$

where $f_{0}$ is a constant depending on bearing type and lubrication method, $v$ is kinematic viscosity in cSt, $\Omega$ is rotational speed in rpm, and $d_{m}$ is bearing mean diameter in $\mathrm{mm}$. For the NJ $406 \mathrm{~J}$ cylindrical roller bearings used in this study under jet-lubricated conditions, $f_{o}=2.2$, and $d_{m}=60 \mathrm{~mm}$. Lastly, $P_{b}$ is defined in $\mathrm{mW}$ as

$$
P_{b}=\left(M_{L}+M_{\nu}\right) \omega
$$

where $\omega=\frac{2 \pi}{60} \Omega$ is the angular velocity of the bearing in radians/sec. Finally, shaft seal power loss in $\mathrm{kW}$ is estimated approximately by [49]

$$
P_{\text {seal }}=2.544 \times 10^{-7} d \Omega
$$


for a Buna type rubber radial lip seal where $d$ is shaft diameter in mm. For the shaft seals used in this study, $d=30 \mathrm{~mm}$.

\subsection{Calculation of Power Loss and Efficiency from Experimental Results}

Total torque loss for both gearboxes $\hat{T}_{T}$ and rotational speed $\Omega$ were measured while operating the experimental test setup at constant speed and under constant torque $T_{c}$ in the power circulation loop. Since the experimental test setup has two gearboxes, the total torque loss for each gearbox is found by $T_{T}=0.5 \hat{T} T$. Measured total gearbox power loss can be decomposed into its load-dependent and load-independent components by writing

$$
P_{T}=P_{m e c h}+P_{\text {spin }}
$$

This requires a two-step measurement procedure. First, the total power loss $P_{T}=\omega T_{T}$ is measured at a certain rotational speed $\Omega$ under a given torque transmitted $T_{c}$. Then, the same test is repeated under no load $T_{c}=0$. In this second test, $P_{\text {mech }} \approx 0$ and the measured power loss is nearly equal to $P_{\text {spin }}$. These two companion tests allow measurement of $P_{\text {mech }}$, according to Eq. (3.8). For the experimental set-up shown in Fig. 2.2, which contains 2 identical gear pairs, 8 identical cylindrical roller bearings and 4 identical shaft seals, load-dependent and load-independent power losses can be further decomposed as 


$$
\begin{aligned}
& P_{\text {mech }}=P_{m}+4 P_{b, L}, \\
& P_{\text {spin }}=P_{\text {churn }}+4 P_{b, v}+2 P_{\text {seal }} .
\end{aligned}
$$

Here $P_{b, L}=\omega M_{L}$ and $P_{b, v}=\omega M_{v}$ where $M_{L}$ and $M_{v}$ are defined earlier in Eq. (3.4) and Eq. (3.5), respectively. Accordingly, the mechanical power loss of an individual gear mesh while rotating at speed $\Omega$ and transmitting torque $T_{c}$ is given in terms of measured total power losses, $P_{T}$ and $P_{\text {spin }}$, and the predicted load-dependent bearing losses $P_{b, L}$ as

$$
P_{m}=P_{T}-P_{\text {spin }}-4 P_{b, L}
$$

Finally, the average total efficiency of each gearbox (gear pair, bearings and seal) and the average gear mesh mechanical efficiency are calculated, respectively, by

$$
\bar{\eta}_{T}=\frac{P_{c}-P_{T}}{P_{c}}, \quad \bar{\eta}_{m}=\frac{P_{c}-P_{m}}{P_{c}} .
$$

\subsection{Gear Mesh Mechanical Power Loss}

The test matrix defined by Table 2.1 covers a wide range of operating conditions, gear module, surface roughness, manufacturing processes, lubricants and thin-film coatings. This allows quantification of the direct influence of these parameters and 
features on gear mesh mechanical power loss $P_{m}$. This section presents experimental results to demonstrate influences of the following specific parameters, lubricants, engineered surface treatments and manufacturing processes on $P_{m}$ :

(i) Rotational speed, $\Omega: \Omega$ will be varied within a range from 2,000 to $10,000 \mathrm{rpm}$ with increments of 2,000 rpm at various $T_{c}$ values, and the resultant $P_{m}$ values will be measured for both fine (40T) and coarse (23T) pitch gear pairs.

(ii) Torque transmitted, $T_{c}$ : This parameter will be varied between 0 (unloaded spin tests) and $684 \mathrm{~N}-\mathrm{m}(504 \mathrm{ft}-\mathrm{lbs})$ at increments of nearly $140 \mathrm{~N}-\mathrm{m}(103 \mathrm{ft}-\mathrm{lbs})$ at various $\Omega$ values to quantify its impact on $P_{m}$.

(iii)Gear module, $m$ : Two different gear pair designs, one 23-tooth pair having $m=3.95 \mathrm{~mm}$ and a 40-tooth gear pair having $m=2.32 \mathrm{~mm}$ are included here. In order to closely match bending strength of the gear teeth, gear face width for 40T gears was slightly larger than for the 23T gears as shown in Table 2.3. However, since other experimental and theoretical studies $[4,16,42]$ have shown that face width has negligible effect on $P_{m}$, the comparison of $P_{m}$ values for these gear pairs at different operating conditions will quantify the influence of $m$ on $P_{m}$.

(iv) Gear manufacturing processes: Two of the most common gear processes, grinding and shaving, will be considered here. The hard grinding process typically achieves more accurate gears since shaved gears must be hardened after shaving, while ground gears are finished after hardening. 40T gear 
specimens produced using these two methods will provide a comparison of their efficiency performance in terms of $P_{m}$.

(v) Surface roughness: Grinding and shaving processes result in gear tooth surfaces that are relatively rough. Knowing that surface roughness is a key parameter in defining the friction coefficient [16], chemically polished gear specimens will be evaluated for their efficiency and compared to ground and shaved specimens to quantify the influence of the surface roughness amplitude on $P_{m}$.

(vi)Low-friction coatings: It has long been claimed that certain PVD coatings designed to reduce friction should improve gear efficiency, but little experimental proof is available. This test matrix includes a number of diamondlike-carbon coatings applied to baseline $40 \mathrm{~T}$ ground and chemically polished gear specimens to assess their effect on $P_{m}$.

(vii) Lubricant type: Four different lubricants, three gear oils of varying mechanical properties, and an automatic transmission fluid, will be used in the efficiency tests and their influence on $P_{m}$ will be quantified.

\section{Influence of Speed and Load}

The influence of $\Omega$ on $P_{m}$ is shown in Fig. 3.1 for ground and chemically polished $23 \mathrm{~T}$ and $40 \mathrm{~T}$ gears at $T_{c}=413 \mathrm{~N}$-m. Here, $P_{m}$ increases nearly linearly with $\Omega$ over the range of rotational speeds studied. The influence of $T_{c}$ on $P_{m}$ is shown in Figure 3.2 for $23 \mathrm{~T}$ and $40 \mathrm{~T}$ ground and chemically polished gears at $\Omega=6,000 \mathrm{rpm}$. Similarly, $P_{m}$ also increases nearly linearly with $T_{c}$. These two figures suggest that the 


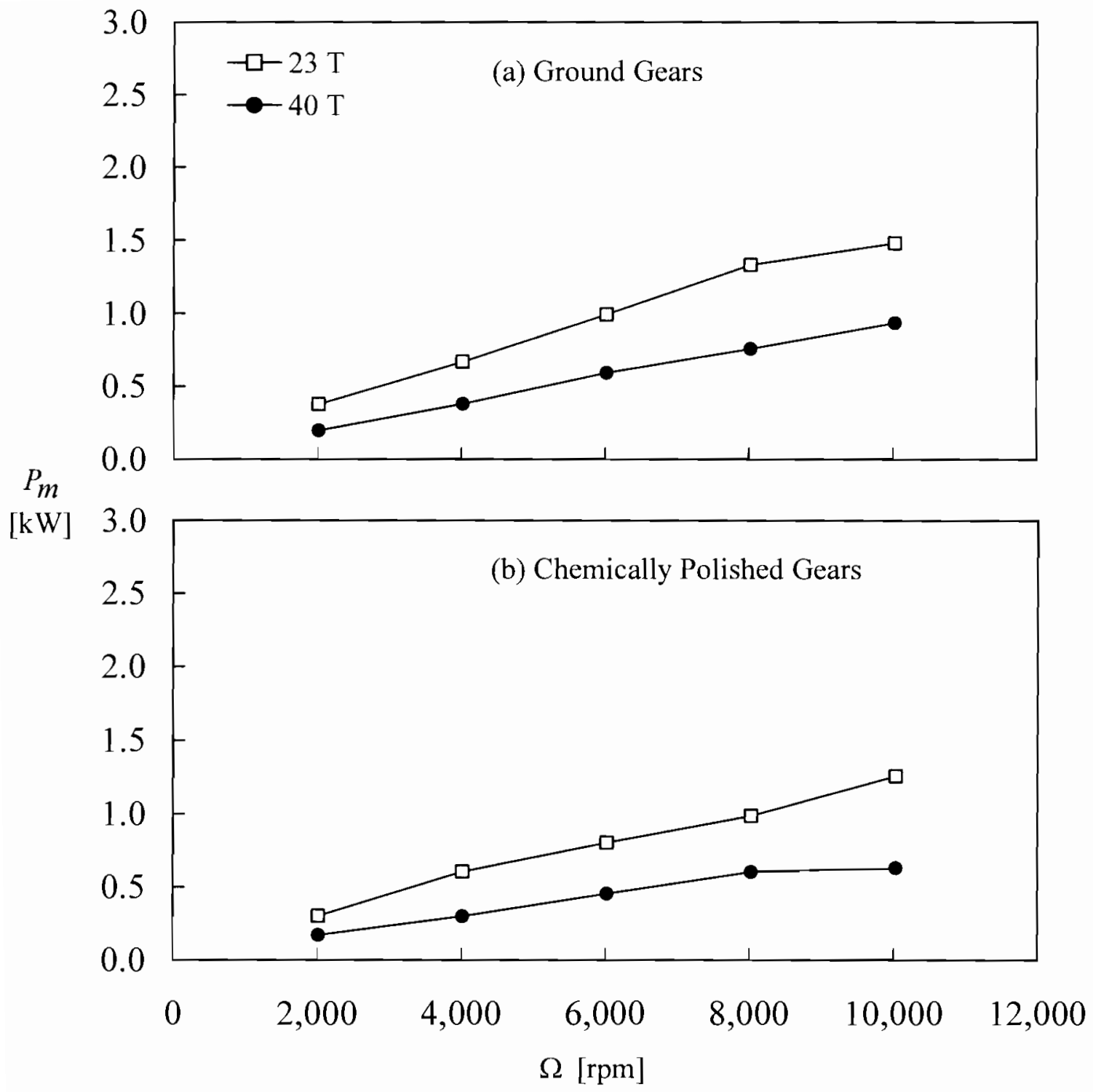

Figure 3.1 Comparison of measured $P_{m}$ for 23T and 40T gear pairs as a function of $\Omega$ for (a) ground gears and (b) chemically polished gears in Lubricant $A$. $T_{c}=413 \mathrm{~N}-\mathrm{m}$. 


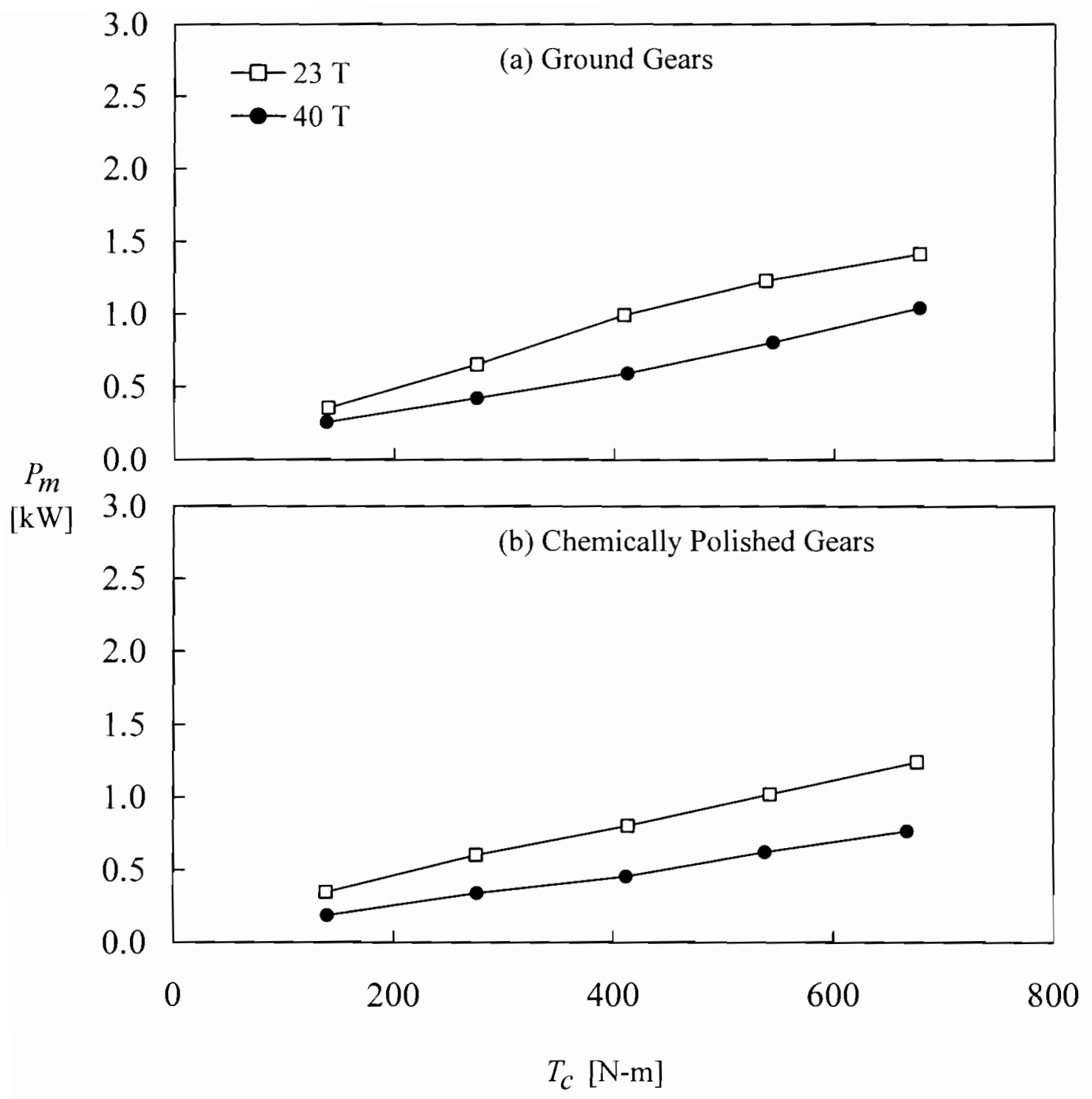

Figure 3.2 Comparison of measured $P_{m}$ for 23T and 40T gear pairs as a function of $T_{c}$ for (a) ground gears and (b) chemically polished gears in Lubricant $\mathrm{A}$. $\Omega=6,000 \mathrm{rpm}$. 
gear mesh mechanical efficiency $\bar{\eta}_{m}$ should remain relatively unchanged within these ranges of $T_{c}$ and $\Omega$ due to the nearly linear influence of $T_{c}$ and $\Omega$ on $P_{m}$. In order to demonstrate this, Fig. 3.3 shows measured gear mesh mechanical efficiency $\bar{\eta}_{m}$ for $23 \mathrm{~T}$ and $40 \mathrm{~T}$ ground gears in Lubricant $\mathrm{A}$ at certain test conditions listed in Table 2.3. Here, the $\bar{\eta}_{m}$ values calculated by Eq. (3.11b) for $40 \mathrm{~T}$ gears range between $99.76 \%$ at test condition $9\left(T_{c}=546 \mathrm{~N}-\mathrm{m}\right.$ and $\left.\Omega=6,000 \mathrm{rpm}\right)$, and $99.81 \%$ at test condition $15\left(T_{c}=\right.$ $546 \mathrm{~N}-\mathrm{m}$ and $\Omega=10,000 \mathrm{rpm})$. For $23 \mathrm{~T}$ gears, measured $\bar{\eta}_{m}$ values range between $99.61 \%$ at test condition $8\left(T_{c}=413 \mathrm{~N}-\mathrm{m}\right.$ and $\left.\Omega=6,000 \mathrm{rpm}\right)$, and $99.70 \%$ at test condition $16\left(T_{c}=684 \mathrm{~N}-\mathrm{m}\right.$ and $\left.\Omega=10,000 \mathrm{rpm}\right)$. For the wider range of $\Omega$ included in Fig. 3.1, measured $\bar{\eta}_{m}$ values for $40 \mathrm{~T}$ ground gears stays nearly constant with $\bar{\eta}_{m}=$ $99.77 \%$ at $2,000 \mathrm{rpm}$ and $99.78 \%$ at $10,000 \mathrm{rpm}$. For the range of $T_{c}$ in Fig. 3.2, measured $\bar{\eta}_{m}$ ranges between $99.70 \%$ at $T_{c}=140 \mathrm{~N}-\mathrm{m}$ and $99.76 \%$ at $684 \mathrm{~N}-\mathrm{m}$. Therefore, the influences of $T_{c}$ and $\Omega$ on $\bar{\eta}_{m}$ are not dominant in the range of test conditions studied.

\section{Influence of Gear Module}

In order to study the influence of gear module on gear mesh power loss, power loss measurements were conducted with both ground and chemically polished gear pairs with the various lubricant types indicated in Table 2.1 over a range of $T_{c}$ and $\Omega$. Figure 3.4 compares measured $P_{m}$ values for ground and chemically polished $23 \mathrm{~T}$ and $40 \mathrm{~T}$ gears in Lubricant A for $T_{c}$ from $413 \mathrm{~N}-\mathrm{m}$ to $684 \mathrm{~N}-\mathrm{m}$, and $\Omega$ from $6,000 \mathrm{rpm}$ to 10,000 


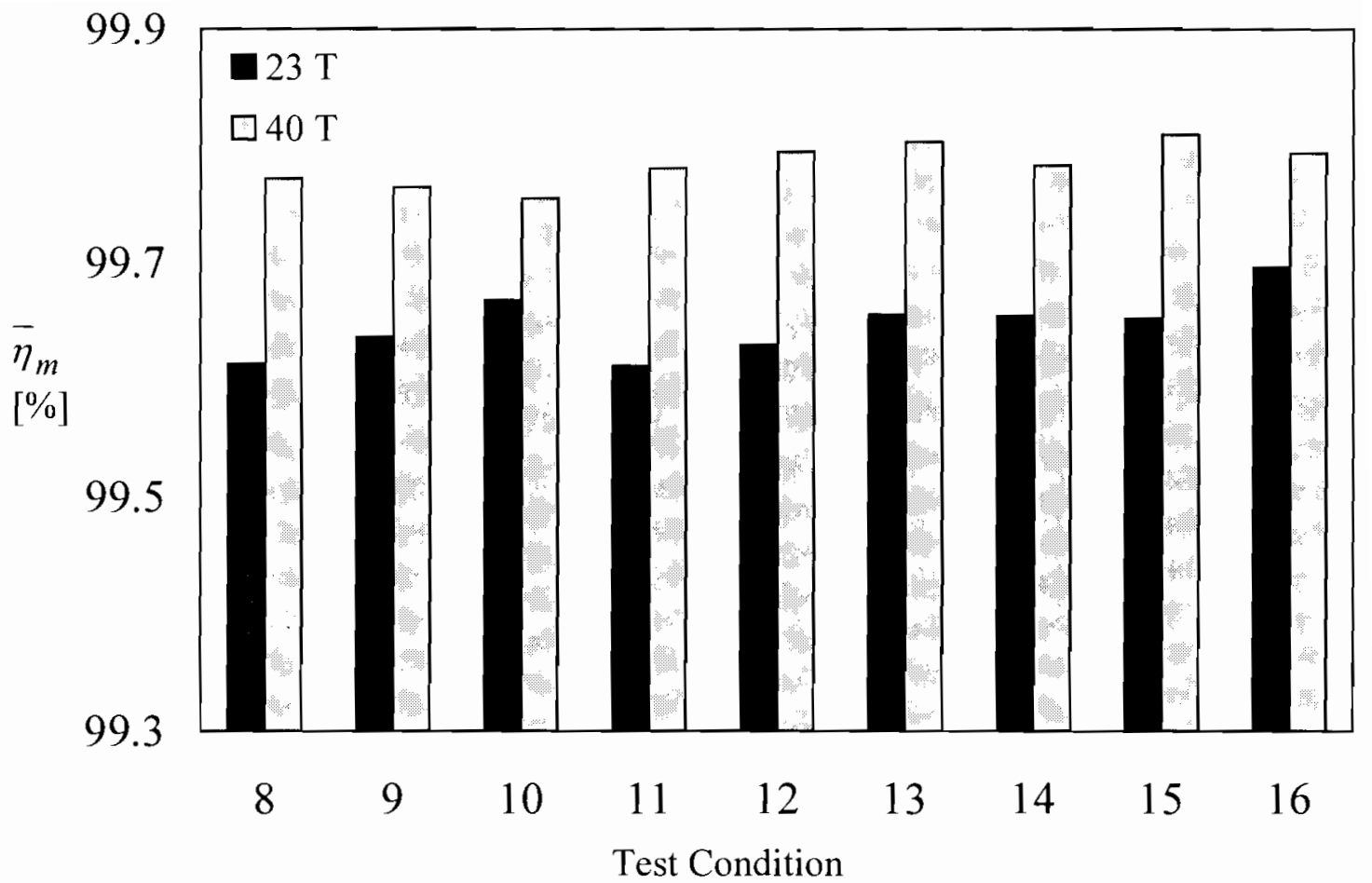

Figure 3.3 Measured $\bar{\eta}_{m}$ values of $23 \mathrm{~T}$ and $40 \mathrm{~T}$ ground gear pairs in Lubricant $\mathrm{A}$ at various test conditions listed in Table 2.3. 


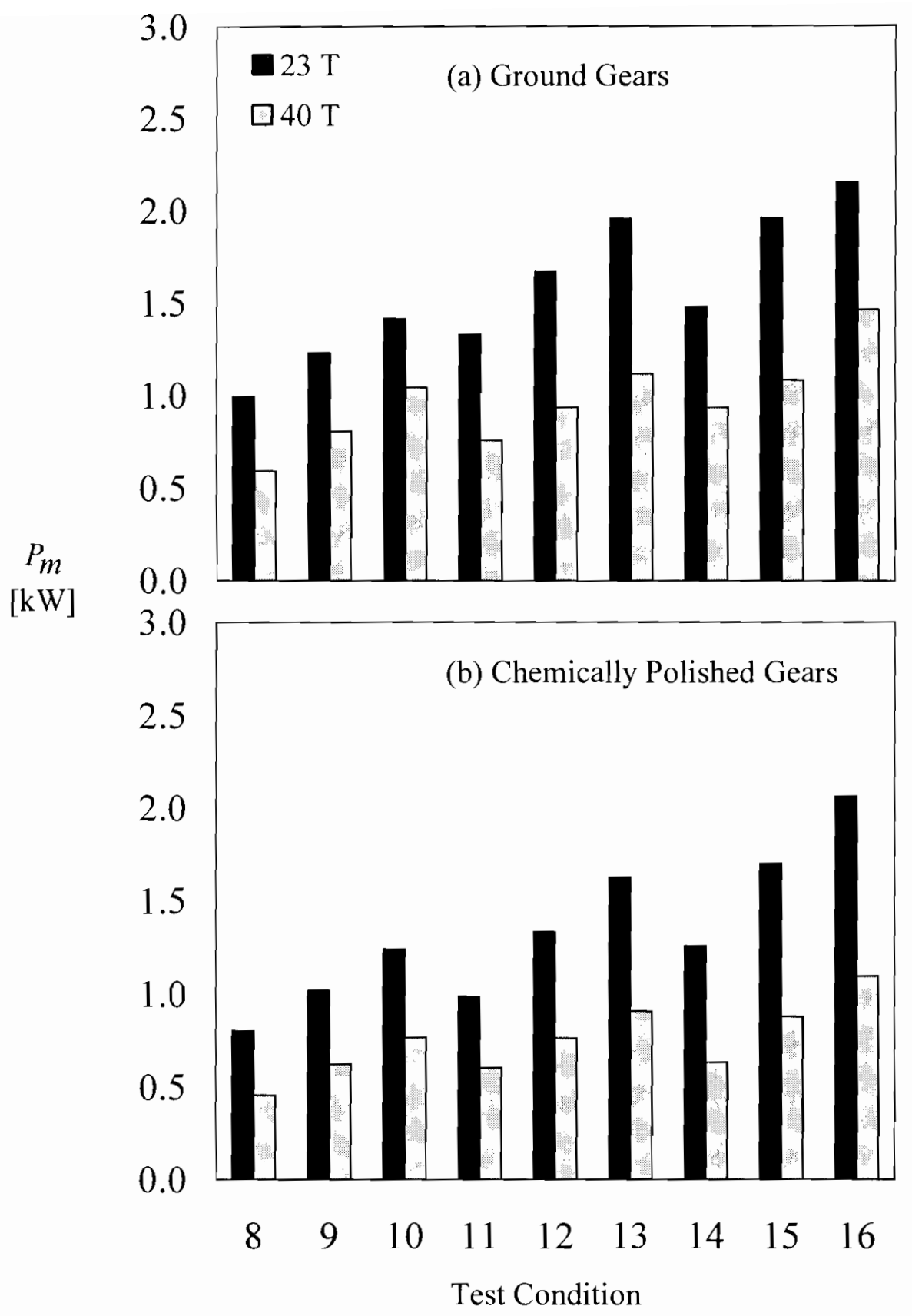

Figure 3.4 Influence of $m$ on measured $P_{m}$ for 23T and 40T gear pairs in Lubricant A; (a) ground gears and (b) chemically polished gears. 
rpm. $P_{m}$ values for the $40 \mathrm{~T}$ gear pairs are on average $38 \%$ and $43 \%$ lower than those for the $23 \mathrm{~T}$ gear pairs formed by ground and chenically polished gears, respectively. Figure 3.5 shows the same comparison, but for gear pairs lubricated with Lubricants B and C. When Lubricant B is used, $P_{m}$ values for ground $40 \mathrm{~T}$ gear pairs are measured to be about $33 \%$ lower than for ground $23 \mathrm{~T}$ gears and about $35 \%$ lower for chemically polished gears. In case of Lubricant $\mathrm{C}, P_{m}$ values for $40 \mathrm{~T}$ ground gear pairs are $35 \%$ lower than those for $23 \mathrm{~T}$ ground gears and $23 \%$ lower for chemically polished gears. Likewise, $P_{m}$ for $40 \mathrm{~T}$ gear pairs in Lubricant $\mathrm{D}$ was on average $32 \%$ and $31 \%$ lower than for $23 \mathrm{~T}$ gear pairs for ground and chemically polished gears, respectively, as shown in Fig. 3.6. Percent reduction in $P_{m}$ for $40 \mathrm{~T}$ gears versus $23 \mathrm{~T}$ gears generally increases slightly with $\Omega$, but there appears to be no definite trend with $T_{c}$. This is in agreement with previous studies $[4-5,16,18,42]$, and is primarily due to the higher sliding velocities in the mesh of gear pairs with larger module $m$. Lastly, since the $40 \mathrm{~T}$ ground gear pairs had a slightly lower surface roughness $\left(R_{a}\right)$ value than the 23T gear pairs as indicated in Table 2.6, the influence of $m$ in this case is somewhat exaggerated.

\section{Influence of Gear Manufacturing Processes}

Since the shaving process is applied prior to case hardening, heat treat distortions make shaved gears typically less accurate than their hard ground counterparts. In chapter 2, this was demonstrated for the test gears used in this study through gear tooth lead, measurements using a gear CMM. Figure 3.7 compares the efficiency performance of 


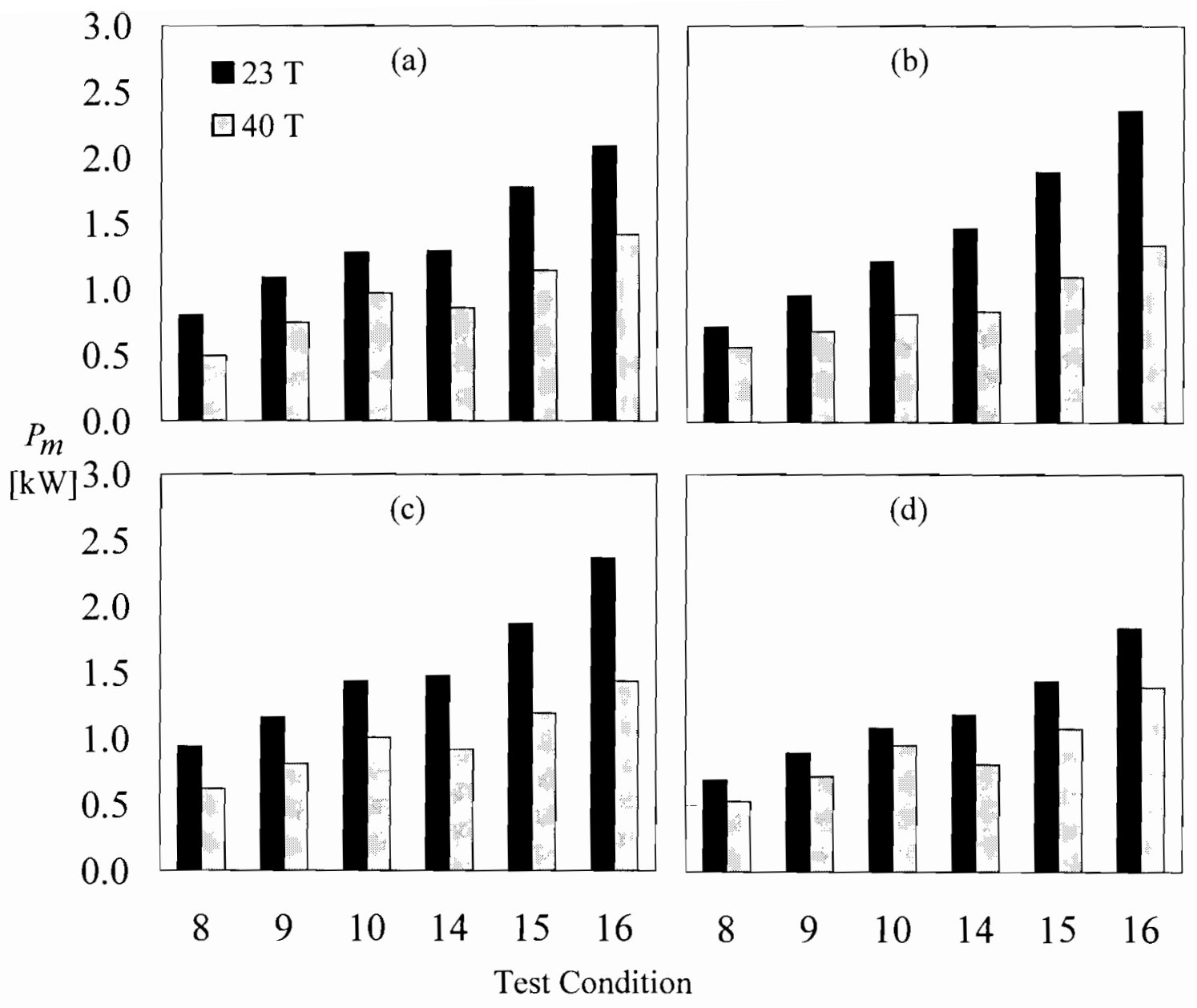

Figure 3.5 Influence of $m$ on measured $P_{m}$ for 23T and 40T gear pairs (a) ground gears in Lubricant B, (b) chemically polished gears in Lubricant B, (c) ground gears in Lubricant $\mathrm{C}$, and (d) chemically polished gears in Lubricant $\mathrm{C}$. 


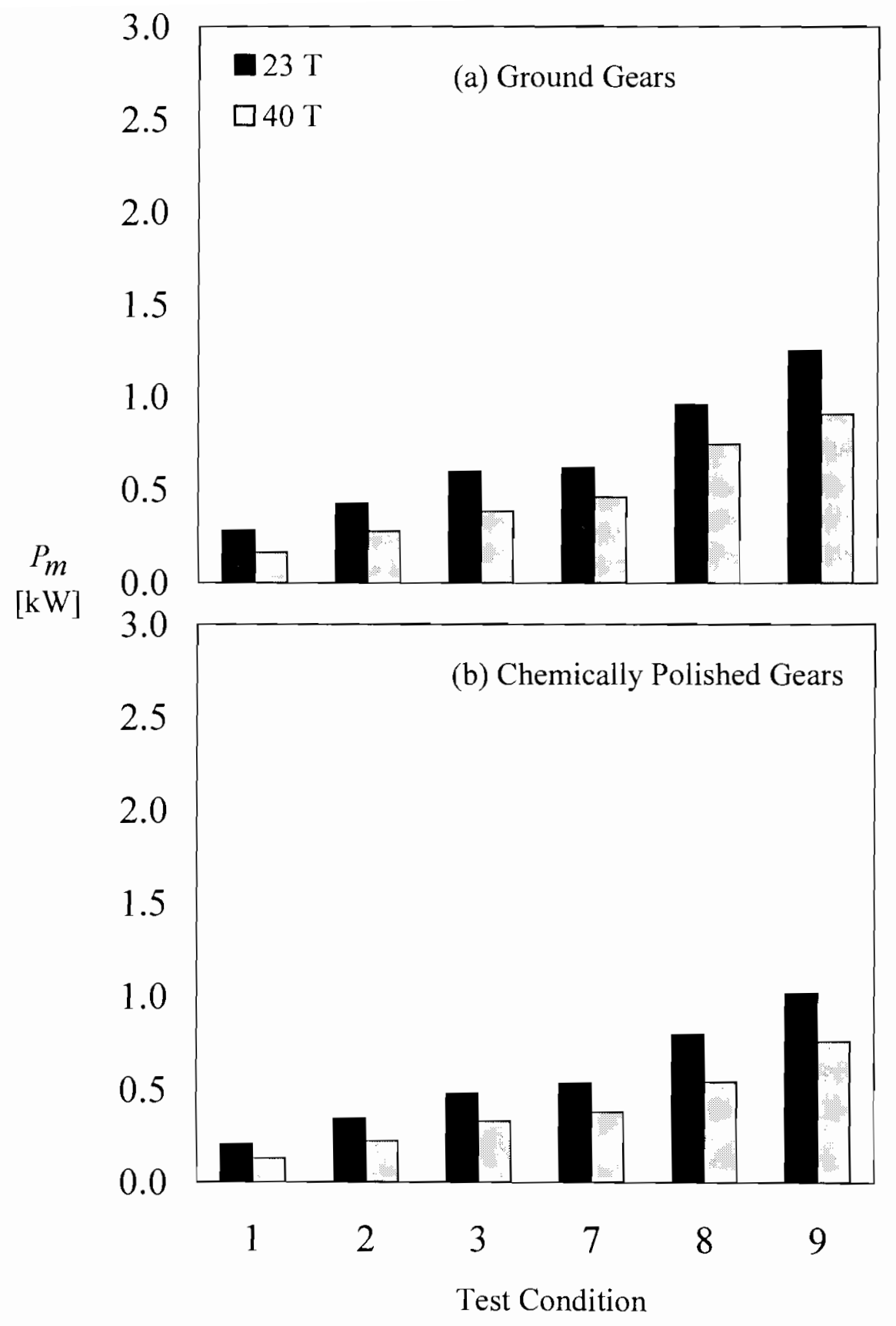

Figure 3.6 Influence of $m$ on measured $P_{m}$ for $23 \mathrm{~T}$ and 40T gear pairs in Lubricant D; (a) ground gears and (b) chemically polished gears. 


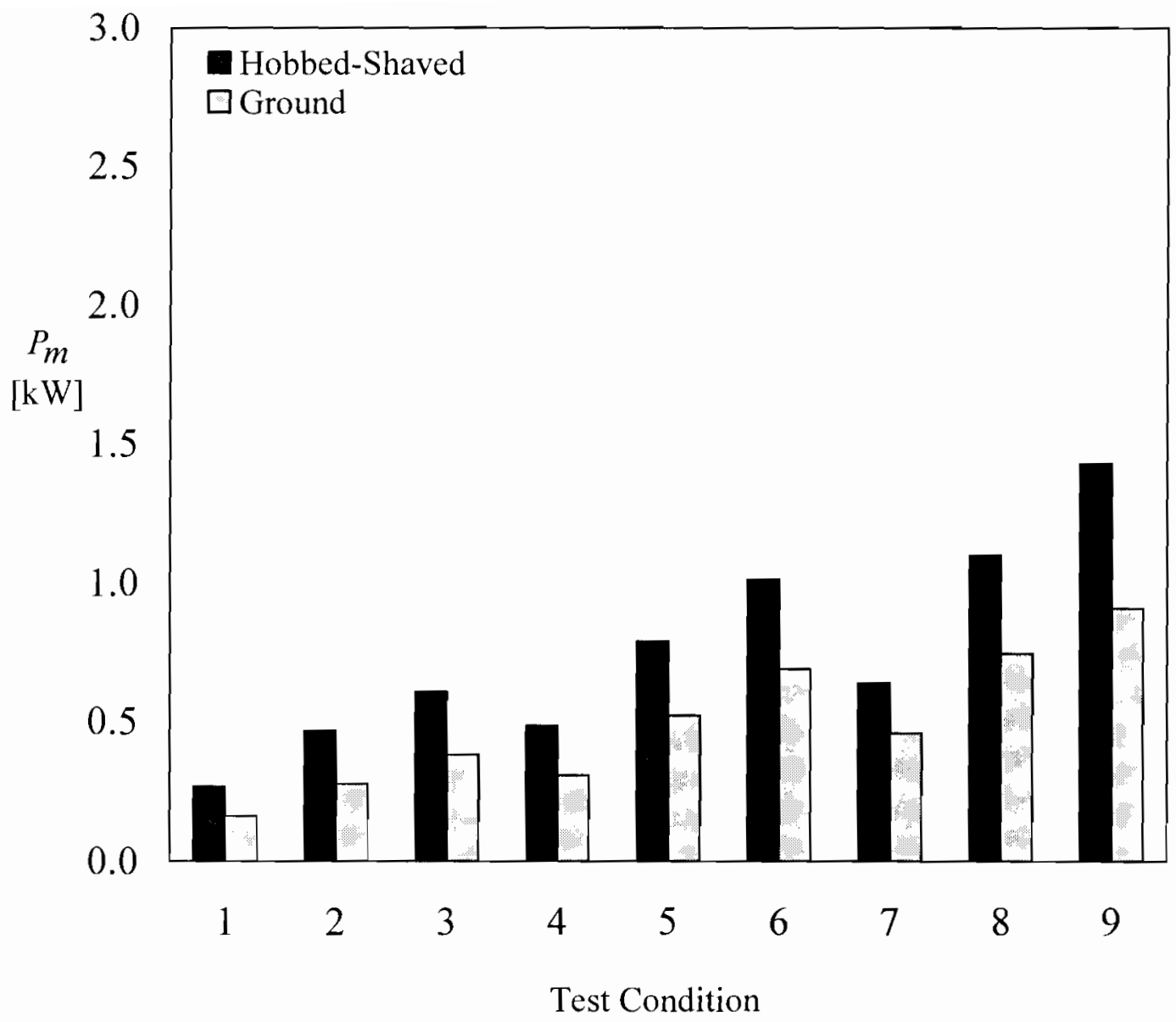

Figure 3.7 Comparison of measured $P_{m}$ for 40T, hobbed-shaved, and 40T ground gears in Lubricant D. 
40T ground gear pairs to 40T hobbed-shaved gear pairs over a range of $T_{\mathcal{C}}$ and $\Omega$ using Lubricant D.

Despite having smoother surfaces as shown in Table 2.6, the hobbed-shaved gears performed consistently worse than ground gears with an average of $35 \%$ higher $P_{m}$, or $0.17 \%$ lower $\bar{\eta}_{m}$. This finding is comparable to the study of Naruse and Haizuka [18], which found that hobbed shaved gear pairs with $m=4.5 \mathrm{~mm}$ loaded between $35 \mathrm{~N}-\mathrm{m}$ and $452 \mathrm{~N}-\mathrm{m}$ at pitch-line velocity of $7.2 \mathrm{~m} / \mathrm{sec}$ exhibited roughly $0.25 \%$ lower $\bar{\eta}_{m}$ than their ground counterparts, despite having a smoother surface finish. While this indicates that the quality of the gears has a sizable effect on the mechanical efficiency of the gear pair, the exact reason for this is not readily available. However, visual inspection of the run-in hobbed-shaved gear surfaces in Fig. 3.8 suggests that the load distribution on a hobbedshaved surface is not as uniform as on a ground surface. Figure 3.8 shows the loaded flank used for efficiency tests. Here, the original pre-heat treat surface finish is still visible as a pattern of fine striations from root to tip of the gear tooth. This pattern indicates that little to no tooth load was carried along these striations, which would concentrate contact pressures over a smaller area than on ground gears. Higher contact pressures would cause the sliding friction coefficient $\mu_{s}$ at such contact locations to be higher, resulting in higher $P_{m}$ values.

\section{Influence of Surface Roughness}

In terms of efficiency, the goal of super-finishing gear surfaces is to reduce asperity contact, and thus reduce sliding friction. Commercially available chemical 


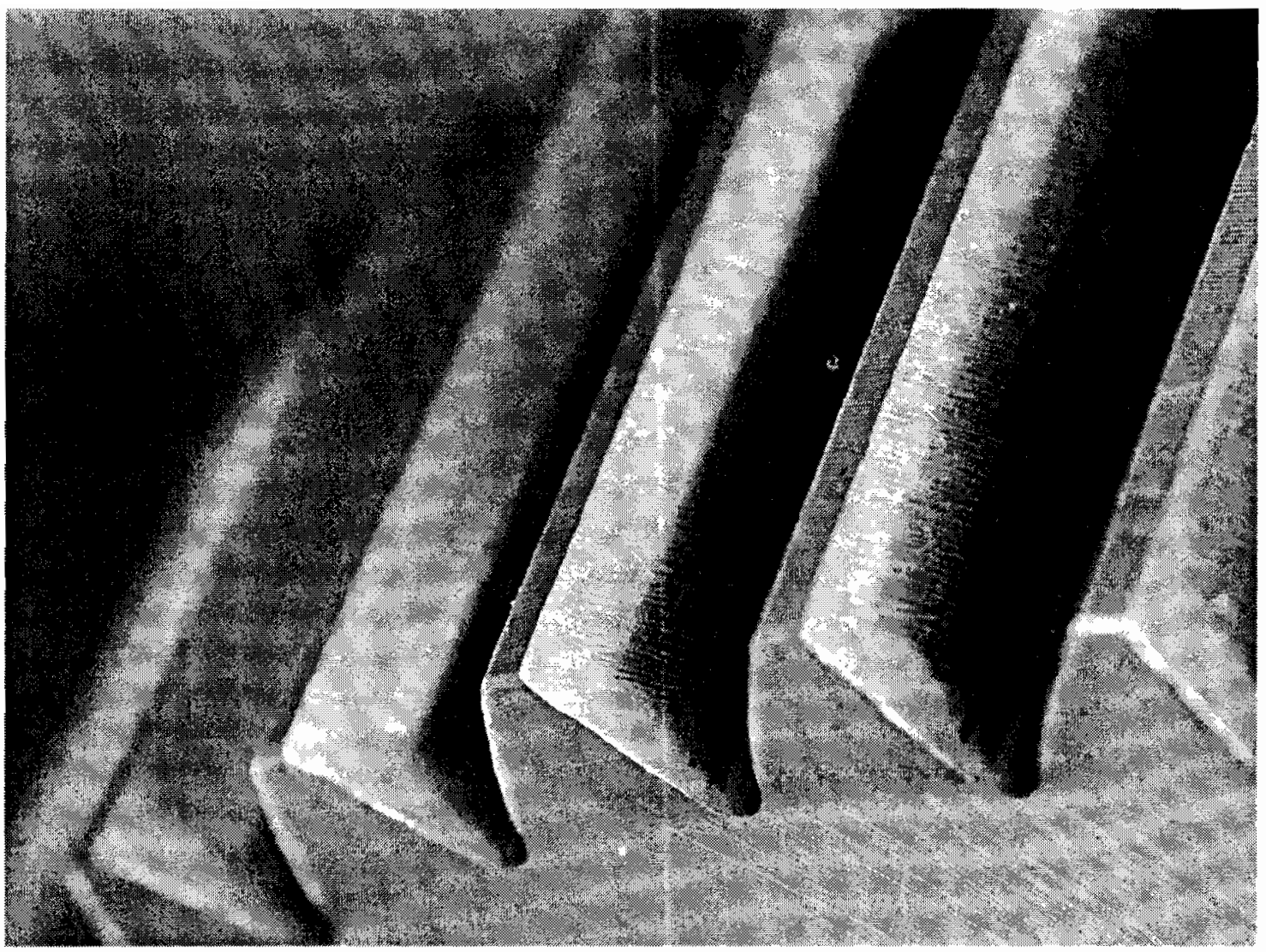

Figure 3.8 The run-in flank of a 40T hobbed-shaved gear after efficiency testing. 
polishing processes have been suggested to improve gear efficiency as they reduce surface roughness amplitude and the resultant sliding friction coefficient of the contacting surfaces $[4,16,26,42]$. However little published experimental proof of this is available, especially when lubricants of different viscosities are considered. In order to provide definitive experimental data on the influence of surface roughness, the measured $P_{m}$ values of $23 \mathrm{~T}$ and $40 \mathrm{~T}$ ground gears are compared to their chemically polished counterparts for all of the four different lubricants listed in Table 2.1.

Figure 3.9 shows the viscosity-temperature characteristics of these lubricants. Lubricant $\mathrm{B}$ has the highest kinematic viscosity at $110^{\circ} \mathrm{C}$ with $v=13.1 \mathrm{cSt}$, followed by Lubricant A with $v=10.7 \mathrm{cSt}$ at the same temperature. Although Lubricant $\mathrm{C}$ is more viscous than Lubricant $\mathrm{D}$ at a given common temperature, tests with Lubricant $\mathrm{D}$ were conducted at $90^{\circ} \mathrm{C}$, whereas tests with Lubricant $\mathrm{C}$ were conducted at $110^{\circ} \mathrm{C}$. The kinematic viscosity of Lubricant $\mathrm{D}$ at $90^{\circ} \mathrm{C}(\nu=8.0 \mathrm{cSt})$ is higher that the viscosity of Lubricant $\mathrm{C}$ at $110^{\circ} \mathrm{C}(v=5.9 \mathrm{cSt})$.

Figure 3.10 shows a comparison of the measured $P_{m}$ values for ground and chemically polished surfaces with Lubricant A over a range of operating conditions. For 23T gears in Fig. 3.10(a), chemical polishing gears to $R_{a}=0.06 \mu \mathrm{m}$ compared to ground gears having $R_{a}=0.24 \mu \mathrm{m}$ reduced $P_{m}$ by as little as $4 \%$ at test condition 16 ( $T_{c}=684 \mathrm{~N}-\mathrm{m}$ and $\Omega=10,000 \mathrm{rpm}$ ), and as much as $26 \%$ at test condition 11 ( $T_{c}=413 \mathrm{~N}-\mathrm{m}$ and $\Omega=8,000 \mathrm{rpm}$ ), with an average reduction of $16 \%$ for all of the test conditions presented in Fig. 3.10. For 40T gears as shown in Fig. 3.10(b), chemical 


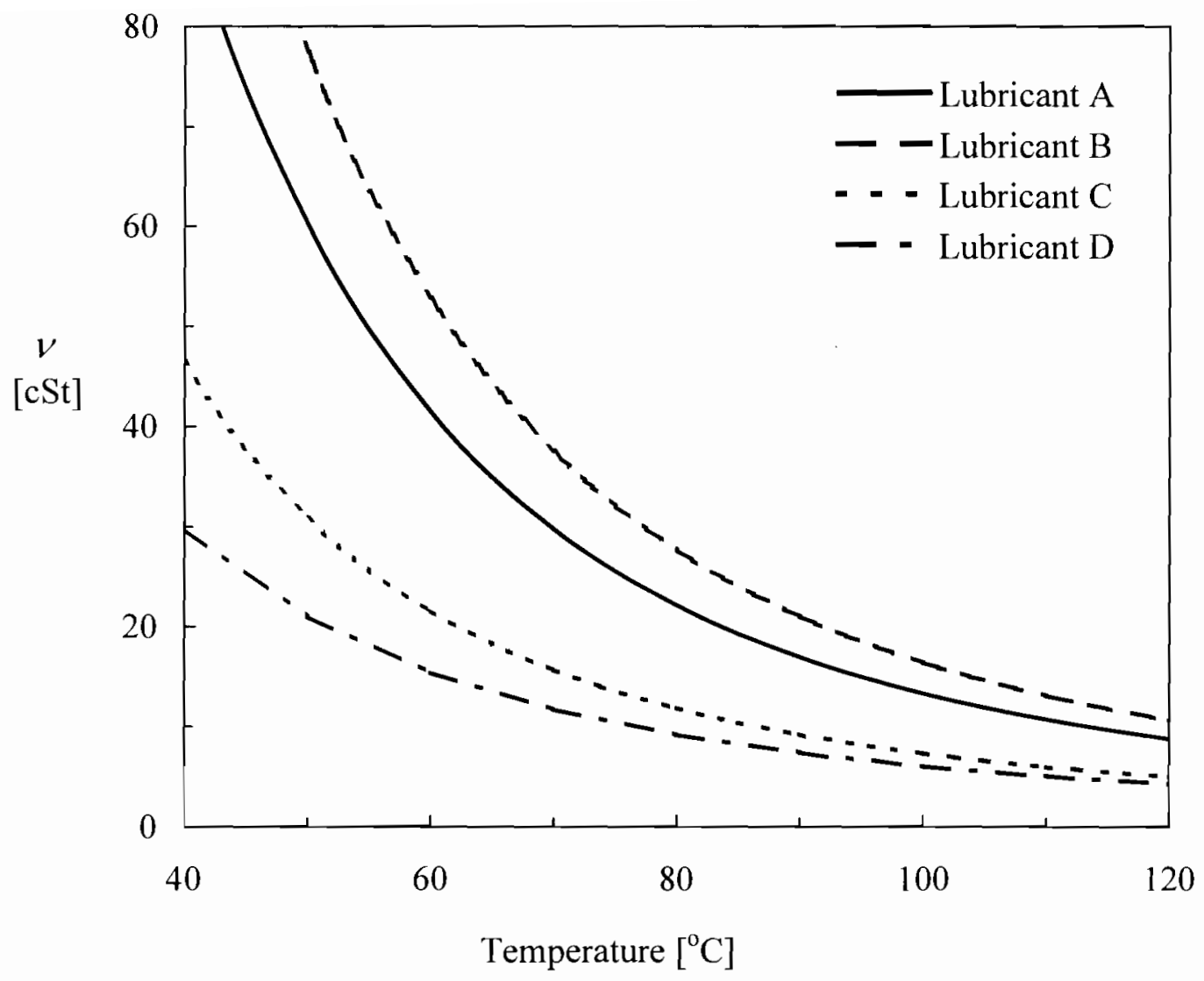

Figure 3.9 Viscosity-temperature characteristic for the lubricants used in this study. 


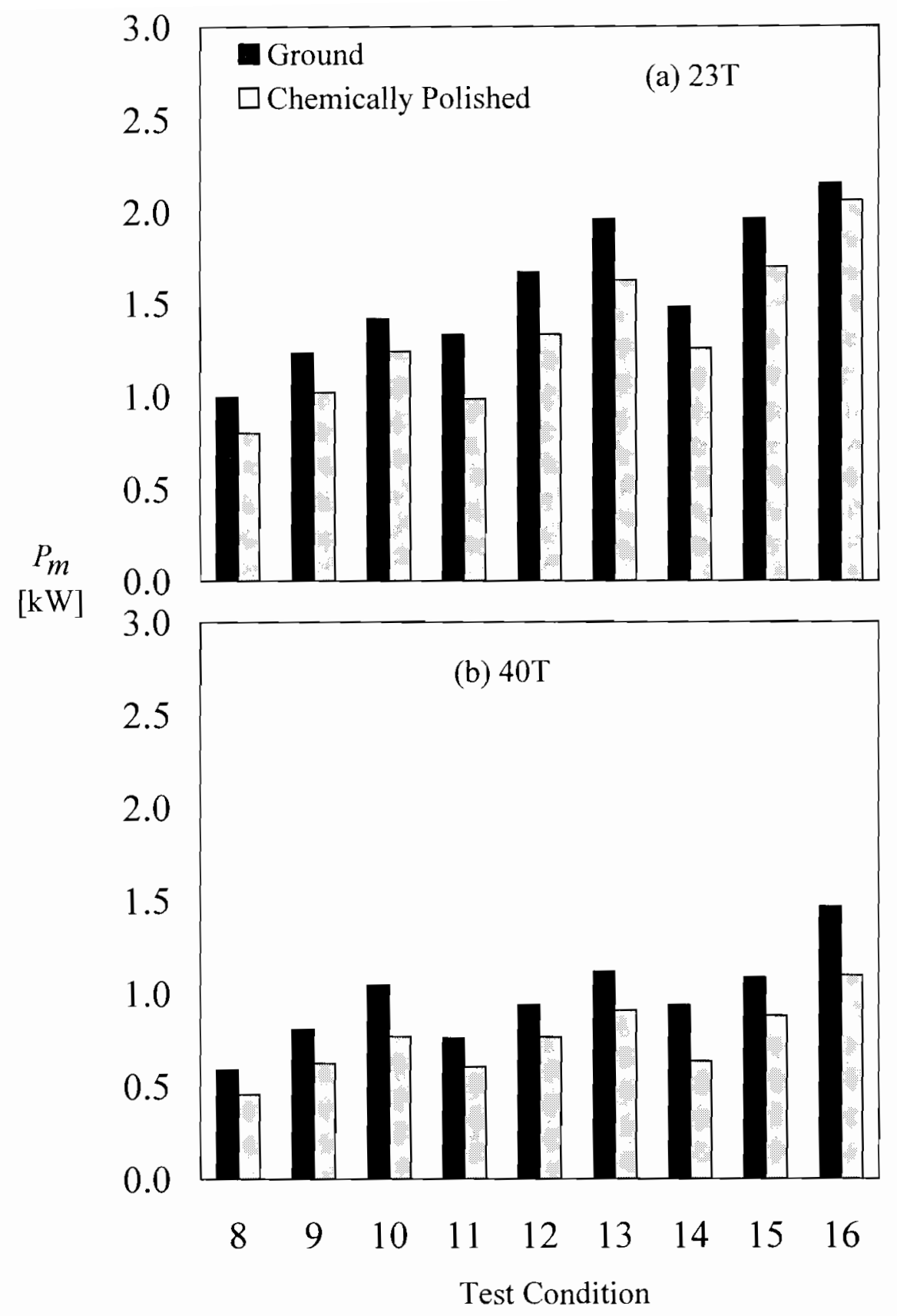

Figure 3.10 Comparison of measured $P_{m}$ for ground and chemically polished gear pairs in Lubricant A; (a) 23T gears and (b) 40T gears. 
polishing gears to $R_{a}=0.05 \mu \mathrm{m}$ compared to ground gears having $R_{a}=0.16$ results in $19 \%$ and $31 \%$ reductions of $P_{m}$ at test conditions $13\left(T_{c}=684 \mathrm{~N}-\mathrm{m}\right.$ and $\left.\Omega=8,000 \mathrm{rpm}\right)$ and $14\left(T_{c}=413 \mathrm{~N}-\mathrm{m}\right.$ and $\left.\Omega=10,000 \mathrm{rpm}\right)$, respectively, with an average reduction of $23 \%$ for all of the test conditions considered.

The general trend in Fig 3.10 is that the measured $P_{m}$ values are reduced by varying amounts when gear surface roughness is reduce significantly through chemical polishing. However, the amount of improvement is dependent on the operating conditions as well as the gear module and the surface roughness amplitudes before and after the chemical polishing process. This trend generally holds with other lubricants as well. Figure 3.11 shows the same experimental comparison for Lubricants B and C. For Lubricant B, chemically polishing the tooth surfaces reduced $P_{m}$ by an average of $9 \%$ for $23 \mathrm{~T}$ gears, and $3 \%$ for $40 \mathrm{~T}$ gear pairs. Comparing this to $23 \%$ when lubricated with Lubricant A, the reduced improvement in Lubricant B can be explained by lubricant viscosity. Since Lubricant $B$ is more viscous than Lubricant $A$, the former provides a thicker oil film. Hence, reducing $R_{a}$ is expected to have less of an effect on $P_{m}$ when gears are operated with a thicker oil film, as asperity contacts are more limited.

With Lubricant $\mathrm{C}$, chemical polishing reduced $P_{m}$ for $23 \mathrm{~T}$ and $40 \mathrm{~T}$ gears by $23 \%$ and $9 \%$, respectively. The larger difference observed for $23 \mathrm{~T}$ gears is to be expected because the $23 \mathrm{~T}$ gears have larger sliding velocities than the $40 \mathrm{~T}$ gears, and hence larger sliding frictional loss $P_{s}$. However, this result is not the same with all lubricants tested because of differing oil viscosities, which is expected to influence both $P_{s}$ and $P_{r}$ at different levels. 


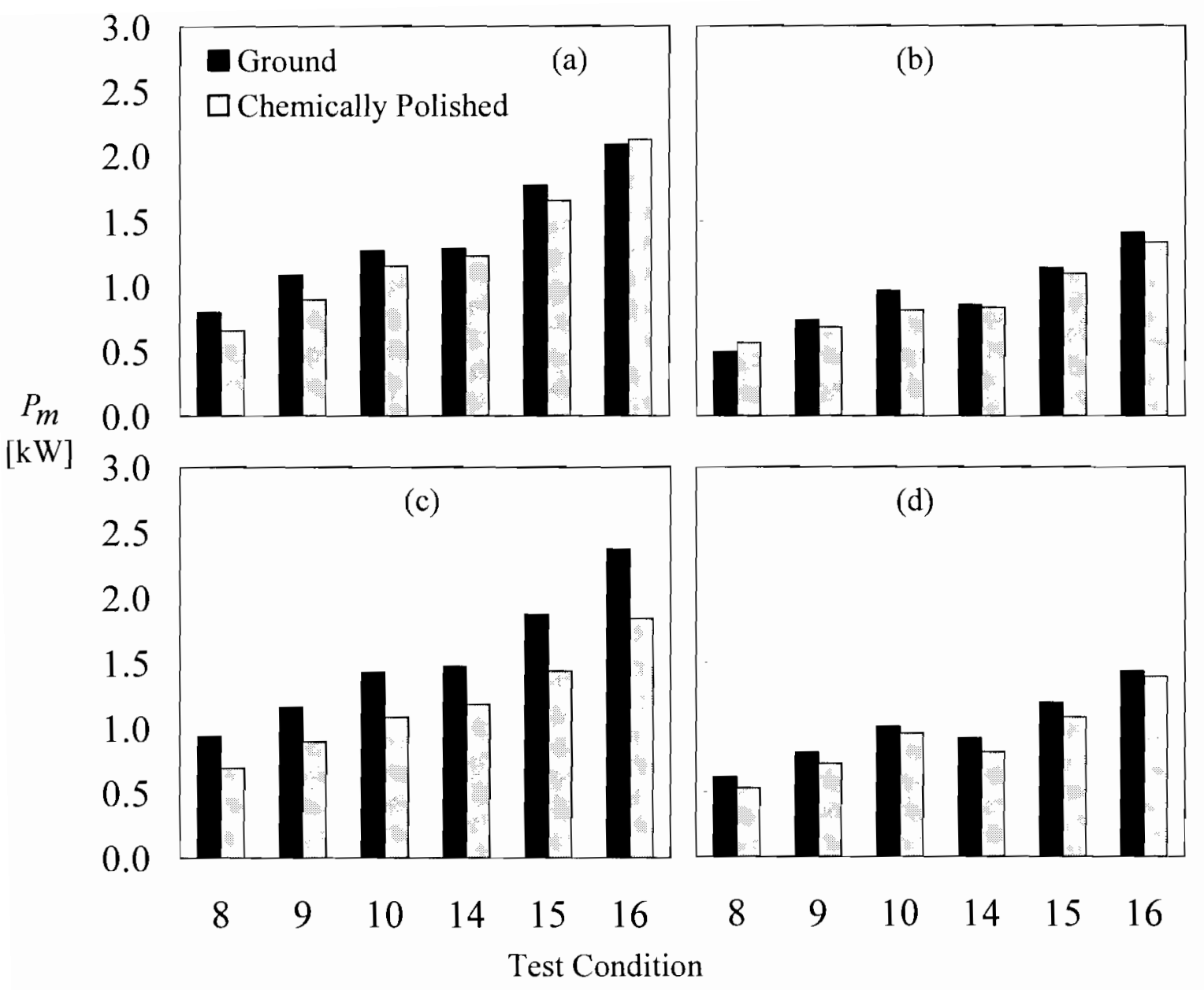

Figure 3.11 Comparison of measured $P_{m}$ for ground and chemically polished gear pairs; (a) 23T gears in Lubricant $\mathrm{B}$, (b) 40T gears in Lubricant B, (c) 23T gears in Lubricant $C$, and (d) $40 \mathrm{~T}$ gears in Lubricant $C$. 
Figure 3.12 compares the $P_{m}$ values of chemically polished $23 \mathrm{~T}$ and $40 \mathrm{~T}$ gears to their ground counterparts with Lubricant D. Here, chemical polishing resulted in $19 \%$ lower $P_{m}$ values for both $23 \mathrm{~T}$ and $40 \mathrm{~T}$ gear pairs. Similarly, Fig. 3.13 shows the measured influence of chemical polishing on $40 \mathrm{~T}$ hobbed-shaved gear surfaces, again lubricated with Lubricant D. Here, the chemically polished gear pairs operated at measured $P_{m}$ values nearly 53\% lower than their hobbed-shaved counterparts. This result suggests that chemical polishing has a larger influence on gears with inaccurate profiles. However, the gear lead measurements of Fig. 2.10 indicate that the hobbedshaved gears that are chemically polished are quite comparible to those of chemically polished ground gears, while the baseline hobbed-shaved gears appear to be less accurate. Therefore, the improvements in $P_{m}$ observed in Fig. 3.13 represent the combined influence of chemical polishing and a more accurate involute profile.

The gear inspections of Fig. 2.10 might lead one to conclude that the chemical polishing process can improve gear accuracy, but one should be cautioned against this conclusion. Although chemical polishing processes are known to reduce surface roughness amplitudes to less than $0.1 \mu \mathrm{m} R_{a}$, they can provide only limited improvements to the larger profile deviations observed with the hobbed-shaved gears. Since gear inspections were not performed prior to the chemical polishing treatment, no conclusions can be drawn as to the effect of this process on gear accuracy.

Lastly, the influence of chemical polishing on a $17 / 26 \mathrm{~T}$ hobbed-shaved gear pair lubricated with Lubricant D and Lubricant $A$ is shown in Fig. 3.14. When Lubricant D is used, the chemically polished gear pair operates at $38 \%$ to $47 \%$ lower $P_{m}$, with an 


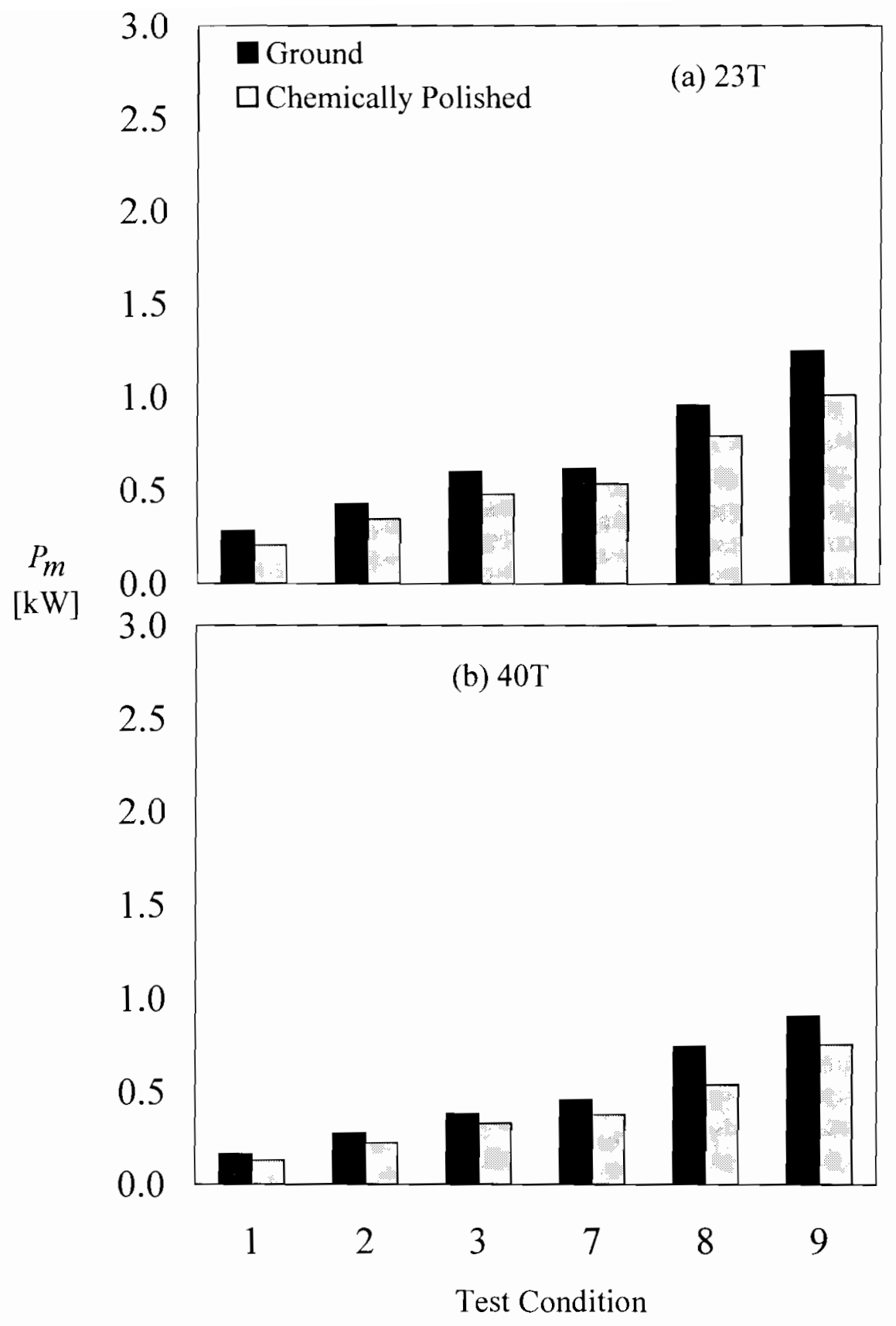

Figure 3.12 Comparison of measured $P_{m}$ for ground and chemically polished gear pairs in Lubricant D; (a) 23T gears and (b) $40 \mathrm{~T}$ gears. 


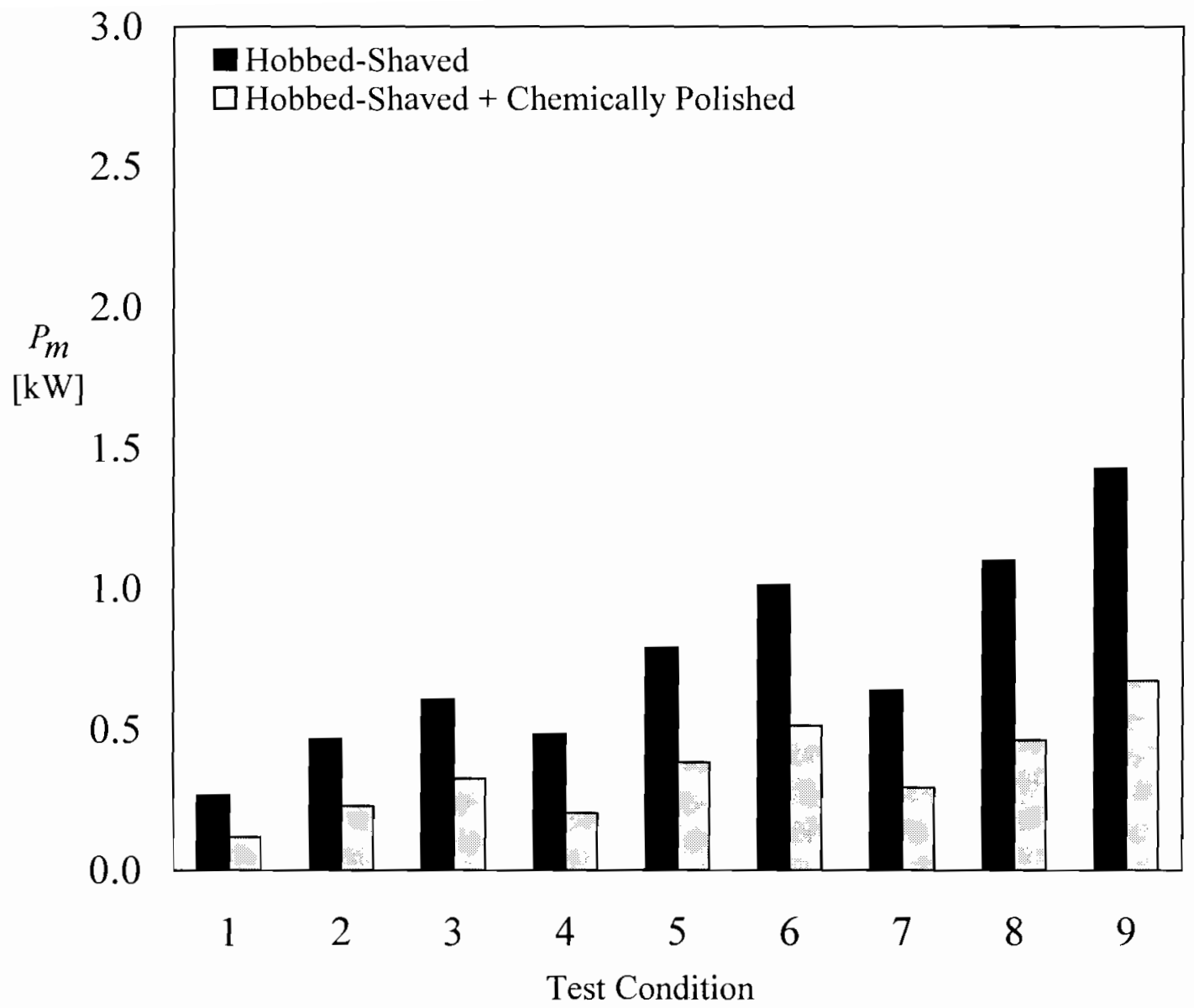

Figure 3.13 Comparison of measured $P_{m}$ for 40T hobbed-shaved, and hobbed-shaved plus chemically polished gear pairs in Lubricant D. 
(a) Lubricant D

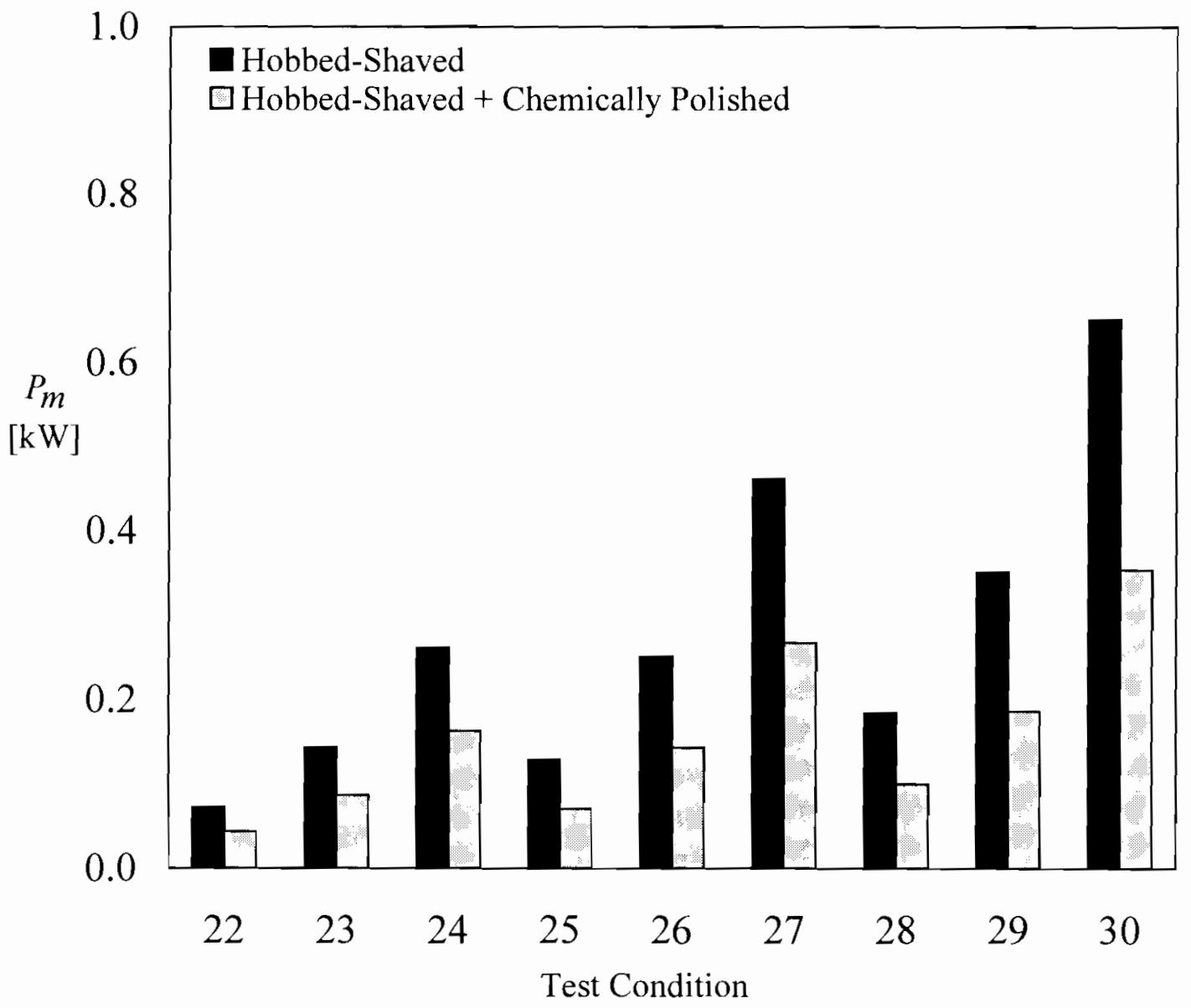

Figure 3.14 Comparison of measured $P_{m}$ for hobbed and shaved, and hobbed and shaved plus chemically polished 17/26T gear pairs in (a) Lubricant D, and (b) Lubricant A. 
Figure 3.14 continued.

(b) Lubricant $\mathrm{A}$

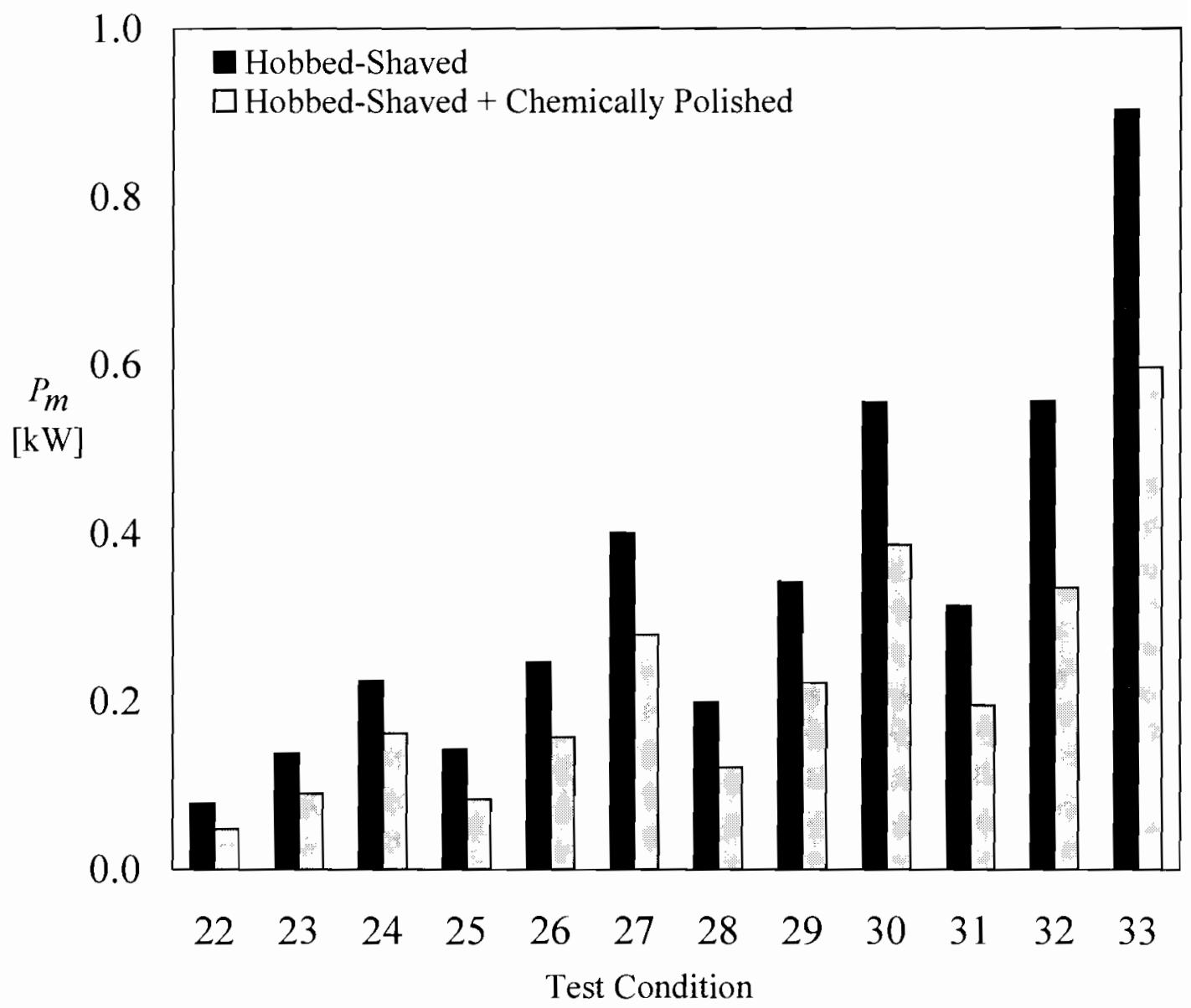


average of $43 \%$ for all operating conditions tested. When Lubricant A is used instead of Lubricant D, $P_{m}$ reductions were between $28 \%$ and $42 \%$, with an average of $36 \%$ for all the operating conditions tested. This sizeable reduction in $P_{m}$ compared to the $23 \mathrm{~T}$ and 40T gears can be attributed primarily to the larger reduction in surface roughness from $R_{a}=0.25 \mu \mathrm{m}$ to $0.03 \mu \mathrm{m}$ due to chemical polishing process, as seen in Table 2.6. Secondly, the pitch-line velocities, and hence rolling velocities, achieved in the 17/26T gear tests were lower as listed in Table 2.6. Since oil film thickness becomes thinner at lower rolling velocities, reductions in surface roughness, and thus asperity contacts, are likely to have a more dominant influence on $P_{m}$. Additionally, the influence of chemical polishing on $P_{m}$ is greater when lubricated with Lubricant D than Lubricant A. Again, this is likely due to the increased asperity contacts with Lubricant D, the less viscous oil, and as a result, measured $P_{m}$ is more sensitive to changes in $R_{a}$. This is consistent with the reduced influence of $R_{a}$ on measured $P_{m}$ for $40 \mathrm{~T}$ gears when lubricated with Lubricant B compared to Lubricant A.

\section{Influence of Low-Friction Coatings}

Diamond-like carbon (DLC) surface coatings are known to reduce dry friction compared to uncoated steel contacts. Traction tests with a ball-on-disk tribometers as well as preliminary studies with gears in a transfer gearbox $[16,50]$ have shown that lowfriction coatings do reduce friction coefficient, and by extension $P_{m}$. However, the extent to which power loss improvements are possible depends on the amount of asperity contact present in the gear mesh. 
In order to evaluate the influence of low-friction coatings, three different DLC coatings were applied to four sets of chemically polished 40T gear pairs and tested with Lubricant $\mathrm{A}$ as the lubricating oil. Figure 3.15 compares measured $P_{m}$ for the four coated gears pairs to a baseline chemically polished gear pair. DLC-A and DLC-B are proprietary coatings supplied by two separate sources, while DLC-C and DLC-D are the same coating supplied by a third source.

All four gear sets exhibited wear of the coating layer to varying extents. The numbers above each bar group in Fig. 3.15 indicate the order in which tests were conducted. Testing began with the lowest load level of $T_{c}=413 \mathrm{~N}-\mathrm{m}$, and highest speed $\Omega=10,000 \mathrm{rpm}$, and progressed downward in speed before increasing $T_{c}$. At each torque level, tests were conducted at 10,000 and $6,000 \mathrm{rpm}$. Observing $P_{m}$ at each condition in the test sequence, it appears that DLC-B and DLC-C exhibited initially lower power loss than the baseline chemically polished gear pair, but as the tests progress, these gains deteriorated. $P_{m}$ for the highest $T_{c}$ at test conditions $10\left(T_{c}=684 \mathrm{~N}-\mathrm{m}\right.$ and $\Omega=6,000 \mathrm{rpm})$ and $16\left(T_{\mathcal{C}}=684 \mathrm{~N}-\mathrm{m}\right.$ and $\left.\Omega=10,000 \mathrm{rpm}\right)$ show the worst performance of these coatings. Hence, it appears that DLC-B and DLC-C initially reduced friction at asperity contacts, but as the coatings wore through, power loss increased to a level consistent with surface roughness as shown in Table 2.6. Figure 3.16(a) shows wear of the coating layer for the DLC-B coated gears and Fig. 3.16(b) shows wear of the coating layer for the DLC-C coated gears.

In summary, before a particular coating can be proposed as a method to improve mechanical gear mesh efficiency, it must be durable enough to sustain a long period of 


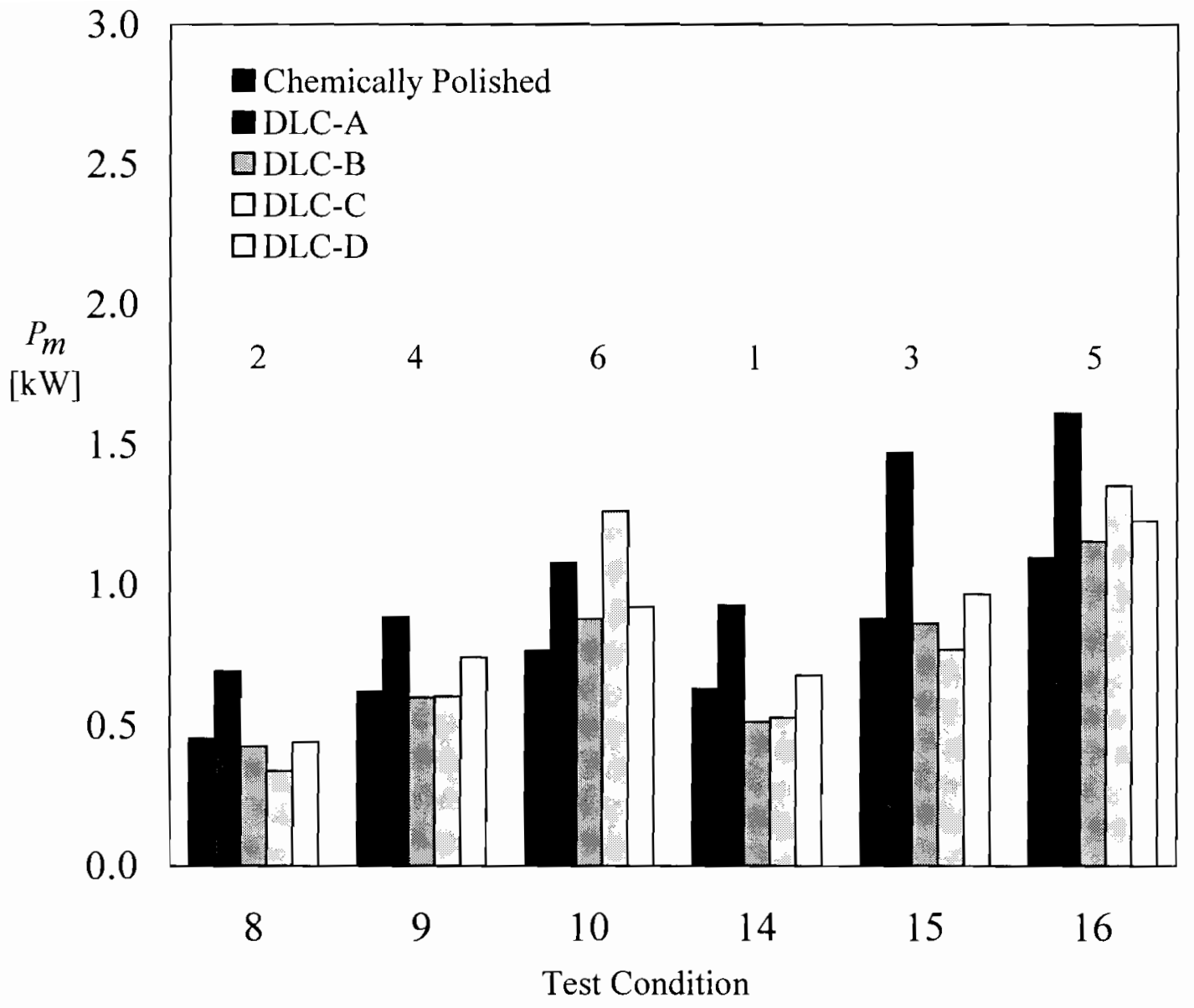

Figure 3.15 Influence of low-friction coatings on measured $P_{m}$ for 40T gear pairs in Lubricant A. 
(a) DLC-B

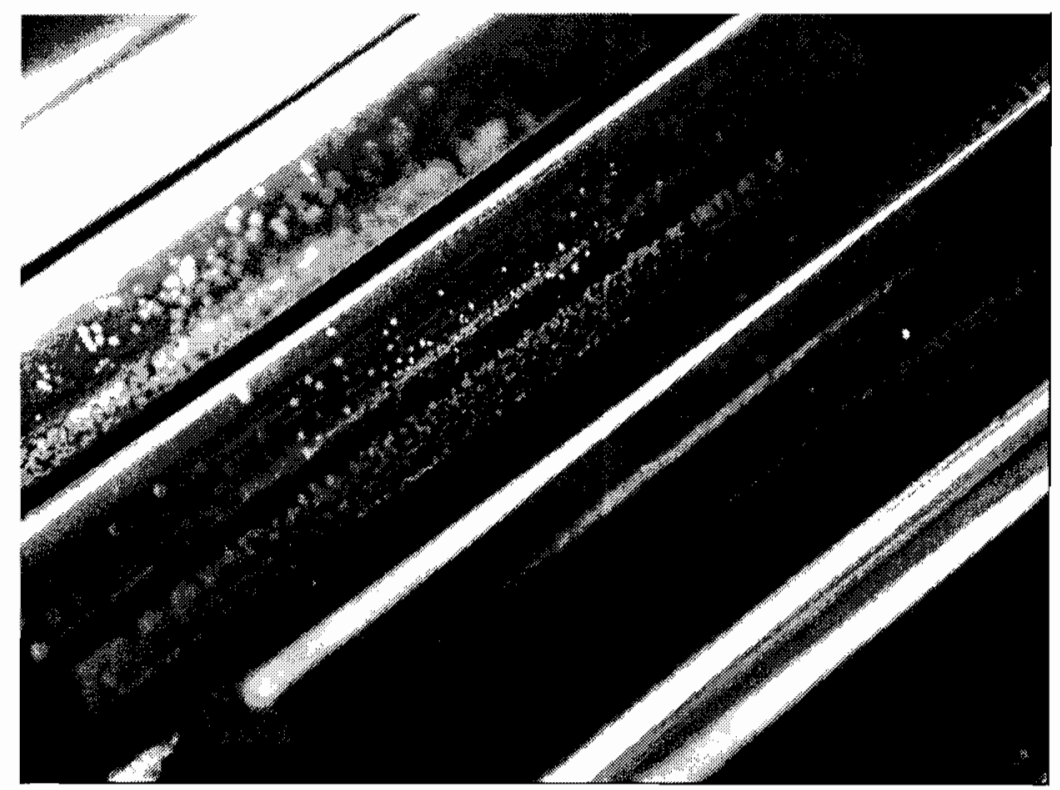

(b) DLC-C

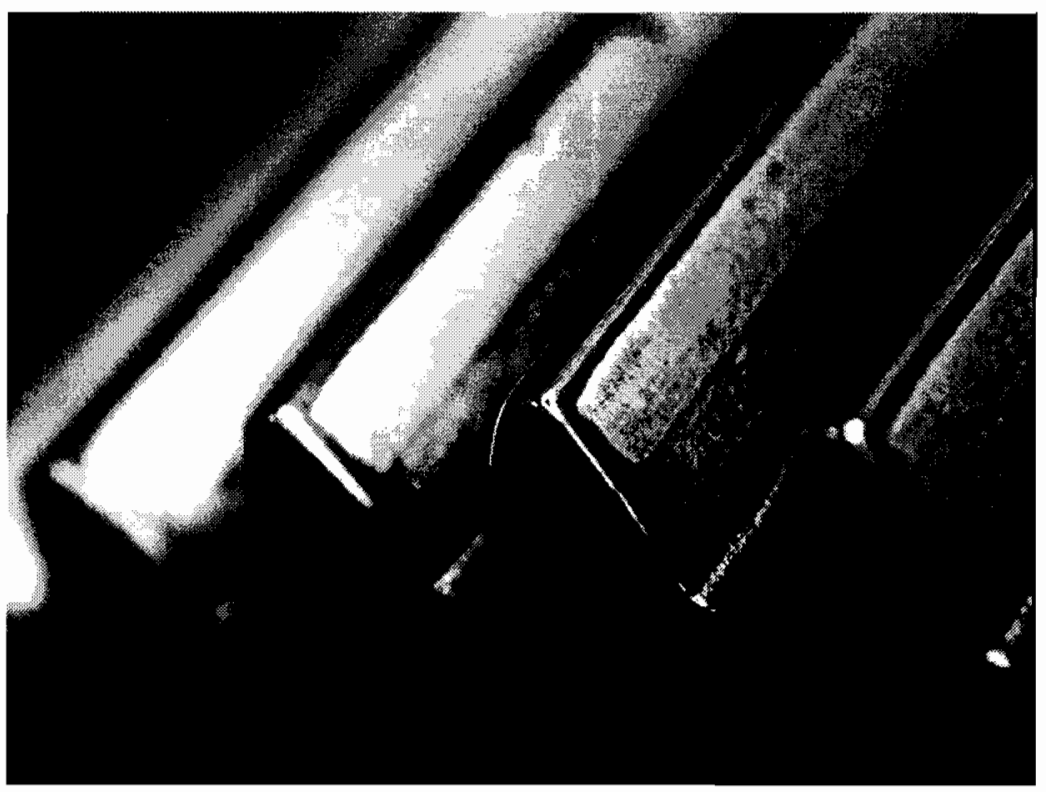

Figure 3.16 Failed DLC coatings after efficiency tests; (a) DLC-B, and (b) DLC-C 
operation without wearing off so that its potential to improve efficiency can be assessed. All four coatings tested in this study failed to endure even several hours of operation needed to complete efficiency tests. Therefore, the data provided in Fig. 3.15 cannot be relied upon to assess the influence of coatings on $P_{m}$.

\section{Influence of Lubricant Type}

Lubricant viscosity $v$ is a key parameter influencing $P_{m}$. Increasing $v$ increases oil film thickness, which helps reduce asperity contacts, and thus reduces the sliding friction component $P_{S}$ of mechanical power loss. Meanwhile, increasing $v$ increases fluid shear forces arising from relative sliding of the two surfaces, potentially increasing $P_{s}$. It also increases rolling power losses $P_{r}$ in the form of fluid squeezing, and pumping in the formation of the film. The goal of lubricant selection for increased efficiency in terms of $P_{m}$ is to reduce both $P_{r}$ and $P_{s}$. Figure 3.17 compares $P_{m}=P_{s}+P_{r}$ for 23T and 40T ground and chemically polished gear pairs lubricated with Lubricants A, B, and C. From this figure, the following observations can be made:

- For all ground gears, $P_{m}$ is minimized when Lubricant B is used. This is likely due to reduced asperity contact that follows a larger film thickness, due to higher viscosity. For $23 \mathrm{~T}$ ground gears, Lubricant $\mathrm{B}$ appears to have a larger impact on $P_{m}$ compared to the other oils. This can be attributed to the higher sliding velocities observed with these gears, which should result in higher $P_{S}$. 
- $23 \mathrm{~T}$ chemically polished gears performed best with the least viscous lubricant, Lubricant C. Here, since the surfaces were chemically polished, there was little asperity contact with all oils, and both the fluid shear component of $P_{s}$ and $P_{r}$. were minimal with the lowest viscosity oil.

- 40T chemically polished gears performed best with the medium-viscosity lubricant, Shell 75W90. This result is not consistent with the $23 \mathrm{~T}$ gears probably due to the lower range of sliding velocities encountered with the 40T gears. Since the sliding friction component of $P_{s}$ represents a smaller portion of $P_{m}$ for the $40 \mathrm{~T}$ gears, the efficiency performance seems to be more dependent on optimizing fluid shear forces versus rolling losses.

Finally, Fig. 3.18 compares $P_{m}$ for 17/26T hobbed-shaved, and hobbed-shaved plus chemically polished gears with Lubricant $\mathrm{D}$ at $90^{\circ} \mathrm{C}$, and Lubricant $\mathrm{A}$ at $48^{\circ} \mathrm{C}$. At these operating temperatures, Lubricant $\mathrm{D}$ has $v=8.0 \mathrm{cSt}$, while Lubricant A has $v=65.2 \mathrm{cSt}$. This comparison serves to illustrate the effect of lubricant viscosity on $P_{m}$ for large differences in $v$. In this comparison, the hobbed-shaved gears (without chemical polishing) benefit marginally from the thicker film afforded by Lubricant $A$ at $v=65.2 \mathrm{cSt}$, indicating that the reduction in asperity friction forces simply offsets increases in fluid shear and rolling losses. Accordingly, it can be expected that hobbedshaved gears that are chemically polished should perform better with Lubricant $D$ at $v=8.0 \mathrm{cSt}$ under the same operating conditions because these gears do not benefit from 


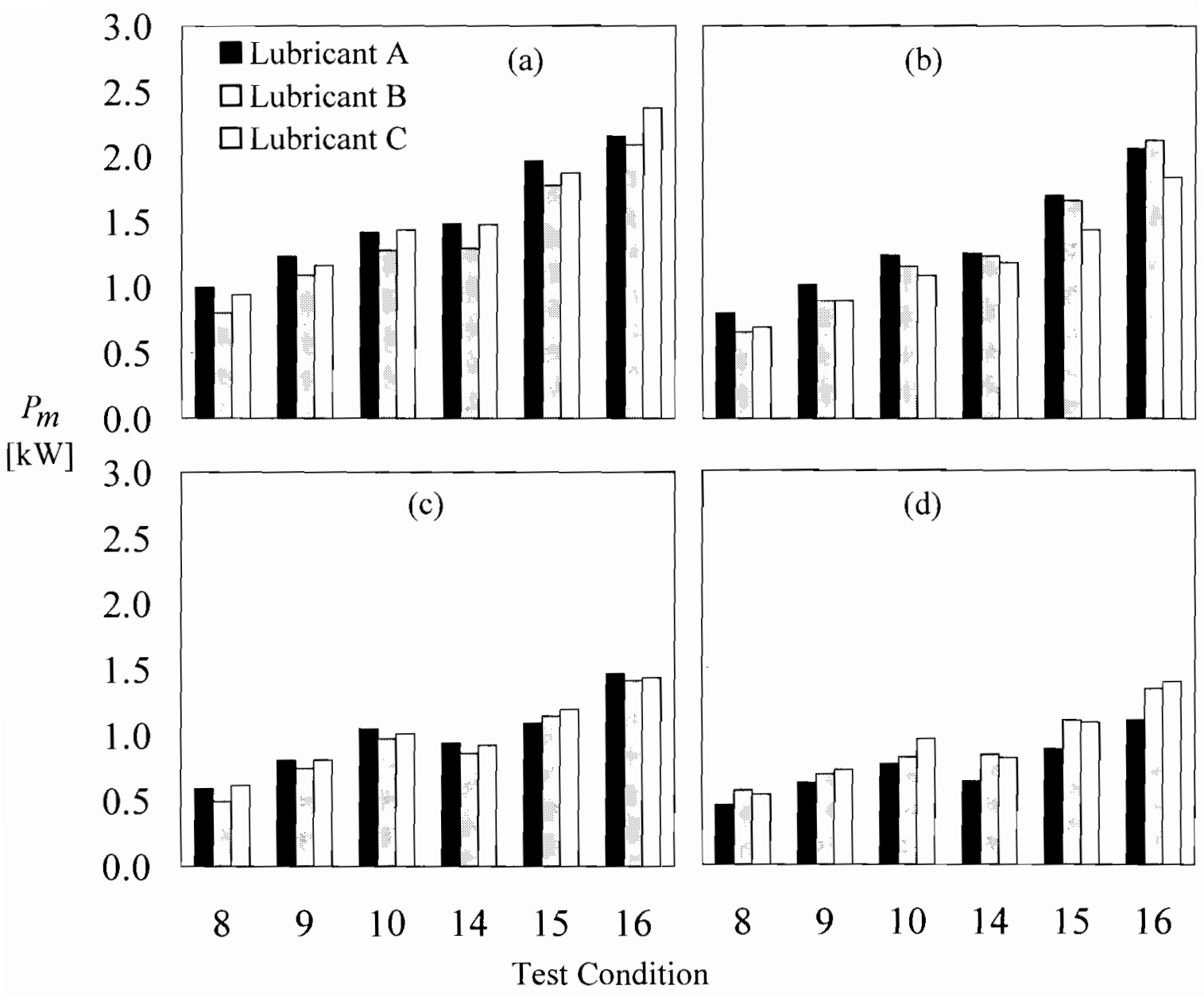

Figure 3.17 Comparison of measured $P_{m}$ for 23T and 40T, and ground and chemically polished gear pairs in Lubricants A, B, and C; (a) 23T ground gears, (b) $23 \mathrm{~T}$ chemically polished gears and, (c) 40T ground gears, and (d) $40 \mathrm{~T}$ chemically polished gears. 


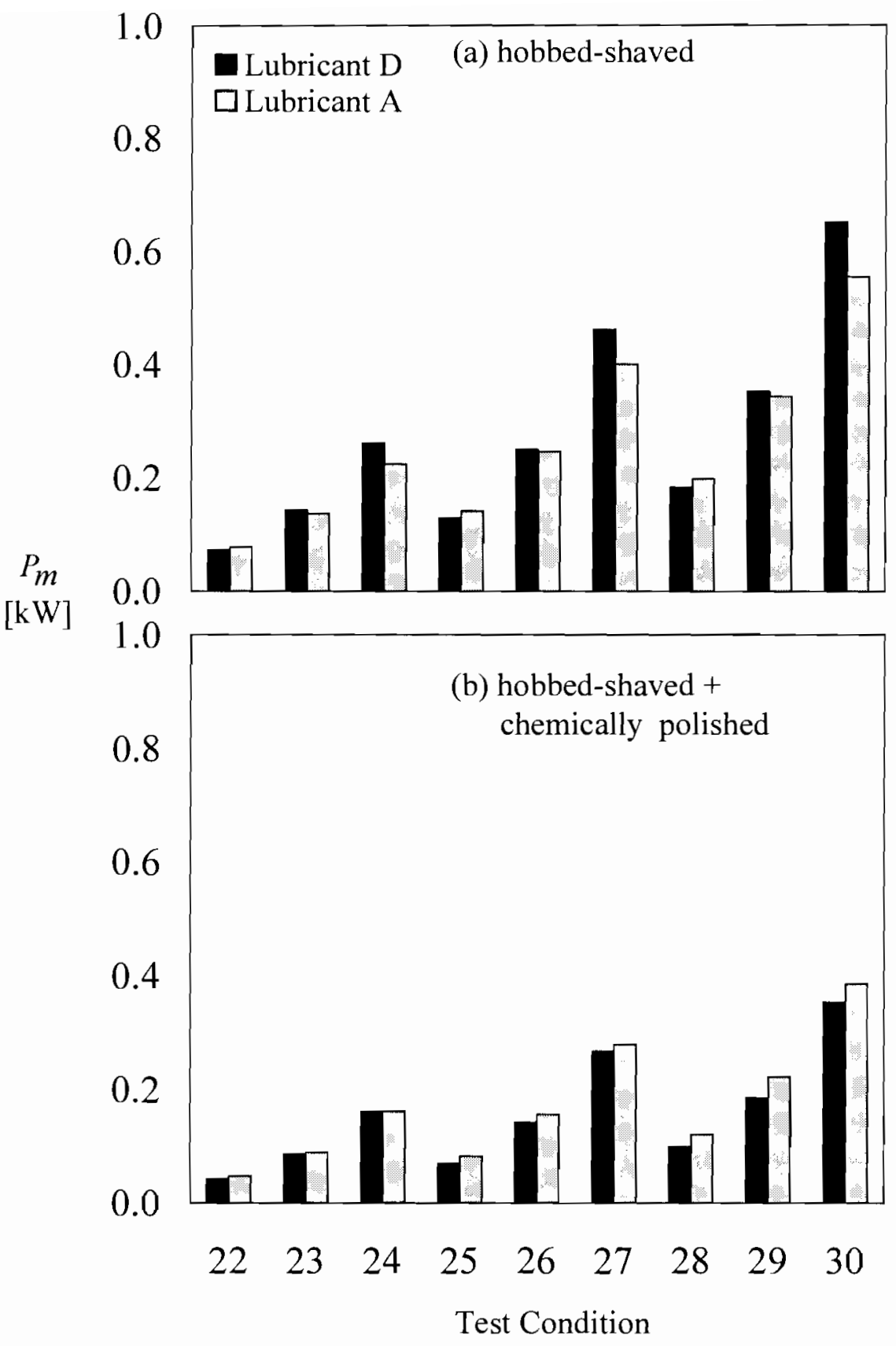

Figure 3.18 Comparison of measured $P_{m}$ for 17/26T hobbed and shaved, and hobbed and shaved plus chemically polished gear pairs in Lubricant $\mathrm{D}$ at $90^{\circ} \mathrm{C}$ and Lubricant $\mathrm{A}$ at $48^{\circ} \mathrm{C}$; (a) hobbed-shaved gears, (b) hobbed-shaved plus chemically polished gears. 
a thicker film as much as their hobbed-shaved counterparts. Figure 3.18(b) bears this out, showing that the chemically polished $17 / 26 \mathrm{~T}$ gears operated at $11 \%$ lower $P_{m}$ in Lubricant D compared to Lubricant A. This observation can be explained by the fact that fluid shear forces and rolling losses dominate $P_{m}$ when lubricant viscosity is high.

Figure 3.19 serves as a summary of the influences of gear module $m$, surface roughness, manufacturing process, and lubricant type on $P_{m}$. For Fig. $3.19, \bar{\eta}_{m}$ was averaged over all of the test conditions. 40T chemically polished gears lubricated with Lubricant A outperformed all other gears in terms of $P_{m}$ with average mechanical efficiency of $\bar{\eta}_{m}=99.83 \%$, while $23 \mathrm{~T}$ ground gears lubricated with Lubricant A performed the worst with average $\bar{\eta}_{m}=99.65 \%$. These results show that module is the most influential parameter in determining $P_{m}$, followed by surface roughness amplitude, then lubricant type. Furthermore, these results indicate that lubricant selection should be considered at the design stage in conjunction with gear parameters in order to maximize efficiency.

\subsection{Gearbox Spin Power Loss}

Total gearbox power loss is defined earlier in Eq. (3.8) as a sum of $P_{\text {mech }}$ and $P_{\text {spin }}$. The previous section focused on minimizing $P_{m}$, and hence $P_{m e c h}$, according to Eq. (3.9a). Although it is important to study $P_{m}$ independently of other sources of power loss, doing so without consideration of gearbox spin power loss can lead to 


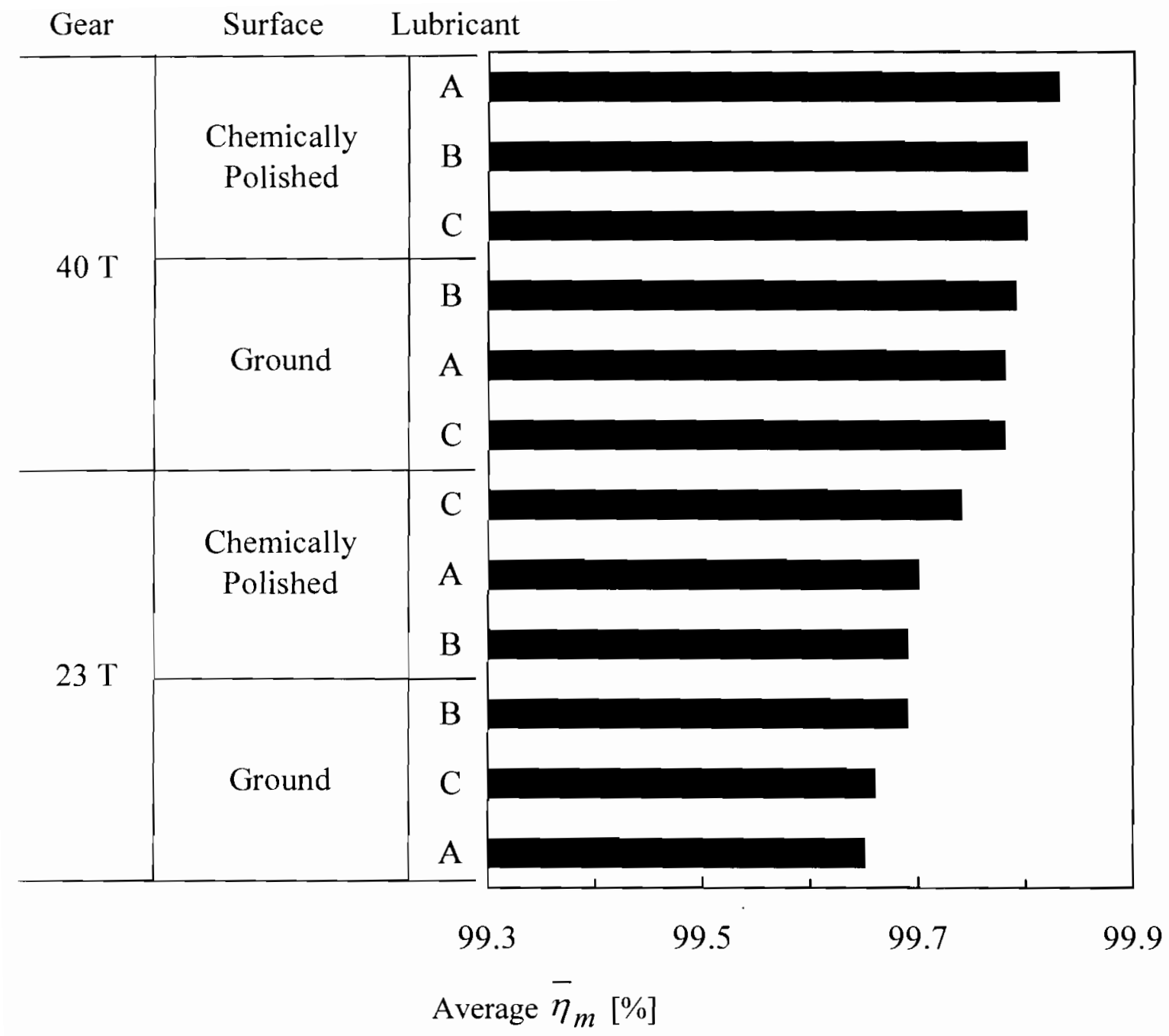

Figure 3.19 Comparison of average measured $\bar{\eta}_{m}$ for $23 \mathrm{~T}$ and $40 \mathrm{~T}$, ground and chemically polished gear pairs lubricated with Lubricants A, B, and C. 
erroneous conclusions regarding lubricant selection on the basis of efficiency. This section will focus on the unloaded gearbox power loss $P_{\text {spin }}$.

In order study the influence of $m$ on the spin power losses, $P_{s p i n}$ was measured for each test outlined in Table 2.1 at rotational speeds of $\Omega=2,000$ to $10,000 \mathrm{rpm}$ in 2,000 rpm increments. In actuality, since the $23 \mathrm{~T}$ and $40 \mathrm{~T}$ gears had different face width $b$, the reported spin losses are the combined influence of $m$ and $b$. However, previous work reported that $m$ is more influential on $P_{\text {spin }}$ than $b$ [27-29]. Therefore, $P_{\text {spin }}$ will be discussed in terms of effect of $m$ with the understanding that the true influence of $m$ is probably slightly higher.

Figure 3.20 shows the influence of lubricant type on $P_{\text {spin }}$ for ground 23T and 40T gears. Since the test machine was unloaded during these tests, i.e. $T_{c}=0$, the loaddependent losses were nearly zero, so that the influence of $m, v$, and $\Omega$ on $P_{\text {spin }}$ can be quantified. Since $23 \mathrm{~T}$ and $40 \mathrm{~T}$ gears are displayed seperately, Fig. 3.20 illustrates the influence of $v$ on $P_{\text {spin }}$ as a function of $\Omega$. Referring to the lubricant temperatureviscosity relationship in Fig. 3.9 , it is observed that $P_{\text {spin }}$ follows $v$. Lubricant $\mathrm{B}$, being the most viscous lubricant studied, exhibited the highest $P_{\text {spin }}$ for both $23 \mathrm{~T}$ and $40 \mathrm{~T}$ gears over the entire range of $\Omega$ considered. Likewise Lubricant $\mathrm{C}$, having lowest $v$, exhibited lowest $P_{\text {spin }} . P_{\text {spin }}$ data was unavailable for Lubricant D at $\Omega=8,000$ and $10,000 \mathrm{rpm}$.

In Fig. 3.20, $P_{\text {spin }}$ varies to a power of $\Omega$ ranging from 1.4 to 1.7 , depending on the gear pair and lubricant. These results do not agree with previous studies on windage 


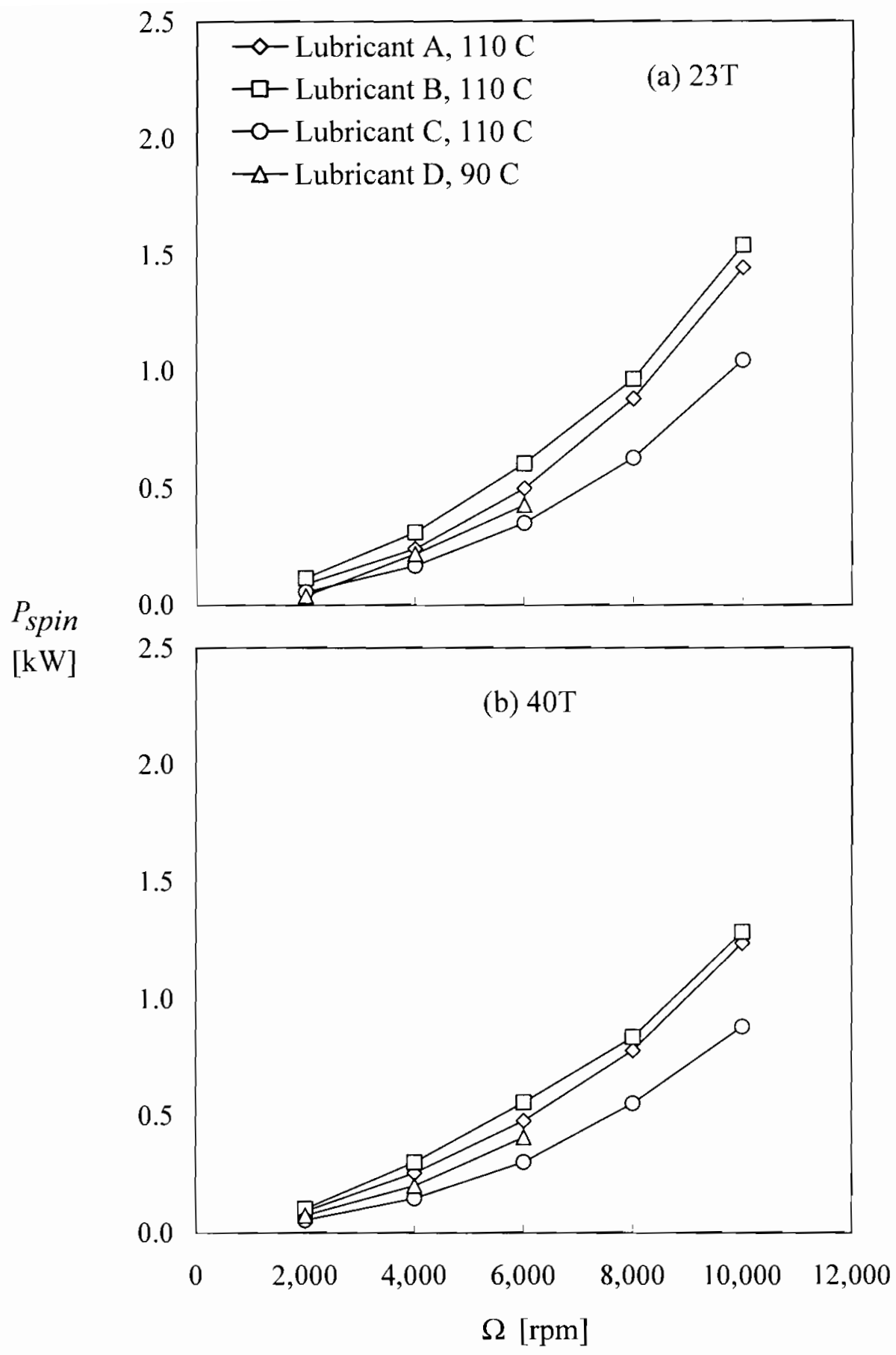

Figure 3.20 Comparison of measured $P_{\text {spin }}$ of 23T and 40T gear pairs lubricated with Lubricants A, B, C, and D as a function of $\Omega$ for (a) $23 \mathrm{~T}$ ground gear pairs and (b) 40T ground gear pairs. 
$[27-29,31]$, for which power loss was found to be proportional to $\Omega^{2.8}$ as a result of applying the kinetic energy theorem to a disc rotating in a viscous fluid. However, the present results do agree with the unloaded power loss measurements of the jet-lubricated gear friction test rig of Britton et al [26]. For example, measured unloaded power losses in this study for the $23 \mathrm{~T}$ gears in Lubricant $\mathrm{A}$ at $110^{\circ} \mathrm{C}$ were found to follow the relation $P_{\text {spin }}=6 \times 10^{-7} \Omega^{1.6} \mathrm{~kW}$, whereas $P_{\text {spin }}=1 \times 10^{-7} \Omega^{1.5} \mathrm{~kW}$ in ref. [26] for a gear pair lubricated with Mobiljet II synthetic oil at $50^{\circ} \mathrm{C}$. These results indicate that the mechanisms of unloaded power loss in gearboxes are not as well understood as loaded power loss, and deserve a more detailed treatment than that in this study.

Although $P_{m}$ was only modestly influenced by oil type, $P_{\text {spin }}$ is shown to be strongly dependent on oil type due to their differences in $v . P_{\text {spin }}$ values for both $23 \mathrm{~T}$ and $40 \mathrm{~T}$ gears were similarly influenced by $v$, with an average of $42 \%$ reduction in $P_{\text {spin }}$ for Lubricant $\mathrm{C}$ compared to Lubricant $\mathrm{B}$. This indicates that the selection of a lubricant is a critical step in optimizing power loss for high-speed gearing.

Prior studies on high-speed gear windage indicated that gear module is an important parameter in gearbox spin losses [27-28]. To show this, Fig. 3.21 compares measured $P_{\text {spin }}$ at $\Omega=2,000$ to $10,000 \mathrm{rpm}$ for $23 \mathrm{~T}$ and $40 \mathrm{~T}$ ground gear pairs lubricated with four gear oils. This figure shows that module plays an important role in $P_{\text {spin }}$ regardless of lubricating oil. At 2,000 rpm, differences in $P_{\text {spin }}$ for $23 \mathrm{~T}$ and $40 \mathrm{~T}$ gears are too small to be reliably captured by the test machine, but at 4,000 rpm, the $40 \mathrm{~T}$ 


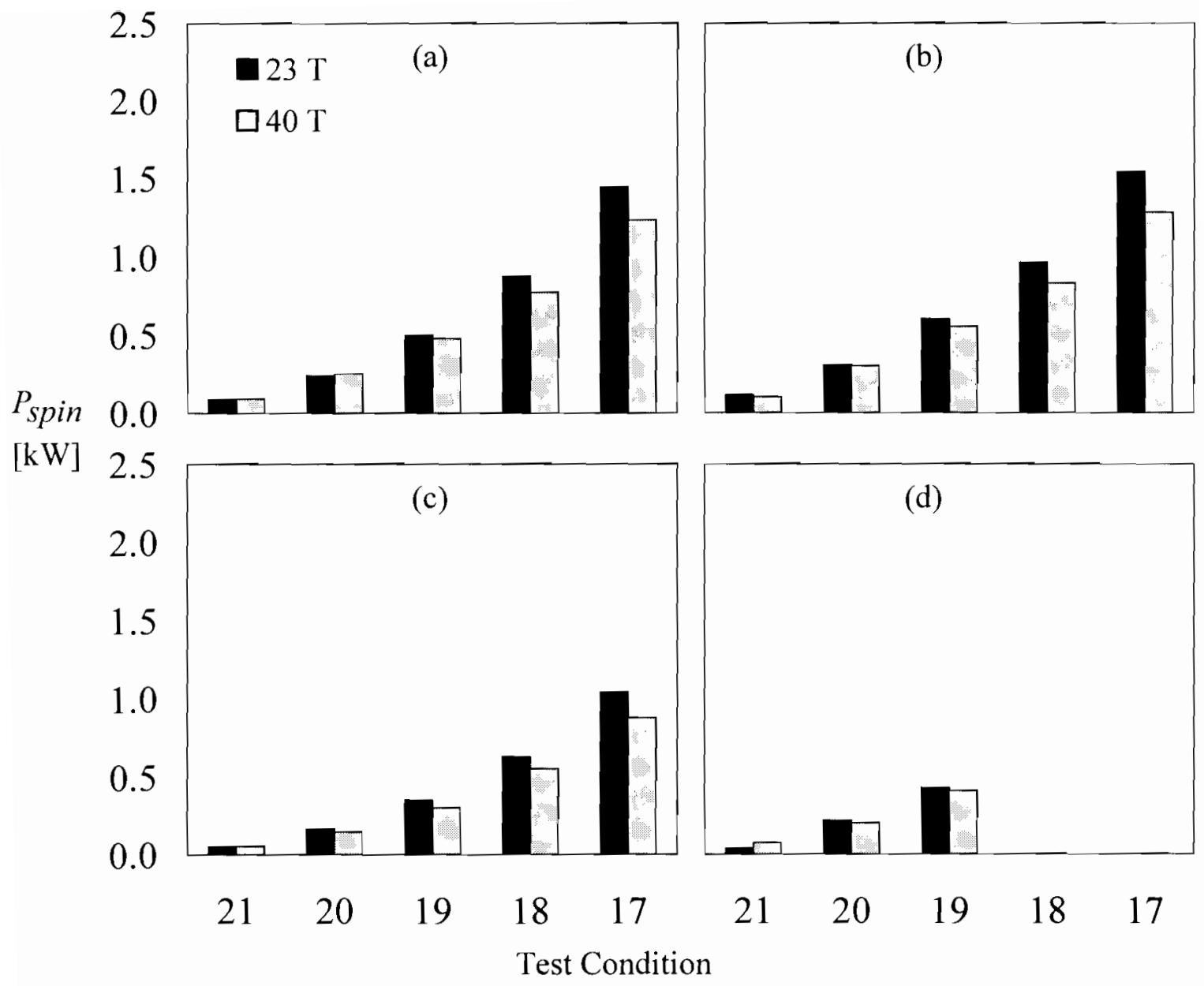

Figure 3.21 Influence of $m$ on measured $P_{s p i n}$ for $23 \mathrm{~T}$ and 40T ground gear pairs lubricated with all oils; (a) Lubricant A, (b) Lubricant B, (c) Lubricant C, and (d) Lubricant D. 
gear pairs operated at an average of $7 \%$ lower $P_{\text {spin }}$ over all oils tested. This difference is increased to an average of $16 \%$ at $\Omega=10,000 \mathrm{rpm}$.

\subsection{Gearbox Total Power Loss}

Although $P_{m}$ was only slightly influenced by lubricant type, it was shown that $P_{\text {spin }}$ is heavily dependent on $v$. While the most viscous oil (Lubricant B) yielded lowest $P_{m}$ for ground gears, it resulted in highest $P_{\text {spin }}$ for the same gears. It is therefore necessary to investigate total gearbox power loss $P_{T}$ in order to determine which combination of gear geometry, surface finish and oil selection resulted in the highest efficiency gear pair. To this end, Fig. 3.22 compares measured $P_{T}$ values for $23 \mathrm{~T}$ and $40 \mathrm{~T}$ ground and chemically polished gears lubricated with Lubricants $\mathrm{A}, \mathrm{B}$, and $\mathrm{C}$. Although there was no clear choice of most efficient gear oil in terms of $P_{m}$, Lubricant $\mathrm{C}$ can be identified as the overall best-performing lubricant. Lubricant $\mathrm{C}$ resulted in the lowest $P_{T}$ for all gears at all operating conditions. For ground gears and 40T chemically polished gears, reduction of $P_{\text {spin }}$ with Lubricant $\mathrm{C}$ offsets improvements in $P_{m}$ with Lubricant B. For 23T chemically polished gears lubricated with Lubricant C, both $P_{\text {spin }}$ and $P_{m}$ are minimum, resulting in the greatest difference in $P_{T}$ between Lubricant $\mathrm{C}$ and Lubricant A.

Finally, influence of lubricant on $P_{T}$ for the 17/26T hobbed-shaved, and hobbedshaved plus chemically polished gears is shown in Fig. 3.23. Due to the large difference 


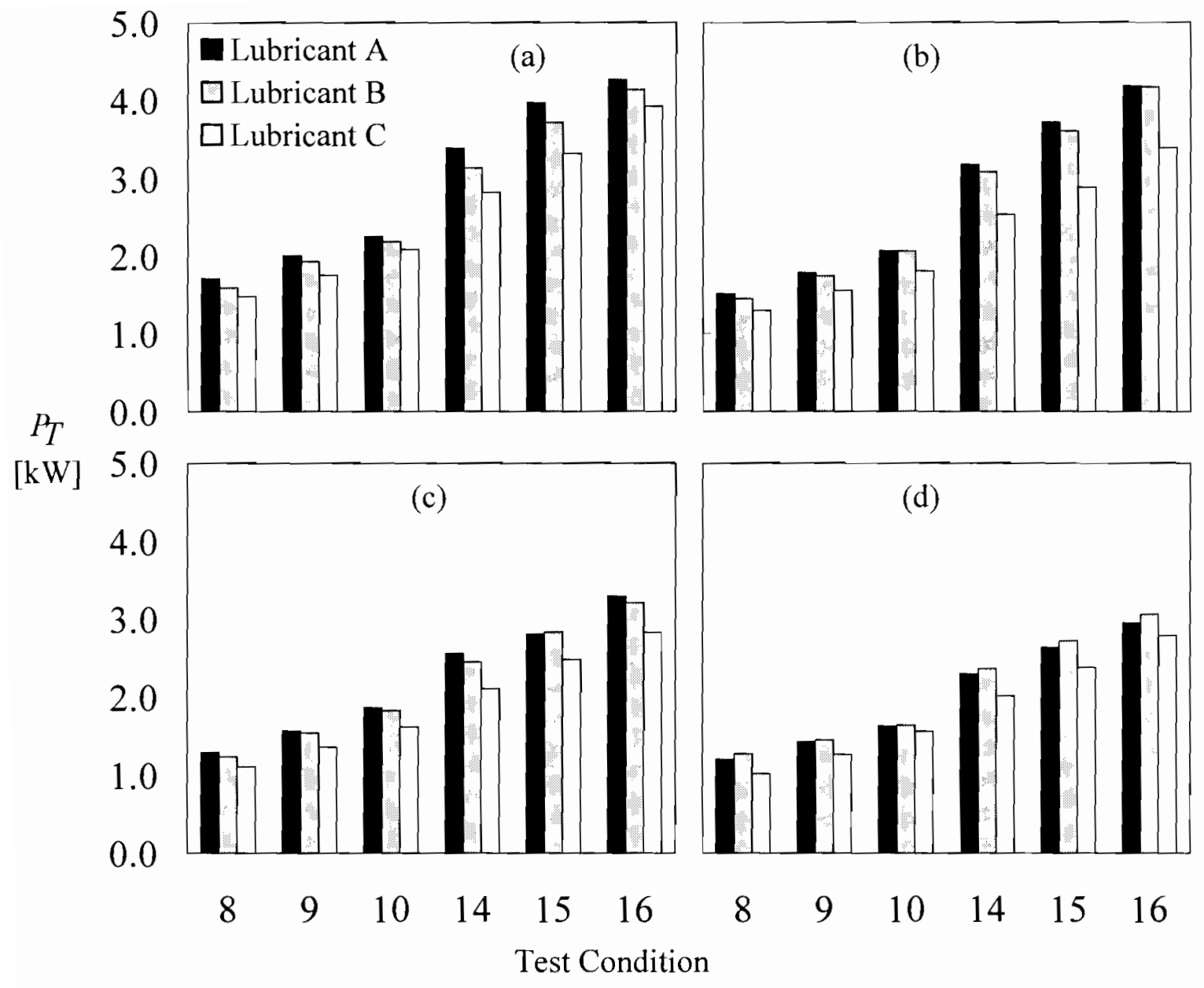

Figure 3.22 Comparison of measured $P_{T}$ for $23 \mathrm{~T}$ and 40T, and ground and chemically polished gear pairs in Lubricants A, B, and C; (a) $23 \mathrm{~T}$ ground gears, (b) $23 \mathrm{~T}$ chemically polished gears and, (c) 40T ground gears, and (d) $40 \mathrm{~T}$ chemically polished gears. 


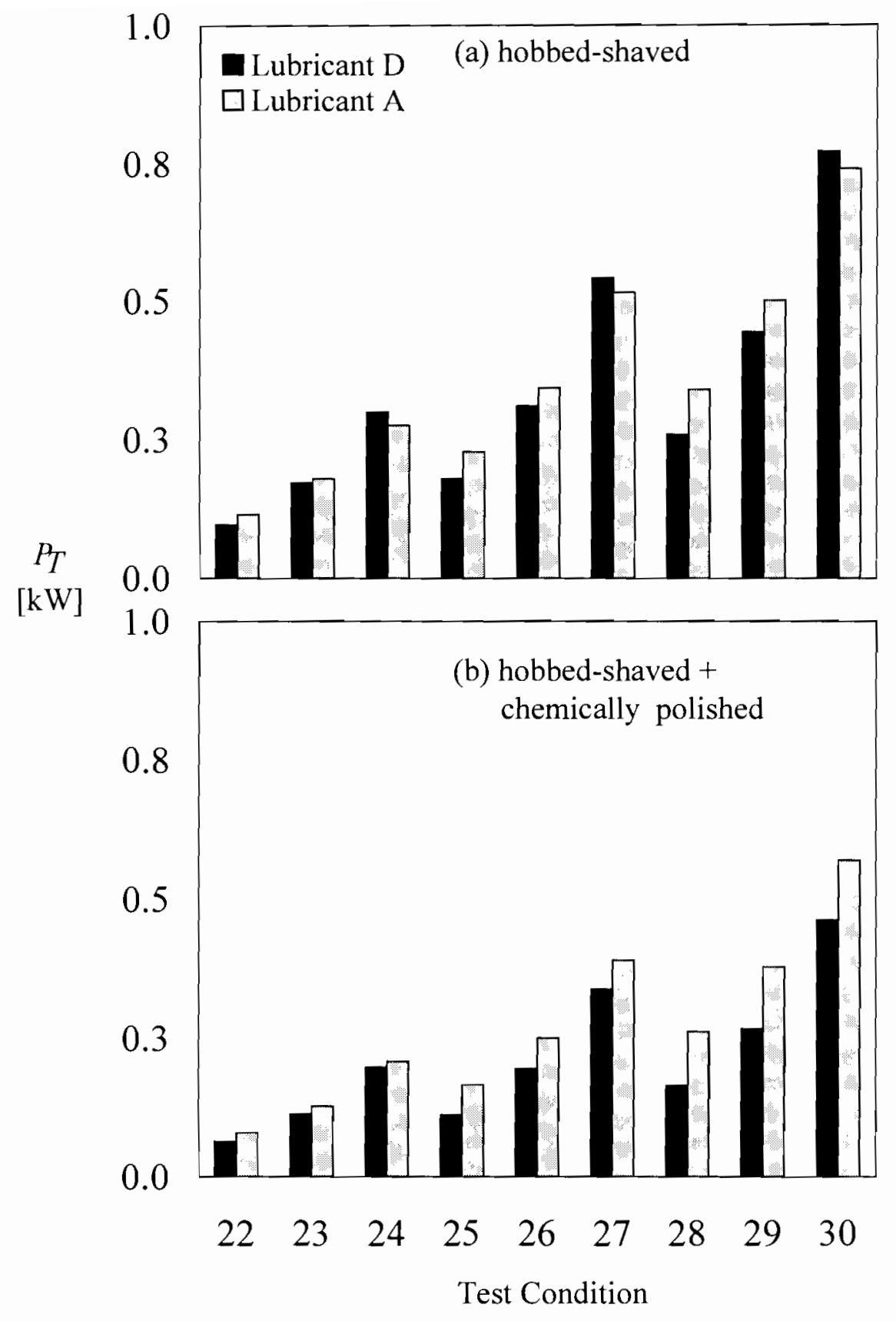

Figure 3.23 Comparison of measured $P_{T}$ for 17/26T hobbed and shaved, and hobbed and shaved plus chemically polished gear pairs in Lubricant D at $90 \mathrm{C}$ and Lubricant A at 48C; (a) hobbed and shaved gears, (b) hobbed and shaved plus chemically polished gears. 
in $P_{\text {spin }}$, both hobbed-shaved and hobbed-shaved plus chemically polished gears performed best in Lubricant D. The baseline hobbed-shaved gears had lower $P_{T}$ with Lubricant A at $T_{c}=413 \mathrm{~N}-\mathrm{m}$ for all $\Omega$ tested. In this case, reduction of $P_{m}$ with Lubricant A due to higher film thickness offset increases in $P_{\text {spin }}$ due to higher $v$.

It was observed in Section 3.4 that $P_{\text {spin }}$ increases with $\Omega^{1.4-1.7}$, while $P_{m}$ increases linearly with $\Omega$. Therefore, $P_{\text {spin }}$ comprises a larger percentage of $P_{T}$ at high speed than at low speed, and it becomes instructive to compare the magnitudes of the components of power loss for the range of operating conditions studied. The percentage of $P_{\text {spin }}$ attributed to $P_{T}$ is largest $(51 \%)$ at low torque and high speed $\left(T_{c}=413 \mathrm{~N}-\mathrm{m}\right.$, $\Omega=10,000 \mathrm{rpm})$, and lowest $(28 \%)$ at high torque and low speed $\left(T_{c}=684 \mathrm{~N}-\mathrm{m}, \Omega=\right.$ $6,000 \mathrm{rpm})$. To demonstrate the effect of $P_{\text {spin }}$ on total efficiency, $\bar{\eta}_{T}$ as calculated by Eq. (3.11a) is shown in Fig. 3.24 for the same test conditions considered in Fig. 3.3. Here, the first three groups correspond to $\Omega=6,000 \mathrm{rpm}$ and a range of $T_{c}$ from $413 \mathrm{~N}$ $\mathrm{m}$ to $684 \mathrm{~N}-\mathrm{m}$. The next three groups correspond to the same values of $T_{\mathcal{c}}$, but at $\Omega=$ $8,000 \mathrm{rpm}$, and the last three groups correspond to $\Omega=10,000 \mathrm{rpm}$. It is observed here that $\bar{\eta}_{T}$ increases as $T_{c}$ increases for any given speed because the load-dependent (mechanical) power loss increases, but the load-independent (spin) power loss remains the same. Conversely, as $\Omega$ increases for any given $T_{c}, \bar{\eta}_{T}$ decreases due to the nonlinear relationship between $\Omega$ and $P_{\text {spin }}$. 


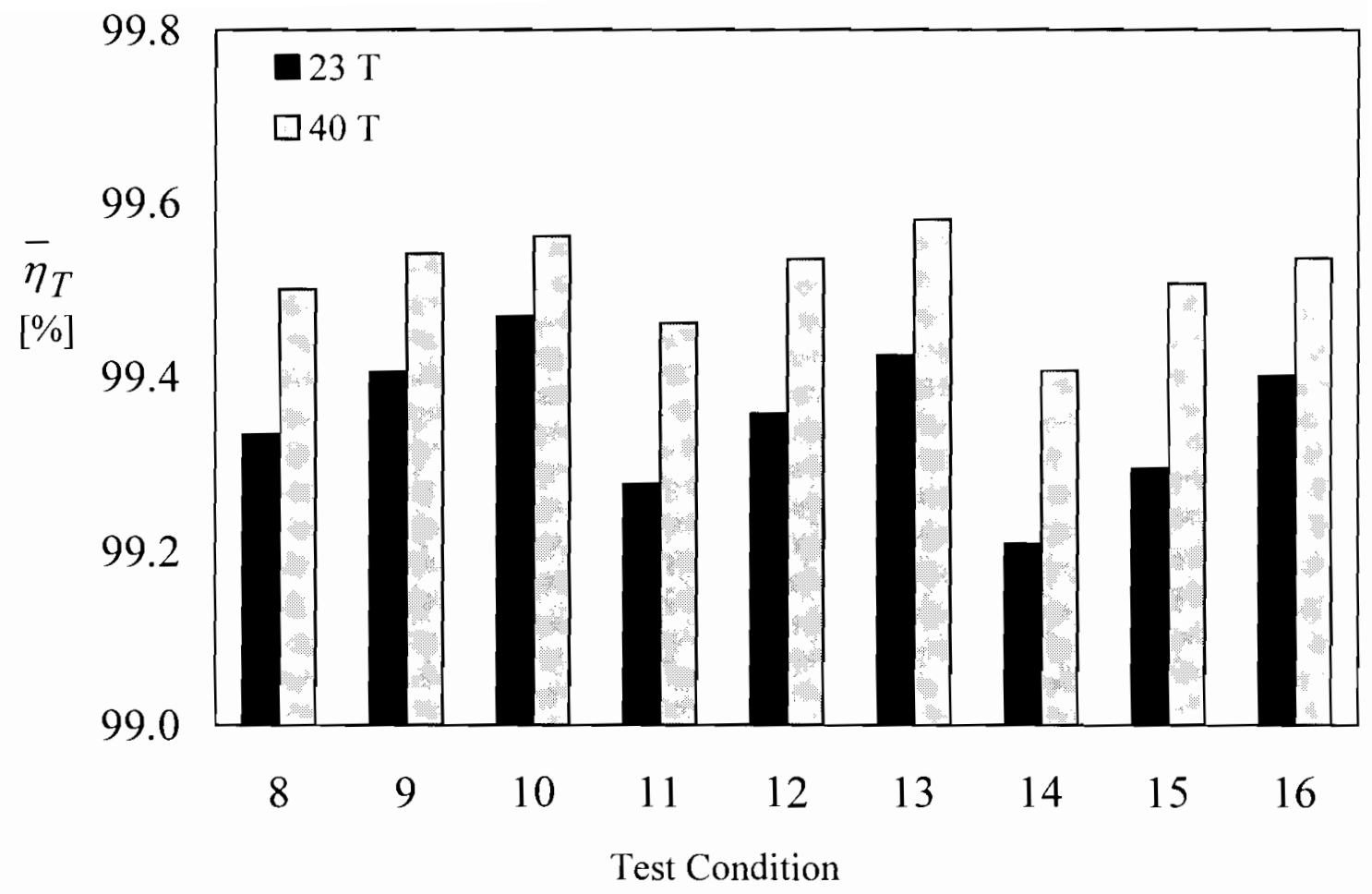

Figure 3.24 Measured $\bar{\eta}_{T}$ values of 23T and 40T ground gear pairs in Lubricant $\mathrm{A}$ at various test conditions listed in Table 2.3. 
Unlike $\bar{\eta}_{m}$, which remained relatively constant, $\bar{\eta}_{T}$ varies more widely due to the inclusion of load-independent power loss. Since $P_{\text {spin }}$ is lower at low $\Omega, \bar{\eta}_{T}$ is found to be highest under high torque, low speed conditions, and lowest under low torque, high speed conditions. For instance, the $23 \mathrm{~T}$ ground gears in lubricant $\mathrm{A}$ operated with $\bar{\eta}_{T}=$ $99.47 \%$ at $T_{c}=684 \mathrm{~N}-\mathrm{m}$ and $\Omega=6,000 \mathrm{rpm}$, but at $\bar{\eta}_{T}=99.21 \%$ at $T_{c}=413 \mathrm{~N}-\mathrm{m}$ and $\Omega=10,000 \mathrm{rpm}$. Similarly, the $40 \mathrm{~T}$ ground gears operated at $\bar{\eta}_{T}=99.56 \%$ and $99.41 \%$ under the same respective operating conditions.

Figure 3.25 is intended to serve as a summary of the influences of $m$, surface roughness amplitude, and lubricant type on $\bar{\eta}_{T}$. Although $\bar{\eta}_{T}$ is not constant with $\Omega$, the influences of $\Omega$ and $v$ on $P_{\text {spin }}$ are well defined and consistent for 23T and 40T gear designs. Therefore, an average $\bar{\eta}_{T}$ value over all test conditions considered represents the overall performance of any gear design, surface finish and oil relative to the others. Here, 40T chemically polished gears lubricated with Lubricant $\mathrm{C}$ outperformed all other gears in terms of $P_{T}$ with $\bar{\eta}_{T}=99.60 \%$, while $23 \mathrm{~T}$ ground gears lubricated with Lubricant A performed the worst with $\bar{\eta}_{T}=99.35 \%$, resulting in a possible $0.25 \%$ overall efficiency improvement.

It is important to note here the relative importance of the parameters studied when considering $\bar{\eta}_{T}$ versus $\bar{\eta}_{m}$. Comparing Fig. 3.19 to Fig. 3.25, it is immediately obvious that $m$ has the largest impact on both $\bar{\eta}_{T}$ and $\bar{\eta}_{m}$ under the operating conditions studied. The reason for this is that $m$ is an important parameter in $P_{m}$ due to its influence on 


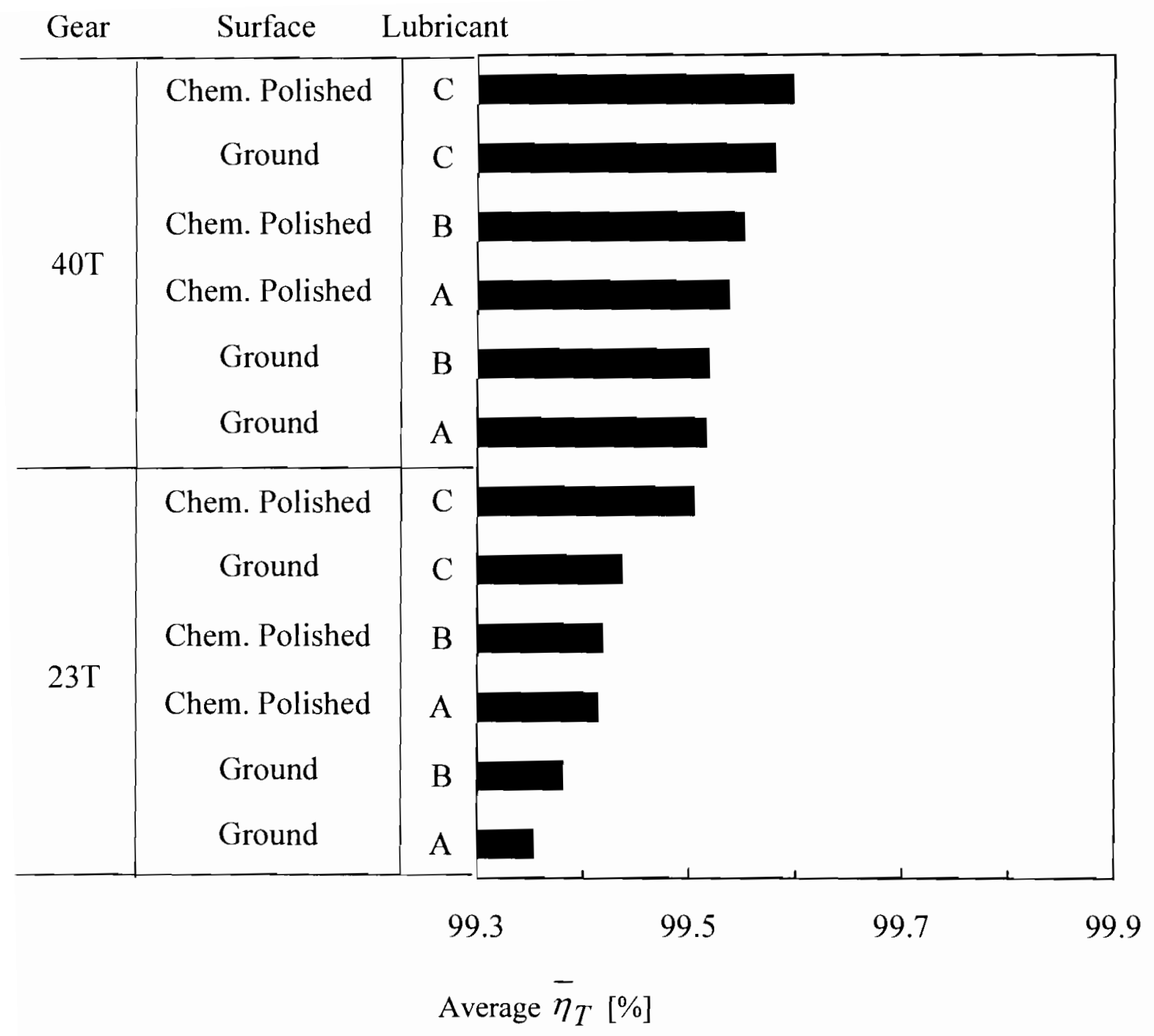

Figure 3.25 Comparison of average measured $\bar{\eta}_{T}$ for $23 \mathrm{~T}$ and $40 \mathrm{~T}$, ground and chemically polished gear pairs lubricated with Lubricants $\mathrm{A}, \mathrm{B}$, and $\mathrm{C}$. 
sliding velocities and $P_{\text {spin }}$ due to its influence on drag losses from the gear teeth. The influence of surface roughness amplitude is the second largest indicator of $\bar{\eta}_{m}$ due to sliding friction arising from asperity contacts, but it is of tertiary importance in $\bar{\eta}_{T}$. The reason for this is that $P_{\text {spin }}$ is heavily influenced by lubricant $v$.

\subsection{Summary}

An experimental test matrix including gears of different modules and surface roughness levels operating under jet lubrication conditions with four different gear lubricants was developed to quantify the influence of these parameters on load-dependent (mechanical) and load-independent (spin) power losses. Experimental data indicate that gear mesh mechanical power losses increase nearly linearly with both rotational speed and applied torque, indicating that gear mesh mechanical efficiency is approximately constant over the ranges of speed and load considered. Experimental results show that gear module is the most influential parameter on gear mesh mechanical efficiency for the operating conditions considered, followed by gear tooth surface roughness. It was shown that gear mesh mechanical power loss for all ground gears was minimized with the most viscous lubricant due to reduction in sliding power losses through decreased asperity contacts. For chemically polished gears, the 40T gears performed best in terms of mesh power losses with the medium-viscosity lubricant, while the $23 \mathrm{~T}$ gears performed best with the lowest viscosity lubricant due to minimization of both rolling and sliding power losses at the gear mesh. 
Experimental results for four different lubricants show that load-independent gearbox (spin) power losses are influenced heavily by lubricant viscosity and to a lesser extent gear module, and can comprise a significant portion of overall gearbox power loss. Due to the inclusion of spin losses, total gearbox power loss was minimized for both ground and chemically polished gear pairs with the lowest-viscosity lubricant studied, despite differing trends in mesh mechanical power loss.

Gear mesh mechanical power losses have been discussed in terms of rolling and sliding power losses, but has been on basis of postulation since these power losses can not be separated experimentally in a geared system. It is therefore desirable to define these sources of power loss on a physical basis and perform efficiency predictions in order to quantify their individual contributions to power loss in a gear mesh. 


\section{CHAPTER 4}

\section{EFFICIENCY EXPERIMENTS UNDER DIP-LUBRICATED CONDITIONS}

\subsection{Introduction}

Up until this point, the method of gear lubrication discussed has been dry sump jet-lubrication, with the oil jet directed at the exit of the gear mesh zone opposite the sense of rotation. While this lubrication method is commonly applied in high-speed gearing applications such as helicopter gearboxes as well as automotive automatic transmissions, it is not used for many low to medium-speed applications where an external oil pump cannot be afforded. Many industrial gearboxes, automotive manual transmissions, rear and front-axle differentials, and transfer cases all employ dip lubrication. In this lubrication method, the gear housing is partially filled with oil. All or some of the gears rotate partially submerged in oil, causing significant amount of splashing and churning of oil. This results in load-independent spin power loss that is typically larger than those for jet-lubricated gear sets. This chapter aims at experimentally investigating the spin losses of dip-lubricated gear pairs. 
A set of simple modifications to the gear efficiency test machine used in the previous chapters allows dip lubricated spin power loss to be quantified under the same conditions as jet-lubricated efficiency experiments using the same gear specimens, test fixtures, and instrumentation. This provides a direct quantitative comparison between spin power loss associated with both lubrication methods. The objective of this chapter is to experimentally quantify the influence of several operating conditions on dip-lubricated spin power loss, and discuss the compatibility of previous churning power loss studies with the present experimental results. The experimental results presented here represent the initial phase of an extensive spur gear efficiency study. The primary objective here is to identify overall trends in measured dip lubricated spin power loss, while detailed analysis is left to future work.

\subsection{Description of Dip-Lubricated Test Setup}

Figure 4.1 shows a picture of the modified test-side gearbox. Same modifications were applied to the reaction-side gearbox as well. For the dip-lubrication power loss study, the oil supply jets to the bearings were removed and the ports were plugged. Oil supply jets directed into the gear mesh were retained for filling the gearboxes with oil between tests and represent a minimal flow obstruction within the gearbox. Ball valves of the oil return lines were closed in order to maintain an oil bath in the gearboxes, and were positioned such that the static oil levels in the gearboxes were equal via a flow path between the gearboxes. Sheet metal baffle plates were added inside the gearboxes in front of the oil drainage ports to minimize oil circulation in the drainage line. Large diameter graduated site glasses were added to the gearboxes to document static oil level 


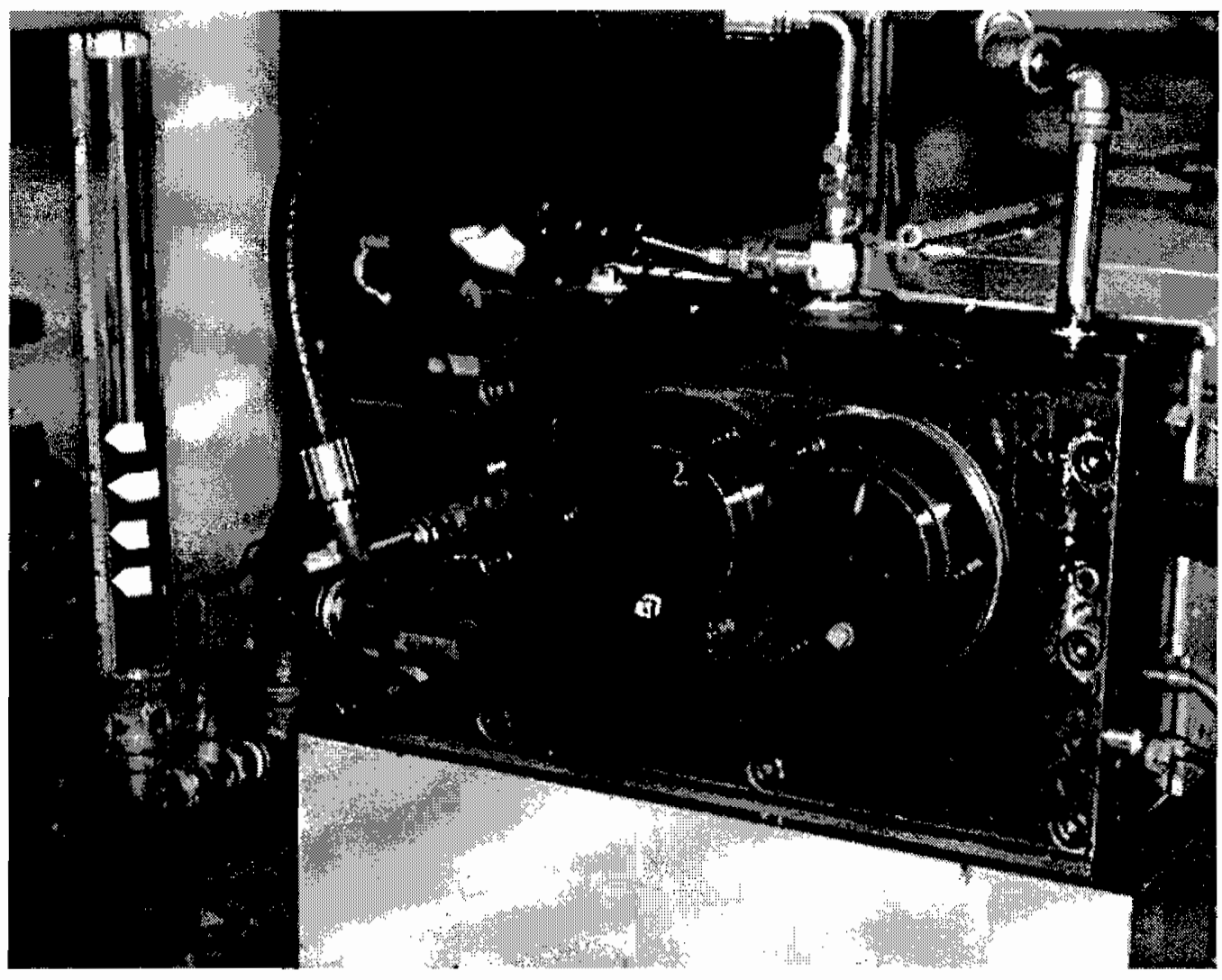

Figure 4.1 Modifications to the jet-lubricated gear efficiency test machine to allow dip-lubricated spin power loss studies. 
within the gearbox. Ball valves were placed between the gearbox and site glasses. These ball valves were closed during machine operation in order to ensure that the site glasses did not act as fluid capacitors.

\subsection{Test Specimens and Test Matrix}

Previous studies on oil churning power loss [37-41] reported conflicting results regarding the influence of operational parameters such as the influence of rotational speed, lubricant viscosity, and static oil bath level. The objective of this study is to quantify these influences using the test machine in hand. Any possible influences of gear surface roughness on oil churning will be excluded here by simply using only the chemically polished test gears. Additionally, all gears used in this study have a gear ratio of unity that eliminates to certain extent the oil swell effect observed in some of the earlier studies [41]. This has the advantage of allowing the influences of the parameters under study to be quantified directly, as well as simplifying the validation of future analytical modes.

In order to investigate the influence of immersion depth oil level on dip-lubricated spin power loss, tests were performed at four different oil levels identified by a $\mathrm{h} / \mathrm{r}$ ratio, where $h$ is the oil level measured from the pitch point at the bottom of the test gears, and $r$ is the pitch radius, shown schematically in Fig. 4.2. Here $h / r=0$ indicates that the static oil level is at tangent to the pitch circles of both gears in the bottom, i.e. only the addendums of both gears are submerged in the oil. Meanwhile, $h / r=1.0$ means the static oil level is a high as gear centers such that exactly half of both gears are within the oil initially. 


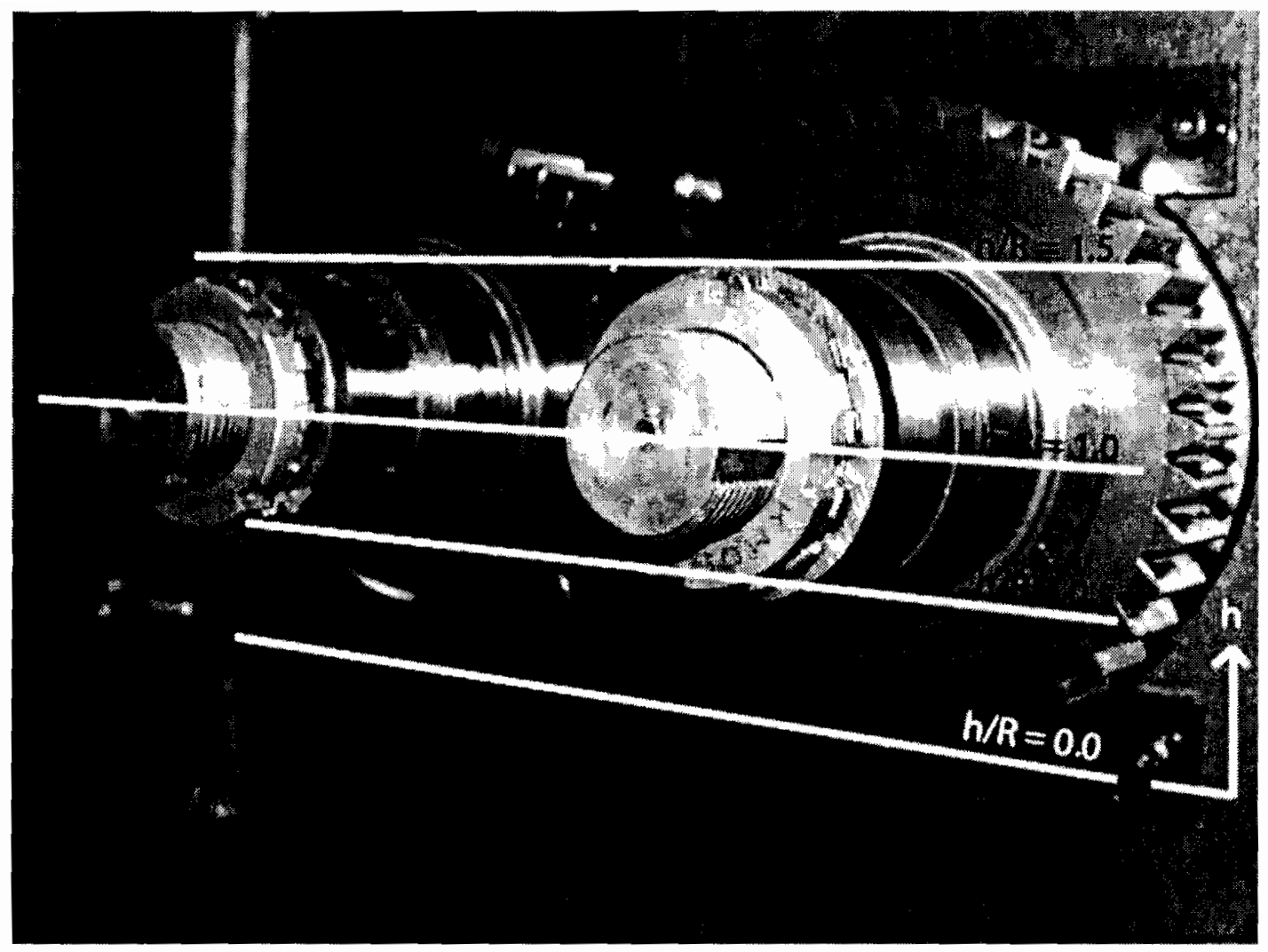

Figure 4.2 A test gearbox in the dip-lubrication arrangement. 
Rotational speeds of $\Omega=1000$ to $7,000 \mathrm{rpm}$ were considered for $h / r=1.0$ in order to quantify the dependence of spin loss on rotational speed. For other $h / r$ values of $0,0.5$ and 1.5 , rotational speed values of $1,000,2,000,4,000$, and 6,000 were selected due to time constraints. At $h / r=1.5$, the $6,000 \mathrm{rpm}$, test point was replaced with a $3,000 \mathrm{rpm}$ test point due to concerns of oil foaming. Table 4.1 shows the test matrix for the dip lubricated spin power loss study. A typical manual transmission fluid (identified in this study as Lubricant E) was used in all of these tests. The viscosity-temperature relationship of this lubricant is shown in Fig. 4.3. Tests were performed within an operating temperature of 30 to $100^{\circ} \mathrm{C}$ so that the influence of oil viscosity on dip lubricated spin power loss can be quantified. The torque loss $\hat{T}_{L}$ was measured continuously as the temperature of the oil changes in time so that real-time torque losstemperature data can be captured.

Since an active control of the oil temperature was not sought in the tests, frictional heating of the oil bath was relied upon to vary operating oil temperature, and hence lubricant viscosity. Since gear box heat balance results in different steady-state temperatures at different $h / r$ and $\Omega$ values, it was not possible to obtain power loss data at particularly high or low temperatures for some of the test conditions. For instance, rapid frictional heating of the oil bath at $6,000 \mathrm{rpm}$ prevented the acquisition of torque data below $50^{\circ} \mathrm{C}$. Similarly for low speed tests, say $\Omega=1,000 \mathrm{rpm}$, frictional heating of the gearboxes was not sufficient to reach the temperatures beyond $90^{\circ} \mathrm{C}$. Figure 4.4 shows the oil temperature-time characteristic of the gearboxes at various $\Omega$ values with 


\begin{tabular}{|c|c|c|c|c|c|}
\hline Test Number & \# of Teeth & Face Width & $h / r$ & Rotation Direction & Purpose \\
\hline $\begin{array}{l}1 \\
2 \\
3 \\
4\end{array}$ & 40 & $19.5 \mathrm{~mm}$ & $\begin{array}{l}1.5 \\
1.0 \\
0.5 \\
0.0\end{array}$ & Up in Mesh & $\begin{array}{l}\text { Viscosity-Speed } \\
\text { Characteristic }\end{array}$ \\
\hline 5 & 40 & $19.5 \mathrm{~mm}$ & 1.0 & Up in Mesh & Repeatability \\
\hline 6 & 40 & $19.5 \mathrm{~mm}$ & 1.0 & Down in Mesh & $\begin{array}{c}\text { Influence of Rotational } \\
\text { Direction }\end{array}$ \\
\hline
\end{tabular}

Table 4.1 Spur gear dip-lubricated spin power loss experimental test plan. 


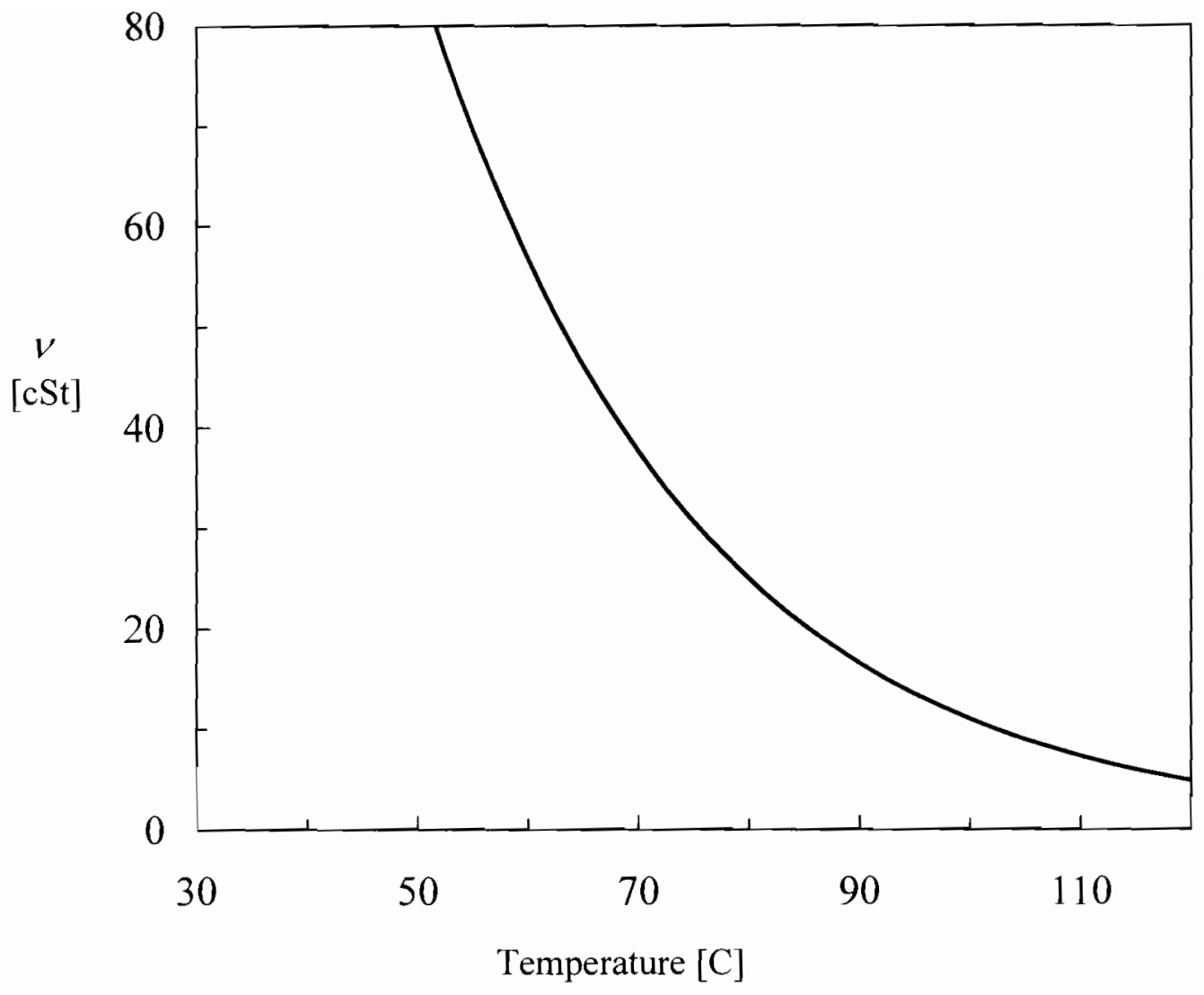

Figure 4.3 Viscosity-temperature characteristic for Lubricant E. 


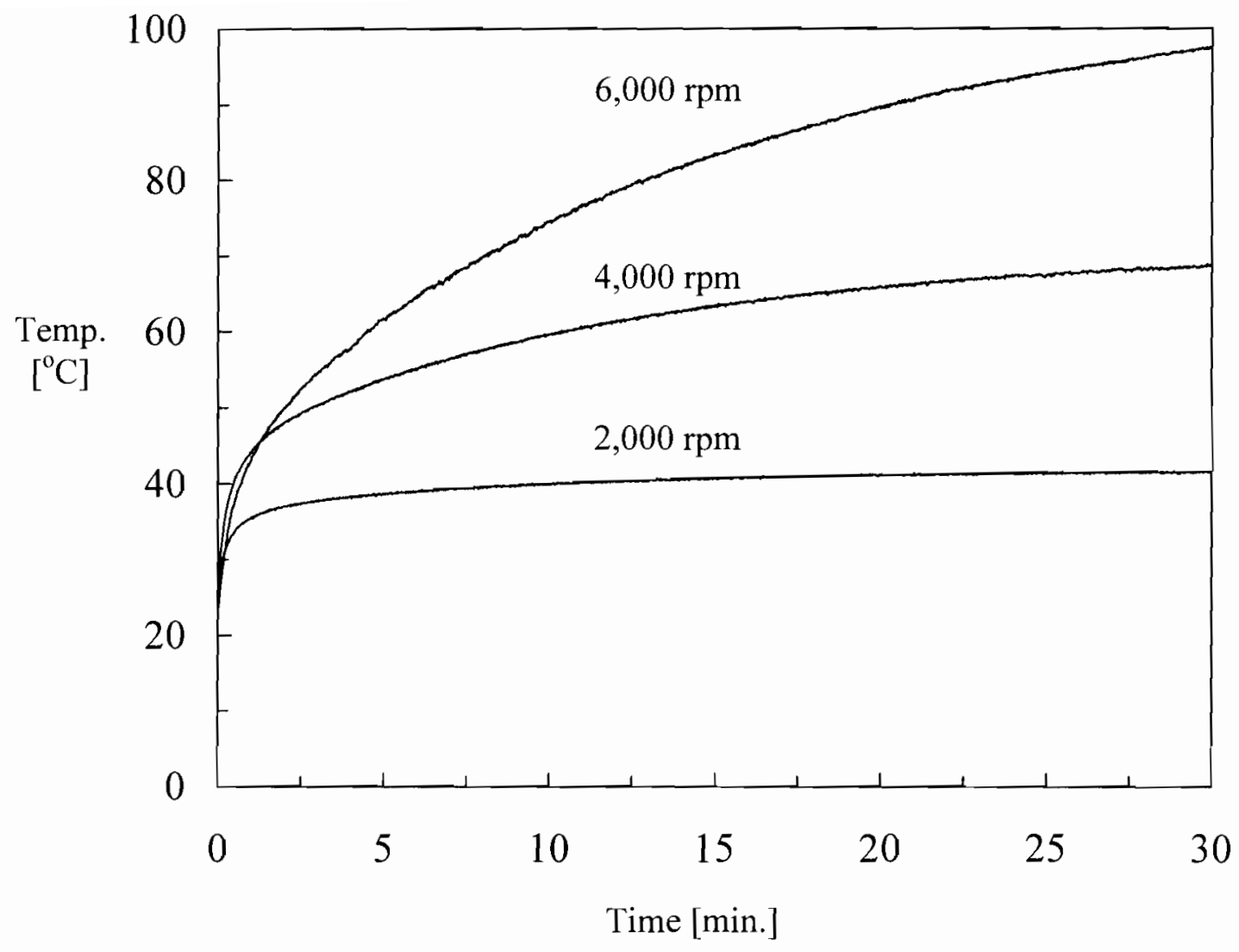

Figure 4.4 Variation of oil temperature as a function of time for several values of $\Omega$. $40 \mathrm{~T}$ chemically polished, $19.5 \mathrm{~mm}$ face width gears rotating upward in the oil bath. 
40T, $19.5 \mathrm{~mm}$ face width gears operating at $h / r=1.0$. Here it is evident that for most rotational speeds, it was not possible to obtain torque data over the full temperature range by relying on frictional heating alone. However, since a real-time torque-temperature signal was acquired by the data acquisition system, torque data was also acquired while the system was cooling from high temperatures achieved by operating at a high speed.

For the low-speed tests, the gearboxes were preheated to nearly $100^{\circ} \mathrm{C}$ by preceding these tests with high-speed tests. In this fashion, by alternating high-speed and low-speed tests, data for the complete range of temperature was collected by simply relying on frictional heating alone.

\subsection{Accuracy and Repeatability}

For data processing purposes, the continuous torque-temperature data was simplified into discrete data points by averaging torque loss and oil sump temperature in $5^{\circ} \mathrm{C}$ increments. The results of this discretization is shown in Fig. 4.5 for $40 \mathrm{~T}, 19.5 \mathrm{~mm}$ face width gears rotating upward in the oil bath. Figure 4.5 shows that such discretization is quite accurate. For the remainder of this chapter, all dip lubricated spin loss data will be displayed in the discretized format.

Test 5 in Table 4.1 is a repeat of test 2 to demonstrate the repeatability of the test machine and fixtures using 40T, $19.5 \mathrm{~mm}$ face width chemically polished gears with $h / r=1.0$ and upward gear rotation in the oil bath. Figure 4.6 demonstrates the repeatability of the test machine over a wide range of rotational speed and oil kinematic viscosity due to changes in temperature. These torque measurements represent over 23 hours of data collection, or nearly 84,000 individual torque measurements. Figure 4.6 


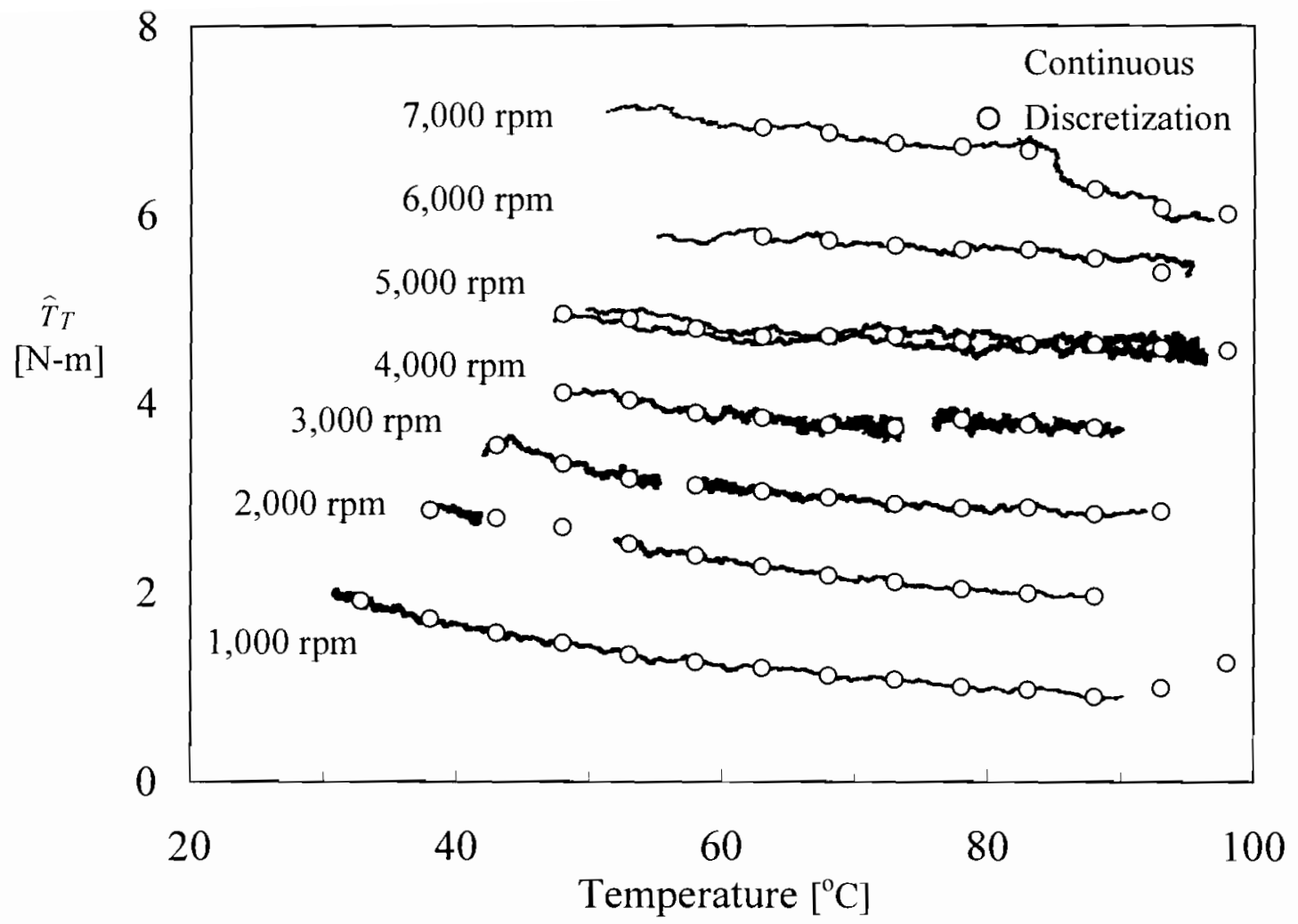

Figure 4.5 Discretization of continuous temperature-torque characteristic. 40T chemically polished, $19.5 \mathrm{~mm}$ face width gears rotating upward in the oil bath. 


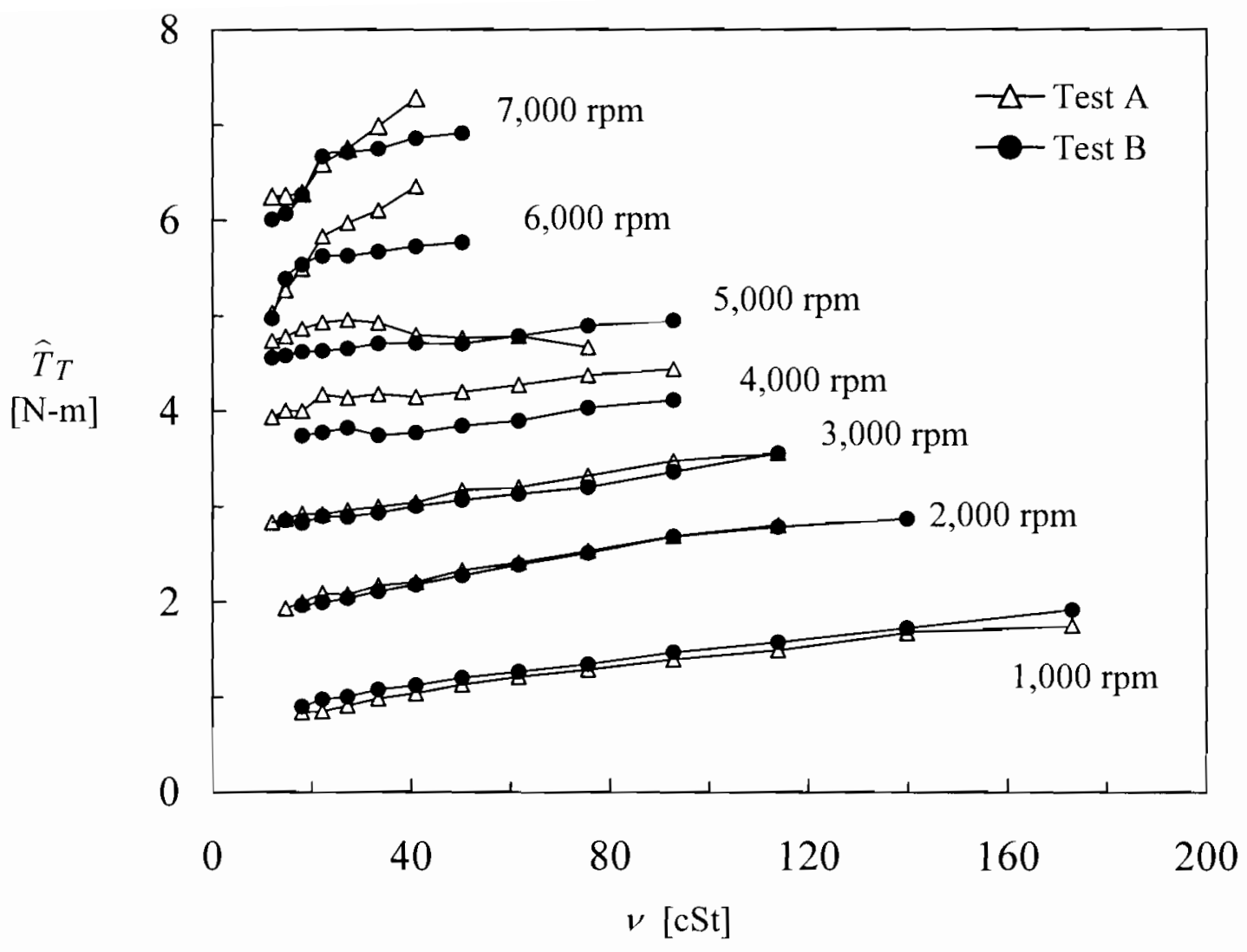

Figure 4.6 Repeatability of measured dip-lubricated spin power loss for 40T chemically polished gears as a function of oil bath kinematic viscosity, $19.5 \mathrm{~mm}$ face width, rotating upward in the oil bath. 
shows repeatability of the data for $\Omega$ in the range of 1,000 to $5,000 \mathrm{rpm}$ is very good, while it is not as good at 6,000 and $7,000 \mathrm{rpm}$, probably due to a high degree of oil/air turbulence inside the gearbox. Since dip lubricated systems are rarely operated at such high rotational speeds, the repeatability of the test fixtures can be considered satisfactory for this study.

\subsection{Experimental Dip Lubricated Spin Power Loss Results}

\section{Influence of Rotational Speed and Oil Level}

Figures 4.7 to 4.10 show measured $P_{\text {spin }}$ values as a function of oil temperature at various $\Omega$ for $h / r=0,0.5,1.0$ and 1.5 , respectively These figures represent $40 \mathrm{~T}$, $19.5 \mathrm{~mm}$ face width gear pairs rotating upward un the oil bath. The $P_{s p i n}$ values at discrete oil bath temperatures of 53,73 , and $88^{\circ} \mathrm{C}$ are extracted from these figures to illustrate the influence of $\Omega$ in Fig. 4.11. Here, $P_{s p i n}$ increases with $\Omega$ to the power 1.35 to 2.05 , depending on $h / r$ and oil temperature. The exponent on $\Omega$ appears to generally increase with oil bath level. For instance, at $73^{\circ} \mathrm{C}, P_{\text {spin }} \sim \Omega^{1.39}$ for $h / r=0$, $P_{\text {spin }}-\Omega^{1.72}$ for $h / r=0.5, \quad P_{\text {spin }}-\Omega^{1.93}$ for $h / r=1.0$, and $P_{\text {spin }}-\Omega^{1.97}$ for $h / r=1.5$. This general trend is consistent over the full temperature range for which $P_{\text {spin }}$ data was available. Additionally, the exponent on $\Omega$ appears to increase slightly with oil bath temperature, or rather increase as oil bath viscosity decreases. As an example, for $h / r=0$, the exponent on $\Omega$ increased from 1.24 at $38^{\circ} \mathrm{C}$ to 1.47 at $88^{\circ} \mathrm{C}$. 


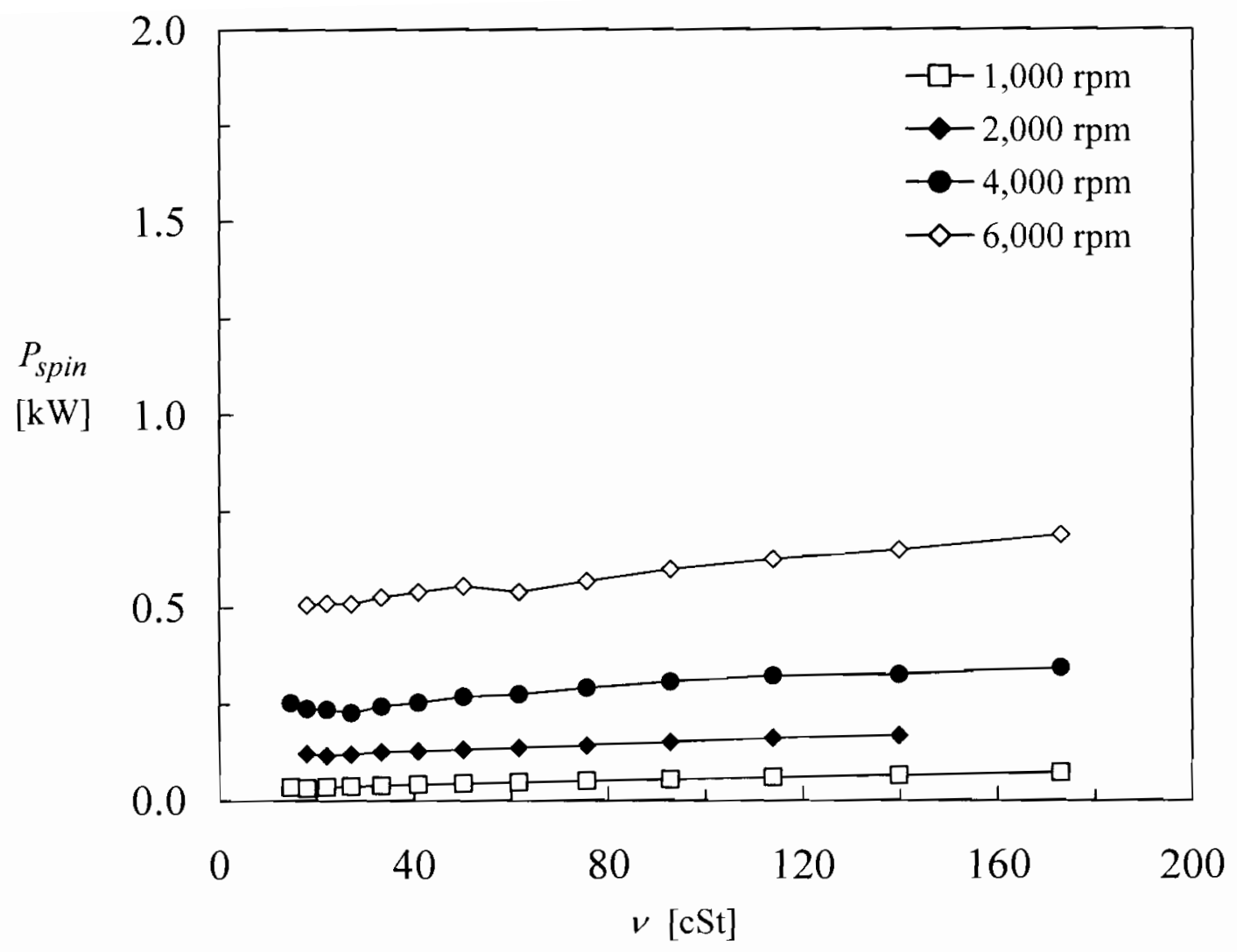

Figure 4.7 Measured dip-lubricated spin power loss for 40T chemically polished gears as a function of oil bath temperature, $19.5 \mathrm{~mm}$ face width, rotating upward in the oil bath. $h / r=0.0$. 


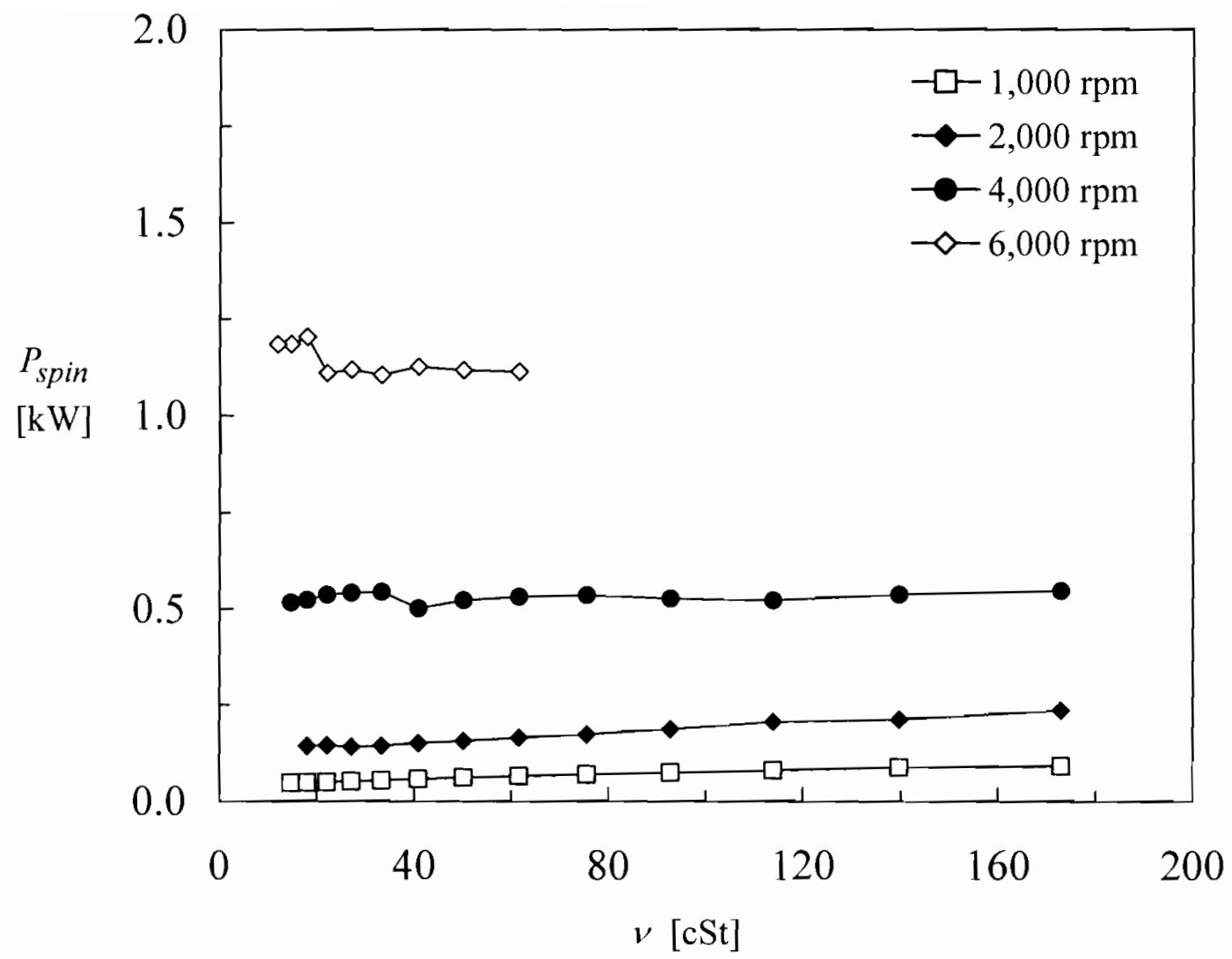

Figure 4.8 Measured dip-lubricated spin power loss for 40T chemically polished gears as a function of oil bath temperature, $19.5 \mathrm{~mm}$ face width, rotating upward in the oil bath. $h / r=0.5$. 


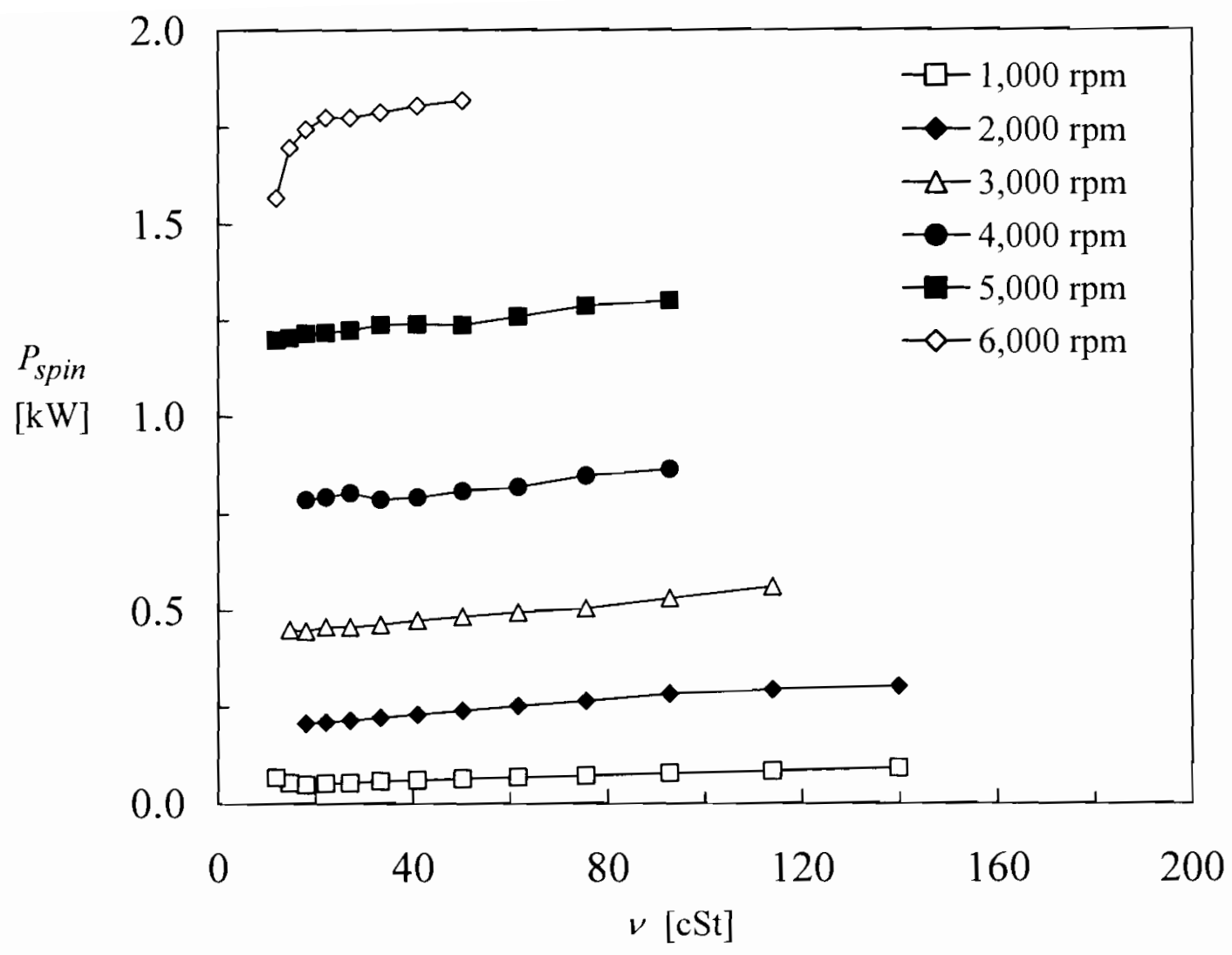

Figure 4.9 Measured dip-lubricated spin power loss for 40T chemically polished gears as a function of oil bath temperature, $19.5 \mathrm{~mm}$ face width, rotating upward in the oil bath. $h / r=1.0$. 


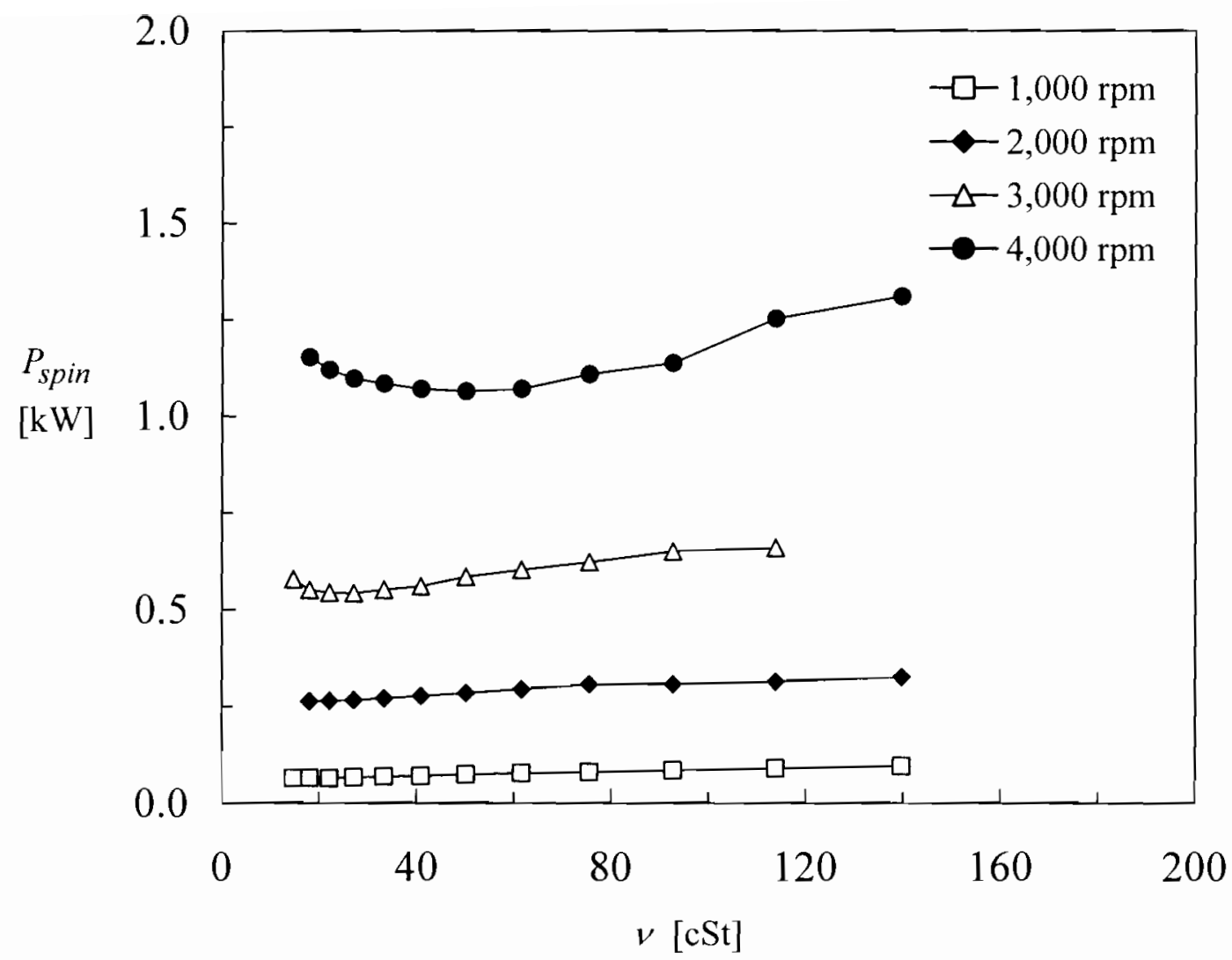

Figure 4.10 Measured dip-lubricated spin power loss for 40T chemically polished gears as a function of oil bath temperature, $19.5 \mathrm{~mm}$ face width, rotating upward in the oil bath. $h / r=1.5$. 


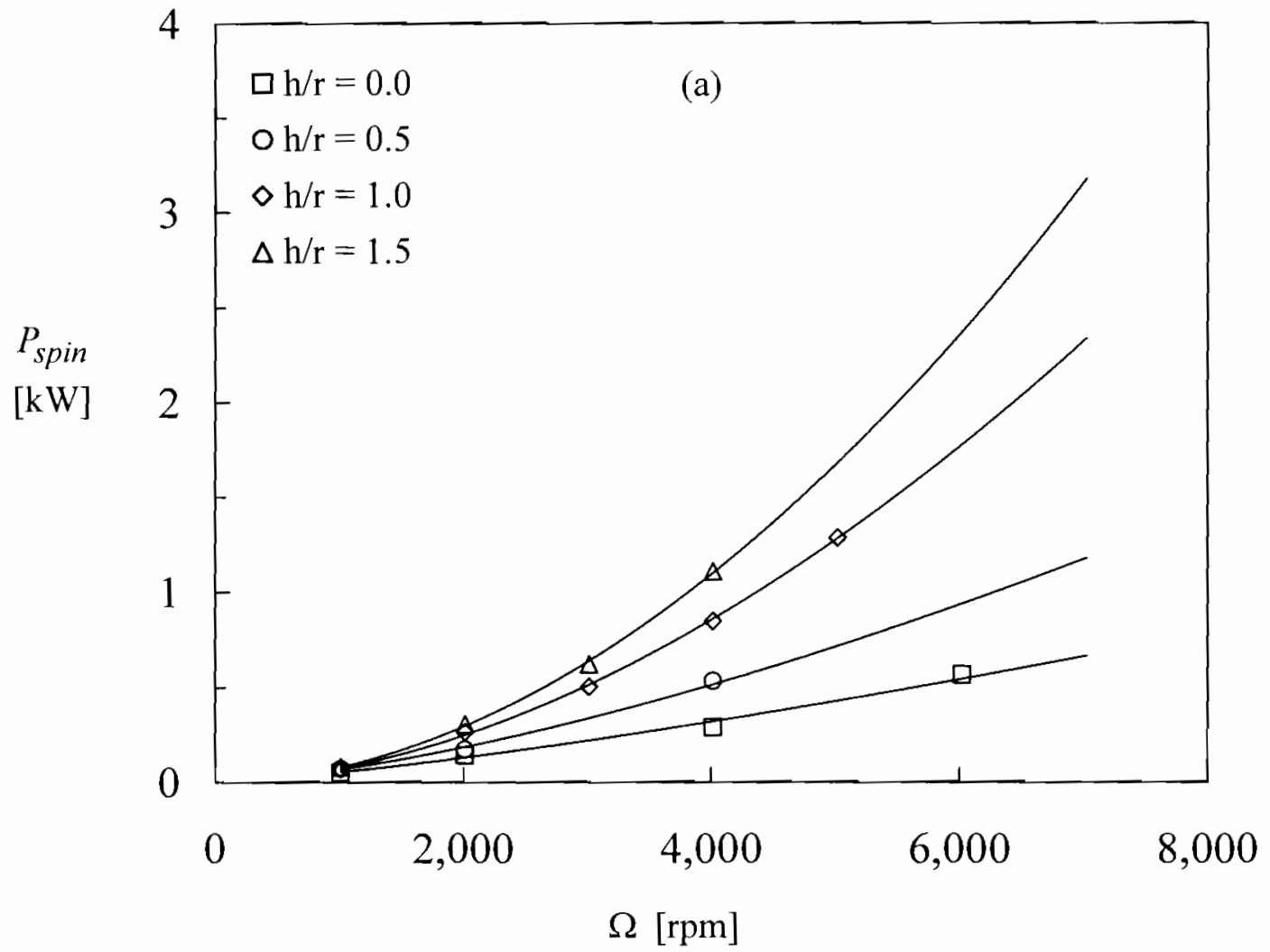

Figure 4.11 Measured $P_{\text {spin }}$ as a function of $\Omega$ for four oil levels; (a) $53^{\circ} \mathrm{C}$ oil bath temperature, (b) $73^{\circ} \mathrm{C}$ oil bath temperature, and (c) $88^{\circ} \mathrm{C}$ oil bath temperature. $40 \mathrm{~T}$ chemically polished gears, $19.5 \mathrm{~mm}$ face width, rotating upward in the oil bath.

(continued) 
Figure 4.11 continued

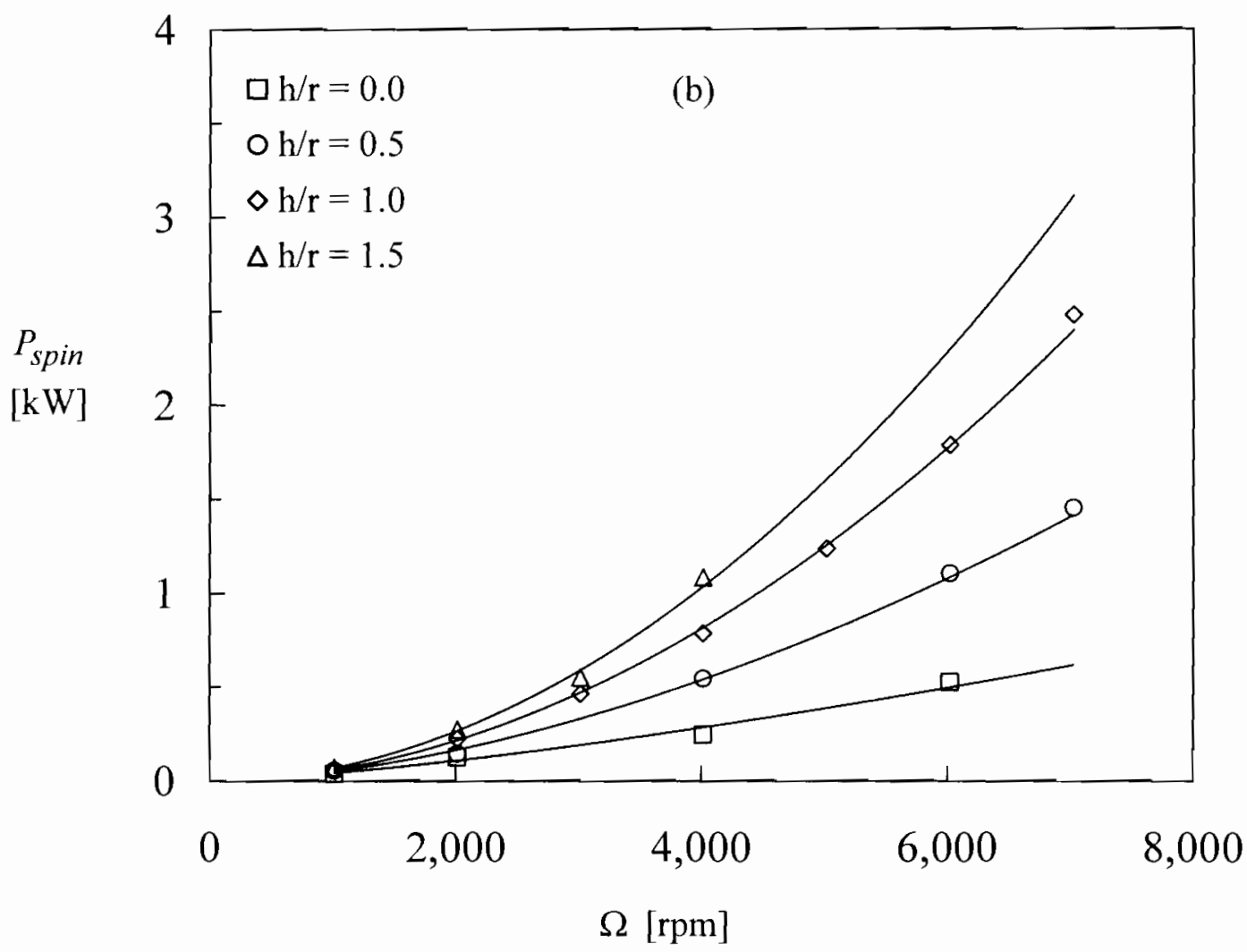

(continued) 
Figure 4.11 continued

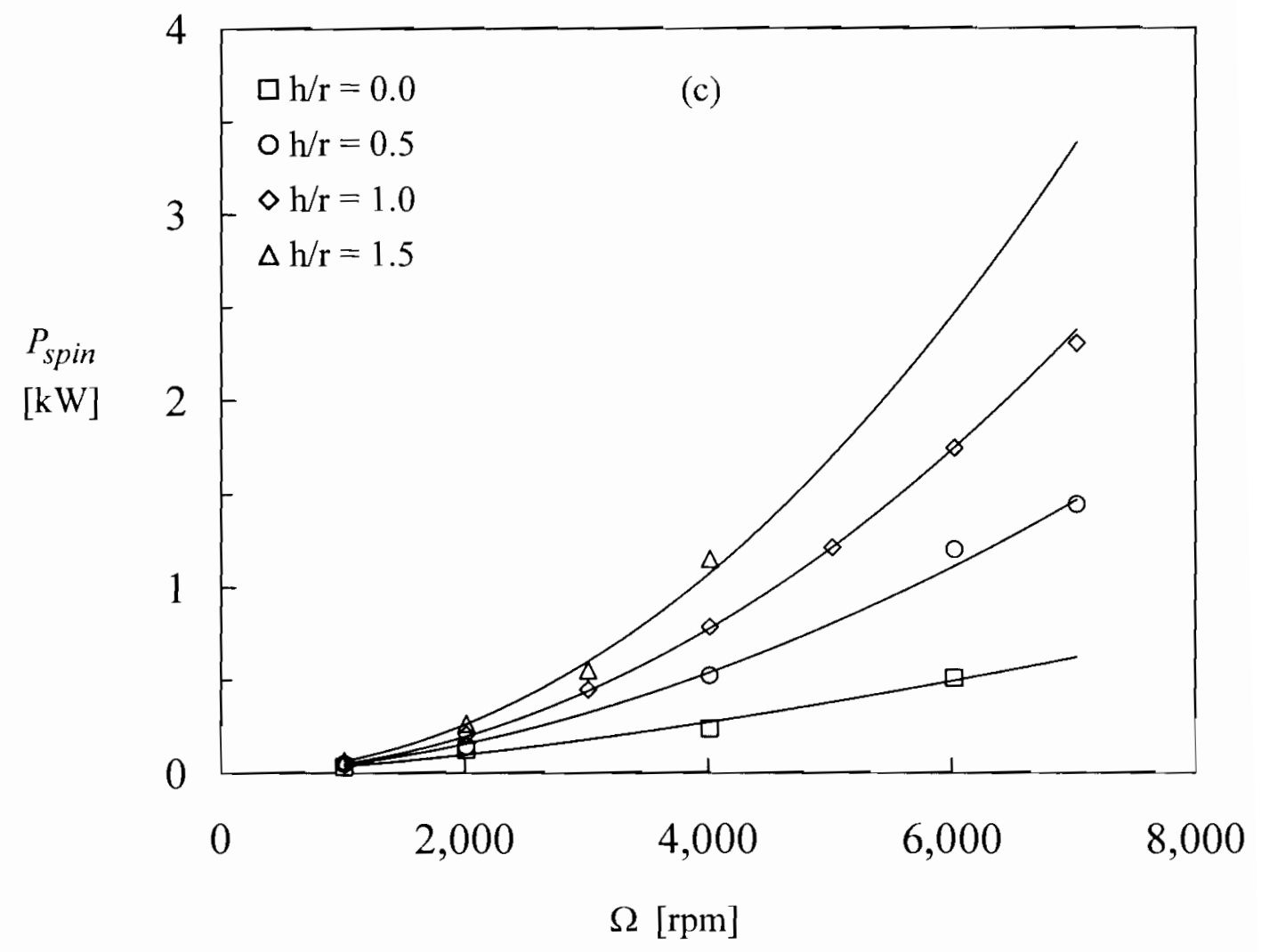


Similarly, for oil levels at the other extreme, $h / r=1.5$, the exponent on $\Omega$ increased from 1.89 to 2.05 for the same temperature range.

Figure 4.11 also shows the influence of oil bath level on $P_{\text {spin }}$ for three different oil bath temperatures. The general trend here is that $P_{\text {spin }}$ decreases as the oil bath level decreases. Taking $h / r=1.0$ as the baseline oil level and averaging over the entire range of $\Omega$ and oil bath temperatures considered, $P_{\text {spin }}$ is reduced by $26 \%$ by reducing the oil level to $h / r=0.5$, and by $49 \%$ by reducing the oil level to $h / r=0.0$. Likewise, by increasing the oil level to $h / r=1.5, P_{\text {spin }}$ increased by $23 \%$. Comparing $P_{\text {spin }}$ for the highest oil level, $h / r=1.5$, to the lowest oil level, $h / r=0$, it is seen that $P_{\text {spin }}$ is approximately four times as large for $h / r=1.5$ at the highest comparable speed of $\Omega=4,000 \mathrm{rpm}$, and 1.7 times as large at $\Omega=1,000 \mathrm{rpm}$.

\section{Influence of Lubricant Viscosity and Rotational Direction}

Figure 4.12 shows directly the influence of oil bath viscosity $v$ on measured $P_{\text {spin }}$ for a range of $\Omega$ using $40 \mathrm{~T}, 19.5 \mathrm{~mm}$ face width gears at $h / r=1.0$ for both upward and downward rotation in the oil bath. Here, $P_{\text {spin }}$ is observed to be weakly dependent on $v$, and is somewhat linear. This observation agrees with the results of references $[40,41]$, who reported that $P_{\text {churn }}$ appears to be weakly dependent on $v$, especially at high $\Omega$. For all oil levels at low $\Omega, P_{\text {spin }}$ decreased by as much as $50 \%$ by reducing $v$ from $140 \mathrm{cSt}$ to $18 \mathrm{cSt}$, representing a typical savings of $0.04-0.05 \mathrm{~kW}$. At 
higher $\Omega, 4,000 \mathrm{rpm}$ for instance, the dependence of $P_{\text {spin }}$ on $v$ was less pronounced, with reductions in $P_{\text {spin }}$ of approximately 5 to $20 \%$ over the same viscosity range, depending on oil bath level. This represents a power savings of $0.01-0.16 \mathrm{~kW}$, depending on oil bath level.

Figure 4.12 shows the influence of rotation direction on $P_{\text {spin }}$ for a range of $\Omega$ and oil bath temperatures using $40 \mathrm{~T}, 19.5 \mathrm{~mm}$ face width gears at $h / r=1.0$. Here, it is shown that the direction of rotation has a quantifiable influence on $P_{\text {spin }}$, with upward direction in the oil bath resulting in higher $P_{\text {spin }}$. The effect of the rotational direction of gears on $P_{\text {spin }}$ is rather negligible for low $\Omega$, while the difference becomes more significant as $\Omega$ increases. Averaging over all test conditions considered, upward rotation in the oil bath resulted in $15 \%$ higher $P_{\text {spin }}$ than for downward rotation in the oil bath for $h i r=1.0$. This phenomenon was also observed in references [37, 41], and can be attributed to a larger magnitude of $P_{\text {trap }}$ for the case of upward rotation in the oil bath. This can be explained by the higher density and viscosity of the lubricating oil compared to air. For the case of upward rotation gears in the oil bath, especially for higher $h / r$ values, the fluid pumping and trapping of the meshing gear teeth consists primarily of the lubricating oil. For the case of downward rotation in the oil bath, the fluid in the meshing zone probably consists of a higher percentage of air than for the former case because oil is flung off of the gear teeth as they exit the bath [52-53]. By the time the gear teeth come back into mesh, there is only a thin film of oil adhering to the surface, and so $P_{\text {trap }}$ consists mainly of power loss due to pumping of air. 


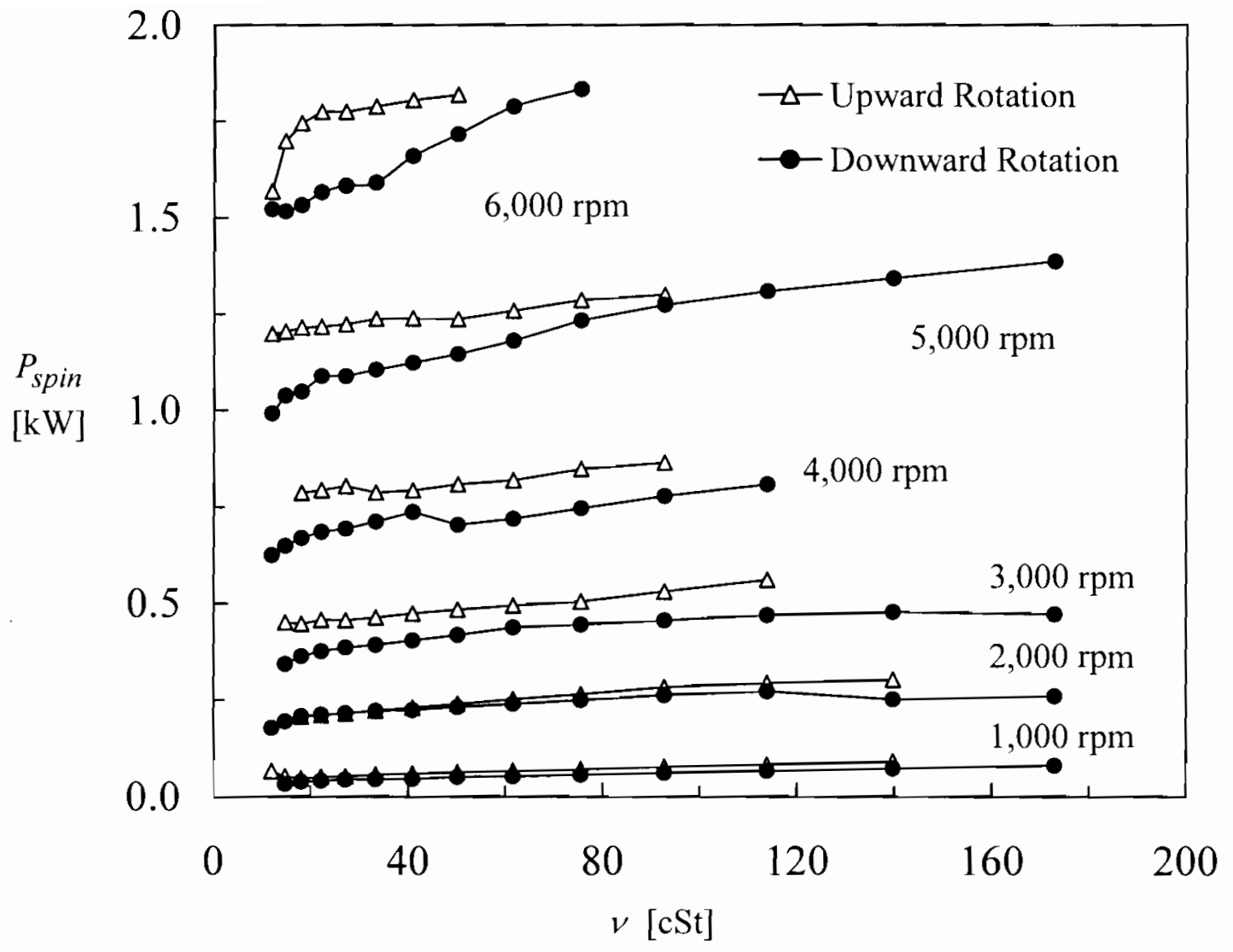

Figure 4.12 Influence of rotation direction on measured $P_{\text {spin }}$ for $40 \mathrm{~T}$ chemically polished gears, $19.5 \mathrm{~mm}$ face width. 


\section{Comparison to Jet Lubricated Spin Power LosS}

The method of jet-lubrication with a dry sump is generally accepted as a more efficient method of lubrication than dip lubrication due to lower magnitudes of $P_{\text {trap }}$ and $P_{\text {churn }}$, but little experimental data is available to support this claim. As the oil bath level in a dip-lubricated system is lowered, the magnitudes of $P_{\text {trap }}$ and $P_{\text {churn }}$ should approach that of a jet-lubricated system. That is, the effects of gear windage become more dominant as oil level lowers. While this argument make sense, no experimental proof of it has been provided. This section attempts to make direct comparisons between the measured $P_{s p i n}$ values the same test gears operated under both jet and dip-lubricated conditions.

To demonstrate the difference in $P_{\text {spin }}$ under jet and dip-lubrication conditions using the same test fixtures, a jet-lubricated spin power loss was conducted using the manual transmission fluid at $110^{\circ} \mathrm{C}$ with $40 \mathrm{~T}, 26.7 \mathrm{~mm}$ face width chemically polished gears. Figure 4.13 compares $P_{\text {spin }}$ under these jet-lubricated conditions to dip-lubricated $P_{\text {spin }}$ values at $h / r=0$ and $88^{\circ} \mathrm{C} 88^{\circ} \mathrm{C}$. Although the oil temperatures for these two tests were not the same, the difference in $v$ was small (about $6 \mathrm{cSt}$ ). Figure 4.13 shows no practical difference in measured $P_{\text {spin }}$ for dip-lubricated and jet-lubricated gear pairs with the oil bath level at the gear pitch line, $h / r=0$. The dip-lubricated $P_{\text {spin }}$ values in Fig. 4.13 correspond to the $h / r=0$ values in Fig. 4.7(c). This result suggests that the 


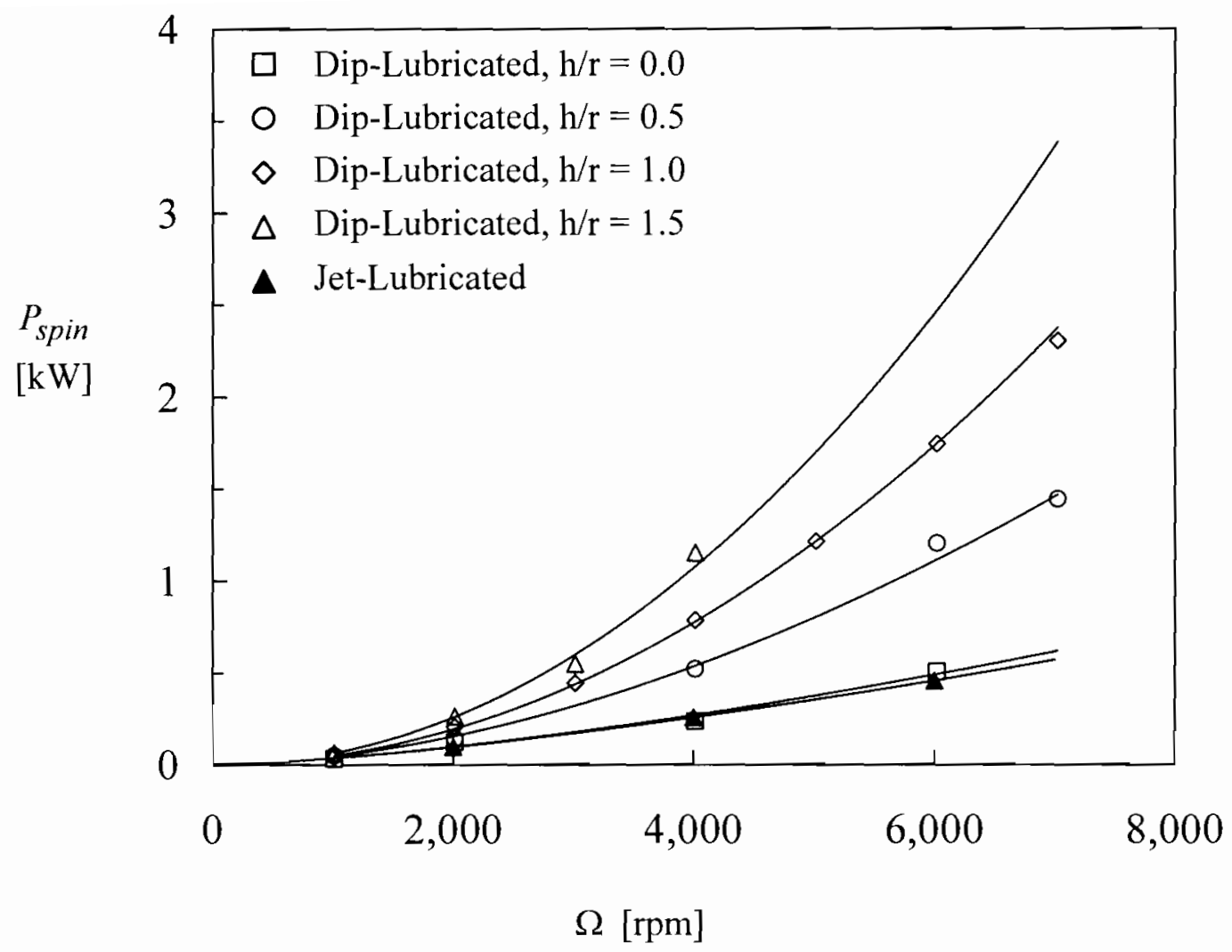

Figure 4.13 Comparison of jet-lubricated spin power loss for $26.7 \mathrm{~mm}$ face width gears at $110^{\circ} \mathrm{C}$ to dip-lubricated spin power loss for $\mathrm{h} / \mathrm{r}=0.0,88^{\circ} \mathrm{C}, 19.5$ $\mathrm{mm}$ face width, upward rotation in the oil bath. 
mechanisms of power loss are very similar for low oil level dip-lubrication and-jet Jubrication.

\subsection{Summary}

The gear efficiency test machine presented in Chapter 2 was modified for diplubricated spin power loss measurements, allowing direct comparison of load independent power loss for dip-lubricated or jet-lubricated conditions using the same test fixtures. An experimental test matrix including unity ratio gears operating in an oil bath of four different levels for a range of rotational speed and oil viscosity was developed. Satisfactory repeatability of the test fixtures was established for rotational speeds less than 5,000 rpm. The influence of rotational speed, oil viscosity, oil bath level, and rotational direction on load independent power loss was quantified.

Experimental data indicate that dip-lubricated spin power loss can be several times higher than jet-lubricated spin power loss under similar operating conditions. It was shown that dip-lubricated spin power loss increases with rotational speed to the power 1.35-2.05, depending on oil bath level, with the higher exponents corresponding to higher oil bath level. This dependence on speed is consistent with the jet-lubricated spin power loss measurements presented in Chapter 3, as well as the measurements of previous researchers $[26,41]$, but does not agree with the widely accepted windage models of Dawson [27-28] and Anderson and Loewenthal [5], or the more recent windage model of Diab et al [29]. Experimental results also show that dip-lubricated spin power loss decreases with oil bath level, and is weakly dependent on oil viscosity. Lastly, dip-lubricated spin power loss for the case of the oil bath level at the lowest point 
of the gear pitch point is found to be nearly identical to the jet-lubricated spin power loss under similar conditions. 


\section{CHAPTER 5}

\section{SUMMARY AND CONCLUSIONS}

\subsection{Summary}

An experimental investigation of high-speed spur gear efficiency was conducted for both jet-lubricated dry sump conditions and dip-lubricated conditions. Inspection methodologies were developed for the documentation of gear surface roughness and wear after each test. Results show that after the initial run-in phase, gear surface roughness amplitudes remained constant throughout the test regimen, and CMM inspections show negligible wear for all gear surfaces. An experimental test matrix including gears of different modules and surface roughness levels operating under jet-lubrication conditions with four different gear lubricants was developed to quantify the influence of these parameters on load-dependent (mechanical) and load-independent (spin) power losses.

The spur gear efficiency test machine was modified for dip-lubricated spin power loss measurements, allowing direct comparison of load-independent power loss for diplubricated or jet-lubricated conditions using the same test fixtures. An experimental test matrix including unity ratio gears of different module and face width operating in an oil 
bath of four different levels for a range of rotational speed and oil viscosity was developed. The influence of rotational speed, oil viscosity, oil bath level, and rotational direction on load-independent power loss was quantified.

\subsection{Conclusions}

The extensive experimental study of spur gear efficiency under highly loaded conditions and unloaded conditions for both jet-lubrication and dip-lubrication has resulted in the following conclusions:

- Gear mesh mechanical power losses increase nearly linearly with both rotational speed and applied torque, indicating that gear mesh mechanical efficiency is approximately constant over the ranges of speed and load considered. Gear mesh mechanical efficiency calculations from measured data support this conclusion.

- Gear module is the most influential parameter on gear mesh mechanical efficiency for the operating conditions considered, followed by gear tooth surface roughness, then lubricant selection.

- Gear mesh mechanical power loss for all ground gears was minimized with the most viscous lubricant due to reduction in sliding power losses through decreased asperity contacts. For chemically polished gears, the fine pitch gears performed best in terms of mesh power losses with the medium-viscosity lubricant, while 
the coarse pitch gears performed best with the lowest viscosity lubricant due to minimization of both rolling and sliding power losses at the gear mesh.

- Experimental results for four different lubricants show that load-independent gearbox (spin) power losses are influenced heavily by lubricant viscosity and to a lesser extent gear module, and can comprise a significant portion of overall gearbox power loss.

- Due to the inclusion of spin losses, total gearbox power loss was minimized for both ground and chemically polished gear pairs with the lowest-viscosity lubricant studied, despite differing trends in mesh mechanical power loss.

- Dip-lubricated spin power loss can be several times higher than jet-lubricated spin power loss under similar operating conditions.

- Dip-lubricated spin power loss increases with rotational speed to the power 1.352.05 , depending on oil bath level, with the higher exponents corresponding to higher oil bath level. Jet-lubricated spin power loss increases with speed to the power 1.4-1.7 for both fine and coarse pitch gears.

- Dip-lubricated spin power loss decreases with oil bath level, and is weakly dependent on oil viscosity. 
- Dip-lubricated spin power loss for the case of the oil bath level at the lowest point of the gear pitch point is found to be nearly identical to the jet-lubricated spin power loss under similar conditions.

\subsection{Recommendations for future work}

Although this experimental investigation of spur gear efficiency was extensive, it was by no means adequate to cover all ranges of gearing applications available. As the topic of gear efficiency becomes more crucial, especially in high-power applications, it will become necessary to expand on some of the objectives in this study. The following are some recommendations for future work:

- Renew attempts to apply DLC coatings: The low friction DLC coatings applied in this study failed to endure even several hours of operation. Since such coatings have been shown to reduce dry friction, efforts should be made to improve coating durability enough that they maintain integrity throughout the life of the gear.

- Expand efficiency testing to include helical and hypoid gears: Helical and hypoid gears are widely used in automotive applications, as well as in industry. Up until this point, only the efficiency of spur gears has been considered. The test methodology and test machine have been proven to be highly accurate and well suited for efficiency testing of spur gears. Simple modifications to the machine 
can expand testing to other parallel axis gears. Additional modifications to the machine are possible to allow testing of cross-axis gears such as hypoid gears.

- Expand dip-lubricated spin power loss test plan: Load independent power losses have been shown to represent a significant portion of overall gearbox power loss, and deserve more detailed study. In particular, the influence of module and face width on dip-lubricated spin power loss still need to be quantified, as well as the oil swell effect caused by non-unity ratio gears. Also of particular interest is the influence of enclosure effects on spin power loss. Enclosure effects have been shown to play an important role in windage, but have not been quantified for diplubricated gearing.

- Quantify gear mesh mechanical power loss under dip-lubricated conditions: Frictional power loss in the gear mesh has been quantified for the case of jetlubrication. However, no experimental studies have investigated whether gear mesh mechanical power loss is the same under dip-lubrication conditions. This is an important step in populating a comprehensive gear efficiency database, and requires no further modification of the existing test fixtures.

- Develop a physics-based spin power loss model: Theoretical models for loaddependent power loss have become increasingly sophisticated and have been shown to agree quite well with experimental data, but no such model exists for load-independent spin power loss. Existing empirical formulae for both windage 
and oil chuming do not agree with experimental data, so calculation of total gearbox power loss cannot be accomplished with confidence. Therefore, there is a need for a physics-based model that applies to both jet and dip-lubrication conditions.

In addition to these suggestions for future experimental and theoretical studies, several modifications to the existing spur gear efficiency test machine can improve experimental accuracy, as well as expand on the capability of the test machine. Suggestions for improving the experimental test machine are as follows:

- Develop a methodology to precisely measure loop torque: For this study, loop torque was calculated based on dead weight and moment arm of the torque arm, but was not measured directly. Since load-dependent gear efficiency is not particularly sensitive to load, this is not a major concern. However, better documentation of experimental parameters will lead to more accurate results.

- Experimentally quantify friction torque of bearings and shaft seals: The diplubricated spin power loss measurements include power losses resulting from viscous friction in the bearings and shaft seals. Formulae exist for calculating these values, but their accuracy is unknown. In order to validate a physics-based spin power loss model, the magnitudes of these power losses must be accurately known. 
- Employ temperature control for dip-lubricated efficiency studies: The jetlubricated loaded efficiency studies employed temperature control in the form of a temperature controlled oil jet. This allowed the test machine to operate at a user-defined steady-state temperature for an extended period of time. In order to obtain similar data under dip-lubrication, it will be necessary to regulate the temperature of the oil bath. This will also permit acquisition of dip lubricated spin power loss data for temperature ranges that were not possible in this study. 


\section{BIBLIOGRAPHY}

[1] Denny, C. M., 1998, "Mesh Friction in Gearing," AGMA Fall Technical Meeting, 98FTM2.

[2] Pedrero, J. I., 1999, "Determination of The Efficiency of Cylindrical Gear Sets," 4th World Congress on Gearing and Power Transmission, Paris, France.

[3] Michlin, Y., Myunster,V., 2002, "Determination of Power Losses in Gear Transmissions with Rolling and Sliding Friction Incorporated," Mechanism and Machine Theory, 37, pp. 167-174.

[4] Höhn, B.-R., Michaelis, K., Wimmer, A., 2005, "Low Loss Gears," AGMA Technical Paper 05FTM11.

[5] Anderson, N. E., Loewenthal, S. H., 1981, "Effect of Geometry and Operating Conditions on Spur Gear System Power Loss," Journal of Mechanical Design, 103, pp. 151-159.

[6] Anderson, N. E., Loewenthal, S. H., 1982, "Design of Spur Gears for Improved Efficiency," Journal of Mechanical Design, 104, pp. 767-774.

[7] Anderson, N. E., Loewenthal, S. H., 1986, "Efficiency of Nonstandard and High Contact Ratio Involute Spur Gears," Journal of Mechanisms, Transmissions, and Automation in Design, 108, pp. 119-126.

[8] Vaishya, M., Houser, D. R., 1999, "Modeling and Measurement of Sliding Friction for Gear Analysis," AGMA 99FTMS1, Lakewood, CO.

[9] Heingartner, P., Mba, D., 2003, "Determining Power Losses in The Helical Gear Mesh; Case Study," Proceeding of DETC'3, ASME 2003 Design Engineering Technical Conferences and Computers and Information in Engineering Conference, Chicago, Illinois.

[10] Diab, Y., Ville, F., Velex, P., 2006, "Prediction of Power Losses Due to Tooth Friction in Gears," Tribology Transactions, 49, pp. 260-270. 
[11] Dowson, D., Higginson, G. R., 1964, "A Theory of Involute Gear Lubrication," Proceeding of a Symposium Organized by the Mechanical Tests of Lubricants Panel of the Institute, Institute of Petroleum, Gear Lubrication, Elsevier, London, 8-15.

[12] Martin, K. F., 1981, "The Efficiency of Involute Spur Gears," Journal of Mechanical Design, 103, pp. 160-169.

[13] Simon, V., 1981, "Load Capacity and Efficiency of Spur ears in Regard to ThermoEnd Lubrication," International Symposium on Gearing and Power Transmissions, Tokyo, Japan.

[14] Wu, S., Cheng, H., S., 1991, "A Friction Model of Partial-EHL Contacts and its Application to Power Loss in Spur Gears", Tribology Transactions, 34, pp. 398-407.

[15] Mihalidis, A., Bakolas, V., Panagiotidis, K., Drivakos, N., 2002, "Prediction of The Friction Coefficient of Spur Gear Pairs," VDI-Berichte, NR. 1665, pp. 705-719.

[16] Xu, H., Kahraman, A., Anderson, N.E, Maddock, D.G., 2007, "Prediction of Mechanical Efficiency of Parallel-Axis Gear Pairs," Journal of Mechanical Design, 129, pp. 58-68.

[17] Naruse, C., Haizuka, S., 1978, "Limiting Loads for Scoring and Coefficient of Friction on a Disk-Machine (Effects of Lubricating Oil, Specific Sliding and Sliding Velocity in the case of Steel/Steel)," Bulletin of JSME, 21, pp. 1311-1317.

[18] Naruse, C., Haizuka, S., Nemoto, R., Kurokawa, K., 1986, "Studies on Frictional Loss, Temperature Rise and Limiting Load for Scoring of Spur Gear", Bulletin of JSME, 29, pp. 600-608.

[19] Naruse, C., Nemoto, R., Haizuka, S., and Takahashi, H., 1991, "Influences of Tooth Profile in Frictional Loss and Scoring Strength in the Case of Spur Gears", JSME International Conference on Motion and Power Transmissions, Hiroshima, Japan, pp. 1078-1083.

[20] Yoshizaki, M., Naruse, C., and Haizuka, S., 1991, "Study on Frictional Loss of Spur Gears (Concerning the Influence of Tooth Form, Load, Tooth Surface Roughness, and Lubricating Oil)", Tribology Transactions, 34, pp. 138-146.

[21] Ikejo, K., Nagamura, K., 2003, "Power Loss of Spur Gear Drive Lubricated with Traction Oil," Proceeding of DETC'3, ASME 2003 Design Engineering Technical Conferences and Computers and Information in Engineering Conference, Chicago, Illinois. 
[22] Coy, J., Mitchell, A., and Hamrock, B., 1984, "Transmission Efficiency Measurements and Correlations with Physical Characteristics of the Lubricant," NASA TM ADA149179.

[23] Handschuh, R., Kilmain, C., 2003, "Preliminary Comparison of Experimental and Analytical Efficiency Results of High-Speed Helical Gear Trains," Proceeding of DETC'3, ASME 2003 Design Engineering Technical Conferences and Computers and Information in Engineering Conference, Chicago, Illinois.

[24] Martins, R., Seabra, J., Brito, A., Seyfert, Ch., Luther, R., Igartua, A., 2006, "Friction Coefficient in FZG Gears Lubricated With Industrial Gear Oils: Biodegradable Ester vs. Mineral Oil," Tribology International, 39, pp. 512-521.

[25] Xiao, L., Amini, N., and Rosen, B.-G., "An Experimental Study on the Effect of Surface Topography on Rough Friction in Gears," JSME International Conference on Motion and Power, Transmission, Nov. 15-17, 2001, Fukuoka, Japan, pp. 547552.

[26] Britton, R.D., Elcoate, C.D., Alanou, M.P., Evans, H.P., Snidle, R.W., 2000, “Effect of Surface Finish on Gear Tooth Friction," Transactions of the ASME, 122, pp. 354360.

[27] Dawson, P.H., 1984, "Windage Losses in Larger High-Speed Gears," Proceedings of the Institute of Mechanical Engineers, 198A, No. 1, pp. 51-59.

[28] Dawson, P.H., 1988, "High-Speed Gear Windage", GEC REVIEW, 4, No. 3, pp. 164-167.

[29] Diab, Y., Ville, F., Velex, P., Changenet, C., 2004, "Windage Losses in High Speed Gears - Preliminary Experimental and Theoretical Results," Journal of Mechanical Design, 126, pp. 903-908.

[30] Ariura, Y., Ueno, T., Sunaga, T., 1973, "The Lubricant Churning Loss in Spur Gear Systems," Bulletin of the JSME, 16, pp. 881-890.

[31] Mizutani, H., 1999, "Power Loss of Long Addendum Spur Gears With Large Chamfer on Tooth Tip-Ends," Fourth World Congress on Gearing and Power Transmission, Paris, France.

[32] Akin, L.S., Mross, J.J, 1960, "Chamber Dimension Effects of Induced Flow and Frictional Resistance of Enclosed Rotating Disks," Journal of Basic Engineering, 82, pp. 217-232. 
[33] Perchersky, M.J., Wittbrodt, M.J., 1987, "An Analysis of Fluid Flow Between Meshing Spur Gear Teeth," MS Thesis, Pennsylvania State University, State College, Pennsylvania.

[34] Diab, Y., Ville, F., Houjoh, H., Sainsot, P., Velex, P., 2005, "Experimental and Numerical Investigations on the Air-Pumping Phenomenon in High-Speed Spur and Helical Gears," Proceedings of the Institute of Mechanical Engineers, 219, Part C, pp. 785-800.

[35] Daily, J., Nece, R., 1960, "Chamber Dimension Effects of Induced Flow and Frictional Resistance of Enclosed Rotating Disks," Journal of Basic Engineering, 82, pp. 217-232.

[36] Mann, R., Martson, C., 1961, "Friction Drag on Bladed Disks in Housings as a Function of Reynolds Number, Axial and Radial Clearance, and Blade Aspect Ratio and Solidity," Journal of Basic Engineering, 83, pp. 719-723.

[37] Terekhov, A.S., 1991, "Basic Problems of Heat Calculation of Gear Reducers," JSME International Conference on Motion and Power Transmissions, Hiroshima, Japan, pp. 490-495.

[38] Boness, R.J., 1989, "Churning Losses of Discs and Gear Running Partially Submerged in Oil," Proceedings of the ASME International Power Transmission and Gearing Conference, Chicago, 1 pp. 355-359.

[39] Höhn, B.-R., Michaelis, K., Vollmer, T., 1996, "Thermal Rating of Gear Drives Balance Between Power Loss and Heat Dissipation," AGMA Technical Paper 96FTM8.

[40] Luke, P., Olver, A.V., 1999, "A Study of Churning Losses in Dip-Lubricated Spur Gears," Proceedings of the Institute of Mechanical Engineers, 213, pp. 337-346.

[41] Changenet, C., Velex, P., 2007, "A Model for the Prediction of Churning Losses in Geared Transmissions-Preliminary Results," Journal of Mechanical Design, Technical Brief, 129, pp. 128-133.

[42] Chase, D. 2005, "The Development of an Efficiency Test Methodology for HighSpeed Gearboxes," MS thesis, The Ohio State University, Columbus, Ohio.

[43] Khonsari, M.M., Booser, 2001, E.R., "Applied Tribology, Bearing Design and Lubrication," John Wiley \& Sons, pp. 459-463.

[44] Xu, H. 2005. "Development of a Generalized Mechanical Efficiency Prediction Methodology for Gear Pairs," PhD dissertation, The Ohio State University, Columbus, Ohio. 
[45] Goksem, P.G. and Hargreaves, R.A., 1978, "The Effect of Viscous Shear Heating on Both Film Thickness and Rolling Traction in an EHL Line Contact," Journal of Lubrication Technology, 100, pp 353-358.

[46] Palmgren, A., 1959, Ball and Roller Bearing Engineering, $3^{\text {rd }}$ ed., Burbank, Philadelphia, pp. 34-41.

[47] Harris, T., 1991, Rolling Bearing Analysis, $3^{\text {rd }}$ ed., John Wiley \& Sons Inc., New York, pp.504-510.

[48] SKF General Catalog 4000 US, $2^{\text {nd }}$ ed., 1997

[49] ISO/TR 14179-1:2001(E)

[50] Amaro, R.I., 2003, "MoST Low Friction Coating For Gears Application," Gears \& Transmissions Workshop, Paper 10, pp. 203-230.

[51] Schlichting, H., 1955, Boundary Layer Theory, $1^{\text {st }}$ ed., Pergamon Press, New York, pp. 176.

[52] De Winter, A., Blok, H., 1974, "Fling-Off Cooling of Gear Teeth," ASME Transactions, Journal of Engineering for Industry, 96, pp. 60-70.

[53] Akin, L.S, Mross, J.J., 1975, "Theory for the Effect of Windage on the Lubricant Flow in the Tooth Spaces of Spur Gears," ASME Transactions, Journal of Engineering for Industry, 97, pp. 1,266-1,272. 